\title{
Outflow reconstruction of the lower extremity in chronic venous obstructive disease
}

Citation for published version (APA):

de Wolf, M. (2018). Outflow reconstruction of the lower extremity in chronic venous obstructive disease. [Doctoral Thesis, Maastricht University]. Proefschriftmaken.nl II Uitgeverij Boxpress. https://doi.org/10.26481/dis.20180706mw

Document status and date:

Published: 01/01/2018

DOI:

10.26481/dis.20180706mw

Document Version:

Publisher's PDF, also known as Version of record

\section{Please check the document version of this publication:}

- A submitted manuscript is the version of the article upon submission and before peer-review. There can be important differences between the submitted version and the official published version of record.

People interested in the research are advised to contact the author for the final version of the publication, or visit the DOI to the publisher's website.

- The final author version and the galley proof are versions of the publication after peer review.

- The final published version features the final layout of the paper including the volume, issue and page numbers.

Link to publication

\footnotetext{
General rights rights.

- You may freely distribute the URL identifying the publication in the public portal. please follow below link for the End User Agreement:

www.umlib.nl/taverne-license

Take down policy

If you believe that this document breaches copyright please contact us at:

repository@maastrichtuniversity.nl

providing details and we will investigate your claim.
}

Copyright and moral rights for the publications made accessible in the public portal are retained by the authors and/or other copyright owners and it is a condition of accessing publications that users recognise and abide by the legal requirements associated with these

- Users may download and print one copy of any publication from the public portal for the purpose of private study or research.

- You may not further distribute the material or use it for any profit-making activity or commercial gain

If the publication is distributed under the terms of Article $25 \mathrm{fa}$ of the Dutch Copyright Act, indicated by the "Taverne" license above, 
OUTFLOW RECONSTRUCTION OF THE LOWER EXTREMITY IN CHRONIC VENOUS OBSTRUCTIVE DISEASE 
Cover \& Layout: Rose Nguyen

Drukkerij: ProefschriftMaken || www.proefschriftmaken.nl

(C) copyright Mark Antonius Friedrich de Wolf, Rotterdam 2018 


\section{OUTFLOW RECONSTRUCTION OF THE LOWER EXTREMITY IN CHRONIC VENOUS OBSTRUCTIVE DISEASE}

\section{PROEFSCHRIFT}

ter verkrijging van de graad van doctor aan de Universiteit Maastricht, op gezag van de Rector Magnificus, Prof. dr. Rianne M. Letschert, volgens het besluit van het College van Decanen, in het openbaar te verdedigen op vrijdag 6 Juli 2018 om I2:00 uur.

door

Mark Antonius Friedrich de Wolf 


\section{Promotor}

Prof. dr. C.H.A. Wittens

Copromotor

Dr. R. de Graaf

\section{Beoordelingscommissie}

Prof. dr. H. ten Cate (voorzitter)

Dr. M.M.P.J. Reijnen (Rijnstate)

Prof. dr. J.E. Wildberger

Prof. dr. W. Wisselink (VU medisch centrum) 


\section{TABLE OF CONTENTS}

$\begin{array}{ll}\text { Chapter I General introduction } & 7\end{array}$

Chapter 2 Incidence and Risk Factors of the Post-Thrombotic 2I Syndrome.

Chapter 3 Minimally Invasive Treatment of Chronic Iliofemoral Venous Occlusive Disease.

$4 \mathrm{I}$

Chapter 4 Short Term Clinical Experience with a Dedicated Venous 57 Nitinol Stent: Initial Results with the Sinus-Venous.

Chapter 5 Iliocaval Confluence Stenting for Chronic Venous Obstructions.

Chapter 6 Indications for endophlebectomy and/or arteriovenous fistula after stenting.

Chapter 7 Endophlebectomy and Arteriovenous Fistula Creation Ancillary to Deep Venous Stenting in Post-Thrombotic Syndrome.

Chapter 8 Venous Outflow Reconstruction of the Lower Extremity in II5 Post-Thrombotic Syndrome and Iliac Vein Compression Syndrome.

Chapter 9 Venous In-stent Thrombosis Treated by Ultrasound Accelerated Catheter Directed Thrombolysis.

Chapter Io Summary and general discussion

$\begin{array}{lll}\text { Addenda Nederlandse samenvatting } & \text { I65 }\end{array}$

$\begin{array}{ll}\text { Valorisation } & \text { I75 }\end{array}$

Dankwoord $\quad$ I79

List of publications $\quad 185$

Curriculum Vitae $\quad$ I9I 

CHAPTER 1

GENERAL INTRODUCTION 


\section{VEINS AND THE VASCULAR SYSTEMS}

A vascular system is one of the most basic necessities in any complex multicellular organism. Its function is essential to maintain cellular homeostasis, and loss of its function generally leads to death of cells, organs, and possibly the organism as a whole. Anatomically and functionally the circulatory system is comprised of three distinct tubular systems; the lymphatic, the arterial, and the venous system. The main function of the lymphatic vessels is to return interstitial fluid, originating from capillary filtration, more or less directly to the heart. Moreover, it has important immunological functions(I). The arteries' main function is to deliver oxygen-rich blood to the organs, muscles, and other tissues. Oxygen is added to the haemoglobin molecule inside red blood cells in the lungs and is subsequently pumped peripherally by the heart. After delivery of oxygen via capillary diffusion to the tissues, the blood is returned to the heart and lungs via the venous system. In contrast to the arterial system, with the heart pushing blood in the direction of gravity towards the periphery (in case of the lower extremities that is), venous return of blood towards the heart goes against the force of gravity. Flow in the venous system is partly generated by the pressure differences between the periphery and the veins at level of the heart, but the most important generator of flow is the contraction of the (lower) extremity musculature. In the lower extremities the muscles of the calves are paramount for adequate venous function, with every contraction of these muscles blood is expelled upward towards the heart. To negate gravity related venous backflow after such a muscle contraction, the inner lumen of the veins is lined with one-way valves. Therefore, similarly to the arterial system there is only one direction of flow (from the periphery towards the heart) in the healthy venous system. Besides the delivery of oxygen and removal of carbon dioxide from cells, other critical functions of the arteriovenous system include: delivery of nutrients to cells, removal of waste products from cells, transport of cells of the immune system, maintenance of a constant body temperature (thermoregulation), and it functions as a conveyor for hormones (necessary for communication between cells). Dysfunction of the arterial system can be fatal, and indeed stroke and myocardial infarction are among the major causes of death in the Western world.(2) Venous pathology in itself can also be fatal in cases of pulmonary embolism, where the circulatory system of the lungs is compromised by a blood clot, generally originating from the peripheral veins.(3) However most diseases involving the veins are non-fatal and are located in the vessels of the lower extremities and/or their outflow tracts. This thesis illustrates the treatment of a number of these types of venous pathologies.

\section{CHRONIC VENOUS DISEASE}

Signs and symptoms of venous pathology and their underlying pathological causes are represented with the overlapping term "chronic venous disease". There are two primary 
pathological mechanisms underlying chronic venous disease.(4) The first is related to the backflow of blood by gravitational force, termed "venous insufficiency". For this to happen there needs to be dysfunction of the one-way venous valves. Dysfunction arises when the valve leaflets are damaged. Only in very rare cases venous valves are congenitally underdeveloped or non-developed. Valve damage can be the result of an inflammatory reaction within the vein (as is the case in venous thrombosis), but in most cases there is no clear cause underlying the insufficiency. In those cases the insufficiency is called "primary", in contrast to "secondary" pathology, which is secondary to another event (usually thrombosis). It is best illustrated by primary varicose vein. In many patients in the Western world varicose veins develop without a clear underlying event, usually gradually and later in life.(5) When examined with duplex ultrasonography, dysfunction of the valves and backflow, i.e. "reflux" of blood, can be found. It is theorised this is because of an inborn relative weakness of the vein walls and/or valves. The reflux induces a rise of venous pressure, which is greatest at the level of the ankle in a standing patient because of the gravitational pull on the column of blood between the ankle and the heart as a whole; i.e. the hydrostatic pressure. The increased pressure then leads to the variety of signs and symptoms related to chronic venous disease via a number of different pathological mechanisms. The second pathological mechanism leading to chronic venous disease is obstruction or occlusion of the lumen of one or more vein segments. In cases of venous obstruction the lumen is reduced and therefore the amount of blood, which can be moved through the segment over a specific time period, is diminished. In cases of occlusion there is absolutely no blood, which can flow through the vessel. In both cases blood needs to leave the extremity via other vein segments (so called "collateral vessels" or "collaterals"), however this is less effective than the original pathway, leading to a higher outflow resistance. This leads to an increase in venous pressure, especially in the caudal veins, and this in turn to the aforementioned signs and symptoms related to chronic venous disease. During exercise this problem increases further as the muscles of the extremity need a higher amount of nutrients and oxygen. Arterial inflow into the extremity therefore increases, and logically the venous outflow also needs to increase. The higher amount of blood however cannot be effectively expelled centrally, leading to relative stasis of blood in the lower extremity. Because of this stasis and its related increased venous pressure, arterial inflow is decreased and muscles tend to fatigue early. In turn this leads to pain in the legs during walking or other forms of exercise. Of special interest is the role of muscle contractions in the extremity during ambulation in patients with either venous insufficiency or obstruction. In insufficiency, in spite of the damaged valves, ambulation will improve venous outflow and thereby decrease venous pressure. This will generally lead to a temporary decrease of symptoms. However, in case of obstruction the increased blood flow during ambulation will be forcefully pumped against the venous network with increased flow resistance, leading to an acute increase in venous pressure distally of any obstruction. Of further note is the fact that in clinical practice both mechanisms, in different severities, may be present in a patient.(5) 


\section{DEEP VEIN THROMBOSIS}

Thrombosis is the formation of a blood clot, which can arise in both arteries and veins. The reasons for clot formation in vessels are encapsulated in Virchow's triad, which states that the combination of stasis of blood flow, endothelial injury, and hypercoagulability can result in thrombosis.(6) In veins thrombosis leads to an acute occlusion of one or more vein segments, with associated acute symptoms of (severe) venous disease. If one or more parts of the localized thrombus break loose from the main thrombus it migrates via the venous system towards the heart and lungs, potentially obstructing a vital part of the lung circulation and possibly leading to death.(7) This is called pulmonary embolism.(3) To prevent this, and to arrest growth of the thrombus, patients experiencing a venous thrombosis are given medication which decreases the ability of blood to form clots, i.e. anticoagulants.(8) There are 3 main groups of anticoagulants in clinical use today for DVT care; vitamin K antagonists (coumarin), heparin and low molecular weight heparin, and the "new oral anticoagulants (NOAC)". (8-II) Because of the complications (patients have a higher tendency for bleeding) associated with these medications, they are generally given temporarily (if medically acceptable, some patients need life-long treatment). During the months following the initial thrombosis the innate remodelling processes of the body tries to recanalise the affected vein segments. This involves an inflammatory process, which can inadvertently lead to fibrosis of the vein wall, destruction of the vein valves and residual intraluminal fibrous strands. Therefore thrombosis may lead to both chronic venous obstruction and valvular insufficiency. To combat these complications, thrombosis patients are treated using compression therapy, generally in the form of compression stockings and bandages. This treatment was shown to prevent thrombosis associated chronic venous disease (i.e. post-thrombotic syndrome) in a great percentage of patients.(I2-I4) As stasis of blood may lead to thrombosis and muscular contraction prevents stasis, patients are also advised to start mobilisation quickly after the thrombosis. Therefore the treatment of deep vein thrombosis (DVT) consists of pharmaceutical anticoagulation, compression therapy and quick ambulation.

\section{THE POST-THROMBOTIC SYNDROME}

The most important cause of venous obstruction is the post-thrombotic syndrome (PTS). In a certain percentage of patients (up to 50\%) after a DVT a specific type of chronic venous disease develops some months to years post-DVT.(I2, I4-I6) This can be explained by the fact that the therapy used to treat DVT is not particularly effective in preventing the long term vein damage caused by the innate inflammatory process associated with a DVT. Because of this the damage to the vein wall and the intraluminal scarification become an irreversible outflow obstruction, in combination with the valve 
destruction, this can lead to chronic increased venous pressure and its associated symptoms.(I7, I8) This is called PTS. Anatomically, PTS is characterised by veins in which the intraluminal diameter is reduced (stenosis), the intraluminal space is filled with fibrous strands (trabeculation) creating multiple canals through the length of the vein, the vein wall is fibrosed, and vein valves are damaged or completely (functionally) absent.

Both the incidence of PTS and its severity are associated with the location of the postthrombotic damage.(I9) Generally proximal/cranial DVTs, those located at the level of the vena cava, iliac veins or the common femoral vein (CFV), are associated with higher incidence and severity of PTS.(I9-2I) This can be explained by the fact that those veins are the ones responsible for the outflow of the greatest volume of venous blood. In contrast, at the level of the calve and upper leg there are generally multiple veins running more or less parallel with each other.(22) Therefore in cases of obstruction at levels below the CFV flow is diverted upwards via other non-obstructed veins; i.e. collaterals. These collateral networks are generally associated with a higher degree of venous resistance, leading to increased venous pressure distally of the obstruction and associated symptoms of chronic venous disease. Blood however does have the ability to leave the lower extremity, so the cardiovascular circulation is maintained. This is in stark contrast to arterial obstruction and occlusion, which may lead to (acute) ischaemia of tissue and cellular necrosis. Given the incidence of DVT being I-2 per I.00o individuals yearly and up to $50 \%$ of these patients developing chronic complications, PTS is a very significant cause of chronic venous disease, its associated morbidity, and healthcare costs. $(23,24)$ Historically its treatment has been primarily based on compression therapy, and to a lesser extend medication.(I2-I4, 25, 26) However this treatment is not aimed at treating the underlying obstruction of the veins. In very select patients, those most severely affected by PTS, surgery was performed in a number of very specialized centres worldwide. $(27,28)$ Surgery consisted of the creation of artificial collaterals, e.g. veno-venous bypasses. Clinical and haemodynamic long-term effectiveness of this type of surgery however was suboptimal. Therefore alternatives were needed.

\section{ILIAC VEIN COMPRESSION SYNDROMES}

The second main cause of venous obstruction is pressure onto the vein from extra luminal sources. The most important source of pressure are the arteries in the vicinity of the veins, especially at the level where arteries cross the veins. And of these arterial crossings, the right common iliac artery traversing the left common iliac vein (CIV) is the most frequent cause of pathology. As the CIV runs across the bony vertebral corpus, the vein may be compressed between the common iliac artery and the vertebra. Signs and symptoms associated with this iliac vein compression are similar to other types of chronic venous disease. The combination of this clinical symptomatology and the anatomical compression of the CIV is termed May-Thurner syndrome (MTS). MTS 
was first described in the early nineteen hundreds, and was recognized as the cause for the predominant occurrence of DVT in the left lower extremity compared to the right leg.(29) A study in subjects without venous disease showed compression of the CIV to be present in the majority of subjects; $66 \%$ of patients had a compression of $>25 \%$ and $24 \%$ showed compression of the CIV to be greater than $50 \%$ (in many studies a compression of $>50 \%$, in combination with clinical symptoms, is considered to be an indication for stent placement, see below).(30, 3I) Other causes of iliac vein compression include pressure on the vein by nearby structures such as tumours, arterial aneurism, haematoma etc. The overlying term used to describe these compression syndromes is iliac vein compression syndrome (IVCS).

\section{RECANALISATION, VENOPLASTY AND STENTING}

Because the lumen is totally clogged in many patients and severely diminished in the rest the first thing to do is to reopen the lost lumen. Recanalisation without the use of open-surgery is performed by use of various guidewires and catheters, introduced into the deep venous system via an introduction sheath in the CFV, femoral vein or popliteal vein. Recanalisation is followed by increasing the newly created lumen by use of balloons. In the 1960's it was shown by Charles Dotter that tubular structures could be expanded by use of intraluminally delivered balloons, which is termed angioplasty in case of blood vessels.(32) In the venous system this technique can also be used. However this "venoplasty" by itself is not effective as recollapse of the postthrombotically damaged or compressed vein occurs quickly after treatment.(33-35) Therefore a device is needed to keep the treated vein segment open on the long term. A stent is such a device. For vascular use these are generally made from some type of metal. Stents are implantable via a catheter into hollow organs, in this case veins. The stent delivers a constant pressure into the vein wall, thereby keeping the vein open. By use of the combination of guidewire recanalisation, venoplasty and stenting of the occluded or obstructed veins physicians aim to reopen the veins and keep these open over a long period. This treatment is thought to normalise venous haemodynamics, decrease venous pressure and thereby signs and symptoms of venous disease can diminish.

\section{DEDICATED VENOUS STENTS}

Historically stenting and angioplasty first gained popularity in arterial and cardiac use. Because of the similarities between arteries and veins the same stents as used in arteries have been used in the venous system.(36) In many studies this has shown very favourable results, however a number of complications related to the use of these stents have nevertheless been identified.(30, 36-40) A number of important differences 
between arterial diseases, i.e. arteriosclerosis, and venous pathology exist. Firstly, even though arteriosclerotic damage can frequently be found at many locations in a patient's arterial system, the stenotic lesions which are treated by stenting are generally only several centimetres in length. In contrast, in patients who suffered a DVT involving their iliac veins the post-thrombotic damage frequently extend from the CIV to the level of the knee (>50 centimetres) or even the calve veins. Even though only the CIV, external iliac vein (EIV) and CFV are generally eligible for stenting, this still involves $>20$ centimetres of vein tract.(4I) Secondly, veins have a greater diameter compared to their corresponding arteries (e.g. the CIV compared to the common iliac artery). Thirdly, veins are more flexible and more subject to external forces compared to arteries, because of the lack of a thick muscular layer in the vessel wall and the lower intraluminal pressure. And fourthly, the rigidity and inward pushing force of atherosclerotic laesions is less compared to fibrotic post-thrombotic laesions. Because of these specific qualities of the venous system, the ideal venous stents has the following characteristics; adequate length and diameter, maximal flexibility, great radial force, and non-crushability.(42) A number of companies have recently developed dedicated venous stents, and some of these have already become available for clinical use. $(42,43)$

\section{ENDOPHLEBECTOMY AND ARTERIOVENOUS FISTULA}

Stent implantation is generally performed in the iliac veins and the CFV.(30) Frequently the femoral, deep femoral, popliteal and calve veins are also affected by post-thrombotic damage.(7) As flow through these vein segments into the stents is reduced and relative stasis of blood can cause clot formation (Virchow's triad), there can be an increased risk of instent-thrombosis and loss of patency. Stenting can be relatively safely done into the CFV when inflow from one of the two major inflow vessels of the CFV, the femoral and deep femoral vein, is adequate. However if both inflow vessels are significantly affected by post-thrombotic damage, the risk of stent occlusion increases. This is partly because of blood flow being diverted to collateral veins, however at the level of the CFV there are less collaterals available. Indeed the CFV is the segment of the venous systems where a number of important collateral vessels of the lower extremity converge to direct flow though the inguinal ligament into the iliac veins. As already stated a number of different canals can be present in a post-thrombotic vein, all creating flow towards the heart, but not necessarily interconnecting. Flow from different side branches of the CFV may flow through different canals within the CFV. When a stent is placed in one of these canals the others are compressed, and blood flow might cease in those canals. Therefore, by stenting a vein the inflow from side branches can be severely diminished, which is generally not an issue in the iliac tract. However at the level of the CFV, stents placed over the orifice of one of the major inflow vessels can totally obstruct flow via these vessels. This can be rather problematic when a significant fraction of the total venous outflow of the leg is obstructed by the stent. This is the reason some authors 
advocate the use of a surgical desobstruction of the CFV, termed an endophlebectomy or endovenectomy.(44-47) This guarantees all canals from all side branches at this level to flow into one channel, and thereby all flow can be concentrated into the stents which are placed in the vein section just cranially of the endophlebectomy. However, the combination of the iliac stenting and the surgical trauma of the endophlebectomy creates a highly thrombogenic environment, therefore measures must be taken to reduce the risk of thrombosis of the stented and endophlebectomized vein segments. For this reason the creation of an ancillary arteriovenous (AV)-fistula can be created (besides the use of anticoagulants). The AV-fistula connects the artery and the vein, and because of the great difference in pressure in both systems, flow through the vein is considerably increased. As stated before, higher flow equals a decrease in risk of thrombosis.

\section{AIMS AND OUTLINE OF THIS THESIS}

The aim of this thesis is to enlighten the indications, technique and clinical effects of venous reconstruction by use of percutaneous transluminal angioplasty (PTA) and stenting, supported in some cases by endophlebectomy and temporary AV-fistula creation, in a population of patients suffering from chronic venous obstructive disease.

Chapter 2 describes the post-thrombotic syndrome from an epidemiological point of view. This review of literature gives an overview of current insights on the incidence of PTS and its risk factors. PTS is a relatively common disease in Western countries. Numerous risk factors are currently known, and there is ongoing research into new ways to predict and prevent PTS development.

Our first experience of PTA and stenting in Maastricht are described in chapter 3. We described the techniques we used for diagnostic imaging and the intervention in the patients treated between 2009 and February 20I2. Moreover, clinical outcome, including patency rates and the effect on symptoms, is described. In this chapter the effect of the "old" non-dedicated stents is described. Also a number of the specific stentrelated problems, such as kinking and stent compression, are described. Following the treatment of the patients described there, we switched to dedicated venous stents.

In chapter 4 our initial experience with one such dedicated venous stent is described. We chose to primarily use the sinus Venous stent (OptiMed, Ettlingen, Germany) in both PTS and IVCS patients. The sinus Venous is a nitinol stent. Nitinol is a specific kind of memory metal frequently used in stent designs. This stent is characterised by a high radial force and a high flexibility. Moreover it is available in diameters and lengths adequate for the venous system. This chapter describes the specific technique used for placement of the stent, and the clinical outcome for both PTS and IVCS cases. 
In a minority of patients with chronic venous obstructive disease both lower extremities are affected. This can be because of two-sided compression syndromes, but in most cases the source is bilateral DVT. Frequently the vena cava inferior is also affected. Treatment in these cases necessitates a specific technique as both iliac tracts and the inferior vena cava need to be stented simultaneously. Reconstruction the iliac confluence is technically demanding. The technique we use to treat this is described in chapter 5, as is its clinical outcome. It is noteworthy that our technique differs from many other available studies. We chose to use balloon-expandable stents at the level of the confluence in conjunction with self-expandable stents proximally and distally from the balloon-expandable stents.

As already stated above, in a significant number of patients not only the CFV is severely damaged by the DVT, but also both main inflow vessels (femoral and deep femoral vein). In those cases we chose to complement the PTA and stent treatment with an endophlebectomy and a temporary AV-fistula creation. The specific clinical indications for this hybrid surgery and the preoperative diagnostic tests performed are illustrated in chapter 6 . The hybrid surgical technique and its clinical outcome is described in chapter 7. The hybrid technique is generally well tolerated and an effective way to reconstruct the venous outflow, however a number of specific complications are associated with it, these are all described in these chapters.

In chapter 8 the totality of our first 7 years of experience with deep venous reconstructions is reported. In contrast to the earlier chapters a more generalised view is used to describe the clinical outcome of all patients treated in our centre by use of PTA and stenting.

Finally in chapter 9 an indepth view is presented on the most important complication of deep venous reconstructions; thrombosis of the treated vein segments. Recent advances in the treatment of acute DVT have led to the increasing use of catheterbased techniques for quick thrombus removal. Generally two types of techniques are available; thrombectomy and thrombolysis techniques. We have used the latter to treat the instent thrombus of patients in whom vein segments reoccluded after stenting. 


\section{REFERENCES}

I. Betterman KL, Harvey NL. The lymphatic vasculature: development and role in shaping immunity. Immunological reviews. 20I6;27I(I):276-92.

2. Yoon PW, Bastian B, Anderson RN, Collins JL, Jaffe HW, Centers for Disease C, et al. Potentially preventable deaths from the five leading causes of death--United States, 2008-20IO. MMWR Morbidity and mortality weekly report. 20I4;63(I7):369-74.

3. Di Nisio M, van Es N, Buller HR. Deep vein thrombosis and pulmonary embolism Lancet. 2016.

4. Bergan JJ, Schmid-Schonbein GW, Smith PD, Nicolaides AN, Boisseau MR, Eklof B. Chronic venous disease. N Engl J Med. 2006;355(5):488-98.

5. Maurins U, Hoffmann BH, Lösch C, Jöckel K-H, Rabe E, Pannier F. Distribution and prevalence of reflux in the superficial and deep venous system in the general populatio - results from the Bonn Vein Study, Germany. Journal of vascular surgery official publication, the Society for Vascular Surgery [and] International Society for Cardiovascular Surgery, North American Chapter. 2008;48(3):680-7.

6. Bagot CN, Arya R. Virchow and his triad: a question of attribution. Br J Haematol. 2008;I43(2):I80-90.

7. Kearon C. Natural history of venous thromboembolism. Circulation. 2003;IO7(23 Suppl I):I22-30.

8. Bauersachs R. Non-vitamin K antagonist oral anticoagulants for the prevention of recurrent venous thromboembolism. Thromb Res. 20I6;144:I2-20.

9. Cohen AT, Hamilton M, Mitchell SA, Phatak H, Liu X, Bird A, et al. Comparison of the Novel Oral Anticoagulants Apixaban, Dabigatran, Edoxaban, and Rivaroxaban in the Initial and Long-Term Treatment and Prevention of Venous Thromboembolism: Systematic Review and Network Meta-Analysis. PloS one. 20I5;IO(I2):eoI44856.

Io. Schulman S, Kakkar AK, Goldhaber SZ, Schellong S, Eriksson H, Mismetti P, et al. Treatment of acute venous thromboembolism with dabigatran or warfarin and pooled analysis. Circulation. 20I4;129(7):764-72.

II. Landman GW, Gans RO. Oral rivaroxaban for symptomatic venous thromboembolism. N Engl J Med. 20II;364(I2):II78; author reply

I2. Brandjes DP, Buller HR, Heijboer H, Huisman MV, de Rijk M, Jagt H, et al. Randomised trial of effect of compression stockings in patients with symptomatic proximal-vein thrombosis. Lancet. 1997;349(9054):759-62.

I3. Kahn SR, Shbaklo H, Shapiro S, Wells PS, Kovacs MJ, Rodger MA, et al. Effectiveness of compression stockings to prevent the post-thrombotic syndrome (the SOX Trial and Bio-SOX biomarker substudy): a randomized controlled trial. BMC Cardiovasc Disord. 2007;7:2I.

I4. Prandoni P, Lensing AW, Prins MH, Frulla M, Marchiori A, Bernardi E, et al. Belowknee elastic compression stockings to prevent the post-thrombotic syndrome: a randomized, controlled trial. Ann Intern Med. 2004;I4I(4):249-56.

I5. Prandoni P, Lensing AW, Cogo A, Cuppini S, Villalta S, Carta M, et al. The long-term 
clinical course of acute deep venous thrombosis. Ann Intern Med. I996;I25(I):I-7.

I6. Prandoni P, Villalta S, Bagatella P, Rossi L, Marchiori A, Piccioli A, et al. The clinical course of deep-vein thrombosis. Prospective long-term follow-up of 528 symptomatic patients. Haematologica. 1997;82(4):423-8.

I7. Lee BB, Nicolaides AN, Myers K, Meissner M, Kalodiki E, Allegra C, et al. Venous hemodynamic changes in lower limb venous disease: the UIP consensus according to scientific evidence. International angiology : a journal of the International Union of Angiology. 2016;35(3):236-352.

I8. Labropoulos N, Volteas N, Leon M, Sowade O, Rulo A, Giannoukas AD, et al. The role of venous outflow obstruction in patients with chronic venous dysfunction. Arch Surg. 1997;132(I):46-5I.

I9. Strijkers RH, Arnoldussen CW, Wittens CH. Validation of the LET classification. Phlebology / Venous Forum of the Royal Society of Medicine. 20I5;30(I Suppl):I4-9.

20. Kahn SR, Shbaklo H, Lamping DL, Holcroft CA, Shrier I, Miron MJ, et al. Determinants of health-related quality of life during the 2 years following deep vein thrombosis. J Thromb Haemost. 2008;6(7):IIO5-I2.

2I. Kahn SR, Shrier I, Julian JA, Ducruet T, Arsenault L, Miron MJ, et al. Determinants and time course of the postthrombotic syndrome after acute deep venous thrombosis. Ann Intern Med. 2008;149(I0):698-707.

22. Baxter GM, Duffy P. Calf vein anatomy and flow: implications for colour Doppler imaging. Clinical radiology. 1992;46(2):84-7.

23. Kahn SR, Hirsch A, Shrier I. Effect of postthrombotic syndrome on health-related quality of life after deep venous thrombosis. Arch Intern Med. 2002;I62(IO):II44-8.

24. Bergqvist D, Jendteg S, Johansen L, Persson U, Odegaard K. Cost of long-term complications of deep venous thrombosis of the lower extremities: an analysis of a defined patient population in Sweden. Ann Intern Med. 1997;I26(6):454-7.

25. Kahn SR. Post-thrombotic syndrome after deep venous thrombosis: risk factors, prevention, and therapeutic options. Clin Adv Hematol Oncol. 2009;7(7):433-5.

26. Kahn SR, Shrier I, Shapiro S, Houweling AH, Hirsch AM, Reid RD, et al. Six-month exercise training program to treat post-thrombotic syndrome: a randomized controlled two-centre trial. CMAJ.I83(I):37-44.

27. AbuRahma AF, Robinson PA, Boland JP. Clinical, hemodynamic, and anatomic predictors of long-term outcome of lower extremity venovenous bypasses. Journal of vascular surgery : official publication, the Society for Vascular Surgery [and] International Society for Cardiovascular Surgery, North American Chapter. I99I;I4(5):635-44.

28. Perrin M. Reconstructive surgery for deep venous reflux: a report on 444 cases. Cardiovascular surgery. 2000;8(4):246-55.

29. May R, Thurner J. The cause of the predominantly sinistral occurrence of thrombosis of the pelvic veins. Angiology. 1957;8(5):419-27.

30. Neglen P, Hollis KC, Olivier J, Raju S. Stenting of the venous outflow in chronic venous disease: long-term stent-related outcome, clinical, and hemodynamic result. Journal of 
vascular surgery. 2007;46(5):979-90.

3I. Kibbe MR, Ujiki M, Goodwin AL, Eskandari M, Yao J, Matsumura J. Iliac vein compression in an asymptomatic patient population. Journal of vascular surgery. 2004;39(5):937-43.

32. Dotter CT, Judkins MP. Transluminal Treatment of Arteriosclerotic Obstruction. Description of a New Technic and a Preliminary Report of Its Application. Circulation. I964;30:654-70.

33. Baekgaard N, Broholm R, Just S. Indications for stenting during thrombolysis. Phlebology / Venous Forum of the Royal Society of Medicine. 2013;28 Suppl I:II2-6.

34. Hartung O, Otero A, Boufi M, De Caridi G, Barthelemy P, Juhan C, et al. Mid-term results of endovascular treatment for symptomatic chronic nonmalignant iliocaval venous occlusive disease. Journal of vascular surgery. 2005;42(6):II38-44; discussion 44 .

35. Neglen P, Raju S. Balloon dilation and stenting of chronic iliac vein obstruction: technical aspects and early clinical outcome. J Endovasc Ther. 2000;7(2):79-9I.

36. AbuRahma AF, Perkins SE, Wulu JT, Ng HK. Iliofemoral deep vein thrombosis: conventional therapy versus lysis and percutaneous transluminal angioplasty and stenting. Ann Surg. 200I;233(6):752-60.

37. Alhalbouni S, Hingorani A, Shiferson A, Gopal K, Jung D, Novak D, et al. Iliac-femoral venous stenting for lower extremity venous stasis symptoms. Ann Vasc Surg. 20I2;26(2):I85-9.

38. Hartung O, Loundou AD, Barthelemy P, Arnoux D, Boufi M, Alimi YS. Endovascular management of chronic disabling ilio-caval obstructive lesions: long-term results. European journal of vascular and endovascular surgery : the official journal of the European Society for Vascular Surgery. 2009;38(I):II8-24.

39. Nazarian GK, Austin WR, Wegryn SA, Bjarnason H, Stackhouse DJ, Castaneda-Zuniga WR, et al. Venous recanalization by metallic stents after failure of balloon angioplasty or surgery: four-year experience. Cardiovasc Intervent Radiol. I996;19(4):227-33.

40. Titus JM, Moise MA, Bena J, Lyden SP, Clair DG. Iliofemoral stenting for venous occlusive disease. Journal of vascular surgery. 201I;53(3):706-I2.

4I. Neglen P, Tackett TP, Jr., Raju S. Venous stenting across the inguinal ligament. Journal of vascular surgery. 2008;48(5):I255-6I.

42. de Wolf MA, de Graaf R, Kurstjens RL, Penninx S, Jalaie H, Wittens CH. Short-Term Clinical Experience with a Dedicated Venous Nitinol Stent: Initial Results with the Sinus-Venous Stent. European journal of vascular and endovascular surgery : the official journal of the European Society for Vascular Surgery. 2015.

43. O'Sullivan GJ, Sheehan J, Lohan D, McCann-Brown JA. Iliofemoral venous stenting extending into the femoral region: initial clinical experience with the purpose-designed Zilver Vena stent. The Journal of cardiovascular surgery. 2013;54(2):255-6I.

44. Comerota AJ, Grewal NK, Thakur S, Assi Z. Endovenectomy of the common femoral vein and intraoperative iliac vein recanalization for chronic iliofemoral venous occlusion. Journal of vascular surgery. 2010;52(I):243-7.

45. Puggioni A, Kistner RL, Eklof B, Lurie F. Surgical disobliteration of postthrombotic 
deep veins--endophlebectomy--is feasible. Journal of vascular surgery : official publication, the Society for Vascular Surgery [and] International Society for Cardiovascular Surgery, North American Chapter. 2004;39(5):I048-52; discussion 52.

46. Raju S, Neglen P, Doolittle J, Meydrech EF. Axillary vein transfer in trabeculated postthrombotic veins. Journal of vascular surgery : official publication, the Society $f$ or Vascular Surgery [and] International Society for Cardiovascular Surgery, North American Chapter. 1999;29(6):I050-62; discussion 62-4.

47. Vogel D, Comerota AJ, Al-Jabouri M, Assi ZI. Common femoral endovenectomy with iliocaval endoluminal recanalization improves symptoms and quality of life in patients with postthrombotic iliofemoral obstruction. Journal of vascular surgery. 20I2;55(I):I29-35. 



\section{CHAPTER 2}

\section{INCIDENCE AND RISK FACTORS \\ OF THE POST-THROMBOTIC SYNDROME}

\section{M.A.F. de Wolf ${ }^{1,2}$ \\ C.H.A. Wittens ${ }^{1,2,3}$ \\ S.R. Kahn ${ }^{4}$}

I Department of Surgery, Maastricht University Medical Centre

2 School for Cardiovascular Diseases (CARIM), Maastricht University, Maastricht, The

Netherlands

3 Department of Vascular Surgery, Aachen University Hospital, Aachen, Germany 4 Division of Internal Medicine, McGill University and Center for Clinical Epidemiology, Jewish General Hospital, Montreal, Canada

Published in Phlebology

DOI: I0.I258/phleb.20II.oI2So6. Phlebology 20I2;27 Suppl I:85-94 


\section{ABSTRACT}

Annually I - 2 in every Iooo adults will develop a deep venous thrombosis of the lower extremity. A third to half of these patients will develop the post-thrombotic syndrome (PTS). However, predicting which patients will develop the PTS remains elusive. Ipsilateral thrombosis recurrence seems to be the most important risk factor. Moreover, residual venous occlusion and valvular reflux seem to predict PTS incidence to some degree. Laboratory parameters, including D-dimers and inflammatory markers, have shown promise in predicting development of the PTS in patients and are currently under investigation. Creating a model based on all combined risk factors and patient characteristics might aid in risk stratification in individual patients. 


\section{INTRODUCTION}

Annually, approximately I -2 in every Iooo adults will develop a deep venous thrombosis (DVT) of the leg, slightly more than half of these are hospital-acquired.I Apart from the acute symptoms, consisting of a painful, swollen, red and warm extremity, at least onethird of these patients will develop the post-thrombotic syndrome (PTS). PTS encompasses a great range of symptoms varying from relatively mild signs (slight swelling, venous eczema, pigmentation and minor complaints) to the gravest of venous symptoms: i.e. severe oedema, venous claudication, chronic pain and recurrent ulcers. PTS incidence in the DVT population is generally accepted to be between $20 \%$ and $50 \%$. Reported percentages depend mostly on patient characteristics, follow-up duration and treatments used (Table I).2 - 35 In 5 - IO\% of DVT patients, severe PTS, characterized by chronic debilitating symptoms, will develop.6,I0,25 Symptoms of PTS normally arise within the first year post-DVT, thereafter only PTS severity rises.27 Quality of life (QoL) is dramatically decreased in these most severe cases, with QoL scores comparable with patients with congestive cardiac failure or chronic obstructive pulmonary disease.18,36,37 Furthermore, enormous socioeconomic costs are associated with PTS, especially when patients develop chronic venous ulcers. $38-40$

\section{PATHOPHYSIOLOGY}

The PTS can be seen as a special form of chronic venous insufficiency, with a clearly definable starting point at the moment of the first DVT and a generally rapid progression towards venous complaints and symptoms, i.e. high CEAP (clinical, aetiological, anatomical and pathological elements) (Table 2), VCSS (Venous Clinical Severity Score) and Villalta (Table 3) scores. The basis of PTS pathophysiology is formed by a triad of venous obstruction by residual thrombus or scarification of venous tracts, venous insufficiency due to valve destruction and reduced mobility leading to impairment of calf muscle pump function. Recent and current studies are clarifying the role of the inflammatory system and the manner of thrombus fibrin degradation in post-DVT vein tracts.4I - 44 Ultimately, these changes in the venous system of the lower extremity might all lead to impaired venous outflow, venous hypertension and finally abnormal capillary perfusion. 
Table I Incidence of the post-thrombotic syndrome2 - 35

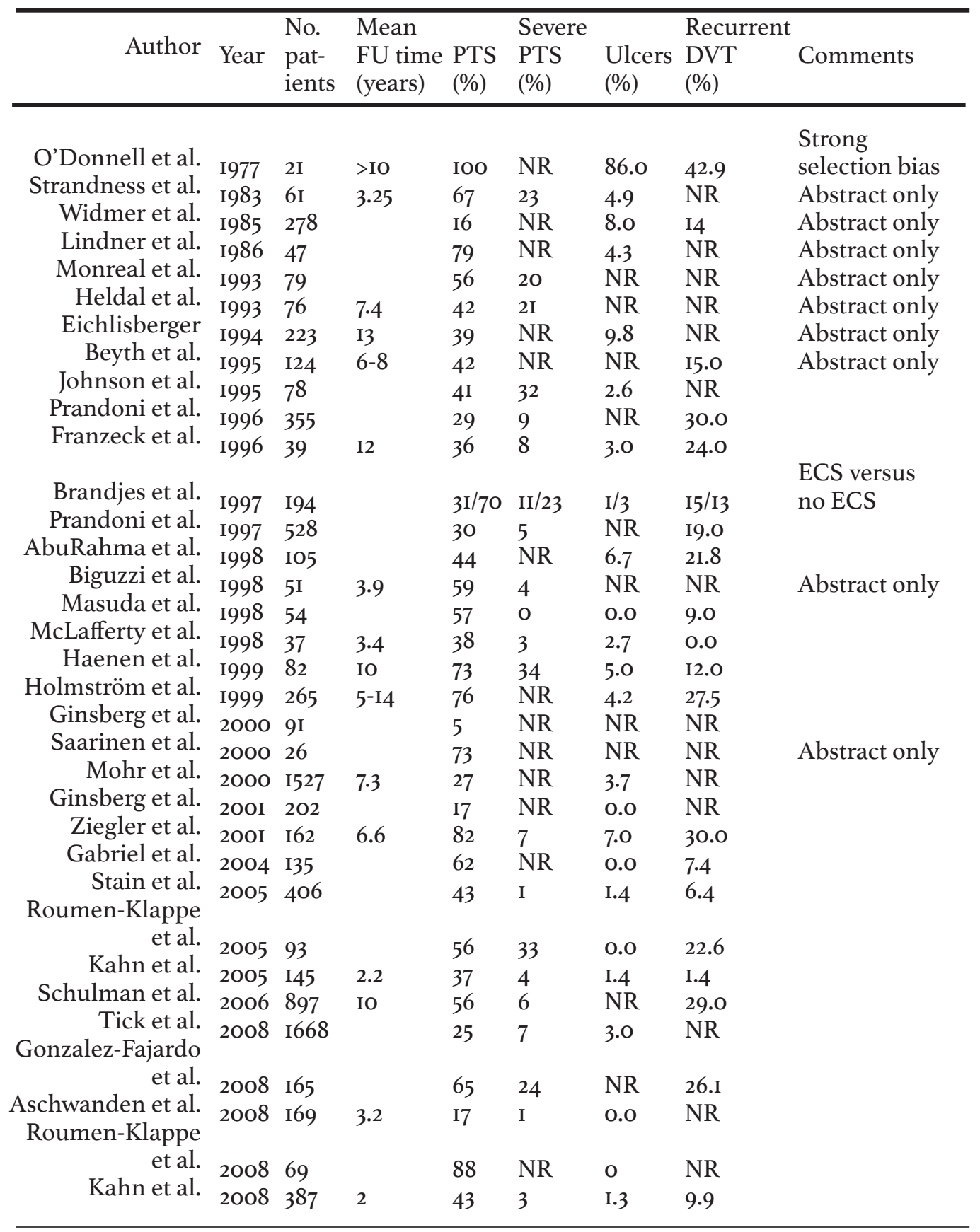

$N R$, not reported; FU, follow-up; ECS, elastic compression stockings; Abstract only, only the abstract of the paper was available to the authors; PTS, post-thrombotic syndrome; DVT, deep venous thrombosis. 
Table 2 CEAP Classification, adapted from Eklöf et al.97

Clinical manifestations

of the revised 2004

CEAP classification Attributed signs and symptoms

$\begin{array}{ll}\text { CEAP Co } & \begin{array}{l}\text { No visible or palpable signs of venousdisease } \\ \text { Telangiectases or reticular veins } \\ \text { CEAP C1 }\end{array} \\ \text { CEAP C2 } & \begin{array}{l}\text { Varicose veins; distinguished from reticular } \\ \text { veins by a diameter of } 3 \text { mm or more }\end{array} \\ \text { CEAP C3 } & \text { Oedema } \\ \text { CEAP C4a } & \text { Pigmentation or eczema } \\ \text { CEAP C4b } & \text { Lipodermatosclerosis or atrophie blanche } \\ \text { CEAP C5 } & \text { Healed venous ulcer } \\ \text { CEAP C6 } & \text { Active venous ulcer }\end{array}$

CEAP, clinical, aetiological, anatomical and pathological elements

\section{CURRENT TREATMENT OPTIONS}

The cornerstone of PTS prevention remains the use of elastic compression stockings (ECS) after a symptomatic DVT event. Studies on long-term use of ECS after a proximal DVT have shown a highly significant reduction in both mild/moderate PTS and severe PTS.45 Therefore, it is generally recommended to prescribe below-knee ECS with a pressure gradient of $30-40 \mathrm{mmHg}$ to patients with symptomatic proximal DVT.46 Use of lower-pressure gradient stockings might increase patient satisfaction and therapy compliance; however, evidence on the lowest amount of pressure needed to prevent PTS is currently unavailable. Also, ECS treatment duration is controversial. Current guidelines advocate the use of ECS for two years or longer after an initial thrombotic event; however, Aschwanden et al.3 recently showed no added effect of prolonging ECS treatment after six months for prevention of skin changes and PTS symptoms, suggesting that a decrease in treatment duration is feasible. Moreover, Roumen-Klappe et al.28 suggest multilayer compression bandaging in the acute phase of DVT to have no effect on the development of the PTS compared with delayed compression therapy with stockings. Starting treatment solely with elastic stockings within two weeks postDVT thus seems feasible.

Prevention of PTS is now the major focus of trials researching catheter-directed thrombolysis to treat proximal DVT (e.g. the Scandinavian CAVENT trial, the American ATTRACT trial and the Dutch CAVA trial).47-49 Thrombolysis in the acute phase of DVT has been proposed to reduce long-term venous occlusion. Furthermore, rapid recanalization of venous tracts may reduce valve damage and avert deep venous insufficiency. Short-term studies have shown the safety and 
feasibility of this treatment modality; however, the long-term effects on PTS development are currently unknown.50-53

Table 3 Villalta score, adapted from Kahn et al.98

\begin{tabular}{lllll}
\hline Symptoms and clinical signs & None & Mild & Moderate & Severe \\
\hline Symptoms & & & \\
Pain & & & \\
Cramps & o points & I point & 2 points & 3 points \\
Heaviness & o points & I point & 2 points & 3 points \\
Paraesthesia & o points & I point & 2 points & 3 points \\
Pruritus & o points & I point & 2 points & 3 points \\
Clinical signs & o points & I point & 2 points & 3 points \\
Pretibial oedema & & & & \\
Skin induration & o points & I point & 2 points & 3 points \\
Hyperpigmentation & o points & I point & 2 points & 3 points \\
Redness & o points & I point & 2 points & 3 points \\
Venous ectasia & o points & I point & 2 points & 3 points \\
Pain on calf compression & o points & I point & 2 points & 3 points \\
Venous ulcer & o points & I point & 2 points & 3 points \\
& Absent & Present & &
\end{tabular}

PTS, post-thrombotic syndrome. Points are summed into a total score (range o-33). PTS is defined by a total score of 5 or the presence of a venous ulcer. PTS is classified as mild if the Villalta score is 5-9, moderate if the Villalta score is IO-I4 and severe if the Villalta score is I5 or a venous ulcer is present. To use the Villalta score as a continuous measure, it is recommended that patients who meet criteria for severe PTS based solely on the presence of an ulcer (i.e. total Villalta score is ,I5) be assigned a score of I5.

During the last two decades a number of invasive treatments have been proposed to treat both deep venous insufficiency and persistent occlusion after a thrombotic event. A number of surgical procedures to treat venous valve insufficiency currently exist: internal and external valvuloplasty,54 external banding,55 the Maleti neovalve56 and axial vein transfer. 57 Valvuloplasty is preferred by most authors. However, in a great number of patients valvuloplasty is not a viable option, due to destruction of the valve leaflets during the recanalization process in post-thrombotic legs. Persistent post-DVT occlusions are now being recognized as being of importance and treated in a number of specialized centres by angioplasty and stenting. Mid- and long-term follow-up show good results with primary patency rates of approximately $80 \%$ two years post-stenting and a clinically significant decrease in PTS symptoms;58 - 6o however, randomized controlled trials of these treatments are lacking. In general, interventional treatment is only offered at select centres with expertise in these techniques to patients with severe persistent symptoms after the initial DVT. 
In light of the limitations of the current treatment options, identification of risk factors for the development of PTS remains of greatest importance. Likewise, identification of high-risk patients will be needed in selecting patients for treatment with catheterdirected thrombolysis in the future.

\section{RISK FACTORS}

\section{Age}

Differences between young and old patients might underlie differences in PTS incidence, though no clear mechanism has been postulated yet. Changes in the vein wall, hormonal factors, innate thrombus lysis, inflammatory response to thrombosis and mobility/calf muscle pump function might all differ by age. Advancing age has been clearly shown to be a risk factor for DVT, with incidence being very low in children (ranging from 34 to 58 cases of venous thromboembolism per I0,00o hospital admissions in children of, I8 years of age) and increasing steadily to 3. I per Iooo by the age of $85-89$ years.6I,62 However, the relation between age and incidence of PTS remains controversial. Conflicting reports in the literature have been put forward; some authors have described a positive correlation,17,30,31,63-65 some reported no correlationi 7 and some even a lower incidence of PTS in older patients. 33 An increase of 0.3 points in the Villalta score per Io-year age increase was found by Kahn et al.,65 whereas Stain et al.3I reported an odds ratio (OR) for PTS development of I.2 for every IO-year age increase. Moreover, Schulman et al.30 showed age above 60 years to be associated with a higher proportion of proximal DVT (58\% versus $42 \%, \mathrm{P} 1 / 4 \mathrm{O}$.00I) and a higher DVT recurrence rate $(31 \%$ versus $25 \%, \mathrm{P} 1 / 40.049)$, compared with younger patients, both of which are independent risk factors for the development of PTS. A relationship between severity of PTS and age, however, has not been noted.I7

\section{Obesity}

Increased body weight has been proposed to lead to poor calf muscle function via lack of physical exercise, increased venous pressure and promotion of venous reflux. Obesity has indeed been associated with an increased risk of PTS.5,I7,31,33,64,66 A I.5fold increase in PTS incidence in patients with a body mass index (BMI) $\geq 30 \mathrm{~kg} / \mathrm{m} 2 \mathrm{has}$ been described.33 An increase in Villalta score of 0.14 and 0.16 per I kg/m2 increase in BMI has been described by Kahn et al.I7,65 in two studies. Furthermore, a higher BMI has been associated with less favourable QoL scores in PTS patients.I8

Sex differences have historically been of great interest within the whole spectrum of venous pathology. However, underlying causes of such differences have been poorly understood. These might include hormonal, mechanical or anatomical dissimilarities. Increased incidence of PTS has been described in both males and females.33 Stain et al. found male gender to be a weak predictor of PTS occurrence (OR I.6) and also found 
an increased incidence of DVT recurrence in men, which is an independent risk factor for PTS development.3I However, a greater number of studies found PTS to be more prevalent in women.33,65 Female sex had no effect on two-year QoL changes in postDVT patients, including PTS patients.I8

Table 4 Summary of risk factors for PTS

\begin{tabular}{rcl}
\hline & Correlation with \\
Risk factor & PTS incidence & Comment \\
Age & + & Also correlates with DVT recurrence risk \\
Obesity & + & \\
Female gender & + & Conflicting evidence \\
Provoked (vs Unprovoked) & \pm & Strong risk factor for venous \\
deepvenous thrombosis & + & thromboembolism recurrence \\
Ipsilateral recurrence & + & Also correlates with severity of PTS \\
Thrombus location & + & Also correlates with severity of PTS \\
(proximal versusdistal) & & \\
Residual occlusion & ++ & \\
Residual reflux & ++ & Deep and superficial reflux \\
Insufficient quality of & + & Conflicting evidence \\
anticoagulant therapy & & Factor V Leiden or the G2O2IoA \\
Thrombophilia & \pm & prothrombin gene mutations \\
D-Dimer & + & Currently being evaluated
\end{tabular}

PTS, post-thrombotic syndrome; DVT, deep venous thrombosis Risk factor's relation with PTS incidence: ++ strong correlation, + moderate correlation, \pm mostly unclear or no correlation

\section{Unprovoked vs. provoked DVT}

While surgery and trauma are associated with a high incidence of provoked DVT (ORs as high as 21.7 and I2.7, respectively67), unprovoked DVT on the other hand might be an indication of an underlying hypercoagulable state that could lead to a higher incidence of recurrent thromboembolic events and PTS. However, a difference in the incidence of PTS after unprovoked versus provoked DVT has not been noted.5,II,3I,68,69

\section{Ipsilateral DVT recurrence}

Ipsilateral recurrent thrombosis is common in DVT patients (Table I). Two or more thrombotic events in the same extremity have been shown to increase the incidence of PTS,4,I2,25,26,31,35,63 and previous ipsilateral thrombosis was associated with a I.78-point increase in Villalta score.I8,65 Conversely, presence of PTS was associated with a 6- to II-fold increased incidence of recurrent DVT in patients treated with anticoagulants.I2 This might be explained by the findings of Young et al.7o who 
showed an increased risk (hazard ratio 2.2) of DVT recurrence in limbs with residual thrombosis, as residual thrombus is also a known predictor of PTS. The mechanism by which DVT recurrence increases PTS incidence and/or severity most likely relates to aggravation of local venous damage and worsening of venous reflux via valvular destruction and extension of residual occlusion of affected vein segments. Kahn et al.65 showed a 9.9\% incidence of recurrent thrombosis during two years after treatment of DVT with anticoagulants; predictors of recurrence were cancer-associated venous thrombosis, unprovoked venous thrombosis, proximal (versus distal) thrombosis, symptomatic pulmonary embolism at study enrolment and male gender. Higher incidences of recurrence in patients with proximal DVT and in males have also been noted after longer patient follow-up.26,30,65 Increased contralateral recurrence has also been noted in a number of studies, probably via systemic vein wall defects, blood hypercoagulability or body habitus.I2,35 A lower incidence of recurrence was seen after DVT provoked by surgery or trauma, conceivably because no underlying systemic venous aberrations were present. 26

\section{Thrombus location}

In many studies, proximal thrombi in the deep venous system (popliteal, femoral, common femoral and iliac veins) have been associated with a worse clinical and haemodynamic outcome and lower QoL scores than distal thrombi (peroneal, tibial, gastrocnemial, and soleus veins).9,15,18,23,31,33,65,71,72 Controversy remains, however, as some studies did not find this correlation.25,63 Kahn et al. found a PTS incidence of $52 \%$ in patients with proximal DVT versus

$4 \mathrm{I} \%$ in distal DVT, and a 2.23-point increase in Villalta score with proximal versus distal DVT.18,65 Similar findings were shown by Holmstro"m et al.I5 QoL scores were also lower in patients with proximal versus distal DVT.I8 Van Ramshorst et al.73 showed thrombus extent to correlate well with the number of refluxing vein segments at followup, but no association was shown for clinical severity. Eichlisberger et al.7 showed a greatly increased incidence of PTS in patients with four-level thrombosis compared with those with popliteal vein thrombosis only ( $55 \%$ versus $4 \%$, respectively) at I 3 years after the initial DVT, and Tick et al. showed a I.3-fold increase in PTS incidence with iliofemoral as compared with popliteal thrombosis. 33

\section{Residual occlusion}

Incomplete recanalization of thrombosed venous tracts is thought to impair the outflow of post-DVT extremities, thereby promoting venous hypertension. Johnson et al.I6 showed residual occlusion to be present in $80 \%$ of post-thrombotic limbs and reflux to be present in $83 \%$ (in $65 \%$ of limbs both occlusion and reflux were present). It takes a mean of $3.4+5.9$ months to achieve 50\% recanalization after DVT.72 Prandoni et al.74 found a relative risk for PTS development of 1.56 with the presence of residual vein thrombosis, and I.69 if both residual vein thrombosis and popliteal vein reflux were present. In another study, they found a hazard ratio of 2.4 for recurrent 
thromboembolism in patients with residual thrombosis compared with those with complete recanalization.75 This was confirmed in another study that showed the risk of DVT recurrence and mortality was increased in patients with residual occlusion after DVT (hazard ratios 2.2 and 3.9, respectively).70 However, controversy remains as Haenen et al.i3 found no relation between non-compressibility or the combination of reflux and non-compressibility and PTS. Kahn et al.I7 found comparable results. Furthermore, the proportion of venous occlusion was reported to be the same in patients with CEAP scores of $\mathrm{Co}-3$ and $\mathrm{C}_{4}-6.76$

\section{Residual reflux}

Loss of venous valve function due to thrombosis has been proposed as one of the main pathological pathways by which PTS develops. Indeed, it has long been shown that reflux in the deep veins of the affected limb correlates well with incidence and severity of PTS.I3,76,77 Yamaki et al.76 showed peak reflux velocity in the popliteal and femoral vein on duplex to correlate highly (OR 60.32 for popliteal vein and 25.77 for femoral vein) with severity of chronic venous insufficiency. Haenen et al.I3 showed reflux in the proximal deep veins to be associated with worse CEAP scores (Table 2), but no such relation was shown for reflux in superficial veins and distal deep veins. In a second study, the same group showed superficial venous reflux to be the most important risk factor for onset of PTS symptoms and $64 \%$ of patients with severe PTS were shown to have a combination of superficial and deep reflux.78 A combination of deep and superficial reflux therefore seems to underlie PTS pathogenesis.

\section{Insufficient quality of anticoagulant therapy}

Vitamin K antagonist treatment is still one of the cornerstones of DVT treatment.46 Insufficient quality of anticoagulation might inhibit the recanalization process and worsen clinical outcome in the affected limb. Ziegler et al.35 indeed showed this relation. They described insufficient anticoagulation measurements in half of the patients suffering from venous ulcers. More recently an increased incidence of PTS (OR 2.7I) was described in patients whose international normalized ratio (INR) level was below 2.0 for $>50 \%$ of the time.64 Moreover, longer treatment duration with oral anticoagulants significantly reduces the risk of recurrent thrombosis, which is an important risk factor for PTS.I5

\section{Thrombophilia}

The presence of factor V Leiden or the G20210A prothrombin gene mutation has been shown to increase the risk of a first venous thrombosis.79,80 Moreover, in family members of patients with one of these mutations, an OR of I.68 was found for DVT incidence.8I There is conflicting evidence on the role of these thrombophilia markers on PTS incidence. Kahn et al.I7 showed factor V Leiden or the prothrombin gene mutation to be independently associated with a decreased incidence of PTS (OR 0.33) and a I.6 decrease in Villalta score. However, in another study by the same group, 
these results could not be replicated and the same is true for a number of other recent studies.3I,33,63-65

\section{D-dimer}

Elevated plasma D-dimer concentration predicts both first and recurrent DVT events.82 - 88 Stain et al.3I showed D-dimer levels to be positively associated (OR I.9) with PTS incidence. The recent finding that D-dimer was strongly reducible by vitamin $\mathrm{K}$ antagonists supports this assumption and reflects the fact that increased INR seems to protect against PTS development.89 Latella et al.9o showed that increased D-dimer levels were associated with occurrence of PTS in both DVT patients treated with and without vitamin $\mathrm{K}$ antagonists, and the association was strongest in those not currently treated (OR 3.79).

\section{Inflammatory markers}

Recently, a number of studies have focused on the role of inflammatory cytokines and adhesion molecules in the development of PTS. These include interleukin 6,8 and Io (IL-6, IL-8 and IL-IO), C-reactive protein (CRP), monocyte chemotactic protein-I (MCPI), intracellular adhesion molecule-I (ICAM-I) and vascular cell adhesion molecule-I (VCAM-I). Studies were based on the hypothesis that the inflammatory response to DVT leads to vein wall abnormalities. PTS patients were shown to have a I.6-fold increase in mean IL-6 level and a trend towards higher median levels of IL-6 four months after DVT diagnosis.44 Roumen-Klappe et al. showed that IL-6 and CRP levels measured on the day of DVT diagnosis did not correlate with Villalta score one year post-DVT and only weakly correlated with CEAP classification one year post-DVT, but strong associations were seen between these markers and venous outflow resistance 90 days post-DVT (which in itself corre-lates with PTS incidence after I year), and in the case of IL-6, Porter's thrombosis score (based on thrombus extent and site involvement).43,9I ICAM-I levels are also associated with PTS.44,92 No correlations between PTS and IL8, IL-IO, MCP-I and VCAM-I were shown.43,44 An association between inflammatory markers and reflux was not seen, supporting the notion that the inflammatory response may act on vein wall characteristics rather than venous valves.43,44,92 However, studies in animal models strongly suggest a role of inflamma-tory pathways in the development of venous valve degradation in chronic venous insufficiency, which indicates that secondary damage due to pathological haemodynamics post-DVT might con-tribute to PTS progression rather than initiation.93,94 Moreover, increased plasma levels of IL-6, IL-8 and MCP-I have been shown to be increased in patients with recurrent DVT, which is an indepen-dent risk factor for PTS development.95 The value of inflammatory markers in the prediction of PTS is currently being evaluated in a large prospective study.96 


\section{CONCLUSION}

General interest and awareness of the PTS have recently been stimulated by improved standardization of PTS measurement and the emergence of new potential treatment modalities such as new oral anticoagulants, catheter-directed thrombolysis and deep venous stenting procedures. However, effective stratification of the risk for progression to PTS in patients presenting with a first or recurrent DVT remains elusive. Recurrence of thrombosis in the same extremity as the index DVT, with resultant increased venous damage, seems to be one of the

most important risk factors for PTS development. Residual venous occlusion and valvular reflux, signifying venous damage, also seem to predict PTS incidence to some degree. Based on promising preliminary work, the value of D-dimer and inflammatory marker levels as a means to predict PTS is currently being investigated. Work to develop a future model that combines the above factors together with patient characteristics could provide a useful tool for stratifying risk of PTS development in individual patients with DVT. 


\section{REFERENCE}

I. Cohen AT, Agnelli G, Anderson FA, et al. Venous throm-boembolism (VTE) in Europe. The number of VTE events and associated morbidity and mortality. Thromb Haemost 2007;98:756- 64

2. AbuRahma AF, Stickler DL, Robinson PA. A prospective controlled study of the efficacy of short-term anticoagu-lation therapy in patients with deep vein thrombosis of the lower extremity. J Vasc Surg 1998;28:630 -7

3. Aschwanden M, Jeanneret C, Koller MT, Thalhammer C, Bucher HC, Jaeger KA. Effect of prolonged treatment with compression stockings to prevent post-thrombotic sequelae: a randomized controlled trial. J Vasc Surg 2008;47:IOI5 - 2I

4. Beyth RJ, Cohen AM, Landefeld CS. Long-term out-comes of deep-vein thrombosis. Arch Intern Med I995; I55:I03I - 7

5. Biguzzi E, Mozzi E, Alatri A, Taioli E, Moia M, Mannucci PM. The post-thrombotic syndrome in young women: retrospective evaluation of prognostic factors. Thromb Haemost I998;80:575- 7

6. Brandjes DP, Buller HR, Heijboer H, et al. Randomized trial of effect of compression stockings in patients with symptomatic proximal-vein thrombosis. Lancet 1997; 349:759 $-62$

7. Eichlisberger R, Frauchiger B, Widmer MT, Widmer LK,

8. Jager K. [Late sequelae of deep venous thrombosis: a I3-year follow-up of 223 patients]. Vasa 1994;23: $234-43$

9. Franzeck UK, Schalch I, Jager KA, Schneider E, Grimm J, Bollinger A. Prospective I2-year follow-up study of clinical and hemodynamic sequelae after deep vein thrombosis in low-risk patients (Zurich study). Circula-tion 1996;93:74- 9

Io. Gabriel F, Labios M, Portoles $\mathrm{O}$, et al. Incidence of post-thrombotic syndrome and its association with various risk factors in a cohort of Spanish patients after one

II. year of follow-up following acute deep venous thrombo-sis. Thromb Haemost 2004;92:328 $-36$

I2. Ginsberg JS, Hirsh J, Julian J, et al. Prevention and treat-ment of postphlebitic syndrome: results of a three-part study. Arch Intern Med 200I;I6I:2IO5 - 9

I3. Ginsberg JS, Turkstra F, Buller HR, MacKinnon B, Magier D, Hirsh J. Post-thrombotic syndrome after hip or knee arthroplasty: a cross-sectional study. Arch Intern Med 2000;160:669- 72

I4. Gonzalez-Fajardo JA, Martin-Pedrosa M, Castrodeza J, Tamames S, Vaquero-Puerta C. Effect of the anticoagu-lant therapy in the incidence of post-thrombotic syn-drome and recurrent thromboembolism: comparative study of enoxaparin versus coumarin. J Vasc Surg 2008;48:953-9

I5. Haenen JH, Janssen MC, van Langen $\mathrm{H}$, et al. The post-thrombotic syndrome in relation to venous hemody-namics, as measured by means of duplex scanning and strain-gauge plethysmography. J Vasc Surg 1999;29: I07I-6

I6. Heldal M, Seem E, Sandset PM, Abildgaard U. Deep vein thrombosis: a seven-year 
follow-up study. J Intern Med 1993;234:7I - 5

I7. Holmstrom M, Aberg W, Lockner D, Paul C. Long-term clinical follow-up in 265 patients with deep venous thrombosis initially treated with either unfractionated heparin or dalteparin: a retrospective analysis. Thromb Haemost 1999;82:1222 - 6

I8. Johnson BF, Manzo RA, Bergelin RO, Strandness DE Jr. Relationship between changes in the deep venous system and the development of the post-thrombotic syn-drome after an acute episode of lower limb deep vein thrombosis: a one- to six-year follow-up. J Vasc Surg 1995;21:307 - I2; discussion 313

I9. Kahn SR, Kearon C, Julian JA, et al. Predictors of the post-thrombotic syndrome during long-term treatment of proximal deep vein thrombosis. J Thromb Haemost 2005;3:718 23

20. Kahn SR, Shbaklo H, Lamping DL, et al. Determinants of health-related quality of life during the two years following deep vein thrombosis. J Thromb Haemost 2008;6:IIO5 - I2

2I. Lindner DJ, Edwards JM, Phinney ES, Taylor LM Jr, Porter JM. Long-term hemodynamic and clinical seque-lae of lower extremity deep vein thrombosis. J Vasc Surg 1986;4:436 42

22. Masuda EM, Kessler DM, Kistner RL, Eklof B, Sato DT. The natural history of calf vein thrombosis: lysis of thrombi and development of reflux. J Vasc Surg I998; 28:67 - 73; discussion $73-64$

23. McLafferty RB, Moneta GL, Passman MA, Brant BM, Taylor LM Jr, Porter JM. Late clinical and hemodynamic sequelae of isolated calf vein thrombosis. J Vasc Surg 1998;27:50 - 6; discussion $56-7$

24. Mohr DN, Silverstein MD, Heit JA, Petterson TM, O’Fallon WM, Melton LJ. The venous stasis syndrome after deep venous thrombosis or pulmonary embolism: a populationbased study. Mayo Clin Proc 2000;75: 1249- 56

25. Monreal M, Martorell A, Callejas JM, et al. Venographic assessment of deep vein thrombosis and risk of develop-ing post-thrombotic syndrome: a prospective study. J Intern Med 1993;233:233-8

26. O'Donnell TF Jr, Browse NL, Burnand KG, Thomas ML. The socioeconomic effects of an iliofemoral venous thrombosis. J Surg Res 1977;22:483 -8

27. Prandoni P, Lensing AW, Cogo A, et al. The long-term clinical course of acute deep venous thrombosis. Ann Intern Med 1996;125:I - 7

28. Prandoni P, Villalta S, Bagatella $\mathrm{P}$, et al. The clinical course of deep-vein thrombosis. Prospective long-term follow-up of 528 symptomatic patients. Haematologica 1997;82:423 $-8$

29. Roumen-Klappe EM, den Heijer M, Janssen MC, van der Vleuten C, Thien T, Wollersheim $\mathrm{H}$. The post-thrombotic syndrome: incidence and prognostic value of non-invasive venous examinations in a six-year follow-up study. Thromb Haemost 2005;94:825 - 30

30. Roumen-Klappe EM, den Heijer M, van Rossum J, et al. Multilayer compression bandaging in the acute phase of deep-vein thrombosis has no effect on the development of the post-thrombotic syndrome. J Thromb Thrombolysis 2009;27:400 - 5

3I. Saarinen J, Kallio T, Lehto M, Hiltunen S, Sisto T. The occurrence of the post-thrombotic 
changes after an acute deep venous thrombosis. A prospective two-year follow-up study. J Cardiovasc Surg (Torino) 2000;4I:44I - 6

32. Schulman S, Lindmarker P, Holmstrom M, et al. Post-thrombotic syndrome, recurrence, and death Io years after the first episode of venous thromboembolism treated with warfarin for six weeks or six months. J Thromb Haemost 2006;4:734- 42

33. Stain M, Schonauer V, Minar E, et al. The post-thrombotic syndrome: risk factors and impact on the course of thrombotic disease. J Thromb Haemost 2005;3:267I -76

34. Strandness DE Jr, Langlois Y, Cramer M, Randlett A, Thiele BL. Long-term sequelae of acute venous thrombo-sis. JAMA I983;250:I289 - 92

35. Tick LW, Kramer MH, Rosendaal FR, Faber WR, Doggen CJ. Risk factors for postthrombotic syndrome in patients with a first deep venous thrombosis. J Thromb Haemost 2008;6:2075 - 8I

36. Widmer LK, Brandenberg E, Schmitt HE, et al. [The fate of the patient with deep vein thrombosis]. Dtsch Med Wochenschr. 1985;II0:993-7

37. Ziegler S, Schillinger M, Maca TH, Minar E. Post-thrombotic syndrome after primary event of deep venous thrombosis Io to 20 years ago. Thromb Res 200I; IOI:23 - 33

38. Carradice D, Mazari FA, Samuel N, Allgar V, Hatfield J, Chetter IC. Modelling the effect of venous disease on quality of life. Br J Surg 20II;98:I089- 98

39. Ware. SF-36 Health Survey, Manual and Interpretation Guide. Boston: Nimrod Press, 1993

40. MacDougall DA, Feliu AL, Boccuzzi SJ, Lin J. Economic burden of deep-vein thrombosis, pulmonary embolism, and post-thrombotic syndrome. Am J Health Syst Pharm 2006;63(Suppl 6):S5 - I5

4I. Bergqvist D, Jendteg S, Johansen L, Persson U, Odegaard K. Cost of long-term complications of deep venous thrombosis of the lower extremities: an analysis of a defined patient population in Sweden. Ann Intern Med 1997;126:454- 7

42. Phillips T, Stanton B, Provan A, Lew R. A study of the impact of leg ulcers on quality of life: financial, social, and psychologic implications. J Am Acad Dermatol 1994;31:49 - 53

43. Fox EA, Kahn SR. The relationship between inflam-mation and venous thrombosis. A systematic review of clinical studies. Thromb Haemost 2005;94:362 - 5

44. Marchena Yglesias PJ, Nieto Rodriguez JA, Serrano Mar-tinez S, et al. [Acute-phase reactants and markers of inflammation in venous thromboembolic disease: corre-lation with clinical and evolution parameters]. An Med Interna 2006;23:105 - I0

45. Roumen-Klappe EM, Janssen MC, Van Rossum J, et al. Inflammation in deep vein thrombosis and the develop-ment of post-thrombotic syndrome: a prospective study. J Thromb Haemost 2009;7:582 - 7

46. Shbaklo H, Holcroft CA, Kahn SR. Levels of inflamma-tory markers and the development of the post-thrombotic syndrome. Thromb Haemost 2009;IOI:505 - I2

47. Kolbach DNSM, Hamulyak K, Neumann HA, Prins MH. Non-pharmaceutical measures for prevention of post-thrombotic syndrome. Cochrane Database Syst Rev 2003; (3) Art. No.: CDoo4I74

48. Kearon CKS, Agnelli G, Goldhaber S, Raskob GE, Comerota AJ; American College of Chest Physicians. Antithrombotic therapy for venous thromboembolic disease: American 
College of Chest Physicians Evidence-Based Clinical Practice Guidelines. (8th Edition). Chest 2006;133(6 Suppl):454S-545S

49. Comerota AJ. The ATTRACT trial: rationale for early intervention for iliofemoral DVT. Perspect Vasc Surg Endovasc Ther 2009;2I:22I - 4; quiz 224- 5

50. Enden T, Sandvik L, Klow NE, et al. Catheter-directed Venous Thrombolysis in Acute Iliofemoral Vein Throm-bosis - the CaVenT study: rationale and design of a mul-ticenter, randomized, controlled, clinical trial (NCToo25I77I). Am Heart J 2007;I54:808 - I4

5I. Grommes J, Strijkers R, Greiner A, Mahnken AH, Wittens CH. Safety and feasibility of ultrasound-accelerated catheter-directed thrombolysis in deep vein thrombosis. Eur J Vasc Endovasc Surg 20II;4I:526 - 32

52. Comerota AJ. Quality-of-life improvement using throm-bolytic therapy for iliofemoral deep venous thrombosis. Rev Cardiovasc Med 2002;3(Suppl 2):S6I - 67

53. Comerota AJ, Throm RC, Mathias SD, Haughton S, Mewissen M. Catheter-directed thrombolysis for iliofe-moral deep venous thrombosis improves health-related quality of life. J Vasc Surg 2000;32:130 - 7

54. Enden T, Klow NE, Sandvik L, et al. Catheter-directed thrombolysis vs. anticoagulant therapy alone in deep vein thrombosis: results of an open randomized, con-trolled trial reporting on short-term patency. J Thromb Haemost 2009;7:I268 - 75

55. Grewal NK, Martinez JT, Andrews L, Comerota AJ. Quantity of clot lysed after catheterdirected thromboly-sis for iliofemoral deep venous thrombosis correlates with postthrombotic morbidity. J Vasc Surg 20I0;5I: I209 -I4

56. Kistner RL, Eklof B, Masuda EM. Deep venous valve reconstruction. Cardiovasc Surg I995;3:129- 40

57. Camilli S, Guarnera G. External banding valvuloplasty of the superficial femoral vein in the treatment of primary deep valvular incompetence. Int Angiol I994;13: 218-22

58. Lugli M, Guerzoni S, Garofalo M, Smedile G, Maleti O. Neovalve construction in deep venous incompetence. J Vasc Surg 2009;49:I56 - 62, I62 eI5I - 2; discussion I62

59. Raju S, Neglen P, Doolittle J, Meydrech EF. Axillary vein transfer in trabeculated postthrombotic veins. J Vasc Surg I999;29:IO50 - 62; discussion I058 - 6I

6o. Neglen P, Hollis KC, Olivier J, Raju S. Stenting of the venous outflow in chronic venous disease: long-term stent-related outcome, clinical, and hemodynamic result. J Vasc Surg 2007;46:979- 90

6I. Titus JM, Moise MA, Bena J, Lyden SP, Clair DG. Iliofe-moral stenting for venous occlusive disease. J Vasc Surg 20I0;53:706 - I2

62. Delis KT, Bjarnason H, Wennberg PW, Rooke TW, Glo-viczki P. Successful iliac vein and inferior vena cava stent-ing ameliorates venous claudication and improves venous outflow, calf muscle pump function, and clinical status in post-thrombotic syndrome. Ann Surg 2007;245:130-9

63. Kniffin WD Jr, Baron JA, Barrett J, Birkmeyer JD, Ander-son FA Jr. The epidemiology of diagnosed pulmonary embolism and deep venous thrombosis in the elderly. Arch Intern Med I994;I54:86I - 6

64. RaffiniL, HuangYS, WitmerC, FeudtnerC.Dramaticincrease in venous thromboembolism 
in children's hos-pitals in the United States from 200I to 2007. Pediatrics 2009;I24:IOOI - 8

65. Prandoni P, Lensing AW, Prins $\mathrm{MH}$, et al. Below-knee elastic compression stockings to prevent the post-thrombotic syndrome: a randomized, controlled trial. Ann Intern Med 2004;I4I:249- 56

66. van Dongen CJ, Prandoni P, Frulla M, Marchiori A, Prins MH, Hutten BA. Relation between quality of anticoagu-lant treatment and the development of the postthrombotic syndrome. J Thromb Haemost 2005;3:939 - 42

67. Kahn SR, Shrier I, Julian JA, et al. Determinants and time course of the post-thrombotic syndrome after acute deep venous thrombosis. Ann Intern Med 2008;149:698 - 707

68. Ageno W, Piantanida E, Dentali F, et al. Body mass index is associated with the development of the post-thrombotic syndrome. Thromb Haemost 2003;89:305 - 9

69. Heit JA, Silverstein MD, Mohr DN, Petterson TM, O'Fallon WM, Melton LJ 3rd. Risk factors for deep vein thrombosis and pulmonary embolism: a population-based casecontrol study. Arch Intern Med 2000;I60:809-I5

70. Kahn SR, Ginsberg JS. The post-thrombotic syndrome: current knowledge, controversies, and directions for future research. Blood Rev 2002;I6:I55 - 65

7I. Ridker PM, Goldhaber SZ, Danielson E, et al. Long-term, low-intensity warfarin therapy for the prevention of recurrent venous thromboembolism. N Engl J Med 2003;348:I425 34

72. Young L, Ockelford P, Milne D, Rolfe-Vyson V, McKelvie S, Harper P. Post-treatment residual thrombus increases the risk of recurrent deep vein thrombosis and mortality. J Thromb Haemost 2006;4:1919-24

73. Asbeutah AM, Riha AZ, Cameron JD, McGrath BP. Five-year outcome study of deep vein thrombosis in the lower limbs. J Vasc Surg 2004;40:II84 - 9

74. Meissner MH, Caps MT, Zierler BK, et al. Determinants of chronic venous disease after acute deep venous thrombosis. J Vasc Surg 1998;28:826 - 33

75. van Ramshorst B, van Bemmelen PS, Hoeneveld H, Eikelboom BC. The development of valvular incompe-tence after deep vein thrombosis: a follow-up study with duplex scanning. J Vasc Surg 1994;19:I059-66

76. Prandoni P, Frulla M, Sartor D, Concolato A, Girolami A. Vein abnormalities and the post-thrombotic syndrome. J Thromb Haemost 2005;3:40I -2

77. Prandoni P, Lensing AW, Prins $\mathrm{MH}$, et al. Residual venous thrombosis as a predictive factor of recurrent venous thromboembolism. Ann Intern Med 2002;137:955-60

78. Yamaki T, Nozaki M, Sakurai H, Takeuchi M, Soejima K, Kono T. High peak reflux velocity in the proximal deep veins is a strong predictor of advanced post-thrombotic sequelae. J Thrombosis Haemost 2007;5:305 - I2

79. Killewich LA, Martin R, Cramer M, Beach KW, Strand-ness DE Jr. An objective assessment of the physiologic changes in the post-thrombotic syndrome. Arch Surg 1985;120:424-6

8o. Haenen JH, Janssen MC, Wollersheim H, et al. The devel-opment of post-thrombotic syndrome in relationship to venous reflux and calf muscle pump dysfunction at two years after the onset of deep venous thrombosis. J Vasc Surg 2002;35:II84 - 9

8I. Poort SR, Rosendaal FR, Reitsma PH, Bertina RM. A common genetic variation in the 
3 -untranslated region of the prothrombin gene is associated with elevated plasma prothrombin levels and an increase in venous thrombosis. Blood 1996;88:3698 -703

82. Bertina RM, Koeleman BP, Koster T, et al. Mutation in blood coagulation factor V associated with resistance to activated protein C. Nature 1994;369:64-7

83. Couturaud F, Leroyer C, Julian JA, et al. Factors that predict risk of thrombosis in relatives of patients with unprovoked venous thromboembolism. Chest 2009;136: I537- 45

84. Cushman M, Folsom AR, Wang L, et al. Fibrin fragment D-dimer and the risk of future venous thrombosis. Blood 2003;IOI:I243-8

85. Palareti G, Cosmi B, Legnani C, et al. D-dimer testing to determine the duration of anticoagulation therapy. N Engl J Med 2006;355:I780 - 9

86. Palareti G, Legnani C, Cosmi B, Guazzaloca G, Pancani C, Coccheri S. Risk of venous thromboembolism recur-rence: high negative predictive value of $\mathrm{D}$-dimer per-formed after oral anticoagulation is stopped. Thromb Haemost 2002;87:7 - I2

87. Palareti G, Cosmi B. Predicting the risk of recurrence of venous thromboembolism. Curr Opin Hematol 2004;II: I92-7

88. Kuruvilla J, Wells PS, Morrow B, MacKinnon K, Keeney M, Kovacs MJ. Prospective assessment of the natural history of positive D-dimer results in persons with acute venous thromboembolism (DVT or PE). Thromb Haemost 2003;89:284- 7

89. Kevorkian JP, Halimi C, Segrestaa JM, Drouet L, Soria C. Monitoring of patients with deep-vein thrombosis during and after anticoagulation with D-dimer. Lancet 1998;35I:57I $-2$

90. Fattorini A, Crippa L, Vigano' D’Angelo S, Pattarini E, D’Angelo A. Risk of deep vein thrombosis recurrence: high negative predictive value of $\mathrm{D}$-dimer performed during oral anticoagulation. Thromb Haemost 2002;88: I62 -3

9I. Gremmel T, Ay C, Seidinger D, Pabinger I, Panzer S, Koppensteiner R. Soluble p-selectin, $\mathrm{D}$-dimer, and high-sensitivity C-reactive protein after acute deep vein thrombosis of the lower limb. J Vasc Surg 20II;54:48S-55S

92. Latella J, Desmarais S, Miron MJ, et al. Relation between D-dimer level, venous valvular reflux and the develop-ment of post-thrombotic syndrome after deep vein thrombosis. J Thromb Haemost 2010;8:2169 - 75

93. Porter JM, Moneta GL. Reporting standards in venous disease: an update. International Consensus Committee on Chronic Venous Disease. J Vasc Surg 1995;21:635 - 45

94. Shbaklo H, Holcroft CA, Kahn SR. Levels of inflammatory markers and the development of the post-thrombotic syndrome. Thromb Haemost 2009;IOI:505-I2

95. Bergan JJ, Pascarella L, Schmid-Schonbein GW. Patho-genesis of primary chronic venous disease: Insights from animal models of venous hypertension. J Vasc Surg 2008;47:183- 92

96. Pascarella L, Schmid-Schonbein GW, Bergan J. An animal model of venous hypertension: the role of inflammation in venous valve failure. J Vasc Surg 2005; 4I:303 - II

97. van Aken BE, den Heijer M, Bos GM, van Deventer SJ, Reitsma PH. Recurrent venous thrombosis and markers of inflammation. Thromb Haemost 2000;83: 536 - 9

98. Kahn SR, Shbaklo H, Shapiro S, et al. Effectiveness of compression stockings to prevent the post-thrombotic syndrome (the SOX Trial and Bio-SOX biomarker sub-study): a 
randomized controlled trial. BMC Cardiovasc Disord 2007;7:2I

99. Eklof B, Rutherford RB, Bergan JJ, et al. Revision of the CEAP classification for chronic venous disorders: con-sensus statement. J Vasc Surg 2004;40:I248 - 52

Ioo. Kahn SR, Partsch H, Vedantham S, Prandoni P, Kearon C. Definition of postthrombotic syndrome of the leg for use in clinical investigations: a recommendation for standardization. J Thromb Haemost 2009;7:879-83 

Mark Antonius Friedrich de Wolf, MD ${ }^{1,2}$

Carsten Willem Arnoldussen, MD ${ }^{3}$

Jochen Grommes, MD4

Shu Gi Hsien, MD ${ }^{1}$

Patricia Joan Nelemans, MD, PhD 5

Michiel Willem de Haan, MD, PhD ${ }^{3}$

Rick de Graaf, MD, PhD ${ }^{3}$

Cees Hendrikus Wittens, MD, PhD ${ }^{1,4}$

I Department of Surgery, Maastricht University Medical Centre, Maastricht

2 School for Cardiovascular Diseases (CARIM), Maastricht University Medical Centre, Maastricht 3Department of Radiology, Maastricht University Medical Centre, Maastricht 4 Department of Vascular Surgery, Aachen University Hospital, Aachen, Germany 5 Department of Epidemiology, Maastricht University Medical Centre, Maastricht

Published in the Journal of Vascular Surgery; Venous and Lymphatic Disorders J Vasc Surg: Venous and Lym Dis 2013;1:I46-53 


\section{ABSTRACT}

\section{Background}

As one of the primary etiologies of the post-thrombotic syndrome, chronic venous occlusion is a huge burden on patient quality of life and medical costs. In this study, we evaluate the short-term and midterm results of endovenous recanalization by angioplasty and stenting in chronic iliofemoral deep venous occlusions.

\section{Methods}

This is a retrospective observational study set ina tertiary medical referral center. Patients with venous claudication or $\mathrm{C}_{4}-6$ venous disease combined with duplex and magnetic resonance-confirmed iliofemoral or caval occlusion were included. Patients with recent deep vein thrombosis ( $<$ I year) were excluded. The intervention was endovascular deep venous recanalization, followed by angioplasty and stenting. Safety and feasibility were clinically evaluated during the procedure and during follow-up. Reocclusions and other treatment failures were evaluated during a maximum followup of 3I months by ultrasound imaging and venography.

\section{Results}

Seventy-five procedures were performed in 63 patients (average age, 44 years; range, $18-75$ years), of whom $86 \%$ had a history of deep venous thrombosis. The mean time between the initial deep venous thrombosis and treatment with PTA and stenting was I2 years (maximum, 3I years). May-Thurner syndrome was present in $57 \%$. Forty-two procedures were performed in the left, six in the right, and II in both lower extremities. The vena cava inferior was partially stented in 25 patients. An average of 2.6 stents (median, 2) were used per procedure. Primary patency was $74 \%$ after I year. Assisted primary and secondary patency rates were $8 \mathrm{I} \%$ and $96 \%$, respectively, at I year. Secondary procedures included restenting, catheter-directed thrombolysis, endophlebectomy of the common femoral vein, and creation of an arteriovenous fistula. No clinically evident pulmonary emboli were noted. A bleeding complication occurred after six procedures and was deemed major in two. No patients died. Relief or significant improvement of symptoms of chronic venous occlusive disease was achieved in $8 \mathrm{I} \%$ of patients.

\section{Conclusions}

Endovenous recanalization by angioplasty and stenting of chronically occluded iliofemoral vein segments is a safe and effective treatment with good short-term results, even when treatment takes place decades after the initial deep venous thrombosis. Most reocclusions can be adequately treated by a secondary procedure. 


\section{INTRODUCTION}

Iliofemoral occlusions are a prevalent cause of chronic venous pathology.I,2 Besides or in combination with chronic deep venous insufficiency, venous occlusive disease is the primary cause of development of venous hypertension and the post-thrombotic syndrome (PTS).2,3 The symptoms associated with occlusion of the deep venous system of the lower extremity range from relatively mild complaints (ie, itching and small superficial varicosities) to venous claudication and venous ulcers. Therefore, iliofemoral occlusions causing PTS are a major cause of morbidity and reduced quality of life (QOL) in Western societies.4-7 Deep venous thrombosis (DVT) and PTS are also a huge burden on direct health care-related costs as well as indirect costs due to work absenteeism.6,8,9

In the acute phase of a DVT, the thrombus creates an occlusion of the vein lumen. At that moment, venous outflow is only possible through collateral veins. This is especially problematic in the iliofemoral veins because no functionally effective collateral network is present.Io Owing to only limited recanalization after acute iliofemoral DVT, the longterm restriction of venous outflow develops.I The natural ability of the vein to adjust its diameter, depending on the amount of venous outflow of the leg, is also restricted, possibly leading to venous claudication during exercise. Furthermore, ipsilateral DVT recurrence, which is frequent in these patients, worsens outcome even more.III7 External compression of a vein is the second most prevalent cause of deep venous obstruction and also an important risk factor for DVT.18,19 May-Thurner syndrome is the most frequently occurring type of external compression and is a frequently missed diagnosis in the DVT population and also in the general asymptomatic population.18-20

The current standard DVT treatment consists of elastic compression stockings, anticoagulation with low-molecular-weight heparin, followed by oral anticoagulation with vitamin $\mathrm{K}$ antagonists, and mobilization. Treatment is primarily aimed at preventing pulmonary embolism and reducing thrombus propagation.2I However, this treatment in most patients can only realize a limited thrombus lysis, especially in cases of iliofemoral DVT.22,23 The effectiveness in preventing long-term occlusion is therefore modest. Treatment of PTS is currently mostly based on compression therapy, a suboptimal treatment that has low patient compliance.3,4,21,24 None of these therapy options prevent the development of venous hypertension, and therefore, the complaints and symptoms of patients are not targeted directly. Percutaneous transluminal angioplasty (PTA) and stenting have been used in the arterial system for decades, and their use in the venous system has been pioneered since the late I990s. Recent work in specialized centers has shown favorable results of these treatments, but their use is still far from accepted as standard patient care.23,25-28

The aim of this study was to evaluate the early results of PTA and stenting in patients 
with extensive chronic, mostly post-thrombotic, venous occlusions, treated at a national referral center.

Methods

In this observational study, we retrospectively included patients treated between January I, 2009, and February I, 2012. The study included patients with chronic complaints of severe venous symptoms (CEAP scores $\mathrm{C}_{4}-6$ ) or venous claudication combined with signs of deep venous occlusion confirmed by magnetic resonance venography (MRV) or duplex ultrasound (DUS) imaging. Patients presenting with recent DVT ( $<\mathrm{I}$ year) or who received catheter-directed thrombolysis before stenting were excluded. Testing for hypercoagulable factors was performed in all PTS patients not currently being treated with oral anticoagulants.

\section{Diagnostic workup}

Patients with suspected chronic iliac vein obstruction were analyzed with DUS imaging and MRV. The scanning protocols and equipment have been described previously.I0,29 When a chronic iliac vein obstruction was suspected, we specifically looked for the location and extent of obstruction to plan our interventional approach. We also evaluated the patency of the common femoral vein, identified the presence of collateral pathways or external compression, or both, and the outflow through the inferior vena cava. Evident external compression of the left common iliac vein with clear diameter reduction on MRV and DUS was considered a May-Thurner syndrome in patients with accompanying clinical signs.

\section{MRV assessment}

MRV examinations were performed on a I.5-T Intera MRI system (Philips Medical Systems, Best, The Netherlands). For signal reception, a dedicated I2-element phasedarray peripheral vascular coil with craniocaudal coverage of $128 \mathrm{~cm}$ (Philips Medical Systems) was used. Patients were placed supine for imaging. A fixed dose of Io-mL gadofosveset trisodium (Ablavar; Lantheus Medical Imaging, Billerica, Mass), a blood pool contrast agent, was administered intravenously as a single dose at a speed of I.O $\mathrm{mL} / \mathrm{s}$ in the median cubital vein, using a remote-controlled injection system (Medrad Spectris, Indianola, Pa). A five-station three-dimensional ultrafast gradient echo sequence with fat suppression (spectral presaturation with inversion recovery) was used for high-resolution steady-state imaging of the venous vasculature, ensuring a coverage of at least the popliteal veins up to the entire IVC. Acquisition parameters were repetition time, $7.8 \mathrm{~ms}$; echo time, $3.8 \mathrm{~ms}$; field of view, $380 \mathrm{~mm}$; matrix, 400 ; 150 axial slices per station, and voxel dimensions (reconstructed) were $0.950 .95 \mathrm{I} .50 \mathrm{~mm}$ for all stations.

\section{DUS imaging}

DUS examinations were performed using a Hitachi Aloka ProSound ALPHA 7 Premier machine (Aloka, Tokyo, Japan). A convex array transducer, UST-9I30 (frequency range, 
3-6 MHz), was used when studying the venous system from the vena cava down toward the tibial veins below the knee, with the patient supine. Consequently, all patients were also examined standing, with scanning from the upper groin to below the knee using a high-frequency UST-54II (frequency range, 5-I6 MHz) compound linear array transducer, with pulsed-wave Doppler $(5 \mathrm{MHz})$ used to test for valvular incompetence. Optimal distal vena cava and common iliac vein diameter distension were analyzed during enhanced flow with vertical leg extension when the patient was supine.

\section{Recanalization, PTA, and stenting.}

Depending on the findings during the diagnostic workup, as described above, the procedure took place in a dedicated intervention room at the radiology department or in a dedicated vascular surgical suite with fluoroscopic assistance, allowing for a combined approach of endophlebectomy of the common femoral vein, with or without an arteriovenous fistula (AVF), and recanalizing the iliac obstruction. Procedures were performed under general anesthesia and local infiltration analgesia. Cannulation of the popliteal vein (with the patient prone) or femoral vein (midthigh, with the patient supine) was performed under ultrasound guidance (CX50 CompactXtreme; Philips). After cannulation, a 5 F sheath (AVANTI; Cordis Corp, Syracuse, NY) was introduced, and an antegrade venogram was performed. After assessing the presence, location, and extent of an obstruction, the interventional radiologist navigated to and through the obstruction with the use of various stiff guidewires (Terumo Medical Corp, Somerset, $\mathrm{NJ}$ ) and catheters. Crossing the obstructed segments could be challenging, but with the anatomic information from the preprocedural MRV combined with $2 \mathrm{D}$ and $3 \mathrm{D}$ angiography images acquired during the procedure, we were able to identify the correct pathway and cross the obstruction in all but three patients. Understanding $2 \mathrm{D}$ and $3 \mathrm{D}$ MRI and angiographic anatomy combined with choosing the most suitable catheter and guidewire is crucial. Depending on the location of the obstruction, predilatation was performed with balloon catheters sized 8 to $12 \mathrm{~mm} 40 \mathrm{~mm}$ (Powerflex; Cordis Corp) or I4 $40 \mathrm{~mm}$ (Foxcross, Abbott Laboratories, Abbott Park, Ill). After dilation, one or more self-expendable stents, sized from $\mathrm{I} 460$ to IOo $\mathrm{mm}$ up to $2680 \mathrm{~mm}$, including Sinus-XL (Optimed, Ettlingen, Germany), Wallstent (Boston Scientific, Natick, Mass), Zilver Vena (Cook Corp), and Andrastent XL (Bioassist, Albuquerque, NM), were deployed at the predilated site. Stent sizing was determined by location and vessel diameter proximal and distal to the occlusion, aiming at $20 \%$ oversizing to ensure anchoring to the vein wall. After stent placement, the stented trajectory was dilated with a semicompliant Coda balloon (Cook Corp), further anchoring the stents to the wall. Venograms above, below, and at the level of the obstruction were repeated to assess the results. At the end of the procedure, the sheath was removed, and local pressure was applied until hemostasis was achieved (Figures I and 2 show preprocedural venography examinations in a case of successful PTA and stenting, Figure 3 shows the control radiograph examination after stent placement, and Figure 4 shows the final control venography). 

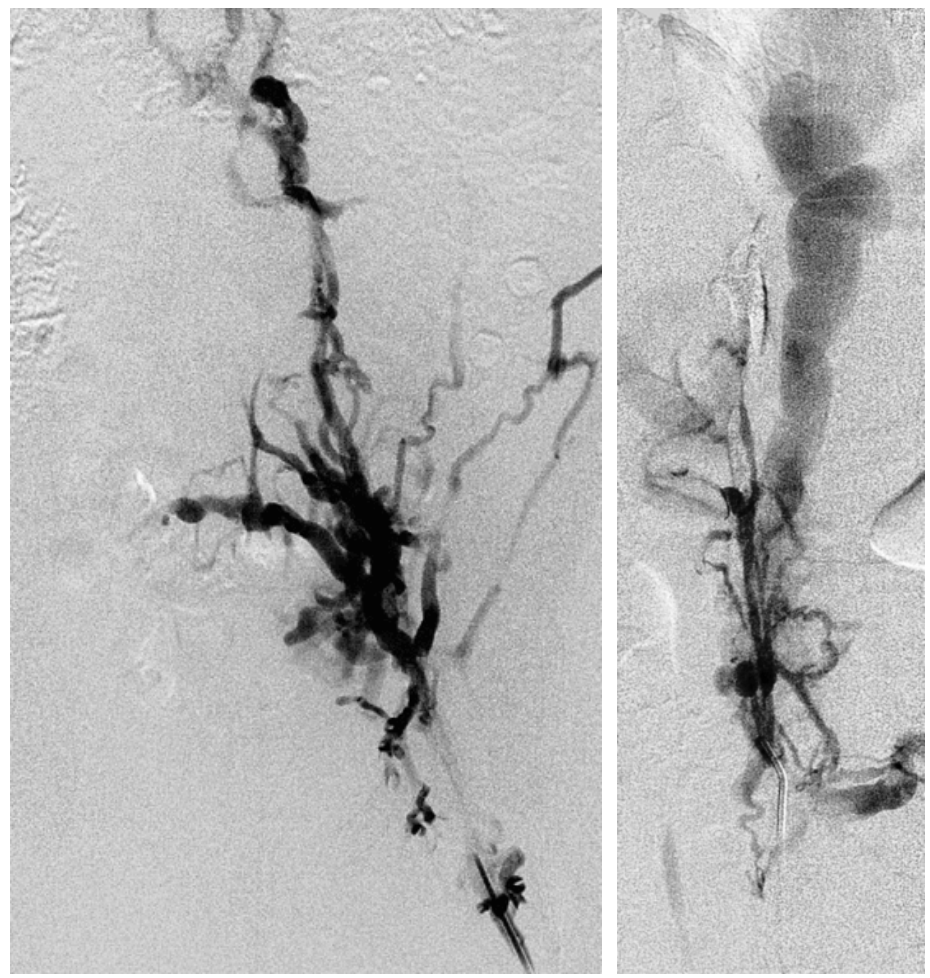

Figure I. Venography of the left common iliac vein shows an occlusion of the common iliac vein, and multiple collateral veins are visible.

Figure 2. Venography of the trajectory of the inferior vena cava shows occlusion of the inferior vena cava with prominent collaterals along the lumbar spine.

During a number of procedures, an endophlebectomy (ie, surgical desobstruction) was performed in which the post-thrombotic vein was longitudinally opened, intraluminal scar tissue was carefully removed, and the venotomy was closed without use of a patch. This was done in patients in whom perioperative inflow into the stent was deemed insufficient and was accompanied in a limited number of patients by the creation of an AVF between the femoral vein and femoral artery to ensure a further improved inflow in the stented tract. Inflow can be expected to be insufficient when extensive postthrombotic aberrations are present in the common femoral vein, because these cannot be adequately treated with PTA alone, and stenting beyond the inguinal ligament has shown unfavorable results. A clear relation between venographically determined poor flow from the profunda femoral vein into the common femoral vein and a reduced flow through the stent was also shown.

Postoperatively, regardless of preoperative anticoagulation, patients were anticoagulated with a regimen of subcutaneous low-molecular-weight heparin for a minimum of 5 days. 
During this period, patients started treatment with oral anticoagulants (acenocoumarol or phenprocoumon) for a minimum of 6 months, with a target international normalized ratio of 2.5 to 3.5. DUS imaging was performed the day after the procedure to assess the venous outflow and stent patency. Patients were usually discharged \#48 hours. Standardized follow-up was planned for each patient at 6 weeks, 3 months, 6 months, and I year. At these visits, clinical symptoms and complaints were assessed as well as patency on DUS (Venous Clinical Severity Score or QOL scoring were not possible because of the retrospective character of this study).
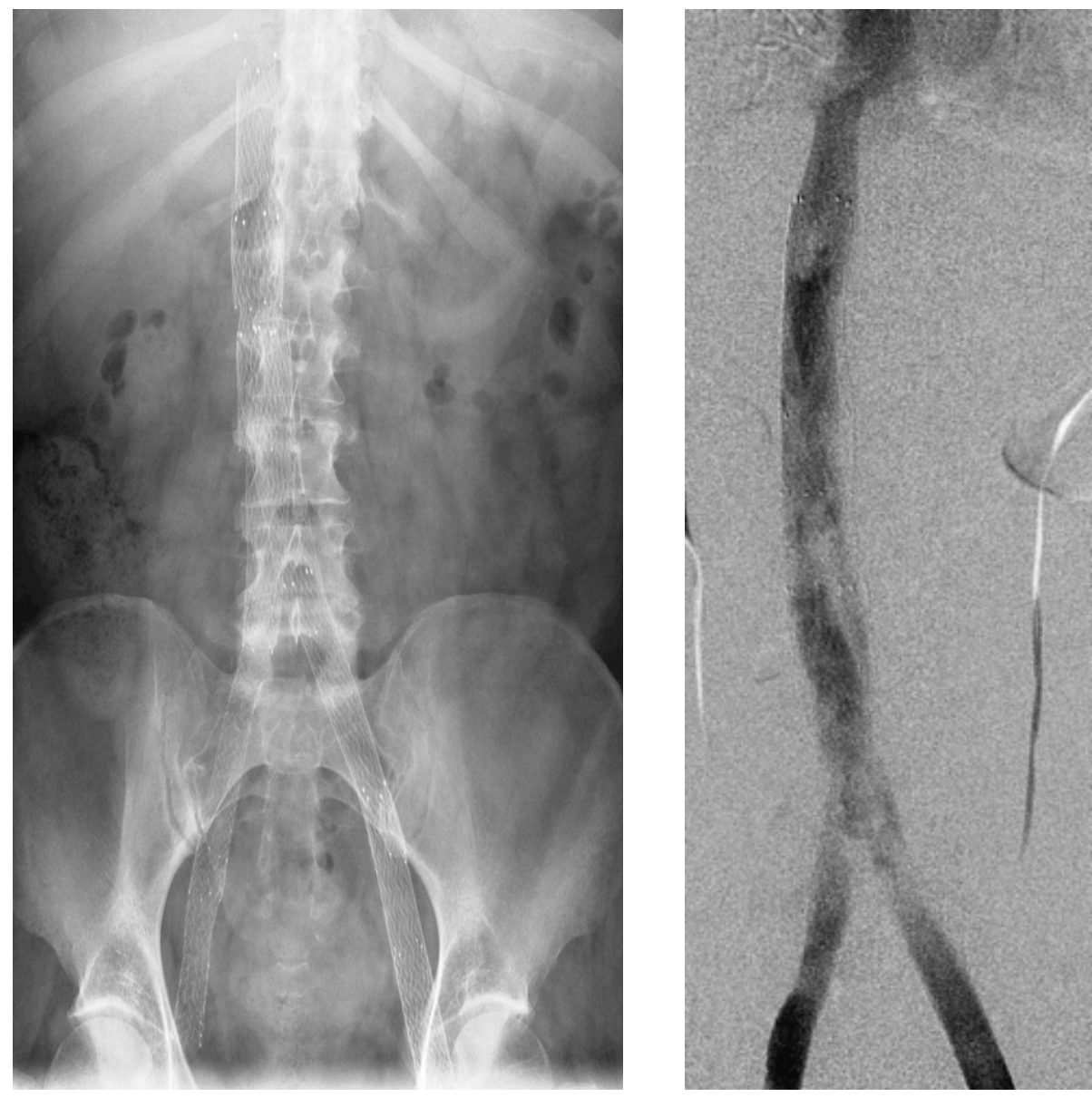

Figure 3. Radiograph of the abdomen after recanalization and stent placement shows multiple stents placed in the inferior vena cava and iliac veins on the left and right side.(left)

Figure 4. Final control venography shows adequate outflow toward the heart in the recanalized and stented inferior vena cava and iliac veins. The collateral pathways are no longer visible, confirming the patency of the newly created iliac-caval outflow pathway.(right) 


\section{Statistical analysis}

Categoric data are presented as frequencies and percentages, and continuous data are presented as mean values 6 the standard deviation or median values with the range, unless otherwise stated. Categoric data were analyzed by c2 test. Cumulative probabilities of patency at 3, 6, and I2 months after initial treatment were calculated using Kaplan-Meier survival analysis. For the evaluation of primary patency, the need for additional treatment by an assisted primary intervention or a secondary intervention, or obstruction, at the end of follow-up was considered a treatment failure. For the evaluation of secondary patency, only obstruction at the end of follow-up was considered a treatment failure. Follow-up time was defined as the period between initial treatment and treatment failure or the period between initial treatment and date of the last observation (in patients without treatment failure). Data were analyzed with SPSS I7.0.I (SPSS, Chicago, Ill) and Stata II.2 (StataCorp. Collage Station, Tex) software. Values of $\mathrm{P} \# .05$ were considered to indicate statistical significance.

\section{RESULTS}

Demographics. During the study period, 63 patients (45 women [71\%]) with chronic deep vein obstructions were treated in our center (Table 5 summarizes demographic data). Patients had a mean age of $44 \pm \mathrm{I} 2.4$ years (range, I8-75 years). The obstruction in 54 patients $(86 \%)$ was secondary to a DVT in the patient's medical history, and $\mathrm{I} 7(27 \%)$ had a history of recurrent DVT. Imaging showed a total occlusion in 39 patients $(62 \%)$, subtotal occlusion in $15(24 \%)$, and May-Thurner syndrome without a history of DVT in nine (I4\%). The interval between the DVT event (the first in those with recurrent DVT) and PTA and stenting was II.9 \pm 9.3 years (median, 9; range, I-3I years). The DVT (if present in patient history) was located on the left side in $37(69 \%)$, on the right in five (9\%), and was bilateral in $12(22 \%)$. May-Thurner syndrome was present in 36 patients $(57 \%)$ and was present in $62 \%$ of women vs $28 \%$ of men; however, this did not reach statistical significance $(\mathrm{p}=.09)$.

Table 5. Demographic information of the study population

\begin{tabular}{ll}
\hline Variable & No. (\%) \\
\hline Patients, No. & 63 \\
Procedures, No. & 75 \\
Male/female sex & I:2.5 \\
Mean age, years (range) & $44(\mathrm{I} 8-75)$ \\
Primary vs secondary etiology & I:6 \\
Deep vein thrombosis & \\
Left side & $37(68.5)$ \\
Right side & $5(9.3)$ \\
Bilateral & I2(22.2) \\
May-Thurner syndrome & $36(57.1)$ \\
Thrombophilia present & II $(52.4)^{\mathrm{a}}$ \\
\hline
\end{tabular}

${ }^{a}$ Thrombophilia testing was only possible in $2 \mathrm{I}$ patients not taking oral

A thrombophilic disorder was found in II of 2I tested patients (52\%), comprising $33 \%$ 
of the total population. Most patients could not be tested for thrombophilia before

Table 6. Preprocedural CEAP clinical CLASS ${ }^{30}$

\begin{tabular}{rll}
\hline CEAP C & No. & $(\%)$ \\
\hline CI & 8 & I2.7 \\
C2 & I3 & 20.6 \\
C3 & I4 & 22.2 \\
C4 & I4 & 22.2 \\
C5 & 8 & I2.7 \\
C6 & 6 & 9.5 \\
\hline
\end{tabular}

or during follow-up because of ongoing anticoagulation treatment. A factor V Leiden mutation was found in seven patients, factor II mutation in two, an antithrombin 3 deficiency in one, and a protein $S$ and $\mathrm{C}$ deficiency in one. The median CEAP classification C score was 3 (mean, 3.3) at presentation (Table 6).30 Thirty-five patients (56\%) were scored as CI-3, and therefore were treated because of their venous claudication.

\section{Procedures}

A total of 75 procedures were performed in 63 legs; of these, 55 (73\%) were performed on the left venous tract, six (8\%) on the right side, II ( $15 \%)$ bilaterally, and in three patients (4\%), only the vena cava was treated. A median of two stents (mean, 2.66 I.6) was used per procedure; the distribution of stent numbers used is reported in Table 7 .

During eight procedures (II\%), an endophlebectomy of the common femoral vein was performed to secure sufficient inflow of the stented vein segments; during four of these procedures (5\%), inflow into the femoral confluence seemed insufficient (according to the operative visual evaluation), and an AVF was created to guarantee adequate inflow. An immediate reocclusion in the stent was noted on the final control venography after three procedures (4\%), and these were adequately treated with direct rePTA and expansion of the stented segment in two patients, and in one patient, delayed surgical thrombectomy and creation of an AVF was performed. All three were patent at last follow-up. Moreover, the control DUS the day after eight stenting procedures (II\%) showed the stented segments were rethrombosed. These were treated with initial catheterdirected thrombolysis in six patients (IO\%), secondary PTA and stenting was performed in five $(8 \%)$, four $(6 \%)$ were treated with surgical thrombectomy, and an AVF was created in five $(8 \%)$.

Table 7. Number of stents used per procedure

\begin{aligned} & \hline Stents used No. (\%) \\ & \hline I $(32.4) \\ & 2(24.3) \\ & 3(2 \mathrm{I} .6) \\ & 4(\mathrm{I} .8) \\ & 5(2.7) \\ & 6(4 . \mathrm{I}) \\ & 7(4 . \mathrm{I}) \\ &$\hline\end{aligned}

Other procedure-related complications included six (IO\%) bleeding-related complications (four nonsevere postprocedure hemorrhages at the puncture site treated by manual compression, one infected hematoma developed necessitating open surgery, and one common femoral artery was punctured during sheath introduction), a heparin-induced thrombocytopenia developed in one patient, and superficial wound 
problems occurred in two patients after surgical desobstruction. No clinically evident pulmonary emboli, no stent migration, and no procedure-related or unrelated deaths were documented.

\section{Follow-up}

Mean follow-up duration was 8.868 .0 months (range, I-3I months). Follow-up data $>6$ months and I year are present for $36(57 \%)$ and I9 patients (30\%), respectively. Primary patency was $88 \%$ after 3 months, $83 \%$ after 6 months, and $74 \%$ after I 2 months. Assisted primary patency rates were $89 \%, 87 \%$, and $81 \%$, and secondary patency rates were $96 \%$, $96 \%$, and $96 \%$ after 3,6 , and 12 months, respectively (Figure 5; Table 8).

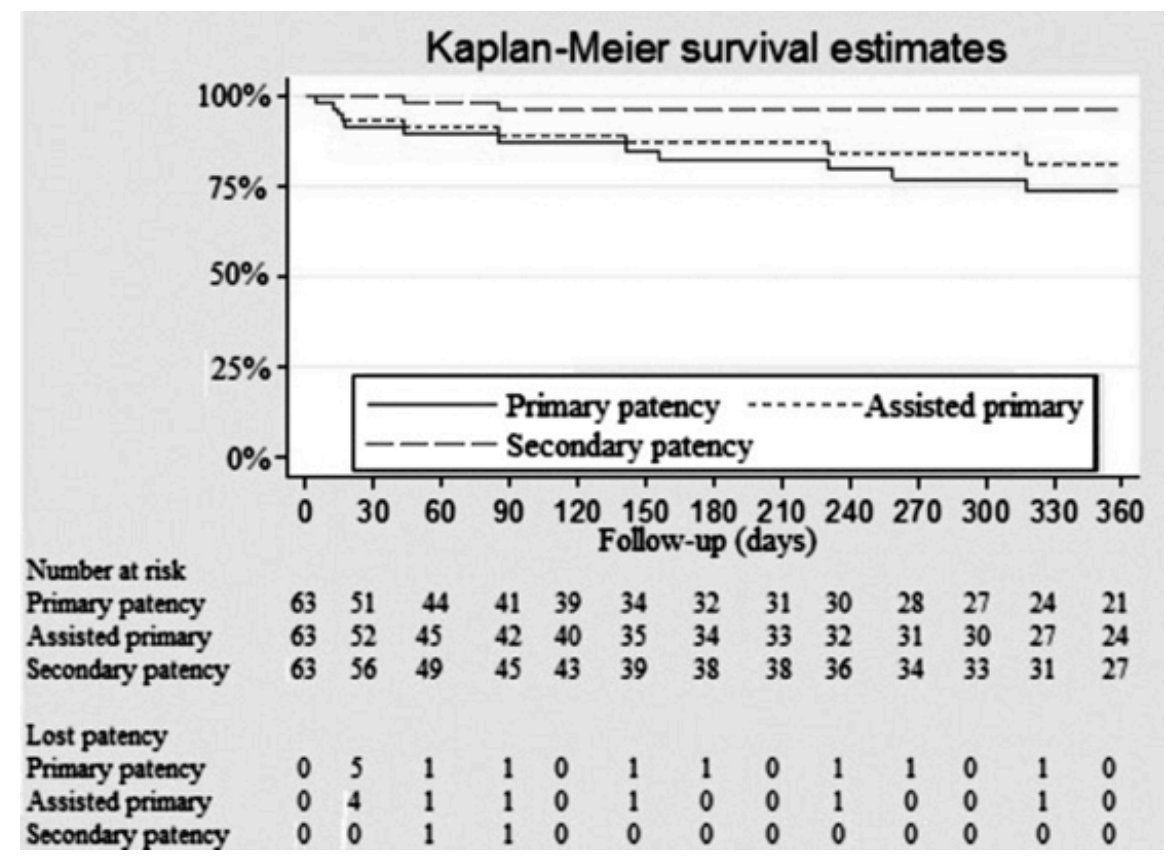

Figure 5. Kaplan-Meier curves show primary, assisted primary, and secondary patency rates. Numbers at risk and lost patency are provided below the graph.

After seven procedures (9\%), rethrombosis of the stented vein segment occurred after discharge from the hospital. After 15 procedures $(20 \%)$, stenosis of the stented vein tract was observed and was deemed clinically and hemodynamically (on DUS) significant in three patients (4\%). Because of reocclusion and stenosis, restenting was performed after eight primary procedures, thrombolysis was performed in seven, an endophlebectomy of the femoral tract was performed in two (during follow-up), and creation of an AVF was performed once during follow-up. Moreover, restenting was performed after two cases of stent kinking, after one stent fracture, and in two patients with chronic stentrelated pain. In short, 23 reinterventions were performed in 13 patients (2I\%). 
Table 8. Kaplan-Meier estimates of primary, assisted primary, and secondary patency rates

\begin{tabular}{|c|c|c|c|}
\hline Variable & 3 months & 6 months & I2 months \\
\hline \multicolumn{4}{|l|}{ Primary patency } \\
\hline Rate $(95 \% \mathrm{CI})$ & $87.6(75.6-93.9)$ & $82.7(69.0-90.7)$ & $74.3(58.5-84.9)$ \\
\hline Standard error & 0.044 & 0.053 & 0.067 \\
\hline Lost to follow-up, No. & I5 & 7 & 8 \\
\hline \multicolumn{4}{|l|}{ Assisted primary patency } \\
\hline Rate $(95 \% \mathrm{CI})$ & $89.3(77.6-95 . \mathrm{I})$ & $87.0(74.3-93.6)$ & 8I.4 (66.7-90.I) \\
\hline Standard error & 0.042 & 0.047 & 0.058 \\
\hline Lost to follow-up, No. & I5 & 7 & 8 \\
\hline \multicolumn{4}{|l|}{ Secondary patency } \\
\hline Rate $(95 \% \mathrm{CI})$ & 96.I (85.I-99.0) & 96.I (85.I-99.0) & 96.I (85.I-99.0) \\
\hline Standard error & 0.027 & 0.027 & 0.027 \\
\hline Lost to follow-up, No. & I6 & 7 & II \\
\hline
\end{tabular}

\section{CI, Confidence interval}

Total relief of symptoms and complaints occurred in 35 patients (6o\%), partial improvement in symptoms and complaints occurred in 12 (21\%), and no improvement was achieved in II patients ( $19 \%)$; follow-up data for this were not available for five patients. Relief of symptoms was seen in $86 \%$ of patients not suffering a rethrombosis and in $75 \%$ of patients in whom a reocclusion occurred, but this did not reach statistical significance $(\mathrm{p}=.34)$.

\section{DISCUSSION}

This study shows favorable short-term technical success rates, reasonable primary and assisted primary midterm patency rates, and excellent secondary patency rates of chronically occluded iliofemoral tract, with and without caval involvement, treated with endovascular PTA and stent placement. Similar results have been presented in other recent studies.22,24-27 Our study and experience show reocclusion to occur in less than one-fourth of patients. Furthermore, in those with reocclusions, the clinical outcome after the acute reocclusion event did not worsen compared with clinical symptoms and complaints before stenting. Also notable is that in the subgroup of 15 patients who developed a reocclusion of the treated vein segment, eight still showed clear clinical improvement, and in four of these patients, any restenting was therefore postponed until clinical signs returned because the treatment window for thrombolysis had passed. The mechanism behind this phenomenon is unclear. Possibly the acute 
occlusion of a rethrombosis ameliorates any previously present venous insufficiency. Most important, our results show that it is possible to safely and effectively treat postthrombotic lesions decades after the initial DVT in patients with severe venous disease ( $\mathrm{C}_{4}-6$ or venous claudication, or both), where previously life-long compression therapy was the only treatment option.

Because we only started using the techniques described in this study in 2009, all patients with chronic deep venous occlusion treated in our hospital were included in this study. Therefore, those patients treated during what one might call our "learning curve" have also been included. This is reflected in the relative high number of early reocclusions (after eight procedures), of which all but one occurred in the first year we performed PTA and stenting. These procedures were generally not performed in a hybrid manner. In cases of insufficient flow, it was therefore not possible for the dedicated venous surgeon to perform an endophlebectomy or creation of an AVF during the primary procedure. Secondary interventions were therefore postponed. These issues have since been addressed, and immediate interventions were possible in all following patients. This, however, underlines the importance of performing these types of treatment in dedicated centers.

Stenting in patients with May-Thurner syndrome showed a statistically nonsignificant lower risk of rethrombosis compared with the subpopulation without the syndrome (reocclusion of $20 \%$ in those with vs $33 \%$ in those without May-Thurner syndrome; $\mathrm{P}=$ =.124), possibly because of more elaborate post-thrombotic aberrations in those without May-Thurner syndrome. Known presence of thrombophilia showed no clear effect on chance of reocclusion. However testing for thrombophilia was not possible in most patients because they were treated with oral anticoagulants at the time of inclusion and follow-up. Poor stent inflow at the end of the procedure has been identified as an important risk factor for reocclusion in our experience. We therefore increasingly perform an endophlebectomy of the femoral tract to guarantee adequate stent inflow.

Compared with other recently published studies, a relative low number of non-postthrombotic patients are included in our study, undoubtedly because of patient selection by physicians referring to our tertiary clinic. Therefore, the number of patients with extensive post-DVT defects was high, and the delay in treatment was very long in many patients. Moreover, because of logistic reasons in The Netherlands, most patients with acute extraluminal compression of deep veins caused by cancer are not referred to our center. We therefore tend to mostly treat long-term sequelae of DVT, which tend to be the most technically complex and clinically complicated cases.

Because nearly all of our patients received at least one Sinus XL stent, we cannot differentiate for outcome between the different stents used. However, we believe from the results of radiographs and venography examinations that many cases of 
rethrombosis and stenosis can be attributed to poor stent adaption to the forces within the venous system. Rigidity and low radial force especially seem to precede stent-related complications. New dedi-cated venous stents, characterized by high flexibility and high radial force, will be commercially available in the near future and should address these problems effectively. We also find it noteworthy that five patients underwent restenting because of stent-related problems (kinking or fracture of the stent and stentrelated chronic pain), without any sign of reocclusion. Re-evaluating the need for stent anchoring in the caval vein, use of anticoagulation, and the method of stent alignment when using these new stents is very important because these might affect patient outcome and will warrant future research.

\section{CONCLUSIONS}

Endovascular recanalization with PTA and stent placement of chronically occluded iliofemoral deep venous tracts is an effective treatment option with good short-term clinical and hemodynamic results, even decades after the initial DVT. Early reocclusion occurred relatively frequent in this series; however, improving logistics addressed this adequately. Secondary patency can be achieved and maintained in nearly all patients. 


\section{REFERENCES}

I. Meissner MH, Moneta G, Burnand K, et al. The hemodynamics and diagnosis of venous disease. J Vasc Surg 2007;46(Suppl S):4S-24S.

2. Bulger CM, Jacobs C, Patel NH. Epidemiology of acute deep vein thrombosis. Tech Vasc Interv Radiol 2004;7:50-4.

3. Wentel TD, Neumann HA. Management of the postthrombotic syndrome: the Rotterdam approach. Semin Thromb Hemost 2006;32: 8I4-2I.

4. Kahn SR. The post thrombotic syndrome. Thromb Res 20II;I27 (Suppl 3):S89-92.

5. Kahn SR, Shbaklo H, Lamping DL, et al. Determinants of health-related quality of life during the 2 years following deep vein throm-bosis. J Thromb Haemost 2008;6:IIO5-I2.

6. Phillips T, Stanton B, Provan A, Lew R. A study of the impact of leg ulcers on quality of life: financial, social, and psychologic implications. J Am Acad Dermatol I994;31:49-53.

7. Kahn SR, Hirsch A, Shrier I. Effect of postthrombotic syndrome on health-related quality of life after deep venous thrombosis. Arch Intern Med 2002;162:II44-8.

8. MacDougall DA, Feliu AL, Boccuzzi SJ, Lin J. Economic burden of deep-vein thrombosis, pulmonary embolism, and post-thrombotic syndrome. Am J Health Syst Pharm 2006;63(20 Suppl 6):S5-I5.

9. Bergqvist D, Jendteg S, Johansen L, Persson U, Odegaard K. Cost of long-term complications of deep venous thrombosis of the lower extremities: an analysis of a defined patient population in Sweden. Ann Intern Med 1997;126:454-7.

Io. Arnoldussen CW, Wittens $\mathrm{CH}$. An imaging approach to deep vein thrombosis and the lower extremity thrombosis classification. Phle-bology 20I2;27(Suppl I):I43-8.

II. de Wolf MA, Wittens $\mathrm{CH}$, Kahn SR. Incidence and risk factors of the post-thrombotic syndrome. Phlebology 20I2;27(Suppl I):85-94.

I2. Franzeck UK, Schalch I, Jager KA, Schneider E, Grimm J, Bollinger A. Prospective I2-year follow-up study of clinical and hemodynamic sequelae after deep vein thrombosis in low-risk patients (Zurich study). Circulation I996;93:74-9.

I3. Haenen JH, Janssen MC, van Langen $\mathrm{H}$, et al. The postthrombotic syndrome in relation to venous hemodynamics, as measured by means of duplex scanning and strain-gauge plethysmography. J Vasc Surg I999;29:IO7I-6.

I4. Holmstrom M, Aberg W, Lockner D, Paul C. Long-term clinical follow-up in 265 patients with deep venous thrombosis initially treated with either unfractionated heparin or dalteparin: a retrospective anal-ysis. Thromb Haemost 1999;82:1222-6.

I5. O'Donnell TF Jr, Browse NL, Burnand KG, Thomas ML. The socioeconomic effects of an iliofemoral venous thrombosis. J Surg Res I977;22:483-8.

I6. Prandoni P, Lensing AW, Cogo A, et al. The long-term clinical course of acute deep venous thrombosis. Ann Intern Med I996;125:I-7.

I7. Prandoni P, Villalta S, Bagatella P, et al. The clinical course of deep-vein thrombosis. Prospective long-term follow-up of 528 symptom-atic patients. Haematologica 1997;82:4238.

I8. Kibbe MR, Ujiki M, Goodwin AL, Eskandari M, Yao J, Matsumura J. Iliac vein compression 
in an asymptomatic patient population. J Vasc Surg 2004;39:937-43.

I9. Raju S, Neglen P. High prevalence of nonthrombotic iliac vein lesions in chronic venous disease: a permissive role in pathogenicity. J Vasc Surg 2006;44:136-43; discussion: I44.

20. van der Laan L, Vos JA, de Boer E, van den Berg JC, Moll FL. [The central-venous compression syndrome: rare, but adequately treatable with endovascular stenting]. Ned Tijdschr Geneeskd 2004;I48:433-7.

2I. Kearon C KS, Agnelli G, Goldhaber S, Raskob GE, Comerota AJ. American College of Chest Physicians. Antithrombotic therapy for venous thromboembolic disease: American College of Chest Physicians Evidence-Based Clinical Practice Guidelines (8th Edition). Chest 2006;133(6 Suppl):454S-545S.

22. Akesson H, Brudin L, Dahlstrom JA, Eklof B, Ohlin P, Plate G. Venous function assessed during a 5 year period after acute ilio-femoral venous thrombosis treated with anticoagulation. Eur J Vasc Surg 1990;4:43-8.

23. Neglen P, Hollis KC, Olivier J, Raju S. Stenting of the venous outflow in chronic venous disease: long-term stent-related outcome, clinical, and hemodynamic result. J Vasc Surg 2007;46:979-90.

24. Raju S, Hollis K, Neglen P. Use of compression stockings in chronic venous disease: patient compliance and efficacy. Ann Vasc Surg 2007;2I:790-5.

25. Ye K, Lu X, Li W, et al. Long-term outcomes of stent placement for symptomatic nonthrombotic iliac vein compression lesions in chronic venous disease. J Vasc Interv Radiol 20I2;23:497-502.

26. Gutzeit A, Zollikofer Ch L, Dettling-Pizzolato M, Graf N, Largiader J, Binkert CA. Endovascular stent treatment for symptomatic benign iliofemoral venous occlusive disease: long-term results 1987-2009. Cardiovasc Intervent Radiol 20II;34:542-9.

27. Hartung O, Loundou AD, Barthelemy P, Arnoux D, Boufi M, Alimi YS. Endovascular management of chronic disabling ilio-caval obstructive lesions: long-term results. Eur J Vasc Endovasc Surg 2009;38:II8-24.

28. Titus JM, Moise MA, Bena J, Lyden SP, Clair DG. Iliofemoral stenting for venous occlusive disease. J Vasc Surg 20II Mar;53:706-I2.

29. Arnoldussen CW, Toonder I, Wittens CH. A novel scoring system for lower-extremity venous pathology analysed using magnetic resonance venography and duplex ultrasound. Phlebology 20I2;27(Suppl I): I63-70.

30. Eklof B, Rutherford RB, Bergan JJ, et al. Revision of the CEAP clas-sification for chronic venous disorders: consensus statement. J Vasc Surg 2004;40:1248-52. 

CHAPTER 4

SHORT-TERM CLINICAL EXPERIENCE

WITH A DEDICATED VENOUS NITINOL STENT:

INITIAL RESULTS WITH THE SINUS-VENOUS STENT

M.A.F. de Wolf ${ }^{1}$

R. de Graaf ${ }^{2}$

R.L.M. Kurstjens ${ }^{1}$

S. Penninx ${ }^{1}$

H. Jalaie ${ }^{3}$

C.H.A. Wittens ${ }^{1,3}$

I Department of Vascular Surgery and Cardiovascular Research Institute Maastricht, Maastricht University Medical Centre, Maastricht, The Netherlands

2 Department of Radiology, Maastricht University Medical Centre, Maastricht, The Netherlands

3 Department of Vascular Surgery, University Hospital RWTH Aachen, Aachen, Germany

Published in the European Journal of Vascular and Endovascular Surgery

Eur J Vasc Endovasc Surg (2015) 50, 518 e526 


\section{ABSTRACT}

\section{Objective}

Deep venous stenting has become the primary treatment option for chronic venous obstructive disease, both for iliac vein compression and post-thrombotic venous lesions. Until recently, only stents aimed at arterial pathology were used, because no dedicated venous stents were available. However, three such stents have now become available. These venous stents are characterized by increased length, diameter, flexibility, and radial force. This study reports an early experience with one of these devices; the sinus Venous stent (OptiMed GmbH, Ettlingen, Germany).

\section{Methods}

Between March 2012 and July 20I4, 75 patients were treated with the sinus Venous stent: 35 cases of iliac vein compression syndrome and 40 cases of unilateral chronic obstruction in post-thrombotic syndrome (PTS). Diagnosis of relevant obstruction was made using clinical evaluation, duplex ultrasound, and magnetic resonance venography. Patency during follow up was assessed with duplex ultrasound. Clinical improvement was assessed by VCSS, Villalta score, rate of ulcer healing, and improvement of venous claudication.

\section{Results}

The cumulative patency rates at 3, 6, and I2 months were $99 \%, 96 \%$, and $92 \%$, respectively. The cumulative assisted primary patency rates were $99 \%$ at 3, 6, and I2 months. The cumulative secondary patency rate at 12 months was I00\%. Differences exist in patency rate between the subgroups of non-thrombotic and post-thrombotic, with the first showing no reocclusions. All rethromboses in the PTS group were treated by ancillary treatment modalities. VCSS and Villalta score decreased significantly after stenting, as did venous claudication. Morbidity was low without clinically relevant pulmonary embolism, and mortality was nil. Although two out of seven ulcers healed temporarily, no ulcer remained healed at 12 months follow up.

\section{Conclusion}

Short-term clinical results using the sinus Venous stent are excellent, with significant symptom reduction, low morbidity rates, and no mortality. Loss of stent patency is seen less often compared with arterial stents described in the literatures. 


\section{INTRODUCTION}

Therapy for chronic deep venous disease has long been characterized by the sole use of conservative treatment modalities, both in cases of valvular insufficiency and venous obstructive disease. Open surgical or endovascular approaches were reserved for the most severe cases, which still holds true for deep venous valvular insufficiency. In recent years, however, the treatment options in chronic deep venous obstructive disease have changed dramatically. Endovascular treatment, by use of percutaneous transluminal angioplasty (PTA) and stenting of post-thrombotic obstructions and venous compression syndromes, such as May-Thurner syndrome (MTS), has become standard care in a large number of specialized centers worldwide. The low morbidity, absence of mortality, and excellent short and long-term results mean that worldwide interest in this type of treatment is rapidly increasing and more and more centers are starting to offer this treatment. It is, therefore, remarkable that until very recently no stents dedicated to deep venous pathology were available.

Neglén et al. showed good results with the Wallstent, a metal stent frequently used in arterial pathology, with high radial force, although limited flexibility and poor positioning qualities.I Also, nitinol stents have been used and show comparable results between study groups.2 Recent study of arterial designed self-expanding nitinol stents in a mostly post-thrombotic population, showed patency rates of $74 \%, 8 \mathrm{I} \%$, and $96 \%$ at I year for primary, assisted primary, and secondary patency, respectively. 3 The arterial design, however, incorporates properties that might hamper applicability in the venous system.4 Arterial and venous anatomy and hemodynamics differ greatly in physiological and pathophysiological conditions; especially in terms of shear stress, vessel diameter, and flexibility. Moreover, PTA and stenting in arterial disease is generally reserved for pathology of atherothrombotic origin, without scarring of the vessel wall and or external compression.

Recently a number of dedicated venous stents have been announced or became available; namely the Veniti Vici (VENITI inc., St. Louis, MO, USA), Zilver Vena (Cook, Bloomington, IN, USA), and sinus Venous (OptiMed, Ettlingen, Germany). All three devices are designed to accommodate the need for greater length, diameter, flexibility, and radial force in the venous system. To the authors' knowledge, only clinical data regarding the Zilver Vena have been published. O'Sullivan et al. showed excellent results for the Zilver Vena stent in a challenging population with many acute DVT patients and malignant venous obstructions; they reported a short-term patency rate of $85 \% .5$

This study evaluates safety and short-term clinical outcome when using the sinus Venous stent in routine patient care at a tertiary venous center. As iliac vein compression syndromes differ greatly in their etiology from post-thrombotic disease, use of the 
device will be evaluated separately for both types of pathology.

\section{METHODS}

The study included 75 patients treated for symptoms and complaints related to unilateral chronic iliofemoral venous obstructive disease with the sinus Venous stent at a tertiary referral hospital, between March 2012 and July 20I4. Patients who were suspected of having iliofemoral deep venous obstruction received both duplex ultrasonography (DUS) imaging and magnetic resonance venography (MRV) to confirm the diagnosis.6 Patients were included when: (A) signs of unilateral iliofemoral deep venous obstruction were present on DUS and MRV (>50\% diameter stenosis and the presence of a collateral network), (B) clinically significant signs and symptoms of chronic obstructive venous disease were present, and (C) the femoral and deep femoral veins were patent. Patients with inferior vena cava involvement or bilateral iliofemoral occlusive disease were excluded. Furthermore, patients were excluded in whom post-thrombotic aberrations extended below the level of the saphenofemoral junction in the common femoral vein, as these patients are treated in a hybrid fashion, stent placement combined with endophlebectomy and AV fistula creation.7 Moreover, patients with a history of DVT less than I year ago were excluded as sufficient natural recanalization might still occur.8 Upon intake baseline data were collected, consisting of CEAP, Venous Clinical Severity Score (VCSS), Villalta score, and assessment of venous claudication.9eII Venous claudication was defined as the onset or worsening of pain and/or heaviness during (mild) exercise, which subsides during rest, especially when sitting or lying down. Venous claudication was only considered in patients with a proven venous obstruction. The location and extent of obstruction or external compression, the presence of collateral veins, the inflow at the common femoral vein from all three major branches (great saphenous vein, femoral vein and deep femoral vein), the outflow through the inferior vena cava and valve competence $(<0.5$ seconds of reflux) all were evaluated. Left iliac vein compression (LIVC) or right iliac vein compression syndrome was considered when external compression of the common iliac vein (CIV) created $>50 \%$ diameter reduction at this point as shown by DUS and/or MRV and collaterals were present.I2,I3

\section{Duplex ultrasonography}

DUS examination was done using a Hitachi Aloka ProSound ALPHA 7 Premier machine (Aloka, Tokyo, Japan) and consisted of scanning the venous system from the suprarenal vena cava down to the common femoral vein in the supine position with a convex array transducer, UST-9I30 (frequency range, 3 e6 MHz). Using a high-frequency UST-54II (frequency range, 5eI6 MHz) compound linear array transducer with pulsed wave Doppler $(5 \mathrm{MHz})$, scanning from the upper groin to below the knee to test for distal obstructive lesions ( $>50 \%$ diameter reduction) and valvular incompetence $(>0.5 \mathrm{~s}$ 
reflux), in the standing position, was performed.

\section{Magnetic resonance venography}

All MRV examinations were performed on a I.5-T MRI system (Achieva, Philips Medical Systems, Best, the Netherlands). The technique has been described in detail before.6 In short, a dedicated I2 element phased array peripheral vascular coil with a craniocaudal coverage of $128 \mathrm{~cm}$ (Philips Medical Systems) was used for signal reception. A fixed dose of $20 \mathrm{~mL}$ gadobutrol (Gadovist I.O, Bayer Schering Pharma, Berlin, Germany) was administered intravenously as a single dose at a rate of $1.0 \mathrm{~mL} / \mathrm{s}$ in the median cubital vein, using a remote controlled injection system (Medrad Spectris, Indianola, PA, USA). A five station three dimensional ultrafast gradient echo (TFE) sequence with fat suppression (SPIR) was used for high resolution imaging of the venous vasculature from the popliteal veins up to the right atrium.

\section{PTA and stenting}

Procedures were performed in a dedicated angiosuite (AlluraClarity, Philips Medical Systems, Eindhoven, the Netherlands). All interventions in post-thrombotic syndrome (PTS) patients were performed under general anesthesia, while iliac vein compressions were treated under local anesthesia. Heparin $(5.000 \mathrm{IU})$ was administered to all patients currently not using oral anticoagulants, and coumadin was continued in all other cases (a maximum INR of 4 was accepted at the time of intervention). Venous access was obtained through the ipsilateral femoral vein, at least $15 \mathrm{~cm}$ distal to the femoral confluence under ultrasound guidance. A IoF sheath was needed to facilitate stent introduction. The technique for traversing stenotic and occluded venous segments has been described before.I4 Predilatation to the size of the anticipated stent is essential for sinus Venous stents. Predilatation was done increasing in size from 12 to $16 \mathrm{~mm}$ from the common femoral vein to the common iliac vein ( $12 \mathrm{~mm}$ powerflex and $\mathrm{I} 6 \mathrm{~mm}$ maxi $\mathrm{LD}$, Cordis, Johnson \& Johnson, Diegem, Belgium; I4 mm Armada, Abbott, North Chicago, IL, USA). Maximum pressure needed for full balloon expansion was I2 atm. All venous segments were stented with the sinus Venous. Postdilatation was always performed. Poststenting assessment of in and outflow was done by single plane anteroposterior angiography. Conebeam CT imaging was performed to evaluate stent configuration and apposition. Post intervention, patients were generally discharged the next day. The anticoagulation regimen consisted of 6 months of treatment with coumadin, with a target INR of $3 \mathrm{e} 4$, according to Dutch guidelines for thrombosis service.I5 This regimen was started the evening after the intervention. Full dose tinzaparine was started directly post-intervention and continued until the INR was $>3$ on two separate days. Antiplatelets were not used. In patients already using coumadin prior to the intervention, these drugs were continued during hospitalization.

\section{Follow-up}

Standardized follow up was performed at 2 and 6 weeks and 3, 6, and I2 months post 
intervention. Follow up data collection consisted of VCSS and Villalta score assessment, rate of relief of venous claudication and ulcer healing (defined as full reepithelialization). DUS was performed to assess patency at every visit. Patency was defined as flow in a lumen with $<50 \%$ diameter compared with the stent diameter. All data were collected prospectively using a preset protocol.

\section{Statistical analysis}

Frequencies and percentages were used to present categorical data. Median values with the range were used for continuous data. Categorical data were analyzed by the c2 test. KaplaneMeier survival analysis was used to calculate patency rates. An a of .05 was used to indicate statistical significance.

\section{Ethical approval for research}

Under Dutch law, patients treated at a university hospital give automatic consent for their anonymized data to be used in research, unless explicit objections are made.

\section{RESULTS}

\section{Demographics}

Seventy-five patients with unilateral chronic iliofemoral venous obstruction (CVO) were treated by placement of the sinus Venous stent during the study period. The median age was 45 years (range I8e77), and 49 (65\%) patients were female. Complaints and symptoms were caused by post-thrombotic disease in $40(53 \%)$ patients. In the other $35(47 \%)$ patients, CVO was caused by primary iliac vein compression syndrome (left sided in 33 patients). In the post-thrombotic patient group, 35 (88\%) had suffered a DVT in their medical history. In the other five patients no DVT was ever diagnosed clinically; however, there were signs on MRV and DUS of vein wall scarification and trabeculation in the common and/or external iliac vein, consistent with prior DVT (Table 9). All post-thrombotic iliofemoral obstructive lesions were occlusive on the intraprocedural venogram. Post-thrombotic occlusion was restricted to the CIV in two (5\%) patients, present in CIV and external iliac vein (EIV) in five (13\%), present in the EIV and common femoral vein (CFV) above the saphenofemoral confluence in four (IO\%) and extending from the CIV to the CFV above the saphenofemoral confluence in $29(73 \%)$ patients. C class of CEAP was C4e6 (i.e. skin changes) in 2I $(28 \%)$ patients. Forty $(53 \%)$ patients presented with venous claudication. Based on the Villalta scale, I3 (33\%) legs were scored as having mild, II (28\%) moderate, and I3 (33\%) severe PTS. In three (8\%) patients the Villalta scale was $<5$ points, that is venous claudication was the indication for treatment in those patients (which highlights the inability of the Villalta scale to adequately assess PTS in some cases). Venous claudication was present in 25 (63\%) patients in the PTS and I6 (46\%) in the iliac vein compression groups. Seven (9\%) patients had an active venous ulcer, four in the PTS, and three in the iliac vein 
compression syndrome group. Other demographics and subdivision into subgroups can be found in Table 9.

Table 9. Demographics of the total, PTS, and iliac vein compression subgroups

\begin{tabular}{|c|c|c|c|c|c|c|}
\hline Baseline & \multicolumn{2}{|c|}{ Total } & \multicolumn{2}{|c|}{ PTS } & \multicolumn{2}{|c|}{ IVCS } \\
\hline $\mathrm{N}$ & 75 & & 40 & & 35 & \\
\hline Number of females & 49 & $65 \%$ & 24 & $53 \%$ & 25 & $7 \mathrm{I} \%$ \\
\hline Average age (years) & 45 & $(\mathrm{I} 7-77)$ & 45 & $(\mathrm{I} 7-68)$ & 44 & $(\mathrm{I} 8-77)$ \\
\hline Single DVT & 38 & $51 \%$ & 28 & $70 \%$ & 5 & $\mathrm{I} 4 \%$ \\
\hline Recurrent DVT & 9 & $12 \%$ & 7 & $\mathrm{I} 8 \%$ & 2 & $6 \%$ \\
\hline Silent DVTa & 5 & $7 \%$ & 5 & $13 \%$ & $\mathrm{O}$ & O\% \\
\hline Time between DVT & & & & & & \\
\hline and treatment (years) & 6 & $(\mathrm{I}-37)$ & 6 & $(\mathrm{I}-37)$ & & \\
\hline Left sided DVT & & & 29 & $83 \%$ & & \\
\hline Right sided DVT & & & 5 & $\mathrm{I} 4 \%$ & & \\
\hline Bilateral DVT & & & I & $3 \%$ & & \\
\hline Left sided stenting & 72 & $96 \%$ & 39 & $98 \%$ & 33 & $94 \%$ \\
\hline Right sided stenting & 8 & II\% & 6 & $15 \%$ & 2 & $6 \%$ \\
\hline C-class o & 8 & II $\%$ & 4 & IO $\%$ & 4 & II $\%$ \\
\hline C-class I & 9 & $\mathrm{I} 2 \%$ & 7 & $\mathrm{I} 8 \%$ & 2 & $6 \%$ \\
\hline C-class 2 & $\mathrm{I} 3$ & $\mathrm{I} 7 \%$ & 6 & $15 \%$ & 7 & $20 \%$ \\
\hline C-class 3 & 24 & $32 \%$ & II & $28 \%$ & $\mathrm{I} 3$ & $37 \%$ \\
\hline C-class 4 & II & $15 \%$ & 6 & $15 \%$ & 5 & $\mathrm{I} 4 \%$ \\
\hline C-class 5 & 3 & $4 \%$ & 2 & $5 \%$ & I & $3 \%$ \\
\hline C-class 6 & 7 & $9 \%$ & 4 & $10 \%$ & 3 & $9 \%$ \\
\hline Median Villalta & & & II. 5 & $(2-24)$ & & \\
\hline Venous claudication & 40 & $53 \%$ & 25 & $63 \%$ & I6 & $46 \%$ \\
\hline Superficial venous reflux & 6I & $8 \mathrm{I} \%$ & 33 & $83 \%$ & 28 & $80 \%$ \\
\hline Deep venous reflux & I9 & $25 \%$ & I2 & $30 \%$ & 7 & $20 \%$ \\
\hline Perforator vein reflux & I7 & $23 \%$ & 5 & $\mathrm{I} 3 \%$ & $\mathrm{I} 2$ & $34 \%$ \\
\hline
\end{tabular}

a Silent DVT: no anamnestic history of DVT, but clear signs of previous DVT on imaging.

\section{Procedure}

All post-thrombotic occlusions required recanalization. Technical success was achieved in all cases. In 43 patients (57\%) one stent was used, in 27 patients (36\%) two stents, and in five patients $(7 \%)$ three stents were used. When applicable, the stent was placed as accurately as possible at the iliac confluence to cover the obstruction, with special care not to cover the contralateral inflow.

In three patients, however, one in the PTS group and two in the iliac vein compression group, positioning was deemed too central into the inferior vena cava (IVC), touching the IVC wall and thereby covering the contralateral inflow. No further action was taken. In a fourth patient acute thrombosis of the stented tract was observed during the 
procedure and was directly and successfully treated by percutaneous thrombectomy. Throughout follow up this patient's stents remained patent. Intraprocedural kinking and/or fracture of stents were not seen.

\section{Follow-up}

The ultrasound examination at 2 weeks showed suboptimal positioning of the CIV stent in two patients with iliac vein compression lesions. In both cases, the stents were placed too peripherally, resulting in persistent compression of the left CIV by the overlying right common iliac artery (which did not require restenting as the recurrent stenosis was $<50 \%$ ). Optimal stent distention was seen in all cases distal to the CIV. Mild compression, that is oval rather than round configuration of the stent was noticed at the level of the left common iliac vein because of the overriding right iliac artery in most cases (Figure 6); however, no significant diameter stenosis (>50\%) was seen, compared with the diameter of a fully expanded stent.

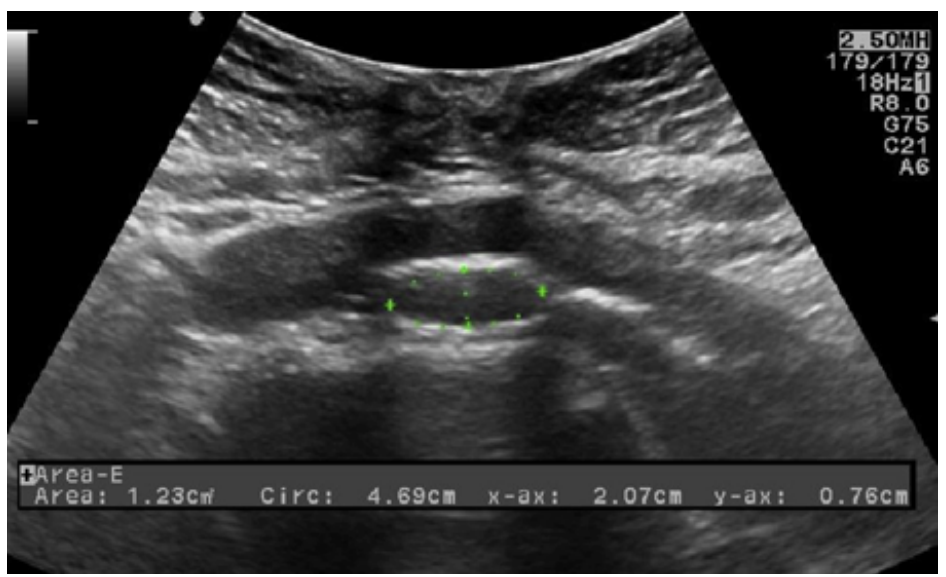

Figure 6. Ultrasound control after stenting the common iliac vein on the left side to treat MayThurner syndrome, showing the typical oval shape of the stent with sufficient radial force to lift the overlying right common iliac artery. Smallest intraluminal diameter is $7.6 \mathrm{~mm}$, compared with $12 \mathrm{~mm}$ more distally, but with a very adequate surface area of $1.23 \mathrm{~cm} 2$.

Patient follow up had a median duration of 5.4 (range I.oI8.0) months. The overall cumulative primary patency was $99 \%$ at 3 months, $96 \%$ at 6 months, and $92 \%$ at 12 months. Assisted primary patency rates were $99 \%$ at 3, 6 and 12 months, and the secondary patency rate was $100 \%$ during the total follow up period (Figure $7 \mathrm{~A}$ ). Cumulative primary patency rates for the iliac vein compression group were $100 \%$ during follow up (Figure $7 \mathrm{~B}$ ). The cumulative primary patency rates of the post-thrombotic group at 3,6 , and $\mathrm{I} 2$ months were $97 \%, 93 \%$, and $85 \%$, respectively (Figure $7 \mathrm{C}$ ). For all reported patency rates the standard error of the mean was < $<$ IO.O. Loss of primary patency was seen in three post-thrombotic patients, in all cases rethrombosis occurred (Figure 8). 
Residual compression in one patient with a history of a spondylodesis by metal rods and screws led to quick stenosis and thrombosis of the stented common iliac vein.

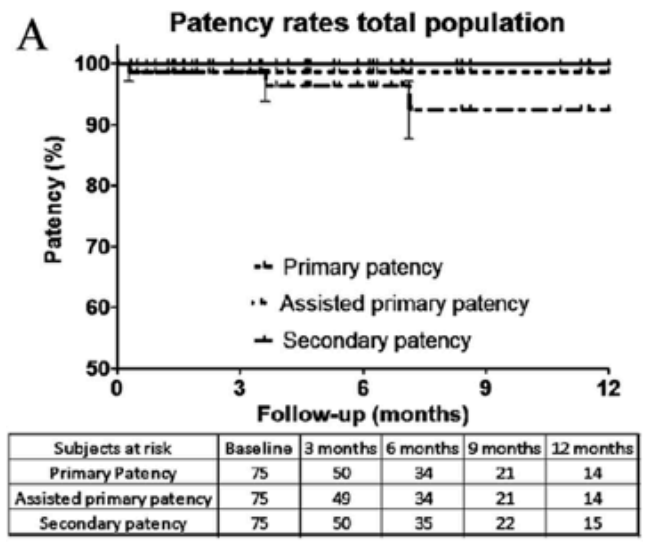

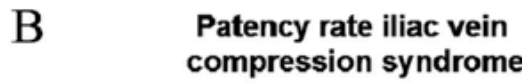

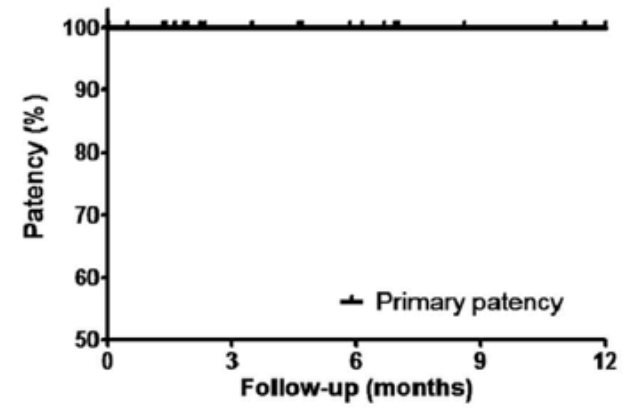

\begin{tabular}{|c|c|c|c|c|c|}
\hline Subjects at risk & Baseline & 3 months & 6 months & 9 months & 12months \\
\hline Primary Patency & 35 & 25 & 18 & 12 & 7 \\
\hline
\end{tabular}

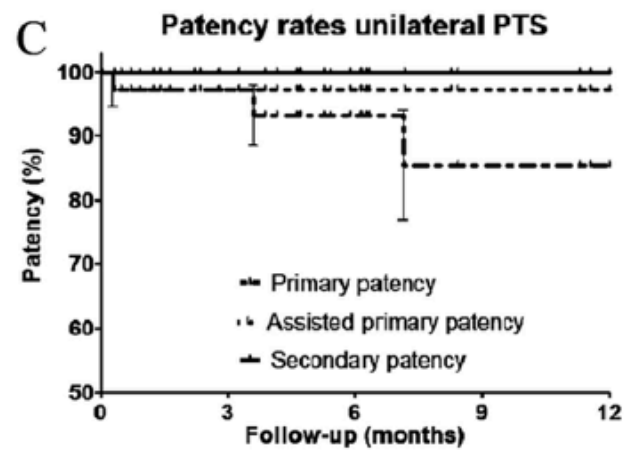

\begin{tabular}{|c|c|c|cc|c|}
\hline Subjects at risk & Baseline & 3 months & 6 months & 9 months & 12 months \\
\hline Primary Patency & 40 & 26 & 17 & 10 & 7 \\
\hline Assisted primary patency & 40 & 25 & 17 & 10 & 7 \\
\hline Secondary patency & 40 & 26 & 18 & 11 & 8 \\
\hline
\end{tabular}

Figure 7. Kaplan Meier analysis of patency rates of (A) the total population, (B) the iliac vein compression syndrome population, and $(C)$ the PTS population. 

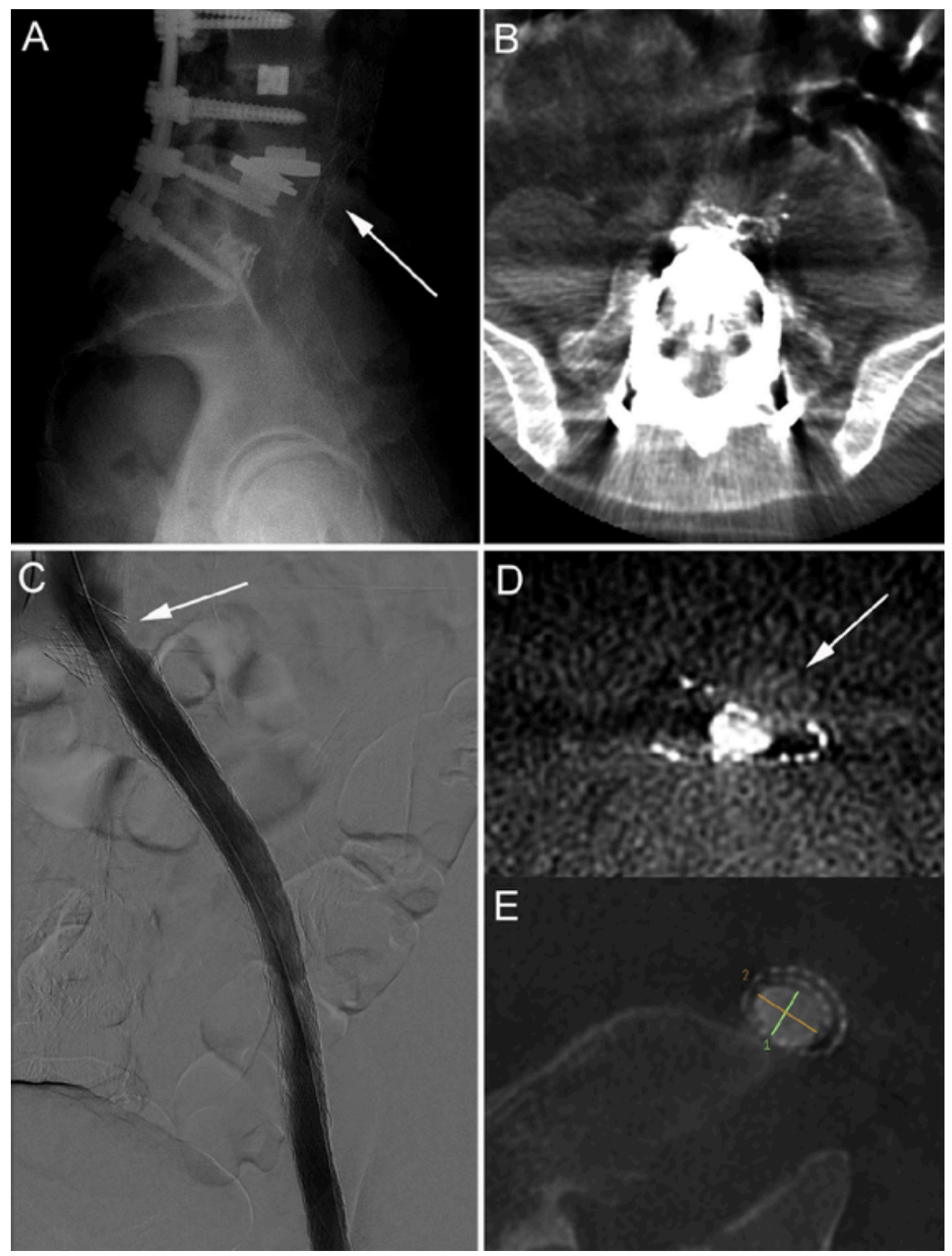

Figure 8. Loss of patency cases. (A) X-ray in lateral projection showing sub-optimal stent configuration because of extensive spondylodesis material leaving a remaining compression (white arrow). (B) Cone beam CT imaging showing significant stent compression, nonresponding to repeated balloon angioplasty. (C) Completion angiography after stenting for post-thrombotic iliac vein obstruction showing a gap between stent segments at the level of the overlying common iliac artery resulting from sub-optimal deployment technique. (D) Cone beam CT imaging showing persistent compression caused by lack of stent material and therefore crush resistance at the level of the common iliac artery (white arrow). (E) Adequate surface area after re-stenting. 
This was treated by catheter directed thrombolysis followed by re-stenting of the CIV with a high radial strength balloon expendable stent (Andrastent XL $43 \mathrm{~mm}$, Andramed, Reutlingen, Germany). In a second patient the stent placed in the CIV was mistakenly stretched during placement, leading to a significant gap between the struts of the stent; at this point the right common iliac artery slipped into the gap causing a persistent stenosis during follow up. This was treated by restenting with a second well placed sinus Venous stent. In the third patient, with a history of IV drug abuse into the common femoral vein, the fibrotic vein was not predilated with enough pressure. During follow up, significant stenosis was seen at this level, which was treated solely using high pressure rePTA. Other complications during follow up are noted in Table Io.

Table Io. Complications after stent placement.

\begin{tabular}{|c|c|c|c|c|}
\hline Complications & $\begin{array}{l}\text { Total } \\
\text { population }\end{array}$ & PTS & IVC & \\
\hline $\mathrm{N}$ & 75 & 40 & 35 & \\
\hline Proximal stent extension into vena cava & $4 \%$ & I $\quad 3 \%$ & 2 & $6 \%$ \\
\hline Minor bleeding during admission & $\mathrm{I} \%$ & $3 \%$ & o & $\mathrm{O} \%$ \\
\hline Stent related pain needing readmission & $\mathrm{I} \%$ & $3 \%$ & o & $0 \%$ \\
\hline Residual stent compression & $3 \%$ & $5 \%$ & 0 & $\mathrm{O} \%$ \\
\hline Stent tapering & $3 \%$ & $5 \%$ & $\mathrm{o}$ & $\mathrm{O} \%$ \\
\hline Stent stenosis & $3 \%$ & $5 \%$ & $\mathrm{O}$ & $0 \%$ \\
\hline $\begin{array}{r}\text { Anticoagulation related minor bleeding } \\
\text { during follow-up }\end{array}$ & $45 \%$ & $10 \%$ & o & $0 \%$ \\
\hline Stent placed proximally of common iliac vein & $4 \%$ & $5 \%$ & 0 & O\% \\
\hline
\end{tabular}

\section{Clinical improvement}

Median Villalta score in the PTS group decreased from II.5 (2-24) before treatment to 5.0 (o-I6) at last follow-up, which constituted a decrease of 6.5 (p .OOI). VCSS decreased 3 points, from 8 (3-2I) preintervention to 5 (O-I6) at last follow up in the PTS group and decreased 2 points from 6 (2-I9) to 4 (I-I6) in the iliac vein compression group, both decreases were statistically significant ( $\mathrm{p}$. .oor and $\mathrm{p}=.0 \mathrm{ol}$ ). Venous claudication subsided in $\mathrm{I} 8$ out of 25 patients in the PTS group (p .ooor) and in $\mathrm{I} 4$ out of $\mathrm{I} 6$ patients in the iliac vein compression group $(\mathrm{p}=.0002)$. Two of four ulcers healed in the PTS group, and none healed in the iliac vein compression group. Both healed ulcers recurred during follow up.

\section{DISCUSSION}

In this study, short-term results for use of the segmental sinus Venous stent in chronic venous obstructive disease are very favorable, both in the post-thrombotic syndrome 
and iliac vein compression syndrome. In a previous study, initial data on PTA and stenting in a similar population from the same center were presented.3 In both studies, PTA and stenting were shown to be safe and feasible when using self-expandable nitinol stents with good patency rates, mild complication rates, and no mortality. Other authors have shown similar favorable results of deep venous stenting during recent decades, including those series in which patients were stented with other stent types, especially the Wallstent (Boston Scientific).I,I6,I7 As the Wallstent suffers from significant foreshortening, precise positioning is sometimes difficult in inexperienced hands and occurrence of skip lesions may occur. Therefore, earlier reports mentioned the need for considerable overlapping of multiple stents to prevent incomplete treatment of obstructive lesions. Multiple centimeter overlaps make the stented segment even more rigid. Furthermore, to prevent retrograde migration the Wallstent has to be placed well into the inferior vena cava, potentially impairing contralateral outflow and increasing the risk of contralateral iliac vein thrombosis. Arterial designed nitinol stents have their own shortcomings and differ from venous designed stents in several ways.

Firstly, the diameter of a vein is greater than that of an artery. This is particularly important in the common iliac tract as generally stent diameters of $16-20 \mathrm{~mm}$ are needed. Arterial stents are generally not offered in these diameters.

Secondly, post-thrombotic obstructions generally cover a greater length of the vein compared with arterial obstructive lesions. Therefore, more than one stent is often required in post-thrombotic patients when using arterial nitinol stents. The increased overlapping areas of the stents further reduce flexibility.

Thirdly, post-thrombotic veins are often heavily scarred and have firm intraluminal fibrotic strands, which may extend over relatively long segments. Predilatation, sometimes with high pressure balloons, is needed to break these fibrotic strands and dilate the fibrotic vein wall. A stent with sufficient resistive radial force is needed to maintain this diameter. This force in arterial designed stents is most often insufficient. In iliac vein compression syndromes the local pressure on a vein caught between the overlying artery and bony structures is high, and therefore calls for stents with sufficiently high resistive radial force.

Fourthly, in contrast to arteries, normal veins have a less supported wall and are more susceptible to external forces. Post-thrombotic veins might be influenced less because of the fibrotic changes. Nevertheless, it is generally recommended to land a stent in a healthy vein segment. It is therefore conceivable that particular stent properties have an effect on the integrity of the vein at this location. Optimally, stents implanted within venous structures should be able to move effortlessly with every movement of the vein. Stents with excessive rigidity might dictate the shape of the vein, thereby perhaps creating suboptimal hemodynamics or damage to the vein wall causing stenosis, 
occlusion, or insufficient flow. This is especially the case when stents cross the internal iliac vein and inguinal ligament where sufficient flexibility is most important.I8 Finally, when a highly rigid stent is forced to maintain its position at two locations, there is an increased risk of kinking which might lead to stenosis (Figure 9).
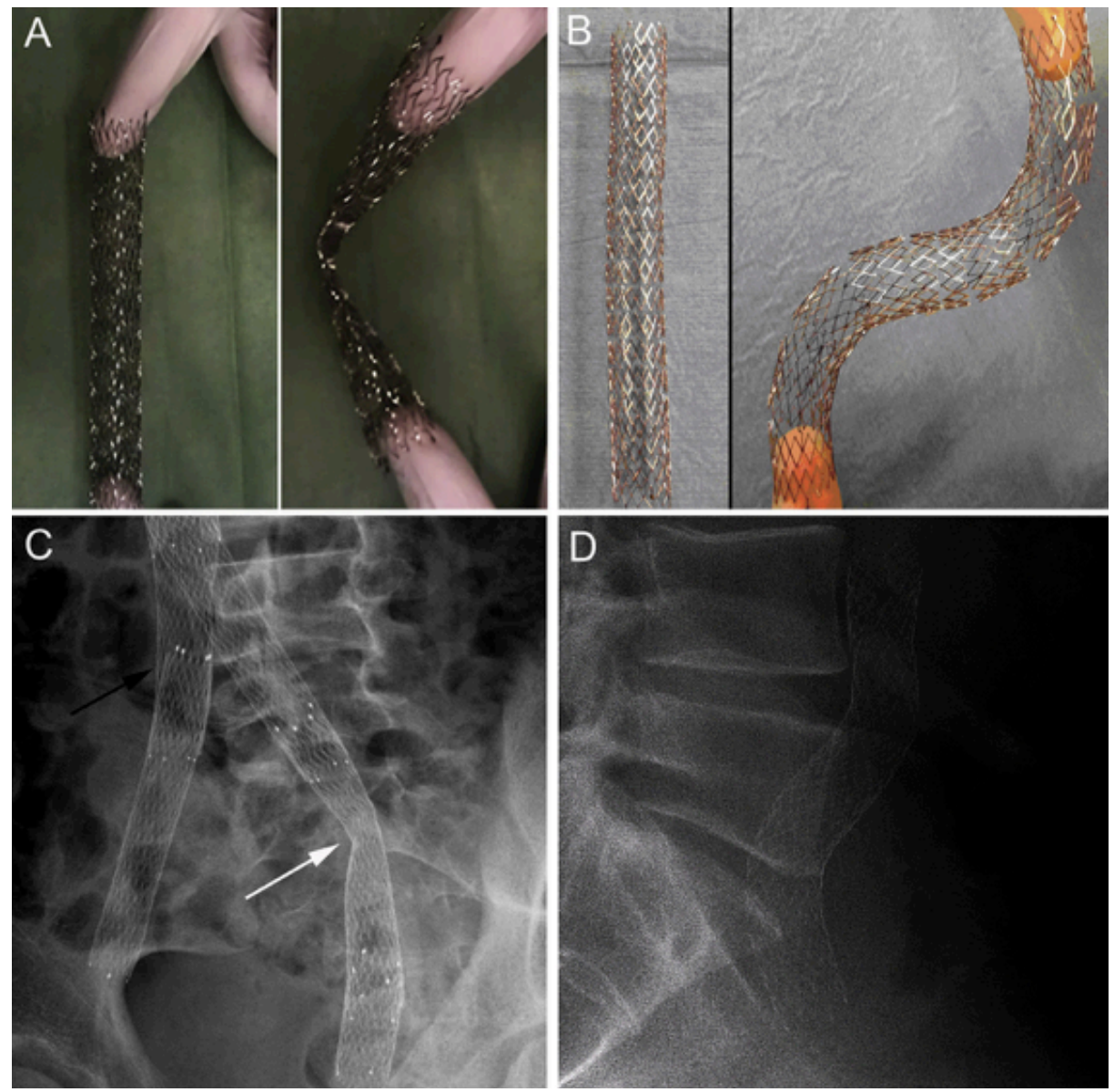

Figure 9. Arterial stent design (sinus XL stent, OptiMed GmbH, Ettlingen, Germany), versus dedicated venous stent design (sinus Venous stent, OptiMed GmbH, Ettlingen, Germany). (A) Forcing an arterial designed stent into a curve increases the risk of kinking. (B) Dedicated venous stents can be shaped easily into an "S" curve. (C) Oblique projection X-ray post stenting with arterial designed stents showing kinking on the left (white arrow) and straightening of a stent-in-stent on the right (black arrow). (D) "S" shape of a venous stent to treat a May-Thurner compression, adapting perfectly to the venous anatomy.

In the authors' opinion, an optimal venous stent should be able to flex at two different points without narrowing at these flex points (Figure 9), thereby preventing kink related stenosis. In general, the venous anatomy should therefore dictate the shape 
of the stent and not vice versa. The sinus Venous stent should prevent kinking by its segmental design. Connecting rings with close-cell design creates a high radial force. Connecting the rings with two tiny connections keeps the system sufficiently flexible (Figure IO). However, a number of concerns exist. Most importantly, at the level of the highest external force the stent segments should be placed in close proximity, to avoid a high pressure point exactly between segments, which makes delivery technically challenging, with the most important being the pressure point at the level of the overriding common iliac artery. A more or less oval shape can be seen at these levels of high compression, but a residual stenosis of more than $50 \%$ would be unacceptable. Other stented segments do not seem to suffer from focal pressure points. Also, the "bare areas" left between separate rings do not appear to predispose to restenosis, at least during the first year, as shown in this study.

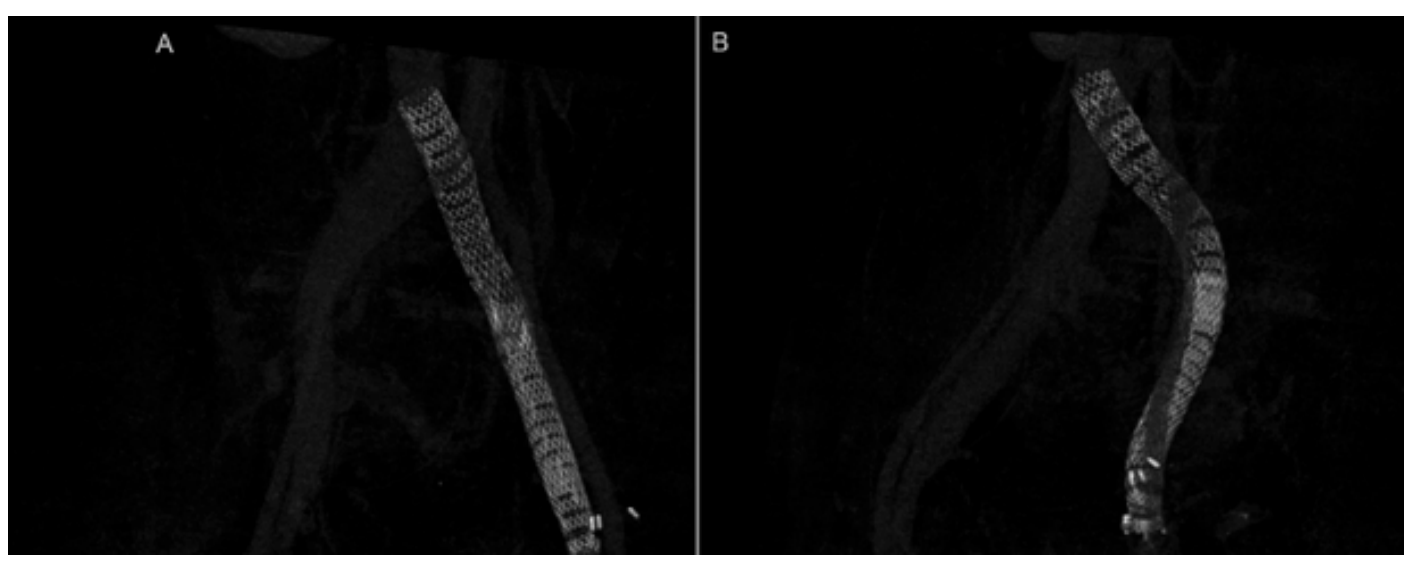

Figure Io. 3D CT reconstruction, antero-posterior (A) and oblique (B) after stenting of the left common and external iliac vein clearly showing the segmented stent design and curved configuration at the level of the internal-external iliac vein confluence and at the level of the common femoral vein, locations known to be prone to kinking or residual compression.

As shown by Neglén et al., significant differences in outcome can be observed when comparing stenting for thrombotic and non-thrombotic disease.I In this series similar differences were observed; no stents occluded in the iliac vein compression subpopulation, and all three loss of primary patency instances were seen in the PTS group. The higher number of reocclusions in this group might be caused by the etiology and severity of PTS and compromised venous inflow from femoral veins resulting from extensive post-thrombotic trabeculations. Limitations of this study include the small population with short median follow up. Moreover, an in depth comparison with the use of other stents, especially the Wallstent, has not been performed. 


\section{CONCLUSION}

Short-term clinical results using the sinus Venous stent are excellent, with significant symptom reduction, low morbidity rates, and no mortality. Stent related loss of patency is seen infrequently. Post-thrombotic lesions showed a lower patency compared with non-thrombotic lesions, a known reported finding. 


\section{REFERENCES}

I. Neglén P, Hollis KC, Olivier J, Raju S. Stenting of the venous outflow in chronic venous disease: long-term stent-related outcome, clinical, and hemodynamic result. J Vasc Surg 2007;46(5):979e9o.

2. George R, Verma H, Ram B, Tripathi R. The effect of deep venous stenting on healing of lower limb venous ulcers. Eur J Vasc Endovasc Surg 20I4;48(3):330e6.

3. Friedrich de Wolf MA, Arnoldussen CW, Grommes J, Hsien SG, Nelemans PJ, de Haan MW, et al. Minimally invasive treatment of chronic iliofemoral venous occlusive disease. J Vasc Surg 20I3;I(2):I46e53.

4. Jalaie H, Arnoldussen C, Barbati M, Kurstjens R, de Graaf R, Grommes J, et al. What predicts outcome after recanalization of chronic venous obstruction: hemodynamic factors, stent geometry, patient selection, anticoagulation or other factors? Phlebology 2014;29(Suppl. I):97ero3.

5. O'Sullivan GJ, Sheehan J, Lohan D, McCann-Brown JA. Iliofe-moral venous stenting extending into the femoral region: initial clinical experience with the purpose-designed Zilver Vena stent. J Cardiovasc Surg 2013;54(2):255e6I.

6. Arnoldussen CW, de Graaf R, Wittens CH, de Haan MW. Value of magnetic resonance venography and computed tomo-graphic venography in lower extremity chronic venous disease. Phlebology 2013;28(Suppl. I):I69e75.

7. de Wolf MA, Arnoldussen CW, Wittens CH. Indications for endophlebectomy and/or arteriovenous fistula after stenting. Phlebology 20I3;28(Suppl. I):I23e8.

8. Markel A, Meissner M, Manzo RA, Bergelin O, Strandness Jr DE. Deep venous thrombosis: rate of spontaneous lysis and thrombus extension. Int Angiol 2003;22(4):376e82.

9. Eklof B, Rutherford RB, Bergan JJ, Carpentier PH, Gloviczki P, Kistner RL, et al. Revision of the CEAP classification for chronic venous disorders: consensus statement. J Vasc Surg 2004;40(6):I248e52.

Io. Strijkers RH, Wittens CH, Kahn SR. Villalta scale: goals and limitations. Phlebology 2012;27(Suppl. I):I30e5.

II. Vasquez MA, Rabe E, McLafferty RB, Shortell CK, Marston WA, Gillespie D, et al. Revision of the venous clinical severity score: venous outcomes consensus statement: special communica-tion of the American Venous Forum Ad Hoc Outcomes Working Group. J Vasc Surg 2010;52(5):1387e96.

I2. Cockett FB, Thomas ML, Negus D. Iliac vein compression.eIts relation to iliofemoral thrombosis and the post-thrombotic syndrome. Br Med J 1967;2(5543):I4e9.

I3. May R, Thurner J. The cause of the predominantly sinistral occurrence of thrombosis of the pelvic veins. Angiology 1957;8(5):419e27.

I4. de Graaf R, Wittens CH. Endovascular treatment options for chronic venous obstructions. Phlebology 20I2;27(Suppl. I): I7Ie7.

I5. van Geest-Daalderop JH, Sturk A, Levi M, Adriaansen HJ. Extent and quality of anticoagulation treatment with coumarin de-rivatives by the Dutch Thrombosis Services. 
Nederlands tijds-chrift voor geneeskunde 2004;I48(I5):730e5.

I6. Hartung O, Otero A, Boufi M, De Caridi G, Barthelemy P, Juhan C, et al. Mid-term results of endovascular treatment for symptomatic chronic nonmalignant iliocaval venous occlusive disease. J Vasc Surg 2005;42(6):I138e44. discussion 44.

I7. Titus JM, Moise MA, Bena J, Lyden SP, Clair DG. Iliofemoral stenting for venous occlusive disease. J Vasc Surg 20II;53(3): 706eI2.

I8. de Graaf R, Arnoldussen C, Wittens CH. Stenting for chronic venous obstructions a new era. Phlebology 20I3;28(Suppl. I): II7e22. 

CHAPTER 5

ILIOCAVAL CONFLUENCE STENTING

FOR CHRONIC VENOUS OBSTRUCTIONS

Rick de Graaf ${ }^{1}$

Mark de Wolf ${ }^{2}$

Anna M. Sailer ${ }^{1}$

Jorinde van Laanen²

Cees Wittens ${ }^{2,3}$

Houman Jalaie ${ }^{3}$

I Department of Radiology, Maastricht University Medical Centre, Maastricht, The

Netherlands

2 Department of Vascular Surgery and Cardiovascular Research Institute Maastricht, Maastricht University Medical Centre, Maastricht, The Netherlands

3 Department of Vascular Surgery, University Hospital RWTH Aachen, Aachen, Germany

Published in CardioVascular and Interventional Radiology

Cardiovasc Intervent Radiol (2015) 38:II98-I204 DOI I0.IOO7/s00270-0I5-IO68-5 


\section{ABSTRACT}

\section{Purpose}

Different techniques have been described for stenting of venous obstructions. We report our experience with two different confluence stenting techniques to treat chronic biiliocaval obstructions.

\section{Materials and Methods}

Between II/2009 and 08/20I4 we treated 40 patients for chronic total bi-iliocaval obstructions. Preoperative magnetic resonance venography showed bilateral extensive post-thrombotic scarring in common and external iliac veins as well as obstruction of the inferior vena cava (IVC). Stenting of the IVC was performed with large self-expandable stents down to the level of the iliocaval confluence. To bridge the confluence, either self-expandable stents were placed stent ( 24 patients, SECS group) or high radial force balloon-expandable stents were placed at the same level (I6 patients, BECS group). In both cases, bilateral iliac extensions were performed using nitinol stents.

\section{Results}

Recanalization was achieved for all patients. In I5 (38\%) patients, a hybrid procedure with endophlebectomy and arteriovenous fistula creation needed to be performed because of significant involvement of inflow vessels below the inguinal ligament. Mean follow-up was $443 \pm 438$ days (range $7-\mathrm{I} 683$ days). For all patients, primary, assistedprimary, and secondary patency rate at 36 months were 70,73 , and $78 \%$, respectively. Twelve-month patency rates in the SECS group were 85,85 , and $95 \%$ for primary, assisted-primary, and secondary patency. In the BECS group, primary patency was IOO $\%$ during a mean follow-up period of I34 \pm II 8 (range 29-337) days.

\section{Conclusion}

Stenting of chronic bi-iliocaval obstruction shows relatively high patency rates at medium follow-up. Short-term patency seems to favor confluence stenting with balloon-expandable stents. 


\section{INTRODUCTION}

Recanalization and stenting of chronic deep venous obstructions is a minimally invasive intervention that has proven effective and safe over the last decades [I]. With low complication rates and substantial clinical improvement, this procedure has been increasingly performed over the last years. Long-term stent patency rates however vary substantially between clinical reports. Although encouraging $92 \%$ stent patency after Io years has been reported by dedicated highvolume centers $[2,3]$, lower results were published by clinics with lesser numbers of patients $[4,5]$. Partly, this variation might be explained by lack in dedicated venous interventional tools, e.g., stents. However, in recent years, a lot has changed both in interventional materials and techniques, which might be vital to achieve an optimal result. Therefore, it is of great importance to report on experience with new developments in stent design and stenting technology to help establish an optimal protocol, both for defining the right indication and choosing the optimal treatment.

Chronic vena cava obstruction can stay asymptomatic for a long time. Extensive collateralization through paralumbar veins and the azygos system might obscure the underlying hemodynamic severity for many years into adulthood. However, many patients will be confronted with decompensation at some point in their life, which becomes clinically evident by acute, and in many cases bilateral deep venous thrombosis (DVT). Reconstruction of the occluded inferior vena cava (IVC) by means of angioplasty and stent placement has been performed previously with satisfactory to excellent results [6-8]. However, stenting of the common iliac vein confluence has only been thoroughly described by Neglén et al. [9]. In their study, different stenting techniques were suggested to reconstruct the iliac confluence, all with their own limitations. In this article, we describe our experience with two confluence stenting techniques, one with merely self-expandable stents, the other with balloon-expandable stents bridging the common iliac vein confluence.

\section{Materials and Methods}

From November 2009 to August 20I4, 74I patients were evaluated for chronic venous insufficiency/post-thrombotic syndrome (CVI/PTS) or acute central venous obstructive complaints at our tertiary medical center. Forty of these patients were diagnosed with chronic iliocaval obstruction. Chronic iliocaval obstruction was defined as $50 \%$ or more venous lumen obstruction [IO] of the IVC involving the confluence on Duplex ultrasound (DUS) or magnetic resonance venography (MRV) with presence of postthrombotic trabecular changes in both common iliac and external arteries. All patients received DUS and MRV before treatment and cases were discussed in a multidisciplinary team consisting of a venous vascular surgeon, interventional radiologists, a dedicated ultrasonographer and experienced nurses. 
All procedures were performed under general anesthesia and full anticoagulation. Patients were administered at least one dose of 5000 IU of heparin during the procedure. After the intervention, patients received a single dose of Low-MolecularWeight Heparin (LMWH, Tinzaparine) and the preintervention anticoagulation regiment was continued, in general aiming for an international normalized ratio (INR) of 3.0-4.o. Patients who did not receive preinterventional anticoagulation were started on coumarins directly poststenting aiming for the same INR range, they received daily LMWH's until this INR range was achieved (with a minimal treatment time of at least 5 days). When no underlying thrombophilia was proven, anticoagulation therapy was continued for at least 6 months.

\section{Stenting Technique}

Patients with IVC and bilateral iliac vein obstruction and debilitating complaints interfering with daily life (most often chronic pain and/or venous claudication), with or without skin changes or ulceration (CEAP $\left.\mathrm{C}_{4}-6\right)$ were offered stent placement. Patients with IVC and bilateral iliac vein obstruction and acute bilateral DVT were also indicated for stenting. Procedures were performed in a dedicated angio suite or hybrid OR. Venous access was obtained through the femoral vein, at least $15 \mathrm{~cm}$ distally to the deep femoral inflow under ultrasound guidance. This access site was chosen to obtain optimal angiographic evaluation about the inflow from the deep femoral vein and the collateral network as well as to provide a sufficient distance to the landing zone for stenting. The technique for traversing stenotic and occluded venous segments has been described before [II]. After successful recanalization thorough predilation was done up to $25 \mathrm{~mm}$ for the IVC and I4-I6 mm for the external and common iliac vein. Due to the elasticity of the lesions, all pathologic venous segments that are being predilated should generally be stented. Based upon the design of the stents used to treat diseased vein segments, we gained experience with two stenting protocols. In our earlier experience, stenting was performed with nitinol self-expandable stents to treat the entire diseased venous segments from the vena cava down to the external iliac vein (SECS group; (Figure II). These self-expandable stents (sinus XL, Optimed, Ettlingen, Germany) are registered for treatment of vena cava obstructions, because of the large diameters available and their high crush resistance. In all cases, the vena cava was stented with a diameter of $24 \mathrm{~mm}$. Bilateral extensions were performed with $16 \mathrm{~mm}$ nitinol stents (sinus XL, sinus Venous and sinus XL-flex, Optimed, Ettlingen, Germany and Zilver Vena (Cook, Galway, Ireland), which were placed parallel inside the vena cava stent with a $2 \mathrm{~cm}$ overlap (Figure II).

In order to minimize stent strut interactions at the confluence, an alternative technique was used where two balloon-expandable stents (AndraStent, Andramed, Reutlingen, Germany) were placed in the vena cava stent toward the common iliac veins (BECS group; Figure I2). Bilateral iliac extensions were then performed with $\mathrm{I} 6 \mathrm{~mm}$ nitinol 
stents (sinus Venous or Zilver Vena stents ). In both groups, postdilation of the entire stented segments was always performed using a balloon with same diameter as the stents implanted. Inflation time was kept to a minimum, with the sole purpose to let the stents deploy completely. In cases of incomplete deployment, high pressure balloons were used to reach full deployment. Poststenting angiography was done by means of Conebeam CT imaging (AlluraClarity, Philips Healthcare, Eindhoven, The Netherlands) to evaluate stent expansion and apposition (Figure I2).
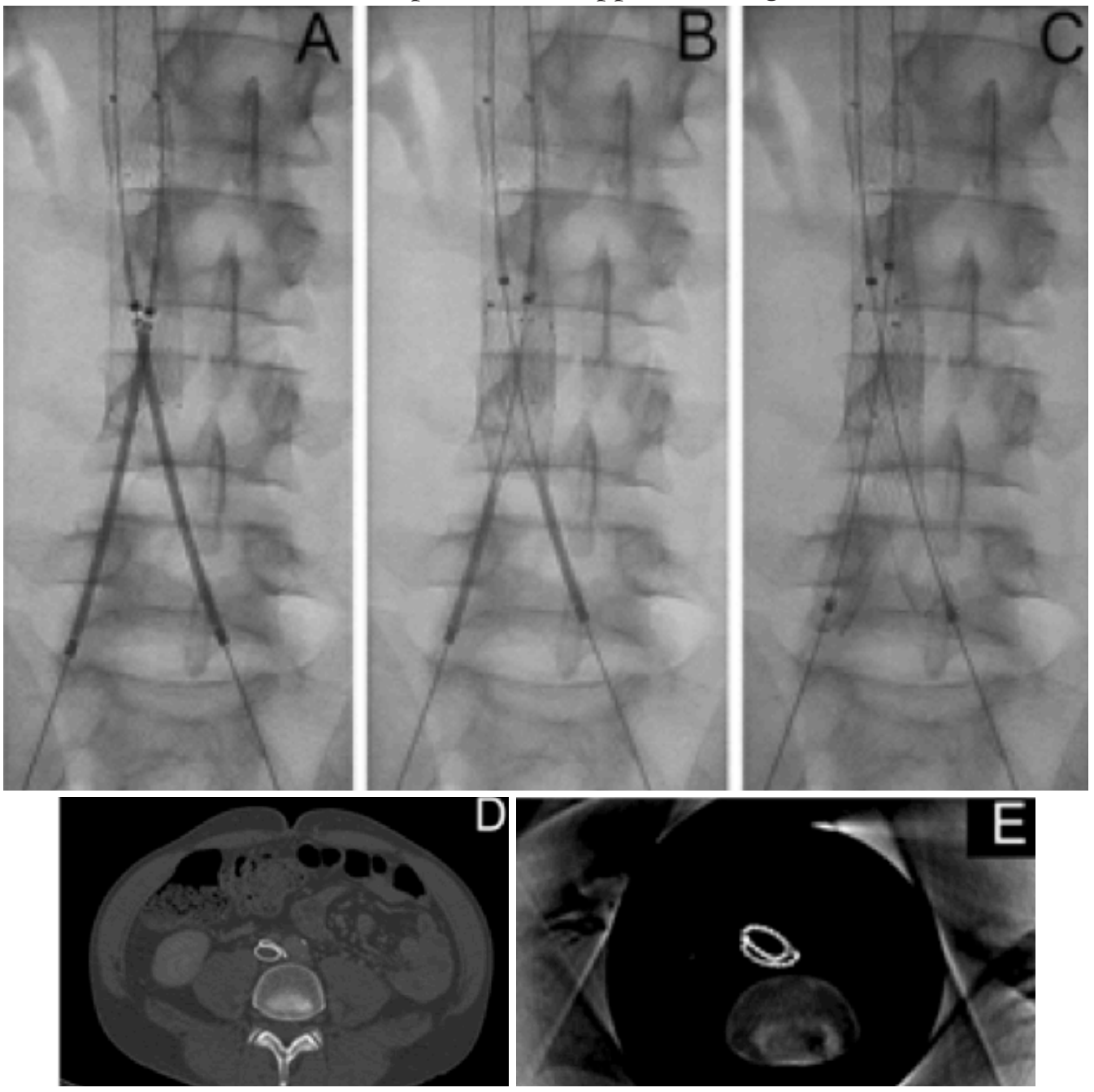

Figure. II Confluence stenting with self-expandable stents (SECS). A-C self-expandable stents are placed within the large diameter IVC stent, extending into the common and/or external iliac veins. D CT shows compression of one iliac self-expandable stent, while the adjacent stent shows adequate expansion. E peroperative conebeam CT shows another example of significant compression by the contralateral stent. 

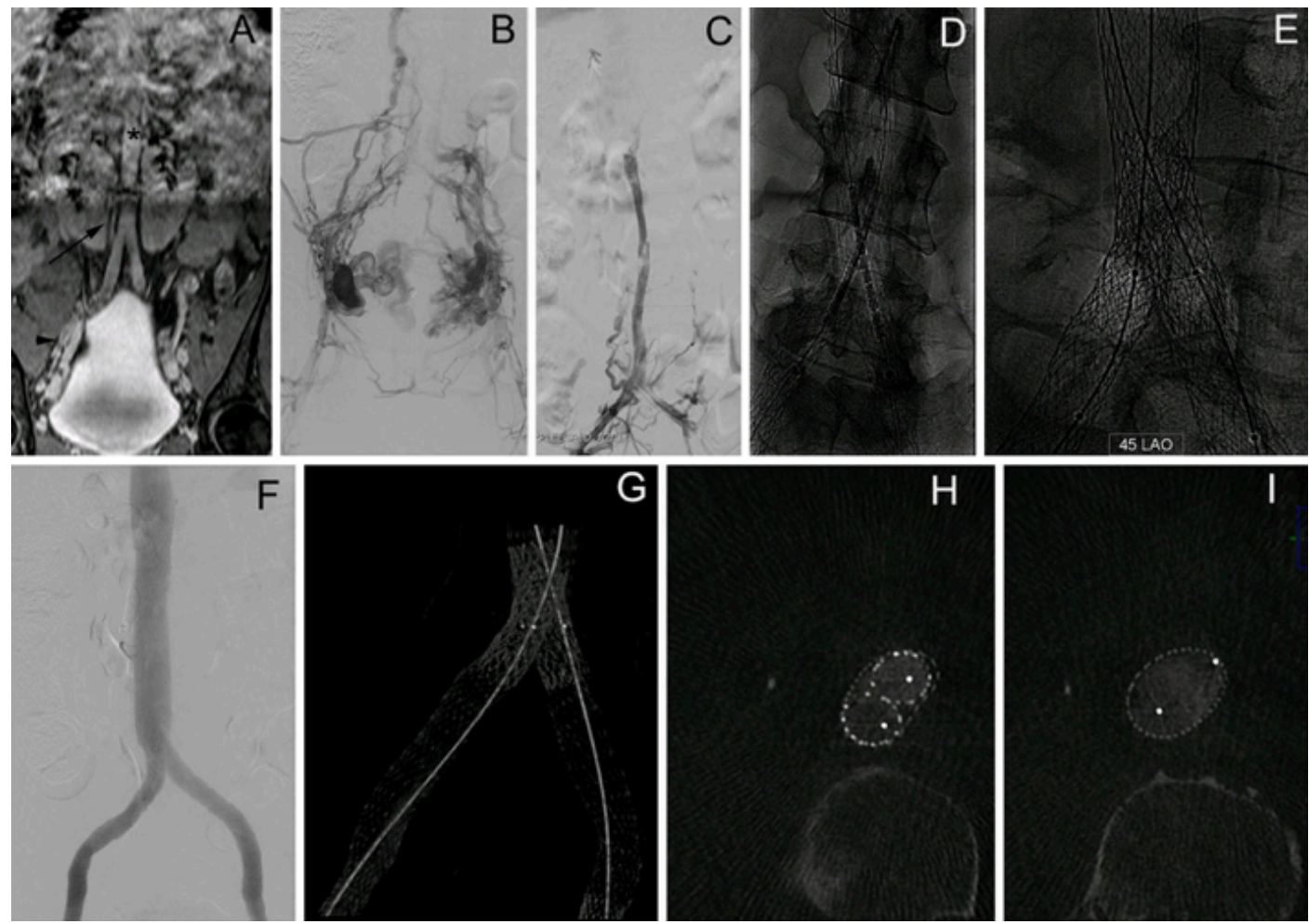

Figure I2 Confluence stenting with balloon-expandable stents (BECS). A preoperative MR venography shows an IVC remnant (arrow). Notice the post-thrombotic scarring in the external iliac vein (arrowhead). Asterisk aorta. B angiography shows severe obstruction of bilateral iliac veins and no filling of the IVC. C after iliac recanalization angiography from the level of the confluence shows an adjacent stent shows adequate expansion. E peroperative conebeam CT shows another example of significant compression by the contralateral stent long stenosis in of the IVC. D and E positioning and deployment of two balloon-expandable stents. F completion angiography shows excellent flow from both iliac limbs through the newly constructed iliac confluence and IVC. G-I Conebeam CT reconstructions showing perfect positioning and expansion of the stents at the confluence and IVC

\section{Endophlebectomy and arteriovenous fistula creation}

Extension of post-thrombotic changes at the level of the femoral vein inflow was seen in $\mathrm{I}_{5}(38 \%)$ patients. The decision to perform adjunctive surgical desobstruction was preoperatively made based on MRV imaging. When trabeculations were visible in the common femoral vein extending to both the femoral and the deep femoral (profunda) vein, peripheral venous inflow was deemed insufficient. Use of MRV imaging for evaluation of severity and extent of the disease (trabeculations) proofed consistent during surgery meaning desobstruction was performed in all the selected cases. In these I5 patients, a hybrid procedure consisting of endovascular recanalization and stenting combined with surgical groin incision, endophlebectomy, and creation of an 
arteriovenous fistula (AVF) was performed to optimize inflow and secure short-term stent patency. In the other 25 patients where no post-thrombotic changes at level of the deep femoral vein inflow were seen, merely recanalization and stenting was performed.

Postoperative stent patency was evaluated by DUS. All patients received follow-up according to a strict protocol consisting of DUS imaging I day postintervention, 2 and 6 weeks after the intervention as well as 3, 6, and I2 months after the intervention and annually thereafter, or if recurrence of symptoms required earlier evaluation. Patency was defined as patency of more than $50 \%$ of the venous lumen on DUS. Direct postinterventional as well as 2 and 6 week DUS examination enabled us to perform timely catheter directed thrombolysis in case of acute reocclusion.

\section{Statistical Analyses}

Categorical data are presented by frequencies and percentages. Continuous data are expressed by mean or median values with range and standard deviation. KaplanMeier survival analysis was used to calculate patency rates per extremity for all patients (80 legs) as well as for the endovascular only group (50 legs); (Graphpad prism version 5.0o for Microsoft Windows, Graphpad Software. San Diego, CA). Survival percentages with a standard error of the mean (SEM) of $>$ IO \% were discarded as being unreliable.

\section{RESULTS}

\section{Patient Demographics}

The patient group consisted of 24 female and $\mathrm{I} 6$ male with a mean age of $4 \mathrm{I} \pm \mathrm{I} 4.9$ years (range I6-62 years). MRV determined IVC obstruction with complete certainty in Ioo \% of cases. In all cases, intraluminal changes, i.e., trabeculations were seen, suggestive of post-thrombotic fibrosis due to earlier DVT. In 6 (I5 \%) patients, no clinically obvious DVT was noted in their medical history, but the combination of DUS and MRV showed post-thrombotic changes in the venous system in all of these patients. Patients were treated on average $\mathrm{I} 2 \pm 8.5$ years (range $2-27$ ) after their first DVT. Clinical signs, as scored in the CEAP classification, are shown in Table II.

Table II Overview of CEAP clinical classification [I6] for the study population (40 right and 40 left legs)

Acute bilateral DVT was the indication for treatment in 6 ( $15 \%)$ patients, skin changes and ulceration in I8 (45\%) patients, venous claudication in $15(38 \%)$ patients, and chronic lower extremity pain without claudication in one (3\%) patient.

\begin{tabular}{rllll}
\hline CEAP C Class & \multicolumn{2}{l}{ Right leg } & \multicolumn{2}{l}{ Left leg } \\
\hline Co & I & $2.5 \%$ & 3 & $7.5 \%$ \\
CI & 5 & I2.5 $\%$ & 5 & I2.5 $\%$ \\
C2 & 7 & I7.5 \% & 7 & I7.5 $\%$ \\
C3 & II & $27.5 \%$ & IO & $25 \%$ \\
C4 & 9 & $22.5 \%$ & 9 & $22.5 \%$ \\
C5 & 4 & I0 $\%$ & 4 & IO $\%$ \\
C6 & 3 & $7.5 \%$ & 2 & $5 \%$ \\
\hline
\end{tabular}




\section{Interventions}

All 40 patients with iliocaval obstructions were recanalized successfully. The average length of vena cava occlusion was 13.8 (range 5-2I) $\mathrm{cm}$. The average total length of iliocaval obstruction was $31.2 \mathrm{~cm}$ (range 24-37). No perprocedural bleedings or other complications were encountered. In 24 patients, self-expandable stents were used to construct the confluence (SECS group), while in I6 patients a combination of balloonexpandable and self-expandable stents was used (BECS group).

\section{Follow-up}

Mean time until latest DUS follow-up examination was $443 \pm 438$ days (range 7-I683 days). In $33(82 \%)$ patients, the vena cava and both iliac veins were patent at latest follow-up. In four (Io \%) of the patients with stent reocclusions, one of the iliac veins was occluded at latest follow-up, while the contralateral side and vena cava remained patent. One patient showed total occlusion of the stented area, however clinical signs remained mild during follow-up, possibly because of a well-developed collateral network, reintervention was therefore postponed indefinitely. Moreover, secondary patency after reocclusion was obtained by sole thrombolysis in three and catheterdirected thrombolysis combined with restenting in another three patients (in one also an AVF was created), in one patient a deep venous bypass was created surgically. This leads to patency rates of treated lower extremities at I2 months of 79,82 , and $90 \%$ (SEM 5.6, 5.5, and 3.8), and at three years of 70, 73, and $78 \%$ (SEM 6.9, 7.I, and 9.0), for primary, assisted-primary, and secondary patency, respectively (Figure I3A).

A Patency rates: total population

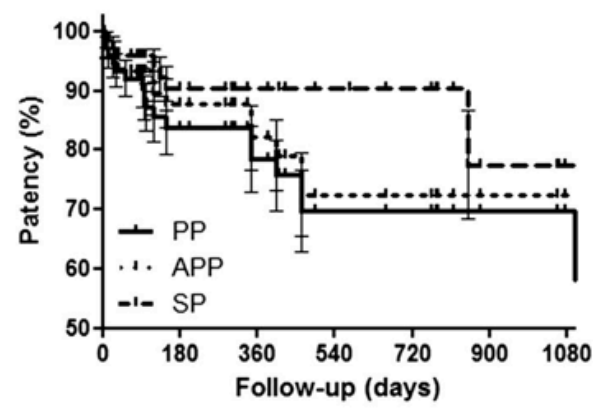

\begin{tabular}{|l|c|c|c|c|c|}
\hline Follow-up (days) & Baseline & 180 & 360 & 720 & 1080 \\
\hline Primary patenc (PP) & 80 & 46 & 32 & 22 & 7 \\
\hline Assized Primary patency (APP) & 80 & 46 & 32 & 22 & 7 \\
\hline Secondary patency (SP) & 80 & 47 & 35 & 26 & 8 \\
\hline
\end{tabular}

\begin{tabular}{|l|l|l|l|l|l|}
\hline Lost patency & Baseline & 180 & 360 & 720 & 1080 \\
\hline
\end{tabular}

\begin{tabular}{|l|c|c|c|c|c|}
\hline Primary patency (PP) & 0 & 11 & 2 & 3 & 0 \\
\hline Assisted Primary patency (APP) & 0 & 8 & 2 & 3 & 2 \\
\hline Secondary patency (SP) & 0 & 6 & 0 & 0 & 0 \\
\hline
\end{tabular}

B Patency rates: endovascular population

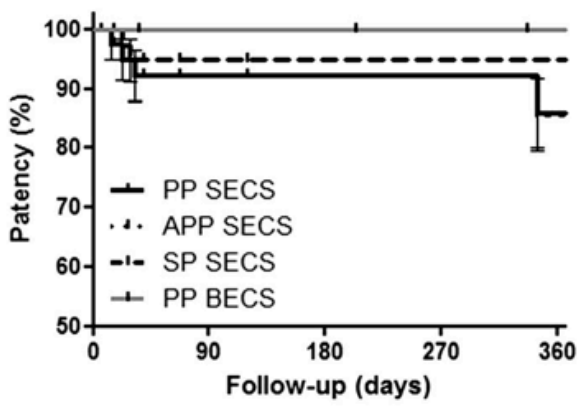

\begin{tabular}{|l|c|c|c|c|c|}
\hline Follow-up (days & Baseline & 90 & 180 & 270 & 360 \\
\hline PP SECS & 42 & 33 & 31 & 31 & 29 \\
\hline APP SECS & 42 & 33 & 31 & 31 & 29 \\
\hline SP SECS & 42 & 33 & 31 & 31 & 31 \\
\hline PP BECS & 8 & 8 & 8 & 6 & 1 \\
\hline
\end{tabular}

\begin{tabular}{|l|c|c|c|c|c|}
\hline Lost patency & Baseline & 90 & 180 & 270 & 360 \\
\hline PP SECS & 0 & 3 & 0 & 0 & 2 \\
\hline APP SECS & 0 & 3 & 0 & 0 & 2 \\
\hline SP SECS & 0 & 2 & 0 & 0 & 0 \\
\hline PP BECS & 0 & 0 & 0 & 0 & 0 \\
\hline
\end{tabular}

Figure I3. Kaplan-Meier analyses of primary and secondary patency of lower extremities in the total population (8o legs) and the cases treated by endovascular means only (50 legs) 
Specific analysis of the population treated by endovascular means only (without endophlebectomy and AV-fistula creation) shows higher patency rates. Twelve-month patency rates in the SECS group were 85, 85, and $95 \%$ for primary, assisted-primary, and secondary patency, respectively (Figure ${ }_{3} \mathrm{~B}$ ). In the BECS group, primary patency was $100 \%$ during a mean follow-up period of $134 \pm$ II8 (range 29-337) days (Figure 13B). Observed complications did not lead to long-term impairment (Table I2). Although reocclusions occurred, no patients reported worsening of their symptoms.

Table I2 Overview and quantification of complications observed in 40 patients treated with caval-bi-iliac recanalization and stenting

\begin{tabular}{rll}
\hline Complication & Frequency & $\%$ \\
\hline Reocclusion in one or both iliac veins or IVC & $\mathrm{IO}^{\mathrm{a}}$ & 25.0 \\
Significant stenosis due to AVF & 4 & $\mathrm{I0.0}$ \\
Major bleeding & 3 & 7.5 \\
Minor bleeding & 3 & 7.5 \\
Lymph leakage/lymphocele & 3 & 7.5 \\
Stenosis deemed non-hemodynamically significant & 7 & $\mathrm{I} 7.5$ \\
Residual compression & 3 & 7.5 \\
Tapering & 5 & $\mathrm{I} 2.5$ \\
Stent kinking & $\mathrm{I}$ & 2.5 \\
Stent fracture & $\mathrm{I}$ & 2.5 \\
\hline
\end{tabular}

${ }^{a}$ Six patients treated by catheter directed thrombolysis

\section{DISCUSSION}

The etiology of IVC obstruction has not yet been determined completely. A congenital origin has been proposed [12]. Central line placement and subsequent thrombosis in premature life might be another explanation [I3]. In the present study population, only two patients had endured such an intervention. Sudden IVC thrombosis in later life might develop in case of compression by benign or malignant masses or adjacent anatomic structures. However, we did not see such underlying pathology in our patient population. True absence of the IVC has also not been noticed in our group of 74I patients evaluated for signs of deep venous obstruction between 2009 and 2014 . Although this might be suspected on angiography because no contrast dye is seen in the extent of the IVC, MRV always showed a visible remnant (Figure I2A-C).

Iliac vein and IVC stenting has been performed successfully since more than a decade, has proven to be effective and is considered the first line of treatment in chronic venous obstructive disease [I4]. Nevertheless, experience was limited to a small number of centers for many years, with the group of Neglén et al. reporting on the largest number 
of patients by far $[3,9,15]$. Recently, recanalization and stenting of chronic venous obstructions became more widespread and probably will increase to mature in years to come. Although the endovenous approach has been suggested straightforward, innovative materials enable us to explore alternative approaches, which might reduce complications and improve results. Specifically, for confluence stenting, only few techniques and stent configurations have been proposed, mainly due to limitations in stent design. In the vast majority, the Wallstent ${ }^{\mathrm{TM}}$ (Boston Scientific ) was selected as the stent of choice, which limited stent configuration options. However, with the introduction of nitinol and cobalt-chromium stents appropriate for use in the venous system, other techniques have become available. We discuss our fenestration technique, the ipsilateral stent is pierced and the contralateral limb is then maneuvred through this fenestration. The confluence technique is performed by large diameter stents in the IVC. With a small overlap, two balloon-expandable or self-expandable stents are used as an extension into both iliac veins experience and patency results with these stents to treat bilateral iliocaval obstruction by means of confluence stenting.

We used two different techniques to construct the new confluence. In our earlier cases, we placed two self-expandable stents within a wide-diameter stent positioned in the distal vena cava just above the confluence, which were extended distally as far as required. With the help of perprocedural rotational angiography and coincidental CT examinations, it was noted though that stent compression was a main issue (Figure II). When two self-expandable stents are placed within a restricted space, one is likely to become greater in diameter than the other one, thereby compressing the contralateral side which is corroborated in the diminished short-term patency in the SECS group. Thus, we decided to optimize our protocol by bridging the confluence with two ultrastrong parallel positioned balloon-expandable stents. The BECS group showed a I00 \% short-term primary patency. Although the present confluence technique has been mentioned before, no clear description of the technique and interventional tools were given. Furthermore, specific outcome data were not discussed [6].

Other stenting techniques to treat the common iliac vein confluence have been described earlier [9]. Neglén et al. evaluated three techniques to perform bilateral stenting at the iliocaval confluence (Figure I4). In our opinion, both the fenestration and apposition technique should be considered inferior to the confluence technique. The fenestration technique requires purposeful fracturing of the contralateral iliac stent, which increases the risk of complications like balloon rupture and subsequent entrapment of devices. Furthermore, reinterventions like thrombectomy might be hampered, which is also true for the apposition technique. Confluence stenting with balloon-expandable stents helps overcome potential problems related to reinterventions. Finally, recreation of the iliac confluence generates flow dynamics that might alternative technique to create an efficient and safe true confluence configuration (Figures I2, I4). Based upon our experience, we suggest the BECS technique to be superior to treat chronic bilateral 
iliocaval obstructions. It should however be noted that the BECS technique might not be the best option in women at child bearing age, since these stents may non-reversibly compress during pregnancy or birth.

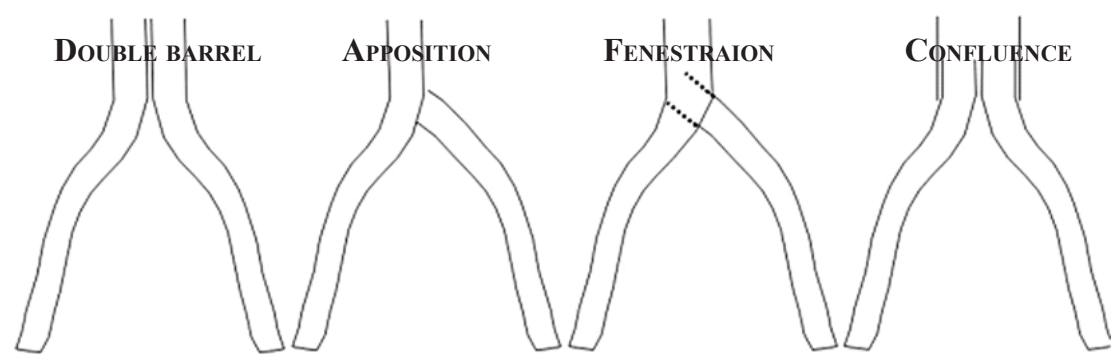

Figure. I4 Techniques to treat caval-bi-iliac venous obstruction. The double barrel technique is performed by placing two parallel stents into the IVC as an extension from both iliac veins. In the apposition technique, the ipsilateral iliac stent is extended into the IVC while the contralateral iliac stent is placed in close contact to the former. In the fenestration technique, the ipsilateral stent is pierced and the contralateral limb is then maneuvred through this fenestration. The confluence technique is performed by large diameter stents in the IVC. With a small overlap, two balloon-expandable or self-expandable stents are used as an extension into both iliac veins.

There are some limitations to our study. First, the observational design of the study makes it difficult to draw strong conclusions toward the optimal confluence stent technique. However, availability of stents on the market precluded the possibility to perform a randomized design of the study. Nevertheless, our experience adds to the knowledge of venous stenting thus far reported and might aid in the process of product development and treatment protocols. Secondly, we used different stents to make peripheral extensions from the confluence toward the groin. In the beginning, we used nitinol closed-cell stents in the iliac veins. Since 2013, "dedicated venous stents" were used. "Dedicated" means that the stent manufacturer implies that the stent is better accommodated to the venous anatomy. Usually, these stents are larger in diameter, show good flexibility and high hoop force. Although these venous stents are supposed to perform better in the venous vasculature, up to now there is no proof that these stents improve outcome. Therefore, we have to conclude that the differences in patency between the SECS and BECS group are more likely based upon the configuration of confluence stenting. Based upon our experience with stenting across the common iliac vein confluence, we suggest preferable stenting technique to treat bilateral iliocaval obstructions. Preservation of bilateral symmetric inflow, protection of stent integrity, and avoidance of abundant stent material at the level of the confluence suggest that the BECS technique is superior to earlier described techniques. Evolution however is continuing, and we await the development of "confluence-stent" devices that have already been recognized in bifurcated aorta repair and might also support venous reconstructions. 


\section{REFERENCES}

I. Mahnken AH, Thomson K, de Haan M, O'Sullivan GJ (20I4) CIRSE standards of practice guidelines on iliocaval stenting. Cardiovasc Intervent Radiol 37(4):889-897

2. Hartung O, Loundou AD, Barthelemy P, Arnoux D, Boufi M, Alimi YS (2009) Endovascular management of chronic disabling ilio-caval obstructive lesions: long-term results. Eur J Vasc En-dovasc Surg 38(I):II8-I24

3. Neglen P, Hollis KC, Olivier J, Raju S (2007) Stenting of the venous outflow in chronic venous disease: long-term stent-related outcome, clinical, and hemodynamic result. J Vasc Surg 46(5): 979-990

4. Nazarian GK, Bjarnason H, Dietz CA Jr, Bernadas CA, Hunter DW (I996) Iliofemoral venous stenoses: effectiveness of treat-ment with metallic endovascular stents. Radiology 200(I): 193-199

5. Knipp BS, Ferguson E, Williams DM, Dasika NJ, Cwikiel W, Henke PK, Wakefield TW (2007) Factors associated with out-come after interventional treatment of symptomatic iliac vein compression syndrome. J Vasc Surg 46(4):743-749

6. Ko“lbel T, Lindh M, Akesson M, Wasselius J, Gottsater A, Ivancev K (2009) Chronic iliac vein occlusion: midterm results of endovascular recanalization. J Endovasc Ther I6(4):483-49I

7. Razavi MK, Hansch EC, Kee ST, Sze DY, Semba CP, Dake MD (2000) Chronically occluded inferior venae cavae: endovascular treatment. Radiology 2I4(I):I33-I38

8. Srinivas BC, Dattatreya PV, Srinivasa KH, Prabhavathi, Manju-nath CN (2OI2) Inferior vena cava obstruction: long-term results of endovascular management. Indian Heart J 64(2):I62-I69

9. Neglen P, Darcey R, Olivier J, Raju S (20I0) Bilateral stenting at the iliocaval confluence. J Vasc Surg 5I(6):I457-I466

IO. Arnoldussen CW, Toonder I, Wittens CH (2012) A novel scoring system for lowerextremity venous pathology analysed using magnetic resonance venography and duplex ultrasound. Phle-bology 27(Suppl I):I63-I70

II. de Graaf R, Wittens CH (20I2) Endovascular treatment options for chronic venous obstructions. Phlebology 27(Suppl I): I7I-I77

I2. Raju S, Hollis K, Neglen P (2006) Obstructive lesions of the inferior vena cava: clinical features and endovenous treatment. J Vasc Surg 44(4):820-827

I3. Grisoni ER, Mehta SK, Connors AF (1986) Thrombosis and in-fection complicating central venous catheterization in neonates. J Pediatr Surg 2I(9):772-776

I4. Raju S (2013) Best management options for chronic iliac vein stenosis and occlusion. J J Vasc Surg 57(4):II63-II69

I5. Neglen P, Tackett TP Jr, Raju S (2008) Venous stenting across the inguinal ligament. J Vasc Surg 48(5):I255-I26I

I6. Eklöf B, Rutherford RB, Bergan JJ, Carpentier PH, Gloviczki P, Kistner RL, Meissner MH, Moneta GL, Myers K, Padberg FT, Perrin M, Ruckley CV, Smith PC (2004) Wakefield TW; American Venous Forum International Ad Hoc Committee for Revision of the 
CEAP Classification. Revision of the CEAP classification for chronic venous disorders: consensus statement. 

CHAPTER 6

INDICATIONS FOR ENDOPHLEBECTOMY

AND/OR ARTERIOVENOUS FISTULA AFTER STENTING

\section{M.A.F. de Wolf ${ }^{1,2}$ \\ C.W.K.P. Arnoldussen ${ }^{3}$ \\ C.H.A. Wittens ${ }^{1,2,4}$}

I Department of General Surgery Maastricht University Medical Center (MUMC), Maastricht, the Netherlands;

2 Cardiovascular Research Institute (CARIM), Maastricht, the Netherlands;

3 Department of Radiology MUMC, Maastricht, The Netherlands;

4 Department of Vascular Surgery University Hospital Aachen, Aachen, Germany

Published in Phlebology.

DOI: I0.II77/o268355513477063. Phlebology 2013;28 Suppl 1:I23-I28 


\section{ABSTRACT}

Endovenous recanalization with percutaneous transluminal angioplasty and stenting in post-thrombotic syndrome patients with iliocaval obstruction is a treatment modality quickly gaining popularity. Studies show good patency and clinical success rates. If the obstruction extends distally, below the inguinal ligament, stenting remains controversial. Without adequate inflow, the patency of stented iliocaval segments drops dramatically. This suggests that treatment of diseased common femoral, femoral and profunda femoral veins is required to ensure adequate inflow. Endophlebectomy, the removal of synechiae and septae from the common femoral vein, is a viable option in these cases. Another option, which can be done concurrently with the endophlebectomy, is the creation of an arteriovenous fistula. Selecting patients for these interventions however remains difficult, as precise preoperative prediction of inflow into the stented segments is difficult. In this paper we describe our experience in using duplex ultrasonography, magnetic resonance venography and conventional venography to assess the patency of the inflow trajectory. We believe this approach is essential in dealing with cases of complex post-thrombotic disease extending below the inguinal ligament. There is a great need to establish criteria to accurately assess pre- and postinterventional flow through treated vein segments. 


\section{INTRODUCTION}

Although arterial percutaneous transluminal angioplasty (PTA) and stenting were first described in 1964 by Charles Dotter and in 1985 by Palmaz et al.I -3 respectively, and the first endovenous stenting already described in 1986, endovascular recanalization and stenting of the deep venous system has only recently gained widespread interest and use. This is partly due to disappointing early results, the lack of interest in the postthrombotic syndrome (PTS) and the unawareness of the relationship between PTS severity and the location and extend of deep venous thrombosis.4 Currently the number of patients treated with deep venous PTA and stenting is increasing exponentially, because of published good clinical results, improved patency rates and low mortality and morbidity rates.5 - 9 Neglén et al.7 showed good overall long-term results, but lower patency rates in cases of post-thrombotic disease compared with non-thrombotic disease. This might be explained by the changed anatomy of post-thrombotic veins, characterized by rigidly scarified vessel walls and intraluminal synechiae and septae, which also create a thrombogenic environment.Io This thrombogenic environment can be treated, both pre and poststenting, by adequate anticoagulation, either with Coumadins, low-molecular-weight heparins or new oral anticoagulants.II - I3 In order address the changed anatomy one needs to recanalize a post-thrombotic diseased segment. Various guidewires are needed to pass the synechiae and septae after which an angioplasty, mostly with high pressure balloons, is needed before stent placement.I4 After stenting the restored patency of the treated caval and/or iliac vein segments should redirect flow through this normal anatomical route and decreases or resolve flow via previously developed collateral veins. This technique has been described previously.I4 However, in case of femoral involvement in post-thrombotic disease, venous inflow into the to-be-stented iliocaval segments is frequently inadequate. Obstruction or occlusion in the common femoral vein can impair outflow of the femoral, deep femoral and great saphenous vein into the stented segment, causing a low flow through the stented segment. As low flow conditions relate strongly with thrombosis and reocclusion, this needs to be addressed. However, stent placement in the common femoral and femoral segments is still under debate.I5 Too effectively, minimally invasively, guarantee adequate inflow from all three, femoral, deep femoral and great saphenous, veins into the stented segment above the saphenofemoral junction (SFJ) a branched stent has to be developed. Without this theoretical opportunity there is always the chance of not being able to cross the different intraluminal planes created by the septae in the common femoral vein. In such a case one would, e.g. only recanalize a portion of the vein and inflow might only be restored from one of the three veins connected to the common femoral vein. Besides this technical problem, we know from arterial stenting across joints that stent fractures may occur,I6 although Neglén et al.I5 showed that stent elongation across the inguinal ligament is safe using Wall stents (Boston Scientific, Natick, MA, USA). Other authors are generally less aggressive in stent placement across joints, especially when Nitinol stents are used, which have a greater tendency to 
fracture when stressed.

Alternatively the obstruction or occlusion of the common femoral vein can be addressed in a surgical manner, which is termed endophlebectomy, endovenectomy or desobstruction.IO,I7,I8 This technique was first described by Gloviczki in I999 in relation to venous bypass surgery. Raju et al.I9 showed feasibility in 1999 in cases of axillary vein transfer and Puggioni et al.ıo in 2004 in cases of deep venous reconstruction. Summarized endophlebectomy entails: the post-thrombotic damaged common femoral vein is longitudinally opened and the intraluminal senechiae and masses are removed. Any post-thrombotic lesions obstructing outflow from the femoral, deep femoral or great saphenous vein need to be removed and inflow into the common femoral vein restored. The venotomy can be primarily closed or by using a patch, in case of a narrowed lumen. This should guarantee physiological inflow into the stented segments. It is vital that the distal end of the stent should at least extend into the 'cleaned' common femoral vein segment. After restoration of the physiological flow combined with adequate anticoagulation, there still might be a highly thrombogenic local environment at the level of endophlebectomy or stents, caused by both surgical damage to the vessel wall and the stent material. This is why an endophlebectomy is frequently combined with the creation of an arteriovenous fistula (AVF) in order to increase flow in the treated area and theoretically reduce the chance of thrombosis.IO,I8,20 - 22 In our center a loop with a $6 \mathrm{~mm}$ externally supported polytetrafluoroethylene (PTFE) graft of about $6-8 \mathrm{~cm}$ long is created between the common femoral artery and vein. We learned that native fistulae are too small or when created with a diameter larger than $5-6 \mathrm{~mm}$ they need to be closed (surgically) after six months because of persistent swelling of the leg. The advantage of using a PTFE loop is that it guarantees a high flow rate in the first months and that it can be percutaneous closed, e.g. with an Amplatzer Vascular Occluder (AGA Medical Corporation, Plymouth, MN, USA).23,24 When PTA, stenting, endophlebectomy, AVF and adequate anticoagulation are combined in these complex and extensive cases of PTS, all three facets of Virchow's triad (blood, flow and vessel) are addressed.

To our knowledge no effective and validated diagnostic tests, and their cut-off values, are currently available to pre- or peri-intervention quantify haemodynamic parameters associated with patency rates after deep venous stenting in order to help us decide if there is an indication for an endophlebectomy with or without an AVF. Ideally such a test should measure flow at the in- and outflow site of the stented segment. At this moment only anatomical parameters, acquired by or duplex ultrasonography (DUS), ascending venography, magnetic resonance venography (MRV), computed tomography venography (CTV) or intravascular ultrasonography (IVUS) are used to indicate if patients are eligible for endophlebectomy and/or AVF.25,26 These parameters include location and extend of post-thrombotic lesions, percentage of lumen reduction, and number and extend of collateral veins. In this paper we described current literature 
and our own experience in the challenge of diagnosing (in)adequate venous flow in post-thrombotic deep veins and indicating patients for ancillary surgery combined with or after PTA and stenting.

\section{Imaging characteristics of patients undergoing endophlebectomy and arteriovenous fistula}

Patients with chronic venous disease in which a deep vein obstruction is suspected require adequate analyses of the deep venous system. Besides clinical examination, e.g. abdominal wall venous collaterals and in some centers functional tests, e.g. plethysmography, a crucial part of this analysis is imaging.27 The initial imaging modality of choice should be duplex ultrasound.28,29 The primary objective is the assessment of the presence and the extent of any deep venous reflux, signs of recanalization and/ or flow impairment, luminal narrowing and vein wall thickening. The veins that need to be examined are the popliteal, femoral, deep femoral and common femoral vein. Additionally, collaterals in the groin and signs of obstruction in the pelvis should be identified. When there are signs of obstruction with collateralization in the groin and/ or pelvis, additional imaging should be performed. The aim of this additional imaging should be to accurately assess the extent of the obstruction, reconstruct the anatomy of the inferior vena cava and the common and external iliac veins and assess the routes of collateralization to assess the extent of the diseased tract. Furthermore, imaging should quantify the chronic, mostly post-thrombotic, vein abnormalities in both the inferior vena cava and iliac veins, as well as the common femoral, deep femoral and femoral vein. In a non-invasive setting, the choice of examination is either MRV or CTV. In our experience, both techniques are capable of identifying obstruction and collateralization, but only MRV is capable of accurately detecting intraluminal post-thrombotic changes, which affect our treatment decisions as we described with the LOVE score (Figures I5 and I6).25 In our treatment approach, conventional venography and IVUS are reserved for those patients in whom we have decided to perform an endovascular recanalization and stenting, since these are invasive procedures that require a hospital admission.

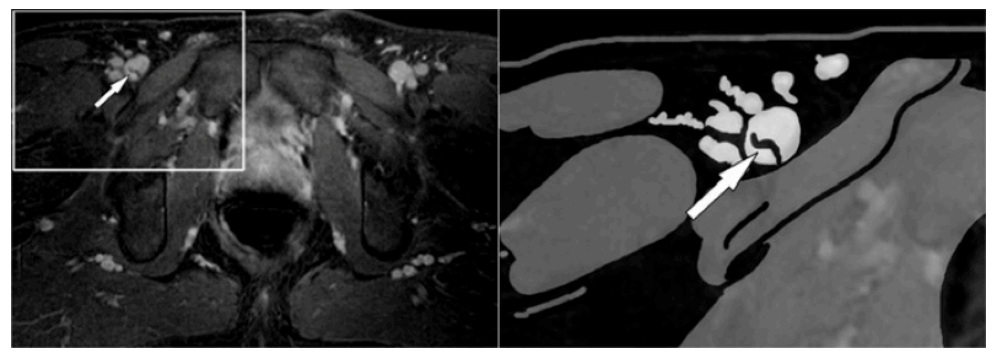

Figure I5. Magnetic resonance venography image in the transverse plane showing the chronically diseased common femoral vein (CFV) in a patient with a post-thrombotic syndrome with an occluded right external and common iliac vein. The arrow marks trabeculations within the CFV as a result of poor recanalization which suggest impaired inflow to the iliac veins 


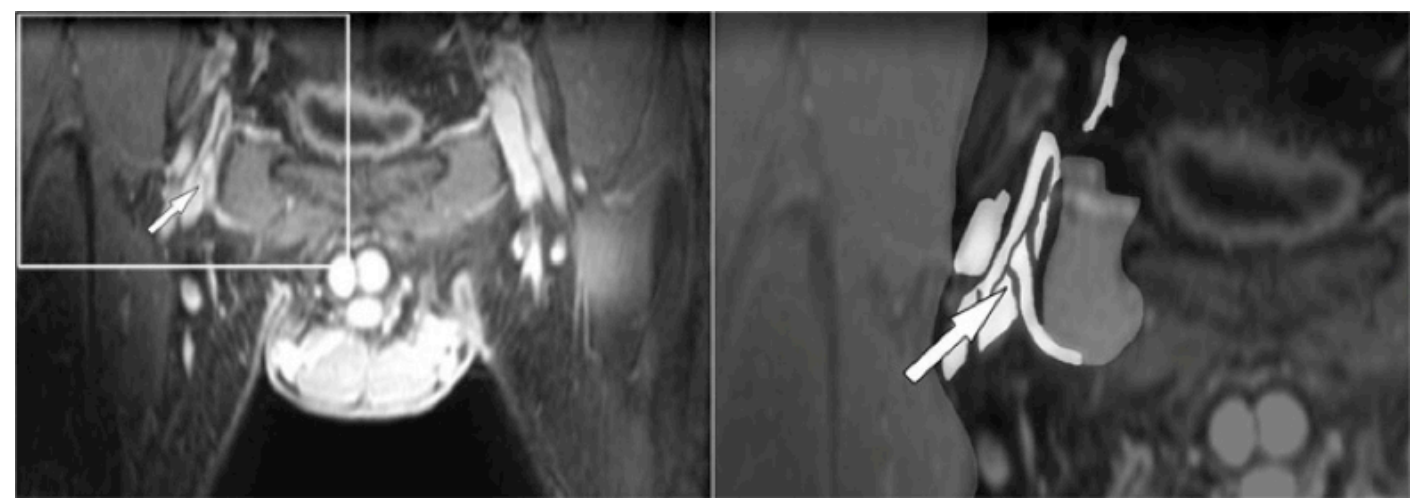

Figure I6. Magnetic resonance venography image in the coronal plane showing a chronically diseased common femoral vein and external iliac vein with trabeculations. Multiple trabeculations can be identified suggesting flow impairment over these segments

In chronic deep venous obstruction, roughly four patterns of disease can be identified. The first pattern is isolated obstruction at the level of the common iliac vein, in virtually all cases associated with compression (May- Thurner syndrome). In these patients there are usually no, or minimal post-thrombotic changes in the external iliac and femoral veins. The second pattern is obstruction of both the common and external iliac vein. In these patients the patterns of collateralization are more extensive and usually the groin shows signs of collaterals with relatively mild or unscarred femoral veins. The third pattern shows occlusion of the common and external iliac vein with involvement of the femoral veins. Collateralization is prominent in these cases, but more importantly severe scarring of the common femoral vein, often combined with impaired recanalization of the femoral and deep femoral vein, is seen. The fourth pattern shows involvement of the inferior vena cava, usually with extensive paralumbar collateralization and hyperplastic azygos and hemiazygos veins. In these cases disease in the iliac and femoral veins can either be symmetrical showing pattern I, 2 or 3 on both sides or asymmetrical, usually related to the occurrence of deep vein thrombosis in the past.

Patients who present with isolated common iliac vein obstruction can be effectively treated with endovascular recanalization and stenting.5 - 8,I4,2I,22 Also in patients with a common and/or external iliac vein obstruction, without common femoral vein involvement below the SFJ endovascular recanalization and stenting can be performed without additional surgical intervention. In patients with a common and/or external iliac vein obstruction with common femoral vein involvement below the SFJ we perform an endophlebectomy. In most cases, in addition to the involvement of the common femoral vein, the femoral and deep femoral vein are also involved in which case we perform an endophlebectomy with an AVF. Lack of inflow into the stented segment, due to the preexisting inflow impairment from the deep femoral and femoral 
vein, combined with an increased thrombogenetic post-thrombotic common femoral vein cause these patients to be at increased risk for in-stent thrombosis due to lack of flow.

In patients where the IVC is involved we decide on our treatment approach based on the extent of the involvement of the vena cava as well as the iliac and femoral axis. In isolated infrarenal IVC involvement an antegrade approach from either the groin or femoral vein usually suffices. In those cases where the suprarenal IVC is involved, access from the jugular vein can be helpful in which case patient positioning and procedure planning is adjusted. By utilizing all our preoperative imaging information as described above we can accurately select patients for what we believe will prove to be the most optimal approach of treating chronic venous obstructions.

At the end of the procedure it is crucial to assess the preferential outflow pattern. In patients with isolated iliac disease, collaterals identified preintervention need to show signs of decreased flow and preferably stasis with primary outflow through the recanalized iliac vein. If collateral outflow persists after common iliac vein stenting, this usually is a sign of inadequate stent extension caudally. The same applies in patients with endophlebectomy with or without AVF creation. Primary outflow should lead into the recanalized iliac tract, not retrograde into the femoral veins or collaterals. It is our conviction that this should also be treated with stent extension, if needed, across the inguinal ligament into the common femoral vein.

Follow-up imaging is primarily aimed at assessing stent and AVF patency, which is most easily done with duplex. Additionally we perform abdominal radiographs in four projections of the stented trajectory (Anterio-Posterior, lateral, left and right anterior oblique). These radiographs are to identify stent kinking, migration, fracture or changes in orientation. Only in selective cases additional imaging is required. Since haemodynamic information is crucial, the next step after duplex is conventional venography which allows us to not only visualize, but also treat any remaining stenosis or obstruction as well as complications in order to increase patency.

\section{DISCUSSION}

Although high grade evidence is still lacking in the emerging field of endovascular treatment of chronic venous obstructive disease, dedicated centres are quickly generating great amounts of clinical experience and more and more patients are treated for complex post-thrombotic aberrations. Iliofemoral obstructions reaching into the common femoral vein are of specific interest as endovascular treatment of the common femoral vein has not been well established, but intervention at the level of the common femoral vein is required to guarantee adequate inflow into to stented iliocaval segments. 
In this paper we describe our experience in assessing iliofemoral flow and indications for ancillary interventions combined with PTA and stenting by use of modern imaging modalities.It is noteworthy that even though techniques like DUS, MRV and IVUS can clearly show the intraluminal post-thrombotic aberrations, the actual aspect of the vein after venectomy with the naked eye is always worse than on imaging, stressing the need for surgical interventions in these patients (Figure i7). Safety and effectiveness of endophlebectomy and AVF in venous disease have been described in a small number of studies. Our own experience will be described elsewhere. As already mentioned Raju et al.I9 described an endophlebectomy technique in 1999 in relation to axillary vein transfer for deep venous reflux correction in post-thrombotic limbs. They performed this operation in 83 limbs, in which the transplant patency rate was $83 \%$ after Io years. They however did not specifically asses parameters of the endophlebectomy itself. Furthermore, their indications for treatment were based on severe PTS symptoms in the presence of venographic intraluminal post-thrombotic lesions, and treatment was aimed at deep venous reflux relief. And therefore the occlusive component of PTS in these patients was not addressed as it is done in current literature. Puggioni et al.ıo described endophlebectomy of 23 vein segments in 13 patients in 2004. They did focus on the obstructive component of PTS, as indications were either to improve inflow into reconstructed vein segments, to allow for valve repair or to increase calf outflow. They reported a primary patency rate of $77 \%$ after a median of eight months. Lastly, Vogel el al.I8 recently described endophlebectomy of the common femoral vein combined with PTA and stenting in Io patients, of five of whom six-month follow-up data were available.

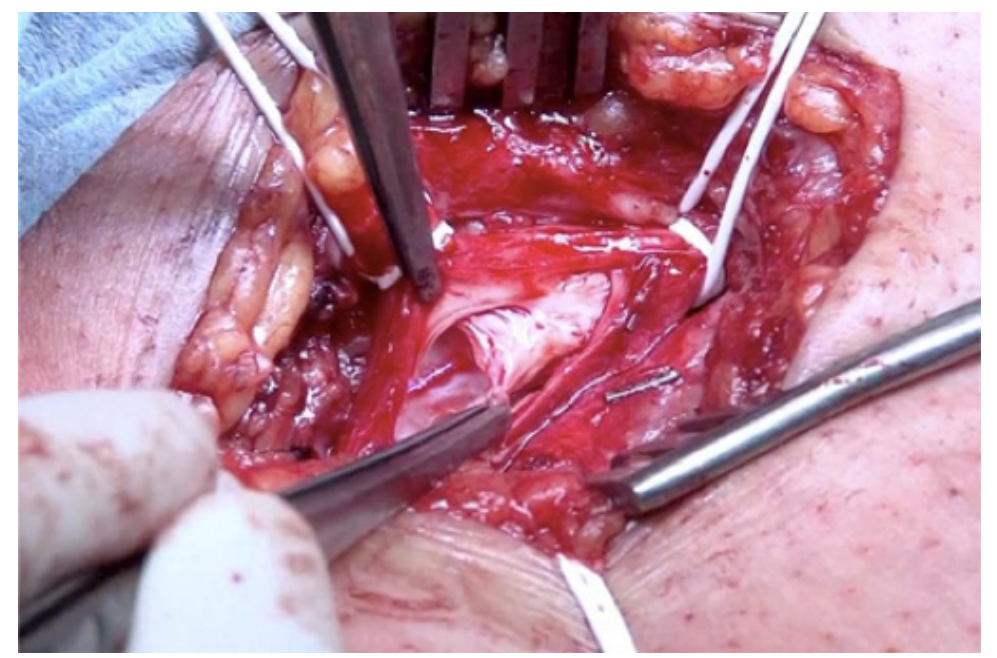

Figure I7. Surgical image showing the extensive intraluminal changes in the common femoral vein as a result of incomplete recanalization after a deep venous thrombosis more than one year ago. These changes correspond with the trabeculations visualized with magnetic resonance venography. 
In two patients an adjunctive AVF was created. Patency was $80 \%$ at six months, and clinical scores (VCSS and Villalta) and quality of life all improved. Interestingly these authors noted that complications rates because of aggressive anticoagulation might have been reduced if AVFs were more frequently used instead. Despite these very favourable results it is important to realize that when combining endophlebectomy and AVF creation with PTA and stenting, outcome assessment is difficult as the individual contributions of these techniques to the final effect are intertwined. With regard to the technique it has not yet been established to what level the stents should be placed, specifically if there is a need to keep stents limited to the region cranial of the endophlebectomy, or to extend the stents into this region. And as new dedicated venous stents are now becoming available, the whole issue of femoral stenting might need to be revised.

Ideally we would like to have a parameter giving us the information in whom we should perform an endophlebectomy and/or an AVF creation to increase patency. To adequately address this still a lot of research has to be done and registries from al centers performing these procedures might give us more answers in the future.

\section{CONCLUSION}

Endovenous recanalization of post-thrombotic vein segments by PTA and stenting is a treatment quickly gaining popularity. Endovascular techniques suffice for iliocaval disease; however in case of femoral involvement adequate inflow from the common femoral vein into the iliac tract needs to be guaranteed. This can be done by performing an endophlebectomy and/or creating an AVF. Indications for these interventions are however at this moment not well established. In our experience careful preoperative assessment with DUS and MRV is needed and helpful. When intraluminal processes are present at the level of the common femoral vein below the SFJ the common femoral, femoral and deep femoral vein outflow are generally impaired, indicating the need for an additional surgical intervention. 


\section{REFERENCES}

I. Charnsangavej C, Carrasco $\mathrm{CH}$, Wallace S, et al. Stenosis of the vena cava: preliminary assessment of treatment with expandable metallic stents. Radiology 1986;16I:295-8

2. Dotter CT, Judkins MP. Transluminal treatment of arter-iosclerotic obstruction. description of a new technic and a preliminary report of its application. Circulation I964;30:654- 703

3. Palmaz JC, Sibbitt RR, Reuter SR, Tio FO, Rice WJ. Expandable intraluminal graft: a preliminary study. Work in progress. Radiology I985;I56:73-7

4. de Wolf MA, Wittens $\mathrm{CH}$, Kahn SR. Incidence and risk factors of the post-thrombotic syndrome. Phlebology 20I2;27(Suppl. I):85 - 94

5. Alhalbouni S, Hingorani A, Shiferson A, et al. Iliac-femoral venous stenting for lower extremity venous stasis symptoms. Ann Vasc Surg 2012;26:I85- 9

6. Hartung O, Benmiloud F, Barthelemy P, Dubuc M, Boufi M, Alimi YS. Late results of surgical venous thrombectomy with iliocaval stenting. J Vasc Surg 2008;47:38I- 7

7. Neglen P, Hollis KC, Olivier J, Raju S. Stenting of the venous outflow in chronic venous disease: long-term stent-related outcome, clinical, and hemodynamic result. J Vasc Surg 2007;46:979- 90

8. Titus JM, Moise MA, Bena J, Lyden SP, Clair DG. Iliofe-moral stenting for venous occlusive disease. J Vasc Surg 20II;53:706- I2

9. $\quad \mathrm{Ye} \mathrm{K}, \mathrm{Lu} \mathrm{X}, \mathrm{Li} \mathrm{W}$, et al. Long-term outcomes of stent placement for symptomatic nonthrombotic iliac vein compression lesions in chronic venous disease. J Vasc Intervent Radiol 20I2;23:497 - 502

Io. Puggioni A, Kistner RL, Eklof B, Lurie F. Surgical disobliteration of postthrombotic deep veins - endo-phlebectomy - is feasible. J Vasc Surg 2004;39:IO48- 52; discussion 52

II. Kearon C, Kahn SR, Agnelli G, Goldhaber S, Raskob GE, Comerota AJ. Antithrombotic therapy for venous thromboembolic disease: American College of Chest Physicians Evidence-Based Clinical Practice Guidelines (8th Edition). Chest 2008;133(Suppl. 6):454S $-545 \mathrm{~S}$

I2. Liew NC, Chang YH, Choi G, et al. Asian venous throm-boembolism guidelines: prevention of venous throm-boembolism. International angiology. Int Angiol 20I2;3I:5OII6

I3. Turpie AG, Kreutz R, Llau J, Norrving B, Haas S. Management consensus guidance for the use of rivarox-aban - an oral, direct factor Xa inhibitor. Thrombo Haemost 20I2;108:87686

I4. de Wolf MAF, Grommes J, Hsien SG, et al. Minimally invasive treatment of chronic iliofemoral venous occlusive disease. J Vasc Surg 20I2; Accepted for publication

I5. Neglen P, Tackett TP Jr, Raju S. Venous stenting across the inguinal ligament. J Vasc Surg 2008;48:I255- 6I

I6. Iida O, Nanto S, Uematsu M, Ikeoka K, Okamoto S, Nagata S. Influence of stent fracture on the long-term patency in the femoro-popliteal artery: experience of 4 years. JACC Cardiovasc Intervent 2009;2:665-7I 
I7. Comerota AJ, Grewal NK, Thakur S, Assi Z. Endovenect-omy of the common femoral vein and intraoperative iliac vein recanalization for chronic iliofemoral venous occlusion. J Vasc Surg 20I0;52:243- 7

I8. Vogel D, Comerota AJ, Al-Jabouri M, Assi ZI. Common femoral endovenectomy with iliocaval endoluminal recanalization improves symptoms and quality of life in patients with postthrombotic iliofemoral obstruction. J Vasc Surg 2012;55:I29- 35

I9. Raju S, Neglen P, Doolittle J, Meydrech EF. Axillary vein transfer in trabeculated postthrombotic veins. J Vasc Surg 1999;29:IO50- 62; discussion $62-4$

20. Jost CJ, Gloviczki P, Cherry KJ Jr, et al. Surgical recon-struction of iliofemoral veins and the inferior vena cava for nonmalignant occlusive disease. J Vasc Surg 200I;33:320- 7; discussion $7-8$

2I. Nazarian GK, Austin WR, Wegryn SA, et al. Venous reca-nalization by metallic stents after failure of balloon angioplasty or surgery: four-year experience. Cardiovasc Intervent Radiol 1996;19:227 - 33

22. Rosales A, Sandbaek G, Jorgensen JJ. Stenting for chronic post-thrombotic vena cava and iliofemoral venous occlusions: mid-term patency and clinical outcome. Eur J Vasc Endovasc Surg 2010;40:234- 40

23. Powell S, Narlawar R, Odetoyinbo T, et al. Early experi-ence with the Amplatzer Vascular Plug II for occlusive purposes in arteriovenous hemodialysis access. Cardio-vasc Intervent Radiol 20I0;33:I50- 6

24. Yildiz AE, Peynircioglu B, Cil BE. Applications of the Amplatzer Vascular Plug 4. Diagn Interv Radiol 20I2; I8:225- 30

25. Arnoldussen CW, Toonder I, Wittens CH. A novel scoring system for lower-extremity venous pathology analysed using magnetic resonance venography and duplex ultrasound. Phlebology 20I2;27(Suppl. I):I63 - 70

26. Arnoldussen $\mathrm{CW}$, Wittens $\mathrm{CH}$. An imaging approach to deep vein thrombosis and the lower extremity thrombo-sis classification. Phlebology 20I2;27(Suppl. I):I43- 8

27. Wittens $\mathrm{CH}$, Bukkems SF, Toonder IT. Abdominal wall venous collaterals: the latent clinical sign for central chronic venous obstruction. Circulation 20I0;122: 2089-90

28. Cavezzi A, Labropoulos N, Partsch H, et al. Duplex ultrasound investigation of the veins in chronic venous disease of the lower limbs - UIP consensus document. Part II. Anatomy. Eur J Vasc Endovasc Surg 2006;31: 288- 99

29. Coleridge-Smith P, Labropoulos N, Partsch H, Myers K, Nicolaides A, Cavezzi A. Duplex ultrasound investi-gation of the veins in chronic venous disease of the lower limbs - UIP consensus document. Part I. Basic principles. Eur J Vasc Endovasc Surg 2006;31:83- 92 



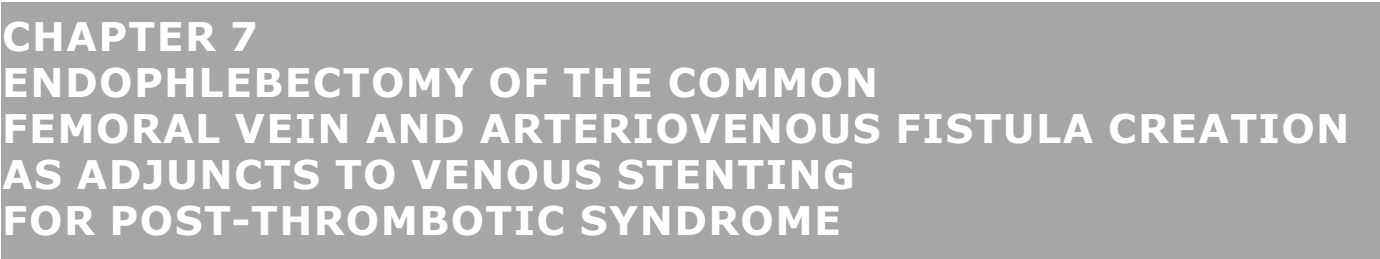

M. A. F. de Wolf $\mathbf{f}^{1,3}$

H. Jalaie ${ }^{4}$

J. H. H. van Laanen ${ }^{1}$

R. L. M. Kurstjens ${ }^{1,3}$

M. J. S. Mensinck ${ }^{1}$

M. J. de Geus ${ }^{1}$

A. Gombert ${ }^{4}$

R. de Graaf 2

C. H. A. Wittens $s^{1,3,4}$

Departments of (I) Surgery and (2) Radiology, Maastricht University Medical Centre, and (3) Cardiovascular Research Institute Maastricht, Maastricht University, Maastricht, The Netherlands, and (4) Department of Vascular Surgery, University Hospital RheinischWestfälische Technische Hochschule Aachen, Nordrhein-Westfalen, Aachen, Germany

Published in the British Journal of Surgery

BJS 20I7; I04: 7I8-725 DOI: IO.IOO2/bjs.IO46I 


\section{ABSTRACT}

\section{Background}

Good results have been reported for angioplasty and stenting of post-thrombotic lesions of the iliac and proximal femoral veins. If lesions at the origin of the superficial femoral and profunda veins are stented, the intraluminal synechiae can be pushed against the orifices of inflow vessels, potentially decreasing stent inflow. Surgical disobliteration of the common femoral vein (endophlebectomy) has been suggested to mitigate this problem. Because of a temporary increase in thrombogenicity, this procedure may be accompanied by arteriovenous fistula creation.

\section{Methods}

Data on consecutive patients treated by hybrid venous reconstruction, between December 2010 and May 2015, were analysed. Standard recording consisted of clinical scoring systems (including Villalta scale) and imaging. Patency was assessed with duplex ultrasonography.

\section{Results}

Seventy-six legs (70 patients) were included. Median follow-up was 379 (range 73-1508) days. Primary, assisted primary and secondary patency rates at I2 months were 5I, 70 and $83 \%$ respectively. Sixty \% of loss of primary patency ( 24 of 40 legs) was related to common femoral vein stenosis, and the rest to rethrombosis. Other complications included wound infection (29\%) and lymphatic leak (39\%). The Villalta score had decreased by a median of 7 points at I-year follow-up.

\section{Conclusions}

The combination of venous stenting, endophlebectomy and arteriovenous fistula creation for patients with extensive post-thrombotic vein damage and severe postthrombotic syndrome is feasible. 


\section{INTRODUCTION}

During the past decade, percutaneous transluminal angioplasty (PTA) and stenting have become established treatments for chronic obstruction of the iliac and caval veins in a growing number of centres worldwide. This treatment for patients with postthrombotic syndrome (PTS) is an alternative to symptom reduction by conservative compression treatment. In a number of patients, post-thrombotic damage extends below the level of the iliac veins. When treated by iliocaval venous stenting, these patients might be prone to increased risk of in-stent rethrombosis, because of decreased venous inflow from the damaged common femoral vein (CFV) and its inflow vessels. Stent extension below the inguinal ligament to the proximal femoral vein has been shown to be effectiver. In arterial stenting, stent extension into the common femoral artery is generally discouraged because of the fear of stent damage by movement of the hip joint, and hyperplasia2. Hyperplasia, however, is not seen in venous stenting, but extending the stent to the distal CFV might hamper inflow from the superficial or deep femoral veins at the femoral confluence, as the synechiae are pushed into the vein wall and over sidebranch orifices. This might impair relief of symptoms and increase the risk of reocclusion.

It has been suggested that iliocaval stenting could be combined with surgical disobliteration of the CFV and the orifices of its side branches, which is termed endophlebectomy (or endovenectomy) $3-6$. The advantage of combining iliac stenting with endophlebectomy is improved inflow into the stents by securing flow from all major side branches of the CFV, which should reduce the risk of rethrombosis. Moreover, it creates a single-lumen landing zone for the stent. However, the increased thrombogenicity resulting from surgical trauma by the endophlebectomy might cause early rethrombosis of the stents, CFV or both. In addition to a strict anticoagulation regimen, here endophlebectomy was combined with creation of a temporary arteriovenous fistula (AVF) to the CFV, to increase flow further through the treated venous tract.

The present study evaluated the feasibility, efficacy and safety of this hybrid venous recanalization procedure.

\section{Methods}

Between December 2010 and May 20I5, consecutive patients with advanced venous disease (subjective complaints and/or objective skin changes) who had post-thrombotic damage affecting iliocaval veins extend-ing into the CFV were considered for surgical treatment. The procedures were undertaken at Maastricht Univer-sity Medical Centre and University Hospital Aachen. All follow-up was done in Maastricht. 


\section{Inclusion criteria}

Age above I8 years and a life expectancy of at least I year. Significant venous disease defined as Clinical Etiologic Anatomic Pathophysiologic (CEAP) class $\mathrm{C}_{4}-6$; debilitating chronic pain or the presence of venous claudication7; post-thrombotic vein wall fibrosis and synechiae in at least the external iliac vein, and femoral or deep femoral vein, seen on duplex ultrasonography and magnetic resonance venography. Exclusion criteria were: unwillingness to receive or contraindications to prolonged anticoagulation treatment and recent deep vein thrombosis (DVT) within I year8.

\section{Procedure}

Access was obtained by ipsilateral ultrasound-guided puncture of the mid-thigh femoral vein. In a minority of patients a contralateral femoral vein or right jugular vein access was required. After gaining access, a smallcalibre (5-Fr) sheath was positioned, and the exact anatomy was visualized by multiplane venography. After administration of 5000 units heparin, a hydrophilic coated guidewire and angulated catheter were used to recanalize the entire obstructed venous tract. Multiangle venography may be needed to check guidewire positioning, as collaterals can mimic the femoral, iliac or caval veins in size and location, especially on single-plane venography. Once recanalization of an unaffected vein cranially from the fibrosis (such as the vena cava) had been achieved, this guidewire was exchanged for a stiff guidewire. After securing successful recanalization, a longitudinal groin incision was made. The common femoral artery was dissected first, as it is easily identified and because it is needed as access for the arterial anastomosis of the AVF. After thrombosis, the inflammatory response is generally not restricted to scarring inside the femoral vein, but also the surrounding tissue, making the dissection significantly more difficult.

After the CFV and all its side branches had been dissected and controlled with vessel loops, an 8-10-cm longitudinal venotomy of the CFV was made, starting just above the origin of the great saphenous vein to the femoral confluence (Figure. I8A). Because there is no natural dissection plane, the intraluminal synechiae had to be removed by sharp dissection. Care was taken to preserve the remaining thin wall of the CFV and avoid perforation (Figure I8B). Venous inflow from all side branches was achieved by the endophlebectomy as far into the orifice as possible and mechanical dilatation beyond, using a smooth clamp, to ensure good inflow. Depending on vessel diameter, the venotomy was closed primarily or with a bovine patch. Next, a 6-mm externally supported polytetrafluoroethylene (PTFE) vascular graft was used to create an AVF between the common femoral artery and CFV. The venous anastomosis of the fistula was created at the cranial or caudal side of the venotomy and venous flow was restoredg. The vascular graft was cut to length, about $60 \mathrm{~mm}$, and the fistula was given a looplike shape to simplify later percutaneous plug occlusion (Figure I8C). The arterial anastomosis was then created and fistula flow released and checked. The venotomy was marked cranially by two surgical clips to determine the exact distal stent position 
later on during fluoroscopy. After meticulous haemostasis (because the patient was fully anticoagulated), the groin incision was closed with a small drain.
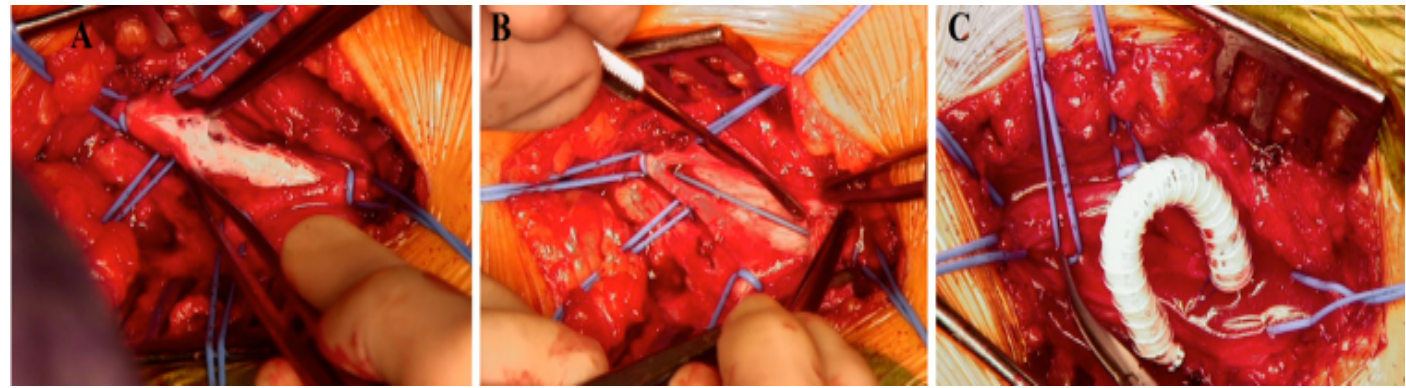

Figure I8. Intraoperative images of endophlebectomy. a Intraluminal post-thrombotic scarring can be identified obstructing the common femoral vein (CFV). Vessel loops are seen controlling the major and minor side branches of the CFV. $b$ After endophlebectomy the majority of fibrotic tissue is removed. The guidewire can be seen intraluminally. $c$ The externally suported polytetrafluoroethylene (PTFE) graft can be seen connecting the common femoral artery and CFF.

PTA of the iliofemoral tract was then performed with non-compliant balloons sizes I6 to I2 mm (I2-mm Powerflex ${ }^{\circledR}$ and I6-mm Maxi ${ }^{\circledR}$ LD, Cordis, Johnson \& Johnson, Diegem, Belgium; I4-mm Armada ${ }^{\circledR}$, Abbott, North Chicago, Illinois, USA). PTA was followed by stent placement (sinus-XL, sinus-Venous and sinus-XL Flex, Optimed, Ettlingen, Germany; Zilver Vena ${ }^{\mathrm{TM}}$, Cook, Galway, Ireland), cranially extending to the inferior vena cava. The caudal landing zone of the stent was just cranial to the venous anastomosis of the PTFE, as marked by the surgical clips. Stents were postdilated and venous flow was checked by multiplane venography (Figure 19). Some patients with bilateral iliac and caval treatment had the confluence reconstructed with balloonexpandable stents (AndraStent ${ }^{\circledR}$; Andramed, Reutlingen, Germany)Io. Antibiotic prophylaxis or an antibiotic-coated sponge was used according to hospital protocol and the surgeon's judgement.

\section{Postoperative care}

Intermittent pneumatic compression of the legs was started after operation in all patients and continued during the hospital stay. In patients already on oral anticoagulation, this was not stopped before surgery and was continued after operation, aiming at an international normalized ratio (INR) of 3-4. In all others, low molecular weight heparin was started directly after the intervention; coumadins were started the next day, if no active bleeding was present, aiming at an INR of 3-4. Anticoagulation was continued for at least 6 months. 


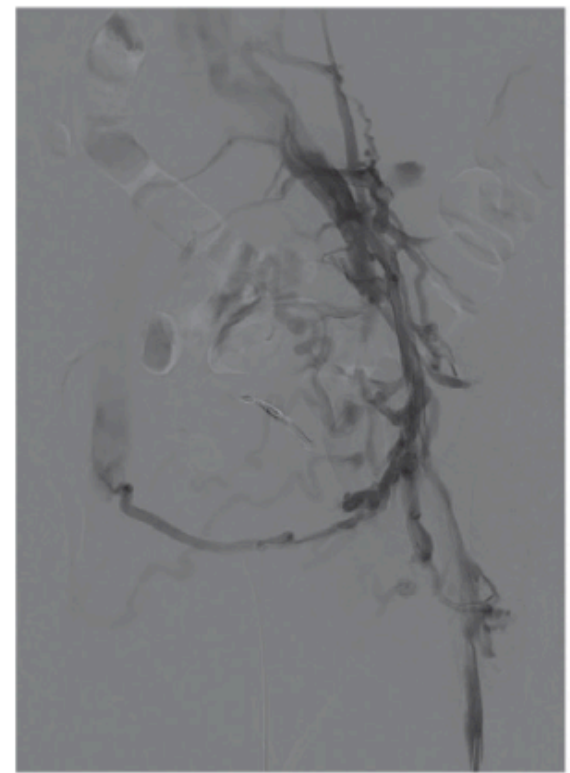

a Before procedure

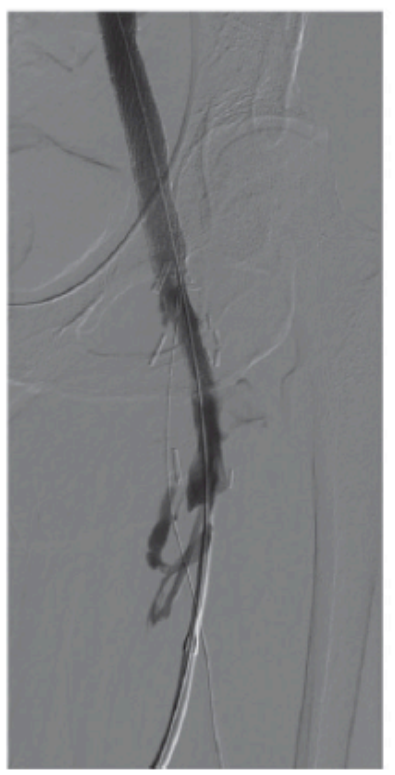

C Close-up of endophlebectomy area

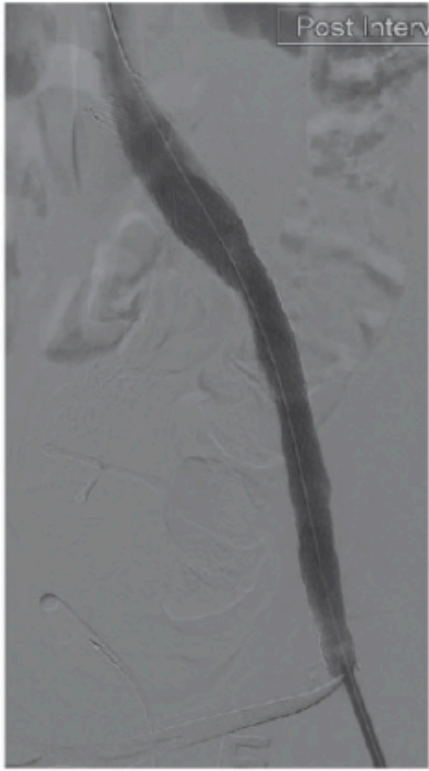

b Stent in place

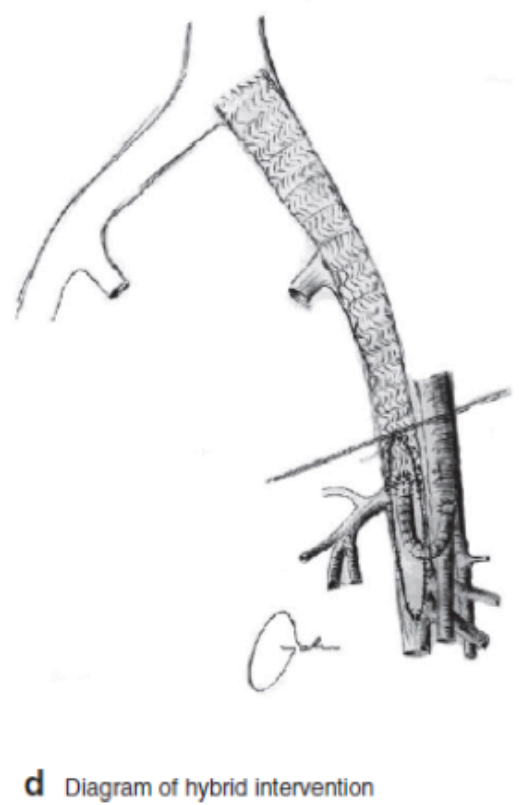

Figure 19. Perioperative venography. a Obstruction of left common and external iliac vein, and common femoral vein (CFV). Multiple collateral veins cross the midline. $b$ Stent in left common and external iliac vein, and CFV. c Close-up of distal stent and vascular clips (arrow) marking the proximal endophlebectomy. d Diagram of stents, endophlebectomy of CVF and arteriovenous fistula 
If no stenoses were found on duplex examination 2-3 weeks after surgery, patients were booked for a second hospital admission, during which the AVF was closed. If a stenosis in the endophlebectomy segment was identified, impairing outflow of the leg and reducing inflow into the stented segment, stent extension was performed before the AVF was closed. AVFs were closed in an endovascular procedure using an Amplatzer ${ }^{\mathrm{TM}}$ vascular plug (St Jude Medical, St Paul, Minnesota, USA) via contralateral transfemoral arterial access. A small number of AVFs were closed surgically.

\section{Data collection}

From 2012 onwards, data were added to a prospective digital database. Data collected before this time point were added retrospectively (4 patients). During follow-up, C of CEAP, Venous Clinical Severity Score (VCSS), Villalta score, venous claudication and the presence of any pubic collateralization were noted,,II,I2. Some of these data were not documented in the interval before the digital database.

\section{Statistical analysis}

Continuous data are presented as median (range), and categorical data as frequencies and percentages. The t-test was used to analyse changes in clinical scores. Patency was defined as less than $50 \%$ flow lumen reduction in a treated vein segment. Patency rates were estimated by use of Kaplan-Meier survival analyses, based on the total number of legs that received endophlebectomy and AVF. All other data are based on the number of patients. $\alpha \leq .050$ was used to demonstrate statistical significance.

\section{RESULTS}

A total of 70 patients (76 legs) were treated. Median age was 39 (I8-75) years and 44 patients $(63 \%)$ were women. All patients had extensive post-thrombotic damage on imaging, and all but one patient reported one (47 patients, $67 \%$ ) or more (22 patients, 3I \%) DVTs in their medical history. One patient had a silent DVT. Patients were treated a median of 5 (I-4I) years after the first DVT. The ipsilateral common iliac vein was affected in 64 patients (9I \%) and the external iliac vein in all patients, as was the CFV. The CFV was affected by post-thrombotic disease in 66 patients (94\%), and the deep femoral vein in 55 (79\%). Other baseline data can be found in Table I3.

\section{Intervention}

Fifty-five patients (79 \%) had unilateral treatment and in six (9\%) the operation was performed bilaterally (in 4 (6\%) the vena cava was also stented). Nine patients (I3 \%) had bilateral stenting (in 8 (II \%) the vena cava was also stented), in combination with unilateral endophlebectomy and AVF creation. Thus, 76 endophlebectomies and AVFs were created. In 37 patients (53\%) a patch was used to close the venotomy; it was closed primarily in the other 33 patients. 
Table 13. Demographics

\begin{tabular}{|c|c|c|c|}
\hline Baseline $(\mathrm{N}=70)$ & & Percentage & Range \\
\hline Number of females & 44 & $62,9 \%$ & \\
\hline Median age (years) & 39 & & I8 - 75 \\
\hline Median BMI & 27.0 & & $2 \mathrm{I} .8-32.8$ \\
\hline Thrombophilia & $20 *$ & $76,9 \%$ & \\
\hline Single DVT & 47 & $67, \mathrm{I} \%$ & \\
\hline Recurrent DVT & 22 & $3 \mathrm{I}, 4 \%$ & \\
\hline \multicolumn{4}{|l|}{ Median time between DVT } \\
\hline and treatment (years) & 5 & & $\mathrm{I}-4 \mathrm{I}$ \\
\hline Left sided DVT & $4 \mathrm{I}$ & $58,6 \%$ & \\
\hline Right sided DVT & 2 & $2,9 \%$ & \\
\hline Bilateral DVT & 27 & $38,6 \%$ & \\
\hline History of PE & II & $\mathrm{I} 5,7 \%$ & \\
\hline \multicolumn{4}{|l|}{ Highest C of CEAP } \\
\hline Co & 6 & $8,6 \%$ & \\
\hline CI & 5 & $7, \mathrm{I} \%$ & \\
\hline $\mathrm{C}_{2}$ & 8 & $\mathrm{II}, 4 \%$ & \\
\hline $\mathrm{C}_{3}$ & $3 \mathrm{I}$ & $44,3 \%$ & \\
\hline $\mathrm{C}_{4} \mathrm{a}$ & II & $\mathrm{I} 5,7 \%$ & \\
\hline $\mathrm{C}_{4} \mathrm{~b}$ & 3 & $4,3 \%$ & \\
\hline $\mathrm{C}_{5}$ & 3 & $4,3 \%$ & \\
\hline $\mathrm{C} 6$ & 3 & $4,3 \%$ & \\
\hline Mean VCSS at baseline & 8 & & $3-19$ \\
\hline Mean Villalta score at baseline & II & & $4-22$ \\
\hline Venous claudication at baseline & 64 & $9 I, 4 \%$ & \\
\hline
\end{tabular}

*28 (40\%) of patients tested for thrombophilia

In unilateral hybrid reconstructions, a median of 2 (I-6) stents were used. In patients with stenting of the vena cava and the bilateral iliofemoral tract, with either unilateral or bilateral endophlebectomy, a median of $6(5-9)$ stents were used. In the three patients with bilateral treatment without stenting of the vena cava a total of four stents were used per patient. AVFs were closed by endovascular means in 28 patients (40 \%) and surgically in four (6\%). In I5 individuals (2I \%) the AVF closed spontaneously, and in 23 (33\%) the AVF was not closed during follow-up, because inflow from the femoral and/ or deep femoral vein was judged to be inadequate. If the AVF was closed, this was done a median of $82(26-742)$ days after its creation.

\section{Patency rates and reinterventions}

Median follow-up was 379 (73-1508) days. The patency rate at I2 months was 5I, 70 and 83\% respectively for primary, assisted primary and secondary patency (Figure 20). In patients who received bilateral stenting with unilateral endophlebectomy and AVF creation, 
nine of the ten iliofemoral tracts treated by sole stenting (without endophlebectomy and AVF) remained patent during follow-up. In total, 40 limbs lost primary patency in 39 patients (56\%) (53\% of treated limbs). This was due to reocclusion in I6 patients (23\%); half of these occurred before AVF closure. Reocclusion was treated by catheter-directed ultrasound-enhanced thrombolysis in seven patients (I0 \%), and was successful in five. Three of the five patients who had successful thrombolysis needed restenting because of inadequate inflow. In nine patients ( $13 \%$ ) thrombolysis or thrombectomy was not considered, either because of an absolute contraindication or because the treatment window had passed. The most frequently performed reintervention was restenting, that is elongation of the stented tract into the endophlebectomy zone, because of restenosis of the CFV. This was necessary in 24 patients $(34 \%)$ and was performed with the same self-expandable stents as used for primary stenting. In another eight patients (II \%) stenosis of the CFV occurred during follow-up, and a wait-and-see approach was chosen, generally because the stenosis was asymptomatic.

Figure 20. Kaplan-Meier analysis of primary, assisted primary and secondary patency rates of vein segments treated by the hybrid intervention, calculated per leg.

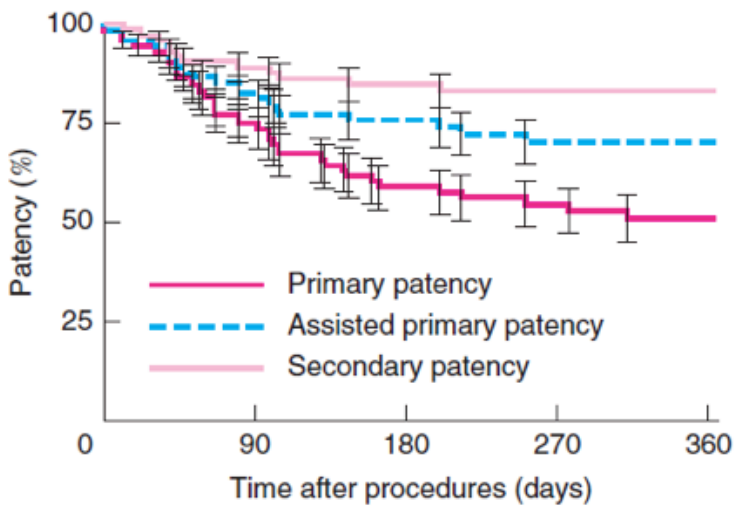

$\begin{array}{llllll}\text { No. at risk } & & & & & \\ \text { Primary } & 76 & 58 & 44 & 33 & 28 \\ \text { Assisted primary } & 76 & 61 & 49 & 32 & 24 \\ \text { Secondary } & 76 & 64 & 53 & 36 & 27\end{array}$

Error bars represent standard error of the mean (all less than Io \%)

\section{Other complications}

Besides reocclusion and CFV stenosis, the most frequent complications related to the groin incision.Twenty patients (29\%) developed wound infections. Surgical incision and drainage was necessary in seven patients (IO \%), intravenous antibiotics were used in II (I6\%) and oral antibiotics in all. The PTFE AVF had to be removed because of persistent infection in two patients ( $3 \%$ ), in both of whom the AVF was already occluded. Twentyseven patients $(39 \%)$ developed a lymphatic leak after surgery, which was managed by 
negative-pressure wound therapy in six (9\%) and by conservative measures in the rest. Other important complications included major bleeding (needing transfusion and/or surgical intervention) in six patients (9\%) (Table I4).

\section{Table I4. Complications}

\begin{tabular}{rll}
\hline Complications & Percentage \\
Reocclusion & I6 & 25 \\
Pulmonary embolism & O & O \\
Stenosis distal to stents & 32 & 46 \\
Wound infection & 20 & $3 \mathrm{I}$ \\
Lymphorrhea & 26 & 40 \\
Minor bleeding & II & I7 \\
Major bleeding & 6 & 9 \\
Neuropraxia & 2 & 3 \\
Heparin induced thrombocytopenia & I & 2 \\
Bladder infection & I & 2 \\
Mild stent tapering (not needing re-intervention) & 7 & II \\
Stent kinking & 2 & 3 \\
Residual stent compression & 2 & I \\
Proximal stent placed too distally & 2 & 3 \\
Stent fracture & o & o \\
\hline
\end{tabular}

\section{Clinical follow-up}

Follow-up data were available for 67 patients $(96 \%)$ at 6 months and $40(57 \%)$ at 12 months. Median VCSS decreased from $8(3-19)$ at baseline to $6(\mathrm{O}-2 \mathrm{I})$ at 6 months and 5 (O-2I) at I2-month follow-up ( $\mathrm{P}<\mathrm{O}$ ooI, baseline versus $\mathrm{I} 2$ months). Median Villalta score decreased from II (4-22) at baseline to 5 (O-I5) at 6 months and 4 (O-2I) at I2 months ( $\mathrm{P}<\mathrm{O}$ ooI, baseline versus I2 months). Based on the categorical Villalta scale (no, mild, moderate or severe PTS) in the 40 patients who completed I-year follow-up, 28 patients improved on this scale, II were unchanged and one had worse symptoms. Among the 64 patients with venous claudication at baseline, this disappeared in 46 (72\%). Two of the patients with active ulcers suffered an early reocclusion (at 43 and 98 days after operation), and the ulcers did not heal during follow-up. A third patient had an ulcer that healed 25 days after the intervention, without recurrence.

\section{Discussion}

This study reports an experience with the use of a hybrid venous reconstruction for PTS: stenting of the (cavo)iliofemoral tract combined with endophlebectomy and AVF creation. Interest in this technique arose some years ago5,6,9,13- 15, but outcome data are still sparse. Clinical results reported here at mid-term follow-up are favourable, especially considering the extent of the post-thrombotic venous changes. However, the primary patency rate of $5 \mathrm{I} \%$ at I year is significantly lower than that after sole iliofemoral 
vein stenting, which is generally reported as being 70-80 \% I6-I8. Assisted primary and secondary patency rates are little different from those after sole iliofemoral stenting.

The technique described suffers from the inherent thrombogenicity of the extensive stenting, but also of the surgically exposed vein wall components (collagen). This is the reason for creating an AVF in all these patients, a decision based on the now infrequently performed surgical thrombectomy for DVTi9. The proportion of patients (46 \%) who developed a stenosis of the CFV during follow-up is of note. This area was free from stenosis at the end of the operation, as checked by completion venography, so the stenoses must have developed during follow-up. Stenosis may be caused by low intravenous pressure and possible compression by fluid extravasation around the endophlebectomy tract. This might be preventable by insertion of an inlay stent. The AVF may also influence this problem, possibly because of its interaction with the newly endophlebectomized CFV or the stents. The role of AVFs in creating venous obstruction, due to intimal hyperplasia, is well known in vascular access surgery9,20, which is why temporary AVFs were used here.

In comparison with other published series of iliocaval venous stenting, the present patency rates fall between the ranges of Garg and colleagues2I, with a primary patency rate of $8 \%$ and secondary patency rate of $30 \%$, and Vogel et al.4 and Puggioni and coworkers5, who reported primary patency rates of around $80 \%$ and secondary patency rates of around $90 \%$. Because of the groin incision many wound complications are noted, especially lymphatic leak and wound infection, which significantly influence the early postoperative phase for these patients. Limitations of this study include the fact that data were partly collected retrospectively (4 patients) and not all patients completed I2-month follow-up. Moreover, a learning curve effect may be present as this series also represents an early experience. However, the intervention and follow-up were standardized, and patency rates and objective clinical scores were both collected.

\section{CONCLUSION}

The combination of venous stenting, endophlebectomy and AVF creation for patients with extensive post-thrombotic vein damage causing severe PTS is feasible. Clinical scores improve significantly. Patency rates are suboptimal but acceptable in this population with extensive post-thrombotic damage, and an alternative to the standard compression treatment. 


\section{REFERENCES}

I. Neglen P, Tackett TP Jr, Raju S. Venous stenting across the inguinal ligament. J Vasc Surg 2008; 48: I255-I26I.

2. Mwipatayi BP, Hockings A, Hofmann M, Garbowski M, Sieunarine K. Balloon angioplasty compared with stenting for treatment of femoropopliteal occlusive disease: a

3. meta-analysis. J Vasc Surg 2008; 47: 46I-469.

4. Comerota AJ, Grewal NK, Thakur S, Assi Z. Endovenectomy of the common femoral vein and intraoperative iliac vein recanalization for chronic iliofemoral venous occlusion. J Vasc Surg 20IO; 52: 243-247.

5. Vogel D, Comerota AJ, Al-Jabouri M, Assi ZI. Common femoral endovenectomy with iliocaval endoluminal recanalization improves symptoms and quality of life in patients with postthrombotic iliofemoral obstruction. J Vasc Surg 2012; 55: I29-I35.

6. Puggioni A, Kistner RL, Eklof B, Lurie F. Surgical disobliteration of postthrombotic deep veins - endophlebectomy - is feasible. J Vasc Surg 2004; 39: I048-I052.

7. Raju S, Neglen P, Doolittle J, Meydrech EF. Axillary vein transfer in trabeculated postthrombotic veins. J Vasc Surg 1999; 29: I050-I062.

8. Eklof B, Rutherford RB, Bergan JJ, Carpentier PH, Gloviczki P, Kistner RL et al.; American Venous Forum International Ad Hoc Committee for Revision of the CEAP Classification. Revision of the CEAP classification for chronic venous disorders: consensus statement. J Vasc Surg 2004; 40: I248-I252.

9. de Wolf MA, Arnoldussen CW, Wittens CH. Indications for endophlebectomy and/or arteriovenous fistula after stenting. Phlebology 20I3; 28(Suppl I): I23-I28.

Io. Kurstjens RL, de Graaf R, Barbati ME, de Wolf MA, van Laanen JH, Wittens CH et al. Arteriovenous fistula geometry in hybrid recanalisation of post-thrombotic venous obstruction. Phlebology 20I5; 30(Suppl): 42-49.

II. de Graaf R, de Wolf M, Sailer AM, van Laanen J, Wittens C, Jalaie H. Iliocaval confluence stenting for chronic venous obstructions. Cardiovasc Intervent Radiol 20I5; 38: II98-I2O4.

I2. Kahn SR. Measurement properties of the Villalta scale to define and classify the severity of the post-thrombotic syndrome. J Thromb Haemost 2009; 7: 884-888.

I3. Vasquez MA, Rabe E, McLafferty RB, Shortell CK, Marston WA, Gillespie D et al.; American Venous Forum Ad Hoc Outcomes Working Group. Revision of the venous clinical severity score: venous outcomes consensus statement: special communication of the American Venous Forum Ad Hoc Outcomes Working Group. J Vasc Surg 20I0; 52: I387-I396.

I4. Scannell JG, Shaw RS. Surgical reconstruction of the superior vena cava. J Thorac Surg I954; 28: I63-I74.

I5. Templeton JY III. Endvenectomy for the relief of obstruction of the superior vena cava. Am J Surg 1962; I04: 70-76.

I6. Breslau RC, Deweese JA. Successful endophlebectomy of autogenous venous bypass graft. Ann Surg 1965; I62: 25I-254.

I7. Friedrich de Wolf MA, Arnoldussen CW, Grommes J, Hsien SG, Nelemans PJ, de Haan 
MW et al. Minimally invasive treatment of chronic iliofemoral venous occlusive disease. J Vasc Surg Venous Lymphat Disord 2013; I: I46-I53.

I8. Neglen P, Hollis KC, Olivier J, Raju S. Stenting of the venous outflow in chronic venous disease: long-term stent-related outcome, clinical, and hemodynamic result. J Vasc Surg 2007; 46: 979-990.

I9. Titus JM, Moise MA, Bena J, Lyden SP, Clair DG. Iliofemoral stenting for venous occlusive disease. J Vasc Surg 20II; 53: 706-7I2.

20. Neglen P, al-Hassan HK, Endrys J, Nazzal MM, Christenson JT, Eklof B. Iliofemoral venous thrombectomy followed by percutaneous closure of the temporary arteriovenous fistula. Surgery I99I; IIO: 493-499.

2I. Oguzkurt L, Tercan F, Yildirim S, Torun D. Central venous stenosis in haemodialysis patients without a previous history of catheter placement. Eur J Radiol 2005; 55: 237-242.

22. Garg N, Gloviczki P, Karimi KM, Duncan AA, Bjarnason H, Kalra M et al. Factors affecting outcome of open and hybrid reconstructions for nonmalignant obstruction of iliofemoral veins and inferior vena cava. J Vasc Surg 20II; 53: 383-393. 



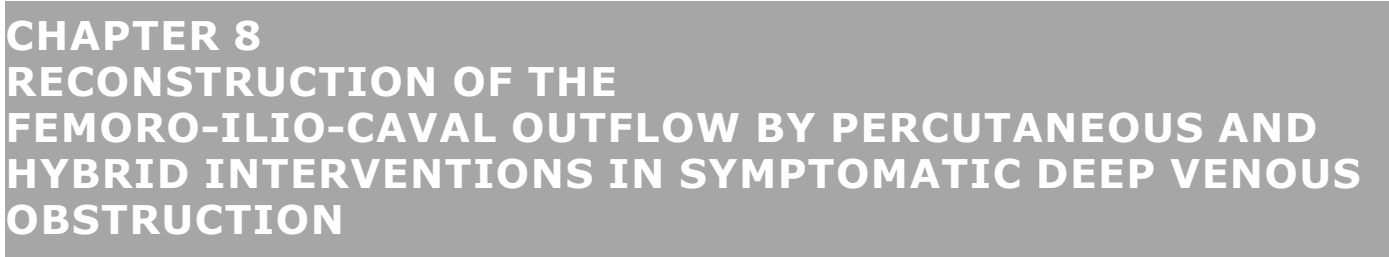

T.M.A.J. van Vuuren ${ }^{1,2}$

M.A.F. de Wolf1,2

C.W.K.P. Arnoldussen ${ }^{3,4}$

R.L.M. Kurstjens ${ }^{1,2}$

J.H.H. van Laanen ${ }^{1}$

H. Jalaie ${ }^{5}$

R. de Graaf ${ }^{3}$

C.H.A. Wittens ${ }^{1,2,5}$

I Department of Surgery, Maastricht University Medical Centre, P. Debyelaan 25, 6202 AZ, Maastricht, The Netherlands

2 Cardiovascular Research Institute Maastricht, Maastricht University, PO Box 616, 6200 MD Maastricht, The Netherlands

3 Department of Radiology, Maastricht University Medical Centre, P. Debyelaan 25, 6202 AZ, Maastricht, The Netherlands

4 Department of Radiology, VieCuri Medical Centre, Venlo, The Netherlands

5 Department of Vascular Surgery, University Hospital RWTH Aachen, Nordrhein-Westfalen, Pauwelsstraße 30, 52074, Aachen, Germany

Published in the European Journal of Vascular and Endovascular Surgery

Eur J Vasc Endovasc Surg (2017) 54, $495 e 503$ 


\section{ABSTRACT}

\section{Objective/Background}

Deep venous obstruction is relatively prevalent in patients with chronic venous disease. Endovascular treatments and hybrid interventions can be used to relieve venous outflow obstructions. This paper assesses mid-term clinical outcomes and patency rates in a large cohort after percutaneous and hybrid interventions.

\section{Methods}

This was a prospectively analysed cohort study. Patients with symptomatic deep venous obstruction who presented at a tertiary referral hospital were divided into three groups: patients who underwent percutaneous stenting for non-thrombotic iliac vein compression syndrome (IVCS group); patients with post-thrombotic syndrome (PTS) treated by percutaneous stent placement (P-PTS group); and PTS patients with obstruction involving the veins below the saphenofemoral junction in which a hybrid procedure was performed, combining stenting with open surgical disobliteration (H-PTS group). Patency rates, complications, and clinical outcomes were analysed.

\section{Results}

A total of 425 lower extremities in 369 patients were treated. At 60 months, primary patency, assisted primary patency, and secondary patency rates were $90 \%$, $100 \%$, and IO0 $\%$ for IVCS, and $64 \%, 81 \%$, and $89 \%$ for the P-PTS group, respectively. The H-PTS group, showed patency rates of $37 \%, 62 \%$, and $72 \%$, respectively, at 36 months. Venous claudication subsided in $90 \%, 82 \%$, and $83 \%$, respectively. At the 24 month follow-up, mean Venous Clinical Severity Score decreased for all patients and improvement in Villalta score was seen in post-thrombotic patients. The number of complications was related to the extent of deep venous obstruction in which patients in the H-PTS group showed the highest complication rates (8I\%) and re-interventions (59\%).

\section{Conclusion}

Percutaneous stent placement to treat non-thrombotic iliac vein lesions, and postthrombotic iliofemoral obstructions are safe, effective, and showed patency rates comparable with previous research. Patients with advanced disease needing a hybrid procedure showed a lower patency rate and more complications. However, when successful, the clinical outcome was favourable at mid-term follow-up and the procedure may be offered to selected patients. 


\section{INTRODUCTION}

Minimally invasive endoluminal interventions have revolutionised many facets of modern medicine. Since the I990s great advances have been made in the treatment of iliac and vena cava obstructions where endovascular treatment options frequently surpass conservative therapy and open surgery.I-5 Caval and iliofemoral venous obstructive disease is common in patients with chronic venous insufficiency and is caused by either post-thrombotic vein damage, extraluminal vein compression, or a combination of both. This post-thrombotic vein damage with vein wall fibrosis, intraluminal scarification, and valvular damage can result after a deep venous thrombosis (DVT), presenting as the so called post-thrombotic syndrome (PTS). 6,7Clinically, this is associated with the same symptoms and clinical signs as other types of chronic venous disease, for example pain (especially during ambulation), oedema, and venous ulceration.

As mentioned, the second most common cause of chronic venous obstruction is related to extraluminal vein compression of which iliac vein compression syndromes (IVCS) are the best known. IVCS consist of symptoms associated with chronic venous disease due to compression of the iliac vein by an extraluminal structure (usually an overlying artery). 8 Additionally, there can be some degree of spurs or webs due to chronic local vein wall irritation in about $30 \%$ of cases.9,Io In this subgroup, a smooth vessel wall and focal indentation will be seen during recanalisation, indicating compression without post thrombotic vein damage.II Both the post-thrombotic and IVCS obstruction impede ambulatory venous outflow of the lower extremity and lead to venous hypertension. Venous outflow of the leg seems most dependent on the iliac tract, which explains the significantly higher incidence of PTS after an iliofemoral DVT when compared with calf level DVTs.6,I2 PTA and stenting of iliac lesions have been shown to improve outflow of affected legs.Ie4 Moreover, stenting is performed and has been proven to be more effective in patients with a common femoral vein (CFV), external iliac vein, common iliac vein (CIV), or inferior vena cava (IVC) obstruction.2e4 Because stenting distal to the CFV has a higher risk of early failure due to low flow, this is generally not offered and is avoided.I,I3eI5 In addition, there is currently no evidence suggesting any clinical benefit from stenting below the common femoral confluence, which is where the deep femoral vein (DFV) and femoral vein (FV) merge into the CFV. However, open surgical disobliteration, may be a solution for selected patients with post-thrombotic changes at and below the CFV.I6-I8 The goal of this study is to report on the experience, clinical outcome, and stent patency in patients treated for IVCS and post-thrombotic femoral, iliac, and caval obstructive lesions by percutaneous and hybrid techniques.

\section{Methods}

In this cohort study data were collected prospectively and analysed retrospectively. All patients eligible for treatment at the authors' tertiary referral care centre (vascular surgery department) were included. Between September 2009 and January 2016, 369 
consecutive patients were treated. All patients showed signs of chronic caval, iliac, or femoral vein obstruction on diagnostic imaging and demonstrated symptoms of venous hypertension like pain interfering with daily activities, and/or clinical signs classified according to the CEAP classification as $\mathrm{C}_{3}$ (edema) or $\mathrm{C}_{4}$-C6 (skin changes). I9Additionally, venous claudication was a symptom indicating treatment and was defined as the onset or worsening of pain during routine exercise, which subsides during rest, especially while sitting or lying down.I4

Patients who received stents after catheter directed thrombolysis for an acute DVT were excluded from this study. Non-fully grown adolescents (bone age analysed if applicable) with a DVT < I year previously, and patients with a life expectancy of < I year were not eligible for treatment. Also, patients with an occlusion extending far into the FV and DFV were not eligible for treatment as it is impossible to reestablish the inflow to the stent. Furthermore, treatment was not offered to those patients who were intolerant of anticoagulant therapy since this was obligatory after the intervention. Patients had magnetic resonance venography (MRV) and duplex ultrasonography (DUS) imaging at baseline, and conventional multiplanar venography during intervention. IVCS was defined as clinical complaints related to a $>50 \%$ lumen diameter reduction on DUS or MRV in combination with compression and a collateral network on venography. Intraluminal synechiae outside the compressed segment, with formation of collaterals, was considered a sign of post-thrombotic obstruction.

On the basis of findings, three groups were created in which interventions were performed. The IVCS patients with non-thrombotic syndrome had percutaneous stent placement alone. Percutaneous stent placement (P-PTS group) patients, had a percutaneous stent placement when obstruction was limited to segments central to the saphenofemoral junction (SFJ) in the CFV or when a trabeculation free landing zone in the CFV between the SFJ and the DFV and FV confluence was identified. The inflow from the FV, DFV, and/or collaterals was minimally impaired. The third group (H-PTS) consisted of patients with PTS and obstruction below the SFJ, especially when the CFV was occluded or when there was a risk that stent placement could displace intraluminal tissue and obstruct FV or DFV inflow. Also, when the orifices of the FV and/or the DFV were occluded patients were included in the H-PTS group. Furthermore, endophlebectomy and arteriovenous fistulae (AVF) were performed as a second stage in some patients treated in the P-PTS group with stent thrombosis and clinical complaints interfering with daily activities. Clinical scores, stent patency rates, complication rates, and number of reinterventions are presented per leg for all three groups.

\section{Clinical assessment pre-intervention}

At baseline, CEAP classification and the Venous Clinical Severity Score (VCSS) were scored for all patients. PTS was diagnosed using the Villalta score. With increasing 
clinical experience, the importance of venous claudication was recognised and a separate scoring for this item was added to the baseline and follow-up data collection. For this reason, not all venous claudication scores were present at baseline. The number of entered data is described in the text. Consequently, scores were inconsistently entered into a digital database at the various follow-up visits and at the discretion of the treating physician.

\section{Duplex ultrasonography}

DUS (MyLab Alpha, Esaote, Genoa, Italy; ProSound Alpha 7 Premier machine, Hitachi Aloka, Tokyo, Japan) at baseline included imaging of the IVC from the level of the liver downward, the renal and gonadal veins, the iliac veins, and any apparent collateral network in the supine position using a convex probe (frequency range Ie8 MHz). Special attention was given to any clues of post-thrombotic damage or IVCS, that is, venous stenosis, external vein compression, vessel wall changes, intraluminal scarification, and enlarged collateral veins. With the patient in an erect position, the femoral, popliteal, and calf veins were examined using a linear array probe (frequency range $3 \mathrm{eI} 3 \mathrm{MHz}$ ). Inflow of the FV, DFV, and GSV into the CFV was evaluated during flow augmentation. Furthermore, the superficial and deep veins were tested for valvular segmental reflux. Insufficiency was scored as retrograde flow $>$ I s for the deep veins and $>0.5 \mathrm{~s}$ for the superficial veins.

\section{Magnetic resonance venography}

A I.5-Tesla MRI system (Intera, Philips Healthcare, Best, the Netherlands) was used. A dedicated I2 element phased array peripheral vascular coil with craniocaudal coverage of $128 \mathrm{~cm}$ (Philips) was used for signal reception. Examinations were performed in the supine position. Prior to contrast injection, all patients had a standard two dimensional non-contrast enhanced balanced turbo field echo (BTFE) sequence to visualise the abdominal and pelvic veins. By use of a remote controlled dual head injector (Spectris; Bayer Medrad, Indianola, PA, USA) the contrast agent (Gadobutrol; Gadavist, Bayer HealthCare, Berlin, Germany) was administered intravenously at I.O mL/second (0.2 $\mathrm{mL}$ per $\mathrm{kg}$ body weight, equal to $0.2 \mathrm{mmol} / \mathrm{kg}$ ) in the median cubital vein. Contrast injection was followed by a $20 \mathrm{~mL}$ saline flush injection at the same flow rate. Acquisition of the first scan volume was started $30 \mathrm{~s}$ after contrast administration. A three dimensional ultrafast gradient echo sequence (Ultrafast GE, THRIVE, Philips Healthcare) with fat suppression (spectral presaturation with inversion recovery) was used for high resolution steady state imaging of the venous system, ensuring coverage of the popliteal veins up to the suprarenal IVC.

\section{Stent placement}

Endovascular interventions were performed in an angiosuite, whereas hybrid procedures were performed in a hybrid operation room. Ultrasound guided venous access was obtained through the ipsilateral midfemoral vein, below the inflow of the 
main deep femoral vein branches. In general, a 6-F sheath was introduced to initiate recanalisation. After successfully traversing the guidewire through the obstruction, the 6-F sheath was changed for a IO-F sheath to facilitate balloon angioplasty and stent deployment. Routinely, 5000 IU of heparin were administered before angioplasty. Predilatation was performed in which balloons were sized according to the diameter of the desired stent, generally between $\mathrm{I} 2$ and $\mathrm{I} 6 \mathrm{~mm}$, increasing from the CFV to the CIV, and up to $25 \mathrm{~mm}$ for the IVC. The type of stents used varied during the course of the study, on the basis of experience. Without specific indication, stents used included the sinus XL, sinus XL-flex, sinus Venous and sinus Obliquus (Optimed GmbH, Ettlingen, Germany), VICI (Veniti, St. Louis, MO, USA), Zilver Vena (Cook, Limerick, Ireland), and Venovo (Bard, Coving-ton, GA, USA). Postdilatation was always performed. Detailed descriptions of the recanalisation and stenting techniques are described elsewhere.I4,I5,20 Poststenting assessment of the in- and outflow of the treated segments was routinely done by multiplanar venography (Figure 2I).
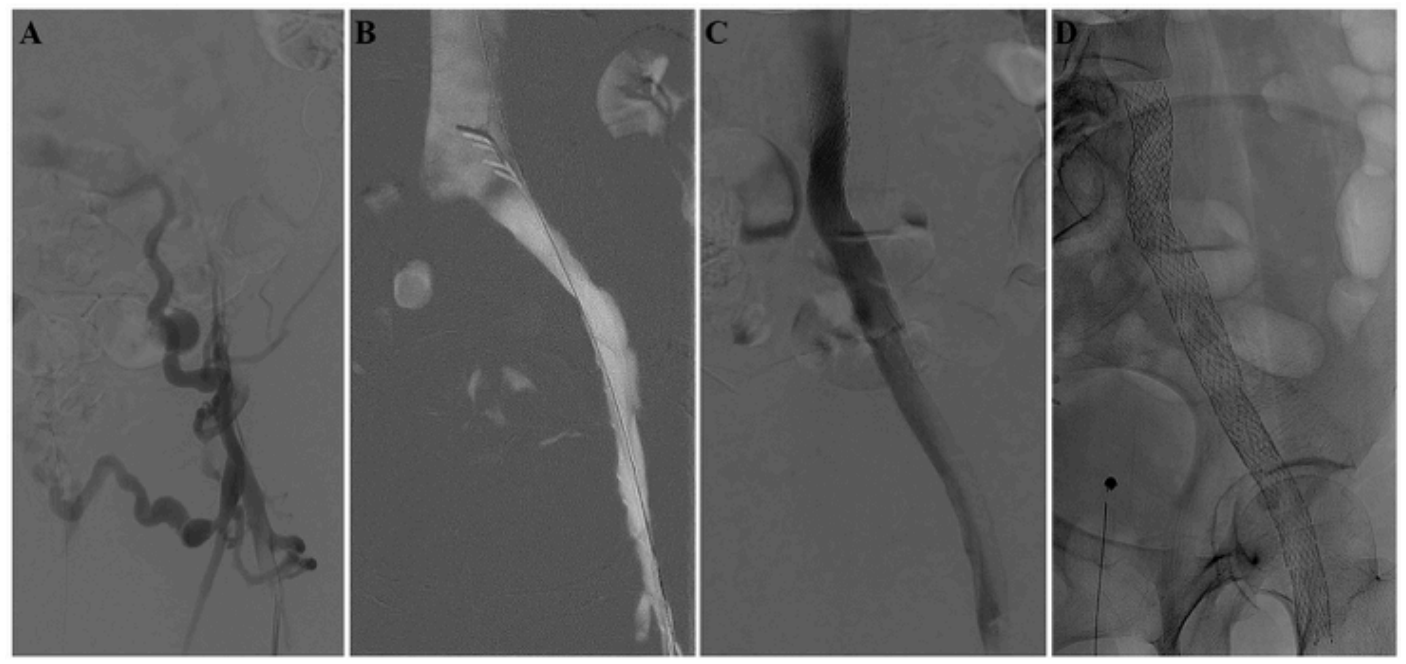

Figure 2I. (A) Preinterventional venography of the left iliac tract in a patient with postthrombotic syndrome who received percutaneous treatment. The proximal iliac tract is not visualised because of lumen occlusion. Multiple collaterals are seen; a secondary sign of vein obstruction. (B) Roadmap image following guidewire recanalisation and percutaneous transluminal angiography of the left iliac tract. Notice the typical translucency in the common iliac vein caused by the compression of the overlying common iliac artery. (C) Venography after stent deployment. Contrast flows freely through the stents. (D) Fluoroscopic image of the stents post-deployment. Stents reach from the proximal common iliac vein into the proximal common femoral vein.

During follow-up, the same DUS techniques as pre-intervention were used, with specific attention to stent and, if applicable, AVF patency, presence of lumen diameter 
reduction of $>50 \%$, presence of post-interventional haematomas, and stent integrity. Features such as stent fracture, kinking, or tapering resulting in lumen reduction and apparent flow impairment were recorded. A suspicion of kinking was scored as any in-stent angulation causing flow impairment, most frequently caused by rigidity of the stent. When the suspicion of kinking arose, a plain X-ray in three planes was performed. Tapering was scored as an indentation at the stent end due to external compression, causing flow impairment with filling of collaterals.

\section{Analysis and statistics}

All continuous data are presented as mean SD, except for non-normally distributed data (presented as median [range]). Categorical data are presented as frequencies and percentages. An $\alpha$ of .05 was considered statistically significant. KaplaneMeier survival estimation was used to calculate patency rates. SEM values of > IO\% were discarded as being unreliable and were not reported. Patency analyses were based on the total number of extremities treated, whereas all other calculations were per patient. Clinical scoring data were absent after 24 month follow-up, as these data were available in < $20 \%$ of patients. A clinically relevant difference of minimally 0.5 times the SD of the difference in pre- and post-treatment scores was used as a cutoff value (of 210 [57\%] patients with both a baseline and at least one follow-up score). The study was registered under number NCT02650453 in the clinicaltrials.gov database.

\section{RESULTS}

\section{Demographics}

The mean age of the total population was $43 \pm$ I4 years (range $17-77$ years) and 257 (70\%) patients were female. Most (26I [93\%]) patients in the P-PTS and H-PTS groups had one or more known DVTs in their medical history. Twenty-one patients (6\%) referred for analysis of chronic venous disease had suffered an occult DVT with post-thrombotic vein damage. Patients in the P-PTS and H-PTS groups had a median of 6 (range I-48) symptomatic years after their first DVT. A minority of IVCS patients was also known to have a history of DVT; however, these were distal or contralateral DVTs. The majority (242 [66\%]) of patients were classified as CEAP class Co-C3. Treatment indication in these patients was based on the presence of venous claudication and other subjective complaints like pain or oedema. At baseline, venous claudication was present in 33 patients with IVCS (of 83 patients in whom claudication was noted at baseline), II 3 P-PTS patients (of I8I patients in whom claudication was noted at baseline) and 70 H-PTS patients (of 83 patients of whom claudication was noted at baseline). All patient characteristics are provided per group in Tables 5 and I6. 
Table 15. Demographics

\begin{tabular}{|c|c|c|c|c|}
\hline & $\begin{array}{l}\text { IVCS } \\
\mathrm{N}=87(24)\end{array}$ & $\begin{array}{l}\mathrm{P}-\mathrm{PTS} \\
\mathrm{N}=\mathrm{I} 96(53)\end{array}$ & $\begin{array}{l}\mathrm{H}-\mathrm{PTS} \\
\mathrm{N}=86(23)\end{array}$ & $\begin{array}{l}\text { Total } \\
N=369\end{array}$ \\
\hline N legs* & $87(2 \mathrm{I})$ & 22I (53) & IO9 (26) & $4 \mathrm{I} 7$ \\
\hline Number of females & $74(85)$ & I27 (65) & $56(65)$ & $257(70)$ \\
\hline Mean age \pm SD $(y)$ & $43 \pm I 3$ & $45 \pm 13$ & $40 \pm I 5$ & $43 \pm I 4$ \\
\hline Single DVT & I8 (2I) & I33 (68) & $53(62)$ & $204(55)$ \\
\hline Recurrent DVT & $6(7)$ & $44(22)$ & $3 I(36)$ & $8 \mathrm{I}(22)$ \\
\hline Silent DVT & N.A. & I9 (IO) & $2(2)$ & $2 \mathrm{I}(6)$ \\
\hline History of PE & $5(6)$ & $3 I$ (I6) & I3 (I5) & 49 (I3) \\
\hline $\begin{array}{r}\text { Median time between DVT } \\
\text { and treatment }(\mathrm{y})\end{array}$ & N.A. & $7(\mathrm{I}-48)$ & $5(\mathrm{I}-40)$ & $6(\mathrm{I}-48)$ \\
\hline
\end{tabular}

Note: Data are $n$ (\% of subgroup) unless otherwise indicated. IVCS= iliac vein compression syndrome, $P$-PTS = post-thrombotic syndrome with percutaneous treatment, $H$-PTS= postthrombotic syndrome with hybrid treatment $P-P T S=$ percutaneous post thrombotic syndrome, $H-P T S=$ hybrid post thrombotic syndrome

* indicates percentage of total number of legs.

$Y=$ years; $D V T=$ deep venous thrombosis; N.A.= not applicable; $P E=$ pulmonary embolism

Table I6. CEAP classification and reflux

\begin{tabular}{|c|c|c|c|c|}
\hline & $\begin{array}{l}\text { IVCS } \\
\mathrm{N}=87(24)\end{array}$ & $\begin{array}{l}\mathrm{P}-\mathrm{PTS} \\
\mathrm{N}=\mathrm{I} 96(53)\end{array}$ & $\begin{array}{l}\mathrm{H}-\mathrm{PTS} \\
\mathrm{N}=86(23)\end{array}$ & $\begin{array}{l}\text { Total } \\
N=369\end{array}$ \\
\hline $\mathrm{N}$ of patients with CEAP & $84(97)$ & I84 (94) & $83(97)$ & 35I (95.) \\
\hline C-class o & $5(6)$ & I6 (9) & $7(8)$ & $28(8)$ \\
\hline C-class I & IO (I2) & I6 (9) & 9 (II) & $35(\mathrm{IO})$ \\
\hline C-class 2 & $20(24)$ & $22(\mathrm{I} 2)$ & IO (I2) & $52(\mathrm{I} 4)$ \\
\hline C-class 3 & $36(43)$ & $60(33)$ & $3 \mathrm{I}(37)$ & I27 (34) \\
\hline C-class $4 \mathrm{a}$ & $6(7)$ & $33(\mathrm{I} 8)$ & I5 (I8) & 54 (I5) \\
\hline C-class $4 \mathrm{~b}$ & $2(2)$ & $8(4)$ & $4(5)$ & I4 (4) \\
\hline C-class 5 & $2(2)$ & $\mathbf{I} 2(7)$ & $3(4)$ & I7 (5) \\
\hline C-class 6 & $4(5)$ & I5 (8) & $4(5)$ & $23(6)$ \\
\hline Superficial venous reflux & $45(52)$ & $72(37)$ & I2 (I4) & $129(35)$ \\
\hline Deep venous reflux & I2 (I4) & $53(27)$ & I5 (I7) & $80(22)$ \\
\hline Perforator vein reflux & $3 I(36)$ & I7 (9) & I2 (I4) & $60(4)$ \\
\hline
\end{tabular}

Note: Data are $n(\%)$ unless otherwise indicated. IVCS = iliac vein compression syndrome, $P$ $P-P T S=$ post-thrombotic syndrome with percutaneous treatment, $H-P T S=$ post-thrombotic syndrome with hybrid treatment PTS= percutaneous post thrombotic syndrome, H-PTS= hybrid post thrombotic syndrome 


\section{Intervention}

In $284(77 \%)$ patients, a left sided intervention was performed, $29(8 \%)$ had a right sided and 52 (I4\%) had bilateral intervention. An isolated IVC treatment was performed in four (I\%) patients. Thus, a total of 425 lower extremities were treated. Unilateral disease was treated with a median number of two (range I-5) stents per patient and a median of five (range 2-8) for bilateral cases. In the H-PTS group 80 (93\%) patients received stenting in combination with endophlebectomy and an AVF. Seven of those 80 patients had a bilateral endophlebectomy and AVF. Four patients were stented with an endophlebectomy without an AVF and two patients received stenting with an AVF but without an endophlebectomy. A bovine patch was used when closing the venotomy in $42(49 \%)$ patients.

\section{Patency rates and reinterventions}

Primary patency rates at the 60 month follow-up were $90 \%$ and $64 \%$ for the IVCS and P-PTS groups, respectively. Assisted primary patency rates were $100 \%$ and $8 \mathrm{r} \%$, and secondary patency rates $100 \%$ and $89 \%$, respectively. The H-PTS group had a shorter follow-up of 36 months showing a primary, assisted primary, and secondary patency rate of $37 \%, 62 \%$, and $72 \%$, respectively. Patency rates are shown in Figure 22.
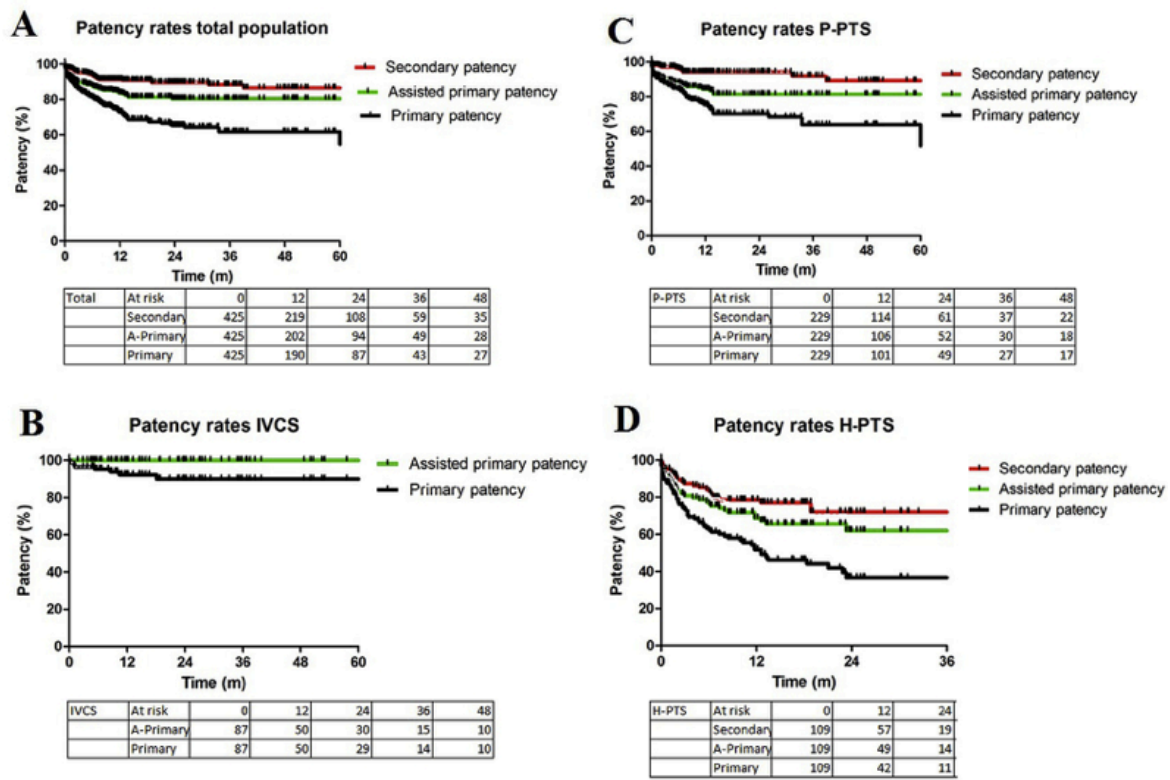

Figure 22. Cumulative patency rates of stented limbs in the total population, and of the iliac vein compression syndrome (IVCS), percutaneous post-thrombotic syndrome (P-PTS) and post-thrombotic syndrome with hybrid treatment (H-PTS; definitions explained in text) subgroups. The number at risk at each interval is given below the graph. All SEM are $<10 \%$. (A) Patency rates of the total population. (B) Patency rates of the IVCS subpopulation. (C) Patency rates of the P-PTS subpopulation. (D) Patency rates of the H-PTS subpopulation. 
In the IVCS group there were no thrombotic stent occlusions. Primary patency loss was due to reinterventions of persistent stenoses. In the P-PTS population 36 (I8\%) patients had a thrombotic stent occlusion. These thrombotic stent occlusions were treated by thrombolysis with secondary stenting in I9 patients, of whom two received thrombolysis twice and two required a thrombectomy. The remaining 15 thrombotic stent occlusions did not induce severe complaints interfering with daily activities and therefore did not receive an additional intervention. In the H-PTS group $33(38 \%)$ patients suffered a thrombotic stent occlusion, of whom IO (I2\%) received thrombolysis. Sixteen cases (8\%) in the P-PTS group and Io cases (I2\%) in the H-PTS group required a secondary open surgical procedure (revision or additional endophlebectomy and/or AVF) to optimise inflow into the stents. Restenting for new or previously unrecognised lesions, residual compression, or stent related issues was performed in seven (8\%), 49 (25\%), and 46 (53\%) cases in the IVCS, P-PTS, and H-PTS groups, respectively (Table 17 ).

Table I7. Number of reinterventions per patient

\begin{tabular}{|c|c|c|c|c|}
\hline & $\begin{array}{l}\text { IVCS } \\
\mathrm{N}=87(24)\end{array}$ & $\begin{array}{l}\mathrm{P}-\mathrm{PTS} \\
\mathrm{N}=\mathrm{I} 96(53)\end{array}$ & $\begin{array}{l}\mathrm{H}-\mathrm{PTS} \\
\mathrm{N}=86(23)\end{array}$ & $\begin{array}{l}\text { Total } \\
\mathrm{N}=369\end{array}$ \\
\hline None & $80(92)$ & I44（74） & $35(4 \mathrm{I})$ & $259(70)$ \\
\hline$>$ I reintervention & $\mathrm{o}(\mathrm{o})$ & 22 (II) & $19(22)$ & $4 \mathrm{I}(\mathrm{II})$ \\
\hline Only PTA & $\mathrm{o}(\mathrm{O})$ & II (6) & IO (I2) & $2 I(6)$ \\
\hline CD-Thrombolysis & $\mathrm{o}(\mathrm{o})$ & 2I (II) & IO (I2) & $3 \mathrm{I}(8)$ \\
\hline Thrombectomy & o (o) & $2(\mathrm{I})$ & $3(4)$ & $5(\mathrm{I})$ \\
\hline Restenting & $7(8)$ & 38 (I9) & $42(49)$ & $87(24)$ \\
\hline Restenting + thrombectomy & $\mathrm{o}(\mathrm{o})$ & $3(2)$ & $2(2)$ & $5(\mathrm{I})$ \\
\hline Restenting + AVF & $\mathrm{o}(\mathrm{o})$ & $\mathrm{I}(\mathrm{I})$ & I (I) & $2(\mathrm{I})$ \\
\hline $\begin{array}{r}\text { Restenting + endophlebectomy }+ \text { AVF } \\
\text { AVF + endophlebectomy }+\end{array}$ & o (o) & $7(4)$ & $\mathrm{o}(\mathrm{o})$ & $7(2)$ \\
\hline restenting after hybrid procedure & $\mathrm{o}(\mathrm{O})$ & $\mathrm{o}(\mathrm{o})$ & I (I) & $\mathrm{I}(<\mathrm{I})$ \\
\hline Endophlebectomy & $\mathrm{o}(\mathrm{o})$ & $\mathrm{o}(\mathrm{o})$ & I (I) & $\mathrm{I}(<\mathrm{I})$ \\
\hline Creating AVF & $\mathrm{o}(\mathrm{o})$ & $4(2)$ & I (I) & $5(\mathrm{I})$ \\
\hline $\mathrm{AVF}+$ thrombectomy & o (o) & $2(\mathrm{I})$ & $\mathrm{o}(\mathrm{o})$ & $2(\mathrm{I})$ \\
\hline $\mathrm{AVF}+$ endoflebectomy + bypass & $\mathrm{o}(\mathrm{o})$ & $2(\mathrm{I})$ & o (o) & $2(\mathrm{I})$ \\
\hline Revision AVF + Thrombectomy & N.A. & N.A. & $6(7)$ & $6(2)$ \\
\hline Excision PTFE AVF & N.A. & $2(\mathrm{I})$ & $4(4)$ & $6(2)$ \\
\hline Transposition & $\mathrm{o}(\mathrm{o})$ & $2(\mathrm{I})$ & $2(2)$ & $4(\mathrm{I})$ \\
\hline Bypass & $\mathrm{o}(\mathrm{o})$ & $\mathrm{o}(\mathrm{o})$ & $\mathrm{I}(\mathrm{I})$ & $\mathrm{I}(<\mathrm{I})$ \\
\hline
\end{tabular}

Note. Data are $n$ (\% of subgroup) unless otherwise indicated. IVCS = iliac vein compression syndrome; $P$-PTS = post-thrombotic syndrome with percutaneous treatment; H-PTS = post thrombotic syndrome with hybrid treatment; $P T A=$ percutaneous transluminal angioplasty; $C D=$ catheter directed; $A V F=$ arteriovenous fistula; $N A=$ not applicable; $P T F E=$ polytetrafluoroethylene . 
All in all, the majority of patients who were treated in a hybrid fashion needed at least one reintervention (59\%) versus $27 \%$ in the P-PTS and $8 \%$ in the IVCS groups. In addition, they needed the first reinterventions earlier after their primary intervention compared with the IVCS group. The median number of days between the first and second intervention in the IVCS group was I43 days (range 20-300 days) versus I4O days (range I7-355 days) in the P-PTS group and 48 days (range II-II5 days) for the H-PTS group.

\section{Other complications}

The most frequent complications were thrombotic stent occlusion and restenosis (Table I8). Contralateral DVT was rare and only seen in two patients (I\%). Mortality was zero and there were no instances of clinical pulmonary embolism.

Table I8. Complications per patient

\begin{tabular}{|c|c|c|c|c|}
\hline & $\begin{array}{l}\text { IVCS } \\
\mathrm{N}=87(24)\end{array}$ & $\begin{array}{l}\mathrm{P}-\mathrm{PTS} \\
\mathrm{N}=\mathrm{I} 96(53)\end{array}$ & $\begin{array}{l}\mathrm{H}-\mathrm{PTS} \\
\mathrm{N}=86(23)\end{array}$ & $\begin{array}{l}\text { Total } \\
\mathrm{N}=369\end{array}$ \\
\hline None & $63(73)$ & $98(50)$ & $25(29)$ & I86 (50) \\
\hline Thrombotic stent occlusion & $\mathrm{o}(\mathrm{o})$ & 36 (I8) & $33(38)$ & 69 (I9) \\
\hline Stent stenosis & $2(2)$ & $30(15)$ & $24(28)$ & 56 (I5) \\
\hline Residual stent compression & I6 (I8) & I4 (7) & $4(5)$ & $34(9)$ \\
\hline Minor bleeding & $2(2)$ & I6 (8) & I4 (I6) & $32(9)$ \\
\hline Major bleeding & $\mathrm{o}(\mathrm{o})$ & $2(\mathrm{I})$ & II (I3) & $\mathrm{I} 3(4)$ \\
\hline Aneurysma spurium & I (I) & $\mathrm{O}(0)$ & I (I) & $2(\mathrm{I})$ \\
\hline DVT distally of stents & $\mathrm{o}(\mathrm{o})$ & I (I) & $3(4)$ & $4(\mathrm{I})$ \\
\hline Contralateral DVT & $\mathrm{o}(\mathrm{o})$ & I (I) & I (I) & $2(\mathrm{I})$ \\
\hline Thrombophlebitis & $\mathrm{I}(\mathrm{I})$ & $2(\mathrm{I})$ & $\mathrm{o}(\mathrm{o})$ & $3(\mathrm{I})$ \\
\hline $\begin{array}{r}\text { Anaphylactoid reaction to contrast } \\
\text { Non-specific }\end{array}$ & $\mathrm{o}(\mathrm{o})$ & $\mathrm{o}(\mathrm{o})$ & $\mathrm{o}(\mathrm{o})$ & $\mathrm{I}(<\mathrm{I})$ \\
\hline Urinary tract infection & $\mathrm{o}(\mathrm{o})$ & $2(\mathrm{I})$ & $\mathrm{o}(\mathrm{o})$ & $2(\mathrm{I})$ \\
\hline Priapism LMWH & $\mathrm{o}(\mathrm{o})$ & I (I) & $\mathrm{o}(\mathrm{o})$ & I $(<\mathrm{I})$ \\
\hline Urinary retention & $\mathrm{o}(\mathrm{o})$ & $\mathrm{I}(\mathrm{I})$ & $\mathrm{o}(\mathrm{o})$ & $\mathrm{I}(<\mathrm{I})$ \\
\hline \multicolumn{5}{|l|}{ Stent integrity issues } \\
\hline Tapering & I (I) & II (6) & $5(6)$ & I7 (5) \\
\hline Kinking & $\mathrm{o}(0)$ & $3(2)$ & I (I) & $4(\mathrm{I})$ \\
\hline Fracture & $\mathrm{o}(\mathrm{o})$ & I (I) & $\mathrm{o}(\mathrm{o})$ & $\mathrm{I}(<\mathrm{I})$ \\
\hline Angulation & $\mathrm{o}(\mathrm{o})$ & $6(3)$ & $3(4)$ & $9(2)$ \\
\hline Implosion & o (o) & $4(2)$ & $\mathrm{I}(\mathrm{I})$ & $5(\mathrm{I})$ \\
\hline Open-surgery related & & & & \\
\hline Wound infection & N.A. & $5 *(3)$ & $23(27)$ & $28(8)$ \\
\hline Seroma & N.A. & $\mathrm{I}^{*}(\mathrm{I})$ & $5(6)$ & $6(2)$ \\
\hline lymphorrhea & N.A. & $\mathrm{I}^{*}(\mathrm{I})$ & $28(33)$ & $29(8)$ \\
\hline Wound dehiscention & N.A. & $\mathrm{o}(\mathrm{o})$ & IO (I2) & IO (3) \\
\hline
\end{tabular}

Note. Data are $n$ (\% of subgroup) unless otherwise indicated. IVCS = iliac vein compression syndrome; $P$-PTS = post-thrombotic syndrome with percutaneous treatment; $H$-PTS = postthrombotic syndrome with hybrid treatment; $D V T=$ deep venous thrombosis; $L M W H=l o w$ molecular weight heparin; $N A=$ not applicable. ${ }^{a}$ Related to secondary open surgical procedures. 
However, minor and major bleeding, necessitating supplementary treatment or reintervention, was seen after treatment of $32(9 \%)$ and $13(4 \%)$ patients, respectively, and occurred mainly in the H-PTS group. Of special concern in the hybrid subpopulation was the high incidence of wound related complications, such as wound infections in 23 (27\%), lymphorrhoea in 28 (33\%), and wound dehiscence in Io (I2\%) patients.

\section{Clinical scores}

Significant improvement in VCSS was seen in all groups during the first 24 months of follow-up (Figure 23). A significant improvement of Villalta scale was seen for the post-thrombotic patients. A clinically positive treatment effect was seen in $63 \%, 72 \%$, and $73 \%$ of patients in the IVCS, P-PTS, and H-PTS groups, respectively. No response to therapy was seen in $24 \%, 23 \%$, and $22 \%$ of patients, respectively. Worsening of symptomatology was observed in $\mathrm{I} 4 \%, 5 \%$, and $6 \%$ of IVCS, P-PTS, and H-PTS patients. A separate analysis for this non-response group of patients will be performed in future research. Venous claudication was calculated in those patients where a baseline score and at least one follow-up score was available. This reduced in $26 / 29$ (90\%) patients with IVCS after a median follow-up of I7 months (range I2-26 months). In 64/78 (82\%) P-PTS patients venous claudication was absent after a median of 13 months (range IIe24 months) and in 50/60 (83\%) H-PTS patients after I6 months (range II-25 months). During follow-up, ulceration healed in $20 / 23(87 \%)$ of the patients presenting with an active ulcer at baseline. However, ulcer recurrence was seen in four (20\%) patients.
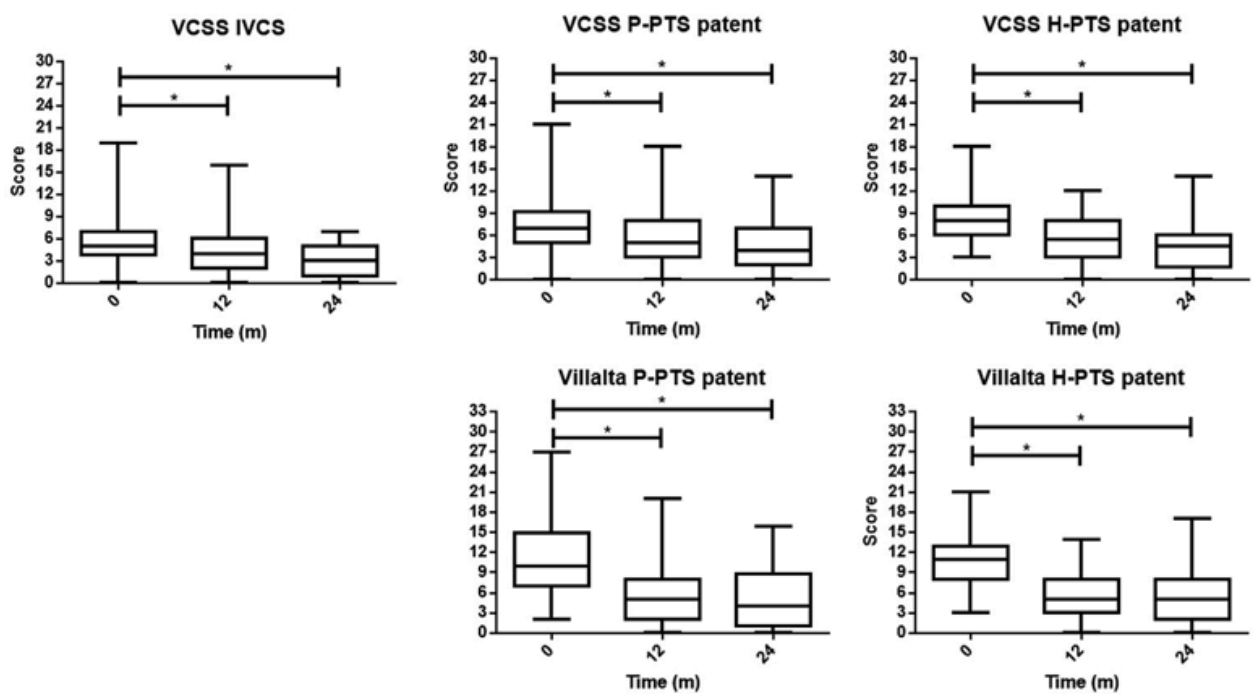

Figure 23. Venous Clinical Severity Score (VCCS) and Villalta score of the three subpopulations given as clinical scores over 24 months. Note. IVCS = iliac vein compression syndrome; P-PTS = percutaneous post-thrombotic syndrome; $H$-PTS = post-thrombotic syndrome with hybrid treatment. 


\section{DISCUSSION}

In this study, the routine clinical use of stenting in 369 patients with PTS and IVCS is described.

Patency rates in patients with IVCS were $90 \%$, I00\%, and I00\% at 60 months and were comparable with previous studies.2,3,4 The main patency related issues were allied to stent geometry and stent placement problems. Regarding this, future outcomes are expected to improve even more with the introduction of dedicated venous stents, as excellent results of a dedicated venous stent during 12 months follow-up already support this.I4

In contrast to the IVCS group, the post-thrombotic subgroups did show stent occlusions. However, secondary patency rates in the P-PTS group were shown to be $89 \%$ and comparable with results described in previous reviews.2,3,4 The primary patency of $64 \%$ in P-PTS patients was most likely lower as a result of inadequate inflow.This is exemplified by the fact that venography during reinterventions frequently showed residual post-thrombotic stenosis distal to the stents. Moreover, patency rates in H-PTS group of $37 \%, 62 \%$, and $72 \%$ at 36 months, proved that impaired flow due to prior thrombosis of the vein tracts below the CFV reduces patency outcomes.

Currently, there is no definitive test available to evaluate the adequacy of inflow prior to stenting or directly after deployment of stents. For this reason, clinical judgment must be relied upon. In general, it is believed that post-thrombotic changes of the CFV below the SFJ with affected orifices of FV and DFV provide inadequate inflow and need a hybrid procedure. Future research should focus on a scoring system to quantify the flow. Afterwards, the evaluation of a cutoff flow value to predict stent inflow and related patency might be performed. Next, decision making based on such a haemodynamic evaluation of DUS, MRV, venography, and IVUS images should be evaluated with respect to the stent patency and clinical outcome. Moreover, if treatment type can be predicted more precisely it is possible to overcome complication related issues, as seen in the H-PTS group.

Since patients in the H-PTS group were more prone to several surgery related complications, like wound infections ( $27 \%)$ and wound dehiscence ( $12 \%)$, the primary patency rate was negatively influenced. Because of the recently disobliterated CFV, this area is more prone to compression by haematomas or lymphocoeles (33\%). Moreover, deployed stents are inherently thrombogenic specifically in combination with the stent material and the exposed collagen of the disobliterated area. Furthermore, the AVF may potentially induce intimal hyperplasia causing stenosis of the distal stents or stenosis of the disobliterated area

In all, but especially in patients treated for PTS, the quality of anticoagulation might 
be an issue, as it is known that INR values can be inconsistent and influence stent patency. Therefore, a post-operative INR target range of 3e 4 (in accordance with Dutch guidelines) was chosen. Since INR levels are regulated by different specialised entities, an analysis of all INR levels was not possible. Of further note is the fact that interventions, including the surgical disobliteration, were performed on patients already anticoagulated. This has the disadvantage of increasing the rate of postoperative bleeding, though it is believed it is necessary to reduce the risk of early thrombotic stent occlusion. To prevent such an acute stent occlusion, all patients are treated with a preoperative INR level of 2.0e2.5. Oral anticoagulants were stopped 24 hours before the intervention to prevent massive haematomas.

Patients with severe post-thrombotic obstructions, needing a hybrid intervention, have a high risk of complications and reinterventions. However, the hybrid treatment may improve quality of life and pain, and significantly reduce venous claudication when successful. It may be offered to a select group of patients with marked impairment of quality of life and debilitating complaints interfering with daily activities. The hybrid procedure should be discussed with the patient in detail, explaining all possible complications, to make an adequate balanced risk/benefit analysis.

Although favourable results have been presented, there are some limitations to this research, which might cause some bias. As there are no large clinical trials to compare the H-PTS outcomes with, clinical outcomes were partly comparable with previous research, but no response to therapy was seen in $24 \%$ of IVCS and $23 \%$ of P-PTS patients, respectively.2,3,4 Besides this, worsening of complaints was shown in $14 \%$ and $5 \%$ of patients, respectively. As venous reflux was present at baseline in many patients and was not routinely assessed during follow-up, this non-response might be explained by residual reflux.

In addition, the incompleteness of clinical score data may be a bias in analyzing the treatment effect. Furthermore, especially in the cases of non-response to stenting in IVCS, an initial indication issue might be present. As symptomatic venous disease and anatomical compression of the iliac veins are both common in the Western population, in some patients the compression might not have been the reason for the symptoms.II Stenting in these patients can be seen as a type of overtreatment. As currently novalidated haemodynamic tests exist to assess the relative influence of the iliac vein compression on the lower extremity, it is impossible to differentiate between symptomatic chronic venous compression and anatomical variance in some patients. Future prospective trials should take the above mentioned issues into account to improve optimal care in patients with deep venous obstruction. 


\section{CONCLUSION}

Percutaneous stent placement to treat non-thrombotic iliac vein lesions, and postthrombotic iliofemoral obstructions is safe, effective, and showed patency rates comparable with previous research. Patients with advanced disease needing a hybrid procedure showed lower patency rates and more complications. However, when successful, the clinical outcome is favourable at mid-term follow-up and the procedure may be offered to selected patients. 


\section{REFERENCES}

I. Neglen P, Hollis KC, Olivier J, Raju S. Stenting of the venous outflow in chronic venous disease: long-term stent-related outcome, clinical, and hemodynamic result. J Vasc Surg 2007;46(5):979e9o.

2. Seager MJ, Busuttil A, Dharmarajah B, Davies AH. Editor's choice e a systematic review of endovenous stenting in chronic venous disease secondary to iliac vein obstruction. Eur J Vasc Endovasc Surg 20I6;5I(I):Iooe20.

3. Wen-da W, Yu Z, Yue-Xin C. Stenting for chronic obstructive venous disease: a current comprehensive meta-analysis and systematic review. Phlebology 2016;31:376e89.

4. Razavi MK, Jaff MR, Miller LE. Safety and effectiveness of stent placement for iliofemoral venous outflow obstruction: sys-tematic review and meta-analysis. Circ Cardiovasc Interv 2015;8(IO):e002772.

5. Wittens C, Davies AH, Baekgaard N, Broholm R, Cavezzi A, Chastanet S, et al. Editor's choice e management of chronic venous disease: clinical practice guidelines of the European Society for Vascular Surgery (ESVS). Eur JVasc Endovasc Surg 2015;49(6):678e737.

6. Kahn SR, Shbaklo H, Lamping DL, Holcroft CA, Shrier I, Miron MJ, et al. Determinants of health-related quality of life during the 2 years following deep vein thrombosis. J Thromb Haemost 2008;6(7):IIO5eI2.

7. Enden T, Haig Y, Klow NE, Slagsvold CE, Sandvik L, Ghanima W, et al. Long-term outcome after additional catheter-directed thrombolysis versus standard treatment for acute iliofemoral deep vein thrombosis (the CaVenT study): a randomised controlled trial. Lancet 2012;379(98Io):3Ie8.

8. Meissner MH, Eklof B, Smith PC, Dalsing MC, DePalma RG, Gloviczki P, et al. Secondary chronic venous disorders. J Vasc Surg 2007;46(Suppl. S):68se83s.

9. May R, Thurner J. The cause of the predominantly sinistral occurrence of thrombosis of the pelvic veins. Angiology 1957;8(5):419e27.

Io. Cockett FB, Thomas ML. The iliac compression syndrome. Br J Surg 1965;52(I0):8I6e2I.

II. Kibbe MR, Ujiki M, Goodwin AL, Eskandari M, Yao J, Matsumura J. Iliac vein compression in an asymptomatic pa-tient population. J Vasc Surg 2004;39(5):937e43.

I2. Kahn SR, Shrier I, Julian JA, Ducruet T, Arsenault L, Miron MJ, et al. Determinants and time course of the postthrombotic syndrome after acute deep venous thrombosis. Ann Intern Med 2008;I49(IO):698e707.

I3. Neglen P, Tackett Jr TP, Raju S. Venous stenting across the inguinal ligament. J Vasc Surg 2008;48(5):1255e6I.

I4. de Wolf MA, de Graaf R, Kurstjens RL, Penninx S, Jalaie H, Wittens CH. Short-term clinical experience with a dedicated venous nitinol stent: initial results with the sinusvenous stent. Eur J Vasc Endovasc Surg 2015;50:518e26.

I5. Friedrich de Wolf MA, Arnoldussen CW, Grommes J, Hsien SG, Nelemans PJ, de Haan $\mathrm{MW}$, et al. Minimally invasive treatment of chronic iliofemoral venous occlusive disease. J Vasc Surg: Venous Lymphat Disord 2013;I(2):I46e53.

I6. Vogel D, Comerota AJ, Al-Jabouri M, Assi ZI. Common femoral endovenectomy with 
iliocaval endoluminal recanalization im-proves symptoms and quality of life in patients with post-thrombotic iliofemoral obstruction. J Vasc Surg 20I2;55(I): I29e35.

I7. Puggioni A, Kistner RL, Eklof B, Lurie F. Surgical disobliteration of postthrombotic deep veinseendophlebectomyeis feasible. J Vasc Surgery: official publication, the Society for Vascular Surgery [and] International Society for Cardiovascular Surgery

I8. 2004;39(5):I048e52. North American Chapter, discussion 52.

I9. Comerota AJ, Grewal NK, Thakur S, Assi Z. Endovenectomy of the common femoral vein and intraoperative iliac vein recan-alization for chronic iliofemoral venous occlusion. J Vasc Surg 20I0;52(I):243e7.

20. Eklof B, Rutherford RB, Bergan JJ, Carpentier PH, Gloviczki P, Kistner RL, et al. Revision of the CEAP classification for chronic venous disorders: consensus statement. J Vasc Surg 2004;40(6):I248e52.

2I. de Graaf R, de Wolf M, Sailer AM, van Laanen J, Wittens C, Jalaie H. Iliocaval confluence stenting for chronic venous ob-structions. Cardiovasc Intervent Radiol 2015;38:II98e204.

22. de Wolf MA, Jalaie H, van Laanen JH, Kurstjens RL, Mensinck MJ, de Geus MJ, et al. Endophlebectomy of the common femoral vein and arteriovenous fistula creation as adjuncts to venous stenting for post-thrombotic syndrome. Br J Surg 20I7;IO4: 7I8e25.

23. Raju S, Neglen P, Doolittle J, Meydrech EF. Axillary vein transfer in trabeculated postthrombotic veins. J Vasc Surgery: official publication, the Society for Vascular Surgery [and] International Society for Cardiovascular Surgery 1999;29(6):I050e62. North American Chapter, discussion 62e64.

24. Norman GR, Sloan JA, Wyrwich KW. The truly remarkable uni-versality of half a standard deviation: confirmation through another look. Expert Rev Pharmacoecon Outcomes Res 2004;4(5):58Ie5. 



\section{R.H.W. Strijkers ${ }^{1}$ \\ M.A.F. de Wolf ${ }^{1}$ \\ C.W.K.P. Arnoldussen ${ }^{2,3}$ \\ M.J.M. Timbergen ${ }^{3}$ \\ R. de Graaf ${ }^{2}$ \\ A.J. Ten Cate-Hoek ${ }^{4}$ \\ C.H.A. Wittens ${ }^{1,5}$}

I Department of Vascular Surgery and Cardiovascular Research Institute Maastricht, Maastricht University Medical Centre, 6202 AZ, Maastricht, The Netherlands

2 Department of Radiology, Maastricht University Medical Centre, 6202 AZ, Maastricht, The Netherlands

3 Department of Radiology, Viecuri Hospital, 5912 BL, Venlo, The Netherlands

4 Laboratory for Clinical Thrombosis and Haemostasis and Laboratory of Haematology,

Department of Internal Medicine and Cardiovascular Research Institute Maastricht, 6202 AZ, Maastricht, The Netherlands

5 Department of Vascular Surgery, University Hospital RWTH Aachen, 52074, Aachen, Germany

Published in the European Journal of Vascular and Endovascular Surgery

Eur J Vasc Endovasc Surg (2015) 49, $440 e 447$ 


\section{ABSTRACT}

\section{Introduction}

Stent placement in the venous system is an increasingly used treatment modality in chronic venous obstruction and as additional treatment after thrombolytic therapy in iliofemoral DVT. We report on our experience in treating in-stent thrombosis with Ultrasound Accelerated Catheter Directed Thrombolysis (UACDT).

\section{Methods}

Retrospective analysis of patients treated for venous stent occlusion, after Percutaneous Transluminal Angioplasty (PTA) and stent placement for either chronic venous occlusive disease or persistent vein compression in patients with acute DVT. Duration of occlusion and suspected clot age were assessed using patient complaints and typical findings on duplex ultrasonography (DUS). DUS and venography were used to assess patency and to determine the cause of reocclusion. Acute treatment of occlusion consisted of UACDT. Additional procedures included: PTA, stent placement, and creation of an arteriovenous-fistula.

\section{Results}

We identified I8 patients, who were treated for occluded stent tracts with UACDT between January 2009 and July 20I4. Median age was 43 years, and 67\% were male. Indications for initial stenting were; treatment of chronic venous obstructive disease in I2 patients and treatment of underlying obstruction after initial thrombolysis in acute DVT in 6 patients. Technical success was achieved in 6I\% (II/I8). Primary patency at last follow-up was $73 \%$ (8/II), during median follow-up of I4 months (0-4I). Additional treatments after successful lysis were; restenting in 7 patients, and creation of an arteriovenous-fistula in 6 patients

\section{Conclusion}

Treatment with ultrasound-accelerated catheter directed thrombolysis of occluded stent tracts is feasible and effective.. Recanalization of the stent tract can be achieved in most cases. Additional interventions were frequently used after successful UACDT treatment. Most stent occlusions were caused by stent related problems. 


\section{INTRODUCTION}

During the last two decades endovenous recanalization, by percutaneous transluminal angioplasty (PTA) and stenting, in chronic deep venous occlusive disease has quickly gained in popularity. Many authors have shown excellent clinical success rates. I-3 Because of this, and as stenting seems to be the only treatment aimed at resolving the underlying pathology in post-thrombotic syndrome (PTS) and iliac vein compression syndromes, it has been implemented in many expert-venous centers worldwide as a first-line treatment. Complication rates have been shown to be mild, with generally no clinically relevant pulmonary embolisms and no procedure related mortality. 3-5 The most important complication is acute reocclusion of the stented venous segments, with or without thrombus propagation into proximal or distal vein tracts. This occurs in 20$30 \%$ of cases, even when adequate anticoagulation regimens are used.4 In cases of stent reocclusion return of signs and symptoms of venous disease can be expected, and in some cases even worsening of complaints compared to the prerecanalization state. An important step in preventing reocclusion is to guarantee adequate in- and outflow for the stents. Inflow problems can arise when veins caudal to the stented segments are also involved in the post-thrombotic process, most notably the femoral and deep femoral vein, as flow volume in those cases might not be sufficient to maintain patency. Outflow problems arise when venous tracts cephalad to the stents are (partly) occluded due to endoluminal pathology or external compression. Furthermore in-stent problems, for example residual compression by overlying arteries or stenosis, kinking or fractures are also thought to lead to higher loss of patency. Prevention by extending stents cephalad or caudal into a healthy vein tract and using stents that withstand the pressure from overlying structures such as arteries and do not kink are therefore very important.6 Adequate antithrombotic therapy is also important in preventing rethrombosis.

In cases where reocclusion does occur removal of as much of the thrombus load as quickly as possible is generally thought necessary.7 One possible option is to remove the thrombus, by means of pharmacomechanical thrombolysis. Ultrasound accelerated catheter directed thrombolysis (UACDT) is used for acute occlusions in the arterial system, DVT and pulmonary embolism. 8-II Literature shows good safety and feasibility for UACDT for these indications. Possible advantages of UACDT over the use of a normal thrombolysis catheter are: shortened treatment duration and less thrombolytics used reducing the risk of (major) bleeding.I2 With adequate patient selection, the chance of gaining technical success is around $90 \%$ in reported literature associated with minimal bleeding risk.13

We report on our experience of treating in-stent thrombosis with UACDT in patients referred to our tertiary center. Furthermore we describe the pitfalls that we have encountered in these cases and provide recommendations how to follow-up on patients after venous stenting. 


\section{METHODS}

\section{Population}

From October 2009 till July 2014 all patients treated for venous stent occlusion by UACDT were eligible for retrospective analysis. All patients were evaluated for bleeding risk. Indication for primary stent placement was either chronic venous occlusive disease or persistent vein compression in patients with acute iliofemoral DVT during thrombolytic therapy. Time between stent placement and occlusion was assessed and divided into two groups (within 6 months after stent placement, and longer than 6 months after stent placement). Occlusion side was noted and if available thrombophilia status was reported. No additional testing for thrombophilia factors was performed. Duration of the occlusion and suspected clot age were assessed using patient complaints and findings on duplex ultrasonography (DUS).I4 Patient complaints were assessed and used as the criterion to categorize patients into two groups; 2I days or shorter interval of complaints and complaints for over 2I days. The last patent duplex scan was taken as a reference value for assessment of clot age. Stent occlusion was diagnosed using DUS with normal B-mode settings, power-flow, e-flow, conventional color and pulse wave Doppler to assess flow in the stent tract. We used at least one of the available modalities or combinations. The venous tract was assessed in both transverse and longitudinal planes. In order to visualize flow in the stented iliocaval tract a number of flow augmenting maneuvers were performed such as inspiration and expiration, dorsiflexion of the foot, and gluteal muscle contraction. Before recanalization and catheter placement, venography was routinely performed, to confirm the diagnosis of stent occlusion. Dutch law allows for retrospective analysis of patient data without specific approval of an ethical committee.

\section{Intervention}

The interventional radiologist placed the UACDT catheter under venographic control. The EKOS ${ }^{\circledast}$ Endowave $^{\mathrm{TM}}$ Peripheral Lysis System (BTG International Ltd, L) consists of a multilumen infusion catheter with removable, coaxial Ultrasound (US) cores and a control unit that simultaneously delivers high-frequency $(2.2 \mathrm{MHz})$, low-energy $(0.45$ W) US energy and thrombolytic drug into the thrombus. All patients received UACDT with the EKOS Endowave system. Urokinase (Medacinase ${ }^{\circledR}$ Lamepro the Netherlands) was in all cases used as the thrombolytic agent. Urokinase was administered with Ioo ooo units/hour after a single bolus of 250 ooo units at the start of treatment. In cases of bilateral occlusion, two catheters were inserted and the drug dosage was evenly divided over the two catheters, each with their own EKOS machine. During thrombolysis fibrinogen levels, Hemoglobin levels (Hb), activated partial thromboplastin time(APTT), prothrombin time standardized to international normalized ratio (INR), thrombocytes and D-dimer levels were routinely monitored. During active thrombolysis, anticoagulant treatment was substituted by intravenous unfractionated heparin guided by APTT (between 40-60 seconds or I.2-I.7 times the reference value of 34 seconds). At the same 
time patients were fitted with intermittent pneumatic compression sleeves. Inferior vena cava filters are not used routinely in our hospital. None of our patients received a caval filter. After thrombolysis, patients either resumed or started oral anticoagulation for at least 6 months or, if indicated lifelong (recurrent DVT). Adequate anticoagulation was achieved with Coumadin with an International normalized ratio (INR) between 2.5 and 3.5 according to the standards of the Dutch federation of thrombosis services (FNT) or Rivaroxaban 2omg once daily. The choice of anticoagulant agent was based on patient preference. Compressive stockings were routinely offered to patients and worn based on preference of the patient. Mobilization was encouraged as much as possible.

\section{Assessment of recanalization}

Phlebographic control was performed on a daily basis to monitor thrombolysis progression and to evaluate obstructions in the venous outflow tract. Duration of thrombolysis was determined by assessment of phlebographic imaging and the point where $>90 \%$ lysis of the clot was achieved. 5 Thrombolysis was continued in a number of cases, because of bridging towards additional treatment. We tried to determine the cause of the stent thrombosis by means of phlebography from multiple angles. In some cases cone-beam CT was used to create a $3 \mathrm{D}$ reconstruction of the stent tract. If the reason for thrombosis of the tract was identified, adequate measures were taken to resolve the problem and prevent future rethrombosis. Objective identification of the underlying cause of stent thrombosis was only possible in patients with successful thrombolysis.

\section{Additional procedures}

After successful UACDT procedures, patients received additional interventions if indicated. Additional procedures were performed as soon as possible after successful thrombolysis. Additional procedures such as, percutaneous transluminal angioplasty (PTA) with or without restenting were performed by the interventional radiologist. Surgical procedures to increase inflow such as construction of an AV-fistula between the common femoral vein and artery or endophlebectomy were performed by the vascular surgeon. We used self-expandable stents for stenting for underlying obstructions (sinus-XL ${ }^{\circledR}$ and sinus-Venous ${ }^{\circledR}$ from Optimed and Zilver vena ${ }^{\mathrm{TM}}$ from Cook $^{\circledR}$ ). Various diameters and lengths stents were used ranging from $\mathrm{I} 2$ to $26 \mathrm{~mm}$ in diameter and 60I50 $\mathrm{mm}$ in length. Stent sizes were determined by multiplanar venography.

\section{Complications}

Complications following thrombolysis and follow-up were categorized into groups. These included bleeding complications, pulmonary embolism (PE), recurrent thrombosis, infections and others. Bleeding was classified as major, if it was overt with a fall in hemoglobin of $\geq 2 \mathrm{~g} / \mathrm{dl}$, or when hemorrhage led to transfusion of 2 units of packed red blood cells (RBCs) or whole blood. Bleeding situated in a critical organ (intracranial, retroperitoneal or pericardial) or, if it contributed to death, was also 
defined as a major bleeding. Bleeding was classified as minor, if it was situated near the catheter-insertion site.

\section{Follow-up}

Standardized follow-up was performed. Patients returned at 2 weeks, 6 weeks, 3 months, 6 months, I year, and yearly thereafter. If the patient experienced complaints, follow-up was performed at the earliest convenience, usually the same or the next day. During follow-up patency of the stent tract was assessed using DUS. A dedicated sonographer performed DUS. Recurrence, retreatment, PE, and other complications were recorded. We standardized routine follow-up after stenting in this manner: the day after stenting, patients were checked with DUS to ensure patency of the tract prior to discharge. At 2 weeks, 6 weeks, 3 months and 6 months after stenting the patients were seen with clinical follow-up and routine DUS examination. The complete stented tract was visualized in every patient. Apparent thrombosis and/or lack of flow in the stented tract were used to determine patency.

\section{RESULTS}

\section{Patients}

A total of 19 legs in 18 patients were treated with UACDT for venous stent thrombosis. The majority of patients were male. The average age of the group was 43 years at time of thrombolysis. In $33 \%$ of cases the initial indication for stent placement was to treat an underlying stenosis after acute iliofemoral DVT treatment with UACDT. The remaining $67 \%$ received PTA and stenting as a treatment for chronic deep venous obstruction and subsequent complaints. Most stents were placed in the left iliac tract (67\%). We noticed that most stent occlusions occurred within 6 months after initial placement of the stents ( $83 \%$ of patients). In $72 \%(n=13)$ of patients we were able to assess the duration of complaints. In the other cases it was not possible to make an indication of duration of complaints, either because of vague complaints or absence of complaints. Eleven patients were assessed as having acute thrombosis (less than 2I days according to the reporting standards in venous disease). Patient characteristics are summarized in Table I9.

Before the UACDT to treat the in-stent rethrombosis, patients had received a median of 3 (I-I3) stents in I-3 stenting sessions. This was done on the left side in I3, on the right side in I and bilaterally in 3 cases; one patient only had stents placed in the inferior caval vein. In all patients Nitinol self-expandable stents were used (sinus XL, sinus repovisual, sinus Venous), in two cases these were combined with Wallstent placement and in one case with balloon-expandable stents (Andramed). 
Table I9 shows the baseline characteristics of the patients.

\begin{tabular}{|c|c|}
\hline \multicolumn{2}{|l|}{ Patiënt characteristics $(\mathrm{N}=\mathrm{I} 8)$} \\
\hline Gender (male) & $67 \%(\mathrm{n}=\mathrm{I} 2)$ \\
\hline Age (in years) mean \pm SD & $43 \pm 15 y$ \\
\hline Range & $15 y-75 y$ \\
\hline \multicolumn{2}{|l|}{ DVT history } \\
\hline First DVT & $56 \%(\mathrm{n}=\mathrm{IO})$ \\
\hline Recurrent DVT & $44 \%(n=8)$ \\
\hline \multicolumn{2}{|l|}{ Primary stent indication } \\
\hline Acute iliofemoral DVT & $33 \%(n=6)$ \\
\hline Chronic venous obstruction & $67 \%(\mathrm{n}=\mathrm{I} 2)$ \\
\hline \multicolumn{2}{|l|}{ Original location stents } \\
\hline Left iliac tract & $73 \%(n=13)$ \\
\hline Right iliac tract & $5 \%(\mathrm{n}=\mathrm{I})$ \\
\hline Inferior vena cava & $5 \%(\mathrm{n}=\mathrm{I})$ \\
\hline Inferior vena cava + left and right iliac tract & $\mathrm{I} 7 \%(\mathrm{n}=3)$ \\
\hline \multicolumn{2}{|c|}{ Time between stent placement and stent occlusion } \\
\hline$<6$ months & $83 \%(\mathrm{n}=\mathrm{I} 5)$ \\
\hline$\geq 6$ months & $17 \%(n=3)$ \\
\hline \multicolumn{2}{|l|}{ Occlusion side } \\
\hline Left iliac tract & $67 \%(n=12)$ \\
\hline Right iliac tract & $\mathrm{II} \%(\mathrm{n}=2)$ \\
\hline Inferior vena cava & $22 \%(\mathrm{n}=4)$ \\
\hline \multicolumn{2}{|l|}{ Thrombophilia* (7 patients tested) } \\
\hline Positive & $28 \%(\mathrm{n}=5)$ \\
\hline Negative & $\mathrm{II} \%(\mathrm{n}=2)$ \\
\hline Not tested & $6 \mathrm{I} \%(\mathrm{n}=\mathrm{II})$ \\
\hline \multicolumn{2}{|l|}{ Estimated clot age (days) } \\
\hline$\leq 2 \mathrm{I}$ days & $6 \mathrm{I} \%(\mathrm{n}=\mathrm{II})$ \\
\hline$>2$ I days & $\mathrm{I} 7 \%(\mathrm{n}=3)$ \\
\hline Unclear & $22 \%(n=4)$ \\
\hline \multicolumn{2}{|l|}{ Days until last patent duplex } \\
\hline$\leq 2 \mathrm{I}$ days & $44 \%(n=8)$ \\
\hline >2I days & $56 \%(\mathrm{n}=\mathrm{IO})$ \\
\hline
\end{tabular}

" Encountered thrombophilia: Factor V Leiden, Anti-Thrombin deficiency, protein C deficiency, and antiphospholipid syndrome.

\section{Treatment results and additional procedures}

All patients underwent UACDT with the EKOS catheter. Catheter placement was successful in all cases. In II of I8 patients patency was successfully regained. This resulted in a $61 \%$ technical success rate for this procedure. All patients with failed thrombolysis had an unknown or estimated clot age of over 2I days and last patent duplex more than 2I days ago. Median lysis time of successfully lysed cases was I9 hours 
(range: II-IOI). In five cases we performed additional stenting and created an AV-fistula to treat an underlying cause such as stenotic lesions not treated previously. Figures 24 and 25 show pre- and post-thrombolysis results. Furthermore we encountered stent related occlusions and insufficient inflow in the stent tract. In two cases we performed additional stenting and in one patient we secured inflow of the stent tract with the creation of an AV-fistula. In total 8/II (73\%) patients needed ancillary interventions after successful thrombolysis. In all cases of UACDT we identified the underlying causes of rethrombosis. These were; suboptimal positioning, failure due to stent characteristics (kinking of stents and stent fracture), insufficient inflow or inadequate anticoagulation. Figure 26 shows an example of stent fracture in the venous system. Most occlusions we encountered were related to stent failure and suboptimal positioning. Table 20 shows the treatment results. Table 2I shows the time between last patent duplex and occlusion, suspected clot age, and suspected reason for reocclusion.

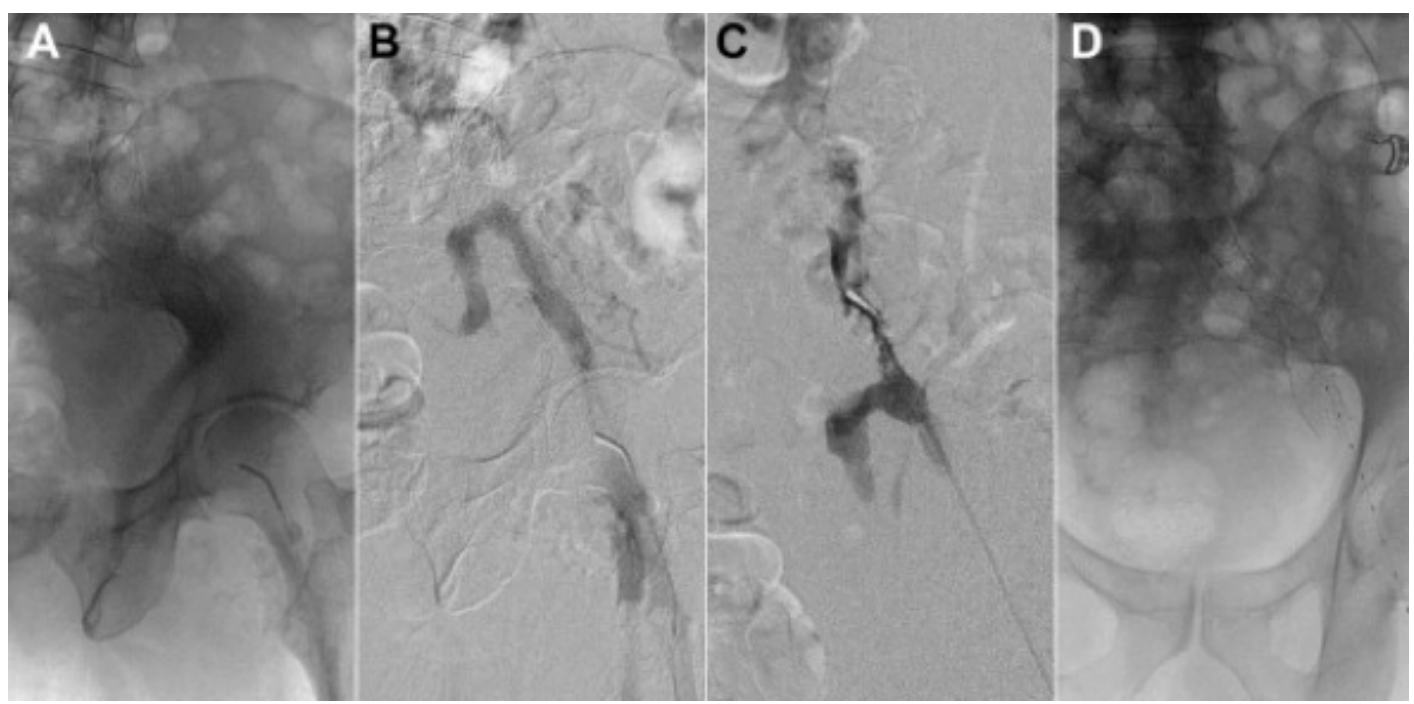

Figure 24. (A) In situ sinus venous stent in the left common iliac vein. (B) Digital subtraction venography with the catheter in the common femoral vein shows contrast filling of the external and internal iliac veins. There is no filling of the (occluded) stent in the common iliac vein. (C) Recanalization of the stent with outflow of contrast to the inferior vena cava. (D) Placement of the EKOS Endowave Peripheral Lysis System (BTG International Ltd, London, UK) thrombolysis catheter through the occluded stent. 


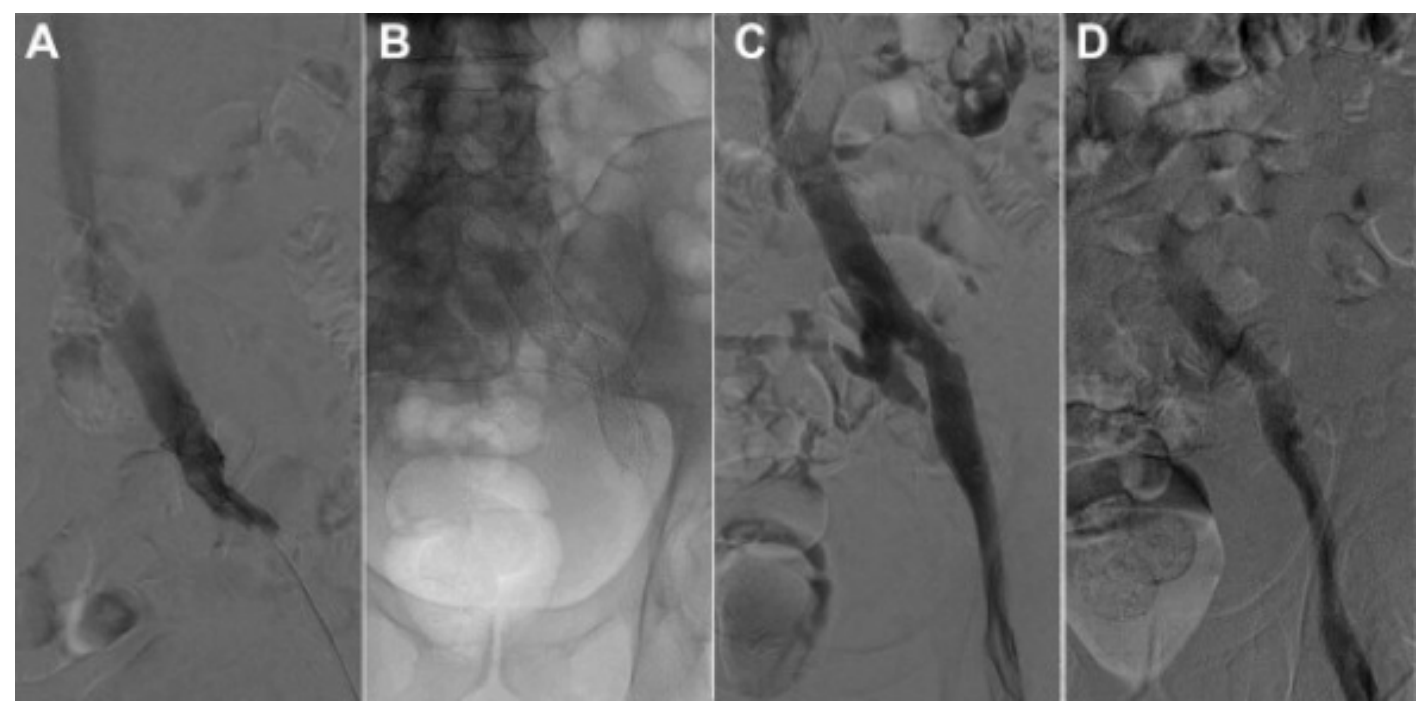

Figure 25. (A) Control venography after extended thrombolysis and balloon angioplasty shows an open lumen with outflow to the inferior vena cava (B) Extension of the stented deep vein tract to the inferior ven a cava and external iliac vein to cover the entire deep vein obstruction $(C)$ Control venography after stenting and balloon angioplasty shows improved (out) flow through the iliac veins with persistent filling of presacral collaterals. (D) Final control venography after additional balloon angioplasty shows adequate flow from the groin to the inferior vena cava without filling of collaterals.

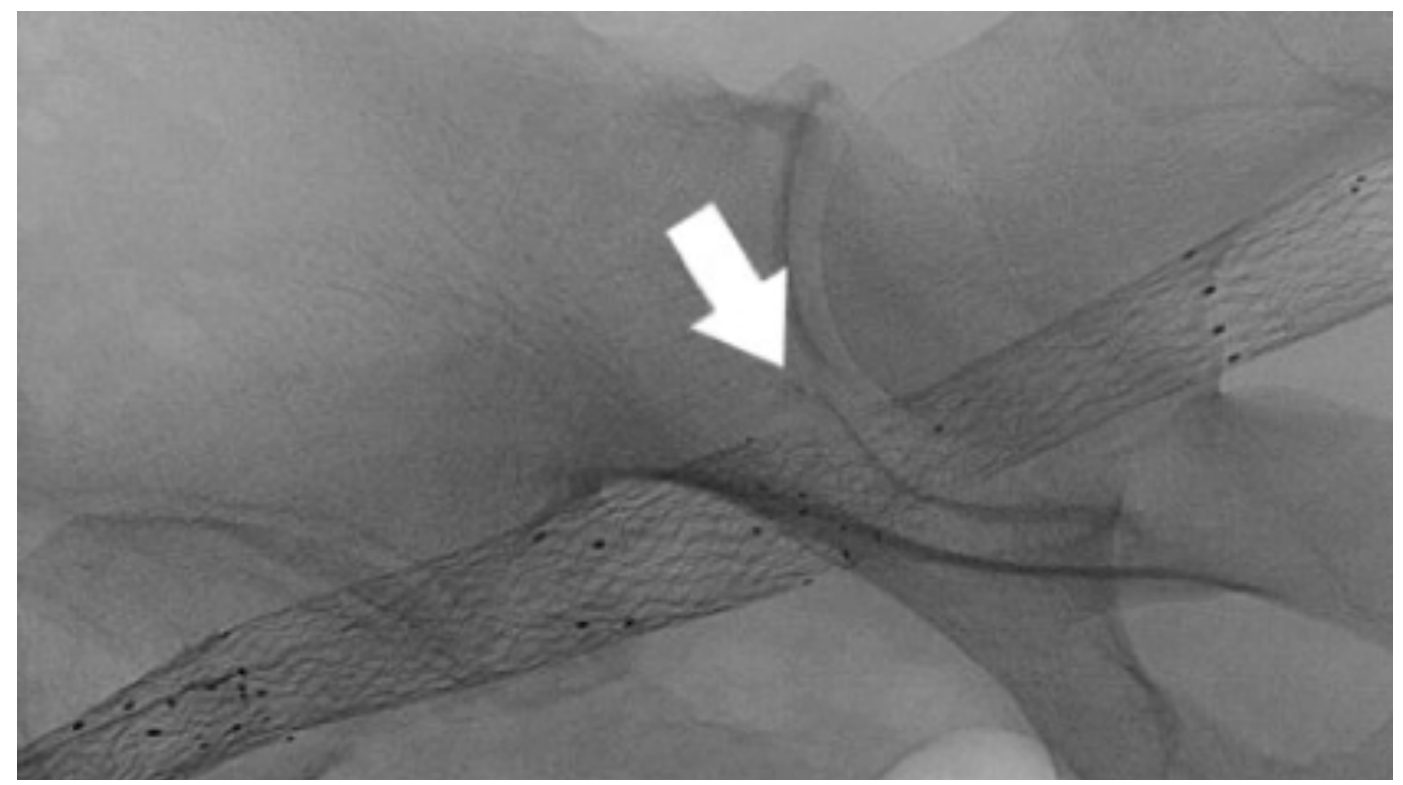

Figure 26. Fractures of the rigid Sinus XL stents in the distal external iliac vein / proximal common femoral vein are seen (arrow). 
Table 20 Treatment results

\begin{tabular}{ll}
\hline UACDT procedures $(\mathrm{N}=\mathrm{I} 8)$ & \\
\hline Successful thrombolysis? & \\
\hline Successful & $6 \mathrm{I} \%(\mathrm{n}=\mathrm{II})$ \\
Not successful & $39 \%(\mathrm{n}=7)$ \\
Duration of successful thrombolysis ( $\mathrm{n}=\mathrm{II})$ & \\
\hline Median & I9 hours \\
Range & II-IOI hours \\
Restenting after successful UACDT ( $\mathrm{n}=\mathrm{II})$ & $64 \%(\mathrm{n}=7)$ \\
\hline Other additional interventions after successful UACDT (n=II) & \\
Arteriovenous fistula & $55 \%(\mathrm{n}=6)$ \\
\hline
\end{tabular}

Table 2I Reocclusion cases

\begin{tabular}{|c|c|c|c|c|}
\hline Patient & $\begin{array}{l}\text { Days since last } \\
\text { patent duplex }\end{array}$ & $\begin{array}{l}\text { Suspected } \\
\text { slot age } \\
\leq 2 \text { I days } \\
>2 \text { I days } \\
\text { unknown }\end{array}$ & $\begin{array}{l}\text { Lysis successful } \\
\text { Yes/No }\end{array}$ & $\begin{array}{l}\text { Reason for } \\
\text { occlusion* }\end{array}$ \\
\hline I & 120 & \multirow{18}{*}{$\begin{array}{l}\leq 2 \text { I days } \\
\leq 2 \text { I days } \\
\leq 2 \text { I days } \\
\leq 2 \text { I days } \\
\leq 2 \text { I days } \\
\leq 2 \text { I days } \\
\leq 2 \text { I days } \\
\leq 2 \text { I days } \\
\leq 2 \text { I days } \\
\leq 2 \text { I days } \\
\leq 2 \text { I days } \\
\text { Unknown } \\
\text { Unknown } \\
\text { Unknown } \\
>2 \text { I days } \\
\text { Unknown } \\
>2 \text { I days } \\
>2 \text { I days }\end{array}$} & Yes & I \\
\hline 2 & I5 & & Yes & $\mathrm{I}, 2$ \\
\hline 3 & 5 & & Yes & I \\
\hline 4 & 0 & & Yes & 3 \\
\hline 5 & 9 & & Yes & I \\
\hline 6 & 9 & & Yes & $\mathrm{I}, 2$ \\
\hline 7 & 5 & & Yes & $\mathrm{I}, 2$ \\
\hline 8 & 42 & & Yes & I \\
\hline 9 & IO & & Yes & $\mathrm{I}, 2$ \\
\hline IO & $4 \mathrm{I}$ & & Yes & 2,4 \\
\hline II & 2I & & Yes & 3 \\
\hline $\mathrm{I} 2$ & 56 & & No & I \\
\hline $\mathrm{I} 3$ & 83 & & No & I \\
\hline I4 & 120 & & No & \\
\hline I5 & 40 & & No & $\mathrm{I}, 2$ \\
\hline I6 & 35 & & No & I \\
\hline I7 & 30 & & No & I \\
\hline I8 & 93 & & No & I \\
\hline
\end{tabular}

"I stent related failure e.g. stent fracture, kinking), 2 suboptimal stent position, 3 inadequate inflow, 4 failed anticoagulation

\section{Complications}

In total 6 patients experienced adverse events. During UACDT 2 patients had a hemoglobin decrease without a bleeding focus, which necessitated erythrocyte transfusion. One patient had minor bleeding at the catheter insertion site that 
was solved with manual compression. One patient experienced heparin-induced thrombocytopenia. Heparin was switched for argatroban intravenous for the further duration of UACDT. One patient complained of blepharo edema and urticaria, which was recognized as an allergic reaction to iodine contrast fluid used for venographic control unrelated to thrombolytic therapy. One patient had fever with positive blood cultures during thrombolysis. In this patient thrombolysis was stopped and treatment with antibiotics was started. None of the patients experienced multiple complications. We did not encounter any clinically relevant pulmonary embolism or treatment related mortality Table 22 is an overview of all complications encountered during UACDT.

Table 22 Complications

\begin{tabular}{rl}
\hline Patients (n=I8) & N (\%) \\
\hline Minor bleeding $^{\mathrm{a}}$ & I (5) \\
Major bleeding $^{\mathrm{b}}$ & $2(\mathrm{II})$ \\
Pulmonary embolism & o (o) \\
Death $^{\mathrm{O}}$ & o (o) \\
Other $^{\mathrm{c}}$ & $3(\mathrm{I} 7)$ \\
\hline
\end{tabular}

${ }^{a}$ Epistaxis, catheter insertion site.

${ }^{b}$ Drop in hemoglobin needing red blood cell transfusion.

${ }^{c}$ Allergic reaction, infection, heparin induced thrombocytopenia.

\section{Follow-up}

Regarding all successfully lysed patients (n=II), 8 remained patent, which translates into a primary patency of $73 \%$. Seven patients experienced complete relief of complaints and two patients had partial relief of complaints. One patients did not benefit from UACDT with regard to relief of complaints. In one case there was an immediate reocclusion the day after successful lysis, due to stent related problems. Table 23 shows the follow-up data for the successfully lysed patients.

\section{Table 23 Follow up data}

\begin{tabular}{|c|c|}
\hline \multicolumn{2}{|l|}{ Follow-up $n=I I$} \\
\hline Follow-up length & 12 months \\
\hline Median in months (range) & $(0-4 \mathrm{I})$ \\
\hline \multicolumn{2}{|l|}{ Patency at follow-up } \\
\hline Patent & $73 \%(\mathrm{n}=8)$ \\
\hline Occluded & $27 \%(n=3)$ \\
\hline \multicolumn{2}{|l|}{ Relief of complaints } \\
\hline Complete relief & $64 \%(\mathrm{n}=7)$ \\
\hline Partial relief & $18 \%(n=2)$ \\
\hline No relief & $9 \%(\mathrm{n}=\mathrm{I})$ \\
\hline unknown & $9 \%(\mathrm{n}=\mathrm{I})$ \\
\hline
\end{tabular}




\section{DISCUSSION}

With the growing number of effective thrombolytic treatments in acute iliofemoral DVT, we expect that an increasing number of patients will be additionally stented for residual stenotic lesions. Some reports show over 50\% of patients are to be stented after thrombolysis.I6 At the same time there are also more interventions performed in patients with post-thrombotic syndrome due to extensive chronic occlusions in the iliocaval tract. As both of these procedures gain in popularity, it can be expected that more venous stenting related complications will be encountered.

We identified reocclusion to be the most frequent and clinically important complication after venous stenting and by our knowledge we are the first to specifically focus on how to treat this important complication. Earlier studies also addressed stent occlusions to be an important complication after venous stenting.4,5,17

We report a technically successful recanalization of occluded stents in the venous system of $61 \%$ and a primary patency of $73 \%$ after a median follow-up of I2 months. In all cases it was possible to get a wire across the occluded segments. In all cases we intended to treat the stent occlusions with a suggested thrombus age of less than 2I days based on complaints or homogenicity on DUS. Thrombolysis within 2I days seems to result in more success than interventions at a later moment in our series. Although there is one report on successful interventions in the chronic DVT phase, we could not reproduce these findings. 18 We believe it is important to accurately assess the time of onset of the thrombosis. We found that patient reported duration of complaints was not useful to determine thrombus age and therefore the success rate of the thombolysis was not predictable. Other techniques like MR-venography, DUS elastography, or intra vascular ultrasound might prove more useful in determining the thrombus age, better predict outcome and be used for patient selection.I9

Regarding the specific usefulness of UACDT in regaining patency, we report a median lysis time to lyse $90 \%$ of the thrombus of 19 hours, which is fairly quick. However in some cases we continued the lysis treatment until the necessary additional procedures could be performed. We encountered two rare complications; HIT and contrast allergy. Two major bleedings requiring transfusion were encountered. Other complications involved catheter insertion site bleeding, which were very minor, and therefore we may conclude that UACDT is a safe procedure. Many stent related flow-complications result in reocclusion of the venous tract. Occlusion of the stent tract nullifies the progress gained by the initial treatment. When encountered in an early stage, the thrombosed stent tract can be cleared by thrombolysis.4 Patency can be regained and most importantly the underlying cause of occlusion can be identified or should be identified during the procedure. UACDT is one of the available options for regaining patency. Other clot removal therapies can also be used for this purpose.20

In all cases of successful thrombolysis the underlying cause of the occlusion was identified. Also in the not successful thrombolysis group we identified stent related causes for occlusion. In total in I5 of all I8 cases we identified stent related failures 
like kinking, fracture and continuous compression of the stents. These stent related problems are potentially due to the stent characteristics. The stents used in this study are primarily designed for arterial use. With new, dedicated venous stents we expect to prevent future stent related occlusions. Ideally, dedicated venous stent with high flexibility, high radial force and large diameters are used in the venous system.2I A number of dedicated venous stents have become commercially available.

Most of the occlusions occurred within 6 months after the initial stenting. A rigid follow-up of patients is therefore paramount. The frequent follow up allowed for timely interventions with UACDT in case reocclusion occurred. At the 6-month visit continuation of anticoagulation was evaluated based on stent configuration, patient risk factors and patient preference. Thrombocyte aggregation inhibitors were not routinely prescribed following cessation of Coumadin although they might be of influence. If at any point between follow-up visits patients experienced complaints, they were seen at the earliest convenience. After 6 months follow-up visits were planned at one year after stenting and afterwards yearly, depending on patient preference.

The most difficult problem we encountered is the patient with bad inflow due to extensive chronic venous occlusive disease with scarring in both major inflow vessels (i.e. femoral and deep femoral vein.). In these patients we noticed the impaired inflow due to extensive scarring of both the femoral and deep femoral vein. At the moment there are no reported successful treatments available for these veins. Endophlebectomy with or without AV-fistula has been described in literature as a treatment option in these cases. 22-24 Stenting might be a possibility for these veins, however the current available material is not suitable for placement in the femoral or deep femoral tract. To reassure adequate inflow in the patient we currently rely on the creation of a temporary AV-fistula, with or without an endophlebectomy of the common femoral vein to secure adequate inflow into the stented tract.25 Further research is needed to improve care in these cases.

One of the drawbacks of our study is the retrospective nature. The expected number of cases per year, \%er is expected to be very low, which would makes it challenging to complete a prospective study. Optimal registration of patient data and pooling of results from retrospective studies could improve patient care considerably. We therefore would like to encourage other centers to report on their experience regarding stent thrombosis and its treatment.

\section{CONCLUSION}

Treatment with UACDT of occluded stent tracts is feasible and effective. Recanalization of the stent tract can be achieved in some cases with recent thrombosis less than 2I days. Additional interventions were frequently necessary after successful UACDT treatment. Most stent occlusions were caused by stent related problems. 


\section{REFERENCES}

I. Comerota AJ, Throm RC, Mathias SD, Haughton S, Mewissen M. Catheter-directed thrombolysis for iliofemoral deep venous thrombosis improves health-related quality of life. Journal of Vascular Surgery. 2000 Jul;32(I):130-7.

2. Mewissen MW, Seabrook GR, Meissner MH, Cynamon J, Labropoulos N, Haughton SH. Catheter-directed thrombolysis for lower extremity deep venous thrombosis: report of a national multicenter registry. Radiology. 1999 Apr;2II(I):39-49.

3. Neglén P, Raju S. Balloon dilation and stenting of chronic iliac vein obstruction: technical aspects and early clinical outcome. J Endovasc Ther. 2000 Apr;7(2):79-9I.

4. de Wolf MAF, Arnoldussen CW, Grommes J, Shu Gi H, Patricia Joan N, de Haan MW, et al. Minimally invasive treatment of chronic iliofemoral venous occlusive disease. Journal of Vascular Surgery. Society for Vascular Surgery; 20I3 Apr I;I(2):I46-53.

5. Titus JM, Moise MA, Bena J, Lyden SP, Clair DG. Iliofemoral stenting for venous occlusive disease. Journal of Vascular Surgery. Elsevier Inc; 201 I Mar I;53(3):706-I2.

6. Mousa AY, Aburahma AF. May-Thurner Syndrome: Update and Review. Annals of Vascular Surgery. 2013 Jul Io.

7. Comerota AJ, Grewal N, Martinez JT, Chen JT, Disalle R, Andrews L, et al. Postthrombotic morbidity correlates with residual thrombus following catheter-directed thrombolysis for iliofemoral deep vein thrombosis. Journal of Vascular Surgery. 2012 Jan 24.

8. Raabe RD. Ultrasound-accelerated Thrombolysis in Arterial and Venous Peripheral Occlusions: Fibrinogen Level Effects. JVIR. Elsevier Inc; 2010 Aug I;2I(8):II65-72.

9. Engelhardt TC, Taylor AJ, Simprini LA, Kucher N. Catheter-directed ultrasoundaccelerated thrombolysis for the treatment of acute pulmonary embolism. Thrombosis Research. 20II Aug;I28(2):I49-54.

Io. Strijkers RH, Grommes J, Arnoldussen CW, de Graaf R, Cate ten AJ, Wittens CH. Ultrasound-accelerated catheter-directed thrombolysis in acute iliofemoral deep venous thrombosis. Journal of Vascular Surgery: Venous and Lymphatic Disorders. Elsevier; 2013.

II. Grommes J, Strijkers RHW, Greiner A, Mahnken AH, Wittens CHA. Safety and feasibility of ultrasound-accelerated catheter-directed thrombolysis in deep vein thrombosis. European Journal of Vascular \& Endovascular Surgery. 20II Apr;4I(4):526-32.

I2. Strijkers RH, Arnoldussen CW, Wittens CH. Thrombectomy without lysis: the future? Phlebology. 20I4 May 19;29(I suppl):I25-34.

I3. Gornik HL, Sharma AM. Duplex ultrasound in the diagnosis of lower-extremity deep venous thrombosis. Circulation. 20I4 Feb 25;I29(8):9I7-2I.

I4. Vedantham S, Grassi CJ, Ferral H, Patel NH, Thorpe PE, Antonacci VP, et al. Reporting standards for endovascular treatment of lower extremity deep vein thrombosis. JVIR. 2009 Jul;20(7 Suppl):S39I-408.

I5. Broholm R, Panduro Jensen L, Baekgaard N. Catheter-directed thrombolysis in the treatment of iliofemoral venous thrombosis. A review. Int Angiol. 2010 Aug;29(4):292-302.

I6. Neglén P, Hollis KC, Olivier J, Raju S. Stenting of the venous outflow in chronic venous disease: Long-term stent-related outcome, clinical, and hemodynamic result. Journal of 
Vascular Surgery. 2007 Nov;46(5):979-990.eI.

17. Dumantepe M, Tarhan IA, Ozler A. Treatment of Chronic Deep Vein Thrombosis Using Ultrasound Accelerated Catheter-directed Thrombolysis. European Journal of Vascular \& Endovascular Surgery. 2013 Jun 25.

I8. Arnoldussen C, Strijkers R, Lambregts D, Lahaye M, de Graaf R, Wittens C. Feasibility of identifying deep vein thrombosis characteristics with contrast enhanced MR-Venography. Phlebology. 20I4 May 19;29(I suppl):II9-24.

19. Karthikesalingam A, Young EL, Hinchliffe RJ, Loftus IM, Thompson MM, Holt PJE. A systematic review of percutaneous mechanical thrombectomy in the treatment of deep venous thrombosis. European Journal of Vascular \& Endovascular Surgery. 20II Apr;4I(4):554-65.

20. de Graaf R, Arnoldussen C, Wittens CHA. Stenting for chronic venous obstructions a new era. Phlebology. 2013 Mar;28 Suppl I:II7-22.

2I. Puggioni A, Kistner RL, Eklof B, Lurie F. Surgical disobliteration of postthrombotic deep veins--endophlebectomy--is feasible. Journal of Vascular Surgery. 2004 May;39(5):I04852-discussion52.

22. Raju S, Neglén P, Doolittle J, Meydrech EF. Axillary vein transfer in trabeculated postthrombotic veins. Journal of Vascular Surgery. 1999 Jun;29(6):I050-62discussionio62-4.

23. Vogel D, Comerota AJ, Al-Jabouri M, Assi ZI. Common femoral endovenectomy with iliocaval endoluminal recanalization improves symptoms and quality of life in patients with postthrombotic iliofemoral obstruction. Journal of Vascular Surgery. Elsevier Inc; 2012 Jan I;55(I):I29-35.

24. de Wolf MAF, Arnoldussen CWKP, Wittens CHA. Indications for endophlebectomy and/or arteriovenous fistula after stenting. Phlebology. 2013 Mar;28 Suppl I:I23-8. 

CHAPTER 10

SUMMARY AND GENERAL DISCUSSION 
150 CHAPTER 10 
Chronic venous disease is pathophysiologically compromised of two distinct mechanisms: venous insufficiency (incompetent venous valves leading to retrograde flow; reflux) and venous obstruction (the lumen of a vein is, partly or totally, blocked).(I, 2) Venous obstruction can be present in all vein segments, but is clinically most relevant in the major outflow tracts.(3-6) In the lower extremity the major outflow tracts are the deep veins, and to a lesser extend the great and small saphenous veins. The most important sources of deep venous obstruction are external compression of the vein (iliac vein compression syndrome; IVCS), and deep venous thrombosis (DVT); both in the acute phase and especially at the long term.(7-I2) In the latter case it is termed the post-thrombotic syndrome (PTS), as chronic obstruction caused by the DVT-associated inflammatory response decreases outflow. There are currently numerous ways to remove a thrombus in the acute setting, all of these techniques hope to prevent PTS on the long term; these novel techniques however are beyond the scope of this thesis.(I3, I4) Treatment options aimed at chronic venous obstruction can be divided in three types. Firstly, conservative treatment, consisting mainly of compression therapy, and to a lesser extent pharmaceuticals.(IO-I2) Conservative treatment is currently still the cornerstone of PTS-treatment in most countries and practices. Secondly, bypass surgery, either crossover bypasses (de Palma bypass, from the ipsilateral common femoral vein to the contralateral common femoral vein) or in-line veno-venous bypasses.(I5) This type of open surgery has historically been reserved for the most severe cases of PTS (patients that were totally unresponsive to conservative treatment), because of its rather invasive character. And thirdly, percutaneous transluminal angioplasty (or venoplasty) and stenting, which has become available during the last three decades through technical advances in the field of interventional radiology.(I6-25) The advent of these endovenous treatment modalities has made venous bypass surgery obsolete, in all but those cases in which both conservative treatment and PTA \& stenting have failed. Conservative treatment itself however is still a valuable addition to endovascular therapy, in PTS and IVCS patients in whom PTA and stenting are not indicated, and in sole deep venous valvular insufficiency.

\section{WHO SUFFERS FROM PTS?}

DVT is a relatively prevalent disease and, because many DVT patients will develop chronic complications, so is PTS. $(8,9,26)$ Extensive research has been conducted aimed at epidemiology and prevention of PTS, however its exact incidence differs greatly between studies. As is shown in chapter 2, most recent studies show incidence rates generally between being $20 \%$ and $80 \%$ for PTS as a whole, and between $5 \%$ and $25 \%$ for severe PTS. Differences are best explained by the difference in target population and varying definitions of PTS between studies. Many risk factors for PTS development have been evaluated, the most significant in daily practice being: age, obesity, gender, ipsilateral recurrence of DVT, the location of the initial thrombus (proximal vs distal), 
and the presence and degree of residual occlusion and reflux post-DVT. Some of these risk factors of course can't be influenced in patients, and others only underscore the importance of conservative therapy in reducing the risk of PTS-development. Moreover, measurements of inflammatory markers, adhesion molecules and other measurable values in DVT patients show promise in working towards a more tailored risk stratification and thereby possibly an individualized secondary prevention protocol in DVT patients.

Looking at the demographics of the follow-up studies presented in this thesis (those in chapters 3-5 and 7-9), a number of observations about the population generally presenting for treatment of their PTS and IVCS can be made. Most are female and these patients are generally young, in their early forties, when treated. The time between a first DVT and the moment of treatment is approximately Io years in our studies. Symptomatic PTS generally reveals itself 6-24 months after a DVT. Therefore, the PTS patients who present themselves at our clinic are generally young working mothers, who can be severely inhibited in their busy daily routine. The potential to significantly improve the lives of these patients and their families is therefore grand. The fact that risk of DVT and PTS increases with age, of course doesn't correspond with this fact of low average age of the patients treated in our studies. The contrast can probably be best explained by a physician-bias in offering stenting and hybrid procedures to patients who are still more (physically) active in life.

\section{WHO TO STENT?}

Whereas the indications for treating patients suffering an acute DVT are clear and well established world-wide, in PTS quite the opposite is true. Literature has suggested that PTS can be prevented by use of compression therapy in the months to years following the thrombosis.(IO-I2) However consensus is lacking on what treatment needs to be offered to what patients. In our studies we included patients based on two major criteria. The first being anatomical in nature: patients who are to be stented logically need one or more stentable lesions in their venous system. Secondly, patients need to suffer on a level of severity which makes offering them an (minimally invasive, however still invasive) intervention acceptable.

The presence of stentable lesions and the severity of obstruction was evaluated by use of two main imaging modalities in our studies. Duplex ultrasonography (DUS) was used to evaluate the levels of obstruction and the degree of stenosis per segment. Magnetic resonance venography (MRV) was used for the same reason, the advantages of MRV being: non-user dependability and the ability to create an overview of the venous system in a patient which DUS cannot do. $(5,27)$ DUS itself has the advantage of being more dynamic and it also has the possibility to assess venous reflux/valvular insufficiency (one of the two main pathological pathways of PTS). Moreover, DUS is 
used in the follow-up period to assess stent patency (the "openness" of the stent) or the presence and degree of any stenosis. Of course we also used multiplane venography to assess the to-be-treated vessels at the time of the intervention.

One of the most important roles of imaging was to assign patients to one of the three treatment subgroups: IVCS, sole endovascular treatable PTS or hybrid treatable PTS. The combination of a lack of a medical history of DVT, the lack of post-thrombotic vein scarring, and the presence of extra-luminal compression on the iliac veins leads to patients being assigned to the IVCS subgroup. In patients who did show post-thrombotic venous scarring on imaging one important distinction was necessary for adequate treatment planning: the presence or absence of involvement of the inflow vessels of the common femoral vein in the post-thrombotic disease process. In a minority of patients inflow into the to-be-stented vein tract was deemed inadequate based on the DUS and MRV imaging, however it was judged that open-surgical removal of the postthrombotic intraluminal scar tissue would be possible to mitigate the inflow problems. In those cases patients were allocated to the hybrid treatment subgroup. In addition to the removal of scar tissue, an arterio-venous fistula was created to counteract the increased thrombogenic state post-operatively. When it was expected that future stent inflow would be no issue, sole-endovascular treatment was planned for the patients. Ultimately this lead to a distribution of half of the patients being treated purely endovascularly for PTS, a quarter being treated in a hybrid fashion for PTS and the remaining quarter being treated endovascularly for IVCS.

The assessment of the level of severity of signs and symptoms in patients was more subjective; any patient suffering to a degree of which the treating physician found it significant enough to offer stent placement or a hybrid treatment was accepted. Generally these patients scored high in the CEAP classification, venous clinical severity score (VCSS) and Villalta scales (the higher the score the higher the severity), however this was not the case in a significant amount of patients. The reason for this lies in the fact that none of these scoring systems include important issues such as venous claudication or inability to function normally in daily life. We therefore chose to use these scoring systems as a measurement of effect after stenting, but they were not used for inclusion into the studies on.

\section{HOW DO THE STENTS PERFORM TECHNICALLY?}

Stents are placed to open up a vessel which was previously partially obstructed or totally occluded, therefore first and foremost stents need to stay patent as long as possible, ideally lifelong. In roughly $65-90 \%$ of cases patients were stented and that was it: no second intervention was needed and the stents remained patent for the rest of the follow-up period (this is called primary patency). In a number of cases a second intervention was needed to keep the stented vein segments patent during follow-up, 
however no reocclusion occurred in these patients (this is called assisted primary patency. In cases such an assisted primary intervention was necessary, 80-99\% remained patent during follow-up. In other patients a second intervention was needed to reopen stents which reoccluded during follow-up (this is called secondary patency). After such interventions, $90-100 \%$ remained patent during the follow-up period.

These patency rates varied somewhat between studies, differences were mainly due to two reasons: the differences in length of follow-up and the exact type of intervention. Most stents which reoccluded seemed to do so during the first year after placement. However, even after this period some stents reoccluded. Therefore it is logically that the studies with a longer follow-up period had lower patency rates. More important for patency rates are the technical details of the intervention. In patients suffering from more severe post-thrombotic lesions, more aggressive techniques were generally used, and therefore patency rate during follow-up was lower This is best shown in the differences between patients stented for PTS and IVCS, with the latter faring better. Another difference is the type of stent used in a patient. When starting in 2009 we used relatively rigid stents, because no other were available with the desired radial force. This rigidity in the venous system led to stents kinking and fracturing in a number of cases, and thereby necessitating re-interventions leading to reduced (primary) patency rates.

Of special note are the cases in which a surgical desobstruction of the common femoral vein (endophlebectomy) was combined with stenting (the so called hybrid treatment) and the cases in which the deep venous system of both legs was treated (unilateral treatment vs bilateral treatment).(28) In the hybrid cases patency rates were much lower compared to sole stenting procedure; primary patency was $35-50 \%$, assisted primary patency was $60-70 \%$ and secondary patency was $70-85 \%$ in the hybrid subpopulation. The reason for this is twofold. Firstly patients needing a hybrid treatment had the most severe post-thrombotic damage to their vein systems to begin with, leading to a lower overall quality of their venous system. Secondly the open surgery had a relatively strong thrombogenic effect, for this reason the arterio-venous (AV) fistulas were needed, but still the change of rethrombosis was relatively high. Moreover, we suspect that the AVfistula itself might have played a role in a number of losses of primary patency as it is known that the specific flow conduction created by AV-fistulas can lead to intimal hyperplasia and stenosis. And again, in this population length of follow-up and the stent types used had an influence on the patency rates. In the bilaterally treated patients patency rates were also somewhat reduced compared to only unilaterally stenting. Also in these patients more severe post-thrombotic vein damage was present in the deep veins which led to a lower quality venous system. Of special note in this population is that in many cases not only the ilio-femoral tracts were affected, but also the inferior vena cava, adding to the severity and extensiveness of the disease.

Do patients improve in their symptoms? 
As already stated above the scoring systems in use in venous literature, namely the VCSS, Villalta scale and the CEAP scoring system, are less than ideal as they are lacking some important symptoms of PTS.(29-33) Nevertheless we chose to use these because of lack of better tools. Moreover these scores are validated in international literature and are frequently used in other studies. To partly mitigate the absence of specific venous claudication scoring in these three scoring systems we chose to score the absence or presence of venous claudication separately.(34) In contrast to the three validated scoring systems this claudication scoring is not validated. We therefore chose to keep it as simple as possible by not assigning any grade of severity to claudication in patients. Of special note, in light of patients' follow-up is the CEAP score, which is known to be insensitive to changes over time. For this reason we chose to only use the CEAP score as a tool to describe our population at baseline, and neglect it for any follow-up analyses.

Overall we saw clinically and statistically relevant improvements in patients' signs and symptoms in all the follow-up studies (those in chapters 3-5 and 7-9). VCSS scores generally dropped 2-3 points during I -2 years follow up in all three treatment groups; i.e. IVCS, endovascular-treated PTS and hybrid-treated PTS. Villalta scores dropped 5-7 points in the same groups during the same follow-up. Venous claudication subsided in about $70-90 \%$ of patients who were noted to suffer from it at baseline measurement. There were no great differences in the absolute number of points, the scores decreased over the three treatment subgroups, however the number of points at baseline was generally a bit lower in IVCS patients compared to endovenous-treated PTS patients, and a bit higher in the hybrid-treated patients. Ulcer healing rates and recurrence rates were also noted in these studies; most ulcers healed (ca. 80\%) and most did not recur during follow-up (ca. 20\% recurrence).

Worsening of symptomatology, expressed as increase in VCSS and/or Villalta score, was seen in less than $10 \%$ of treated patients, and was most prevalent in the IVCS subpopulation. From our studies it is unclear if this is a temporary issue or reflects longterm clinical worsening. Moreover, the relation to loss of patency or other complications is unclear, as it is true that a number of patients with patent stents (especially in the IVCS population) showed increase in clinical scores post-stenting and a number of patients with occluded stent during follow-up showed improved clinical scores.

Also of note is the already stated fact that many patients were treated years after their first DVT; the main time between the DVT and stenting was Io years, and some patients were treated many decades after their first DVT. This forms an important distinction between stenting in PTS and the prevention of PTS by thrombolysis or thrombectomy, which is characterized by the fact that these preventive techniques suffer from a very narrow treatment window. Moreover this means that practically all PTS patients with sufficient symptoms could at this moment be treated. 


\section{WHAT ARE THE DOWNSIDES TO STENTING?}

All in all, the complications noted in all studies were deemed acceptable. Indeed PTA and stenting is generally well tolerated by patients, and complications which do occur are generally mild and temporary. In cases in which a hybrid approach is used, complications are more frequent and more severe, however most are still confined to the immediate post-operative period. In both endovenous and hybrid interventions reocclusion is the most important complication, this is in line with literature.(I5-25) In patients treated because of IVCS however, in contrast to reports by many other authors, no occlusions of the stents have been noted. All loss of primary patency in this subgroup was related to renewed or persistent stenosis after stenting, reasons for this included; compression on stents, stents which were misplaced (placed distally of the compression) and other types of stent-failure. The underlying reasons for reocclusion in the PTS population are thought to relate to problems on one of three levels; inflow into the stents at the level below stenting, at the level of the stents themselves or at the level of outflow above the stents. As we always tried to land stents in healthy vein segments, so above and below the post-thrombotic aberrations, we aimed to reduce inflow and outflow problems. This was generally easily manageable at the outflow end, because mostly post-thrombotic synechiae ended at the caval confluence, so stenting into the cava was generally not needed. However, these synechiae frequently did continue into the femoral and deep femoral veins, which put the inflow into the stents at risk. Of course this was the reason to perform a hybrid procedure in many cases, but with or without the endophlebectomy and AV-fistula, the lesions in the distal femoral, popliteal and deep femoral vein were left untouched. Therefore we suspect inflow problems might have had a significant influence on patency rates. Other important potential influences on patency were on the level of the stents themselves, these included; stent-geometrical problems (such as angulation and articulation between different stents), inadequate anticoagulation (relatively low INR in some patients), extrinsic compression on the stents or endophlebectomy area (for example hematoma or lymphoma which developed after the open-surgical part of the hybrid procedure) or stenosis due to intimal hyperplasia caused by the AV-fistula.

On the long term the restenosis and reoclusions were the only important complications. However, on the short term there were a number of issues related to the invasiveness of the procedures. In the patients treated in a solely endovascular manner the only important complications were related to bleeding, with minor bleeding complications occurring in less than Io percent, and major bleeding complications occurring in less than I percent. The most important contributing factor being the fact that procedures were performed in patients who were anticoagulated at the time of the intervention, which logically increased bleeding risk. In the patients treated by hybrid procedures bleeding complications were more frequent (both major and minor complications occurring in circa 15 percent of patients). In these patients the procedures were also 
performed under full anticoagulation, but of course the surgical trauma was much more severe compared to the endovascularly treated patients. Other important complications in the hybrid subpopulation were also related to surgical trauma, these being: wound infection (circa 30 percent), wound dehiscention (circa Io percent) and lymphorrhea (circa 40 percent). These complications were generally well manageable and had little to no influence on the long term results of the procedure. However, they were a great source of morbidity on the short term and as such an increased length of hospital stay and a prolonged time until patients were fully mobile again post-intervention.

Of note is the fact that there were no clinically evident pulmonary embolisms during follow-up, and also mortality of other causes was nil.

\section{WHAT MIGHT THE FUTURE BRING?}

During the time this thesis was underway, endovascular treatment of IVCS and PTS has become an accepted treatment option worldwide, exemplified in the inclusion of it in many recent guidelines. As such commercial interest has quickly increased, many new tools are quickly becoming available as we speak. Arguably the most important being new types of stents, optimized for use in the venous system. There will probably be a continuation of this trend, with new stents becoming available and others being optimized. Even though logically these might seem superior to the "old" stents, there is currently little to no evidence to back this up. Direct comparison between stents will be needed, however it is questionable if that type of study will be performed in the near future. Of course the most advancements can be made in the group which performs the worst, in this case the patients suffering from extensive PTS who are treated by hybrid means. As frequently the endophlebectomized area tends to stenose or collapse during (early) follow-up, reinforcement of this vein segment might increase early patency rates. One way would be to leave a fixed-diameter stent-like device or inlay in the area post-surgery, preventing collapse or compression (by haematoma or lymphocele). Ideally however one would forego the open-surgical part altogether and also use purely endovascular means in the patients with these most extensive postthrombotic aberrations. Stenting through the common femoral vein and into the femoral or deep femoral vein might be possible and if so be superior compared to the hybrid procedure, as this will mitigate many of the open-surgery related issues.

However, the greatest possibilities for advancement in the field of PTS lie within prevention. Currently a multitude of tools and techniques, both chemical and mechanical in nature, are becoming available which are all aimed at removing the thrombus in the acute phase of the disease. Currently the first clinical results are somewhat disappointing, but in time these modalities might make PTS a disease of the past. This will leave IVCS however, still necessitating PTA and stent placement in the venous system. 
158 CHAPTER 10 


\section{REFERENCES}

I. Bagot CN, Arya R. Virchow and his triad: a question of attribution. Br J Haematol. 2008; I43(2):I80-90.

2. Bergan JJ. The vein book. Amsterdam ; Boston: Elsevier Academic Press; 2007. Xvii, 6I7 p. p.

3. Cockett FB, Thomas ML, Negus D. Iliac vein compression.--Its relation to iliofemoral thrombosis and the post-thrombotic syndrome. British medical journal. 1967;2(5543):I4-9.

4. Raju S, Neglen P. High prevalence of nonthrombotic iliac vein lesions in chronic venous disease: a permissive role in pathogenicity. Journal of vascular surgery : official publication, the Society for Vascular Surgery [and] International Society for Cardiovascular Surgery, North American Chapter. 2006;44(I):I36-43; discussion 44.

5. Arnoldussen CW, Toonder I, Wittens CH. A novel scoring system for lower-extremity venous pathology analysed using magnetic resonance venography and duplex ultrasound. Phlebology / Venous Forum of the Royal Society of Medicine. 20I2;27 Suppl I:I63-70.

6. Arnoldussen $\mathrm{CW}$, Wittens $\mathrm{CH}$. An imaging approach to deep vein thrombosis and the lower extremity thrombosis classification. Phlebology / Venous Forum of the Royal Society of Medicine. 2012;27 Suppl I:I43-8.

7. May R, Thurner J. The cause of the predominantly sinistral occurrence of thrombosis of the pelvic veins. Angiology. I957;8(5):419-27.

8. Gabriel F, Labios M, Portoles O, Guillen M, Corella D, Frances F, et al. Incidence of postthrombotic syndrome and its association with various risk factors in a cohort of Spanish patients after one year of follow-up following acute deep venous thrombosis. Thromb Haemost. 2004;92(2):328-36.

9. Roumen-Klappe EM, den Heijer M, Janssen MC, van der Vleuten C, Thien T, Wollersheim $\mathrm{H}$. The post-thrombotic syndrome: incidence and prognostic value of non-invasive venous examinations in a six-year follow-up study. Thromb Haemost. 2005;94(4):825-30.

Io. Brandjes DP, Buller HR, Heijboer H, Huisman MV, de Rijk M, Jagt H, et al. Randomised trial of effect of compression stockings in patients with symptomatic proximal-vein thrombosis. Lancet. 1997;349(9054):759-62.

II. Kahn SR, Shbaklo H, Shapiro S, Wells PS, Kovacs MJ, Rodger MA, et al. Effectiveness of compression stockings to prevent the post-thrombotic syndrome (the SOX Trial and Bio-SOX biomarker substudy): a randomized controlled trial. BMC Cardiovasc Disord. 2007;7:2I.

I2. Prandoni P, Lensing AW, Prins MH, Frulla M, Marchiori A, Bernardi E, et al. Below-knee elastic compression stockings to prevent the post-thrombotic syndrome: a randomized, controlled trial. Ann Intern Med. 2004;I4I(4):249-56.

I3. Enden T, Sandvik L, Klow NE, Hafsahl G, Holme PA, Holmen LO, et al. Catheter-directed Venous Thrombolysis in acute iliofemoral vein thrombosis--the CaVenT study: rationale and design of a multicenter, randomized, controlled, clinical trial (NCToo25I77I). Am Heart J. 2007;I54(5):808-I4. 
I4. Vedantham S, Goldhaber SZ, Kahn SR, Julian J, Magnuson E, Jaff MR, et al. Rationale and design of the ATTRACT Study: a multicenter randomized trial to evaluate pharmacomechanical catheter-directed thrombolysis for the prevention of postthrombotic syndrome in patients with proximal deep vein thrombosis. Am Heart J. 20I3;165(4):523-30 e3.

I5. AbuRahma AF, Robinson PA, Boland JP. Clinical, hemodynamic, and anatomic predictors of long-term outcome of lower extremity venovenous bypasses. Journal of vascular surgery : official publication, the Society for Vascular Surgery [and] International Society for Cardiovascular Surgery, North American Chapter. I99I;I4(5):635-44.

I6. Alhalbouni S, Hingorani A, Shiferson A, Gopal K, Jung D, Novak D, et al. Iliac-femoral venous stenting for lower extremity venous stasis symptoms. Ann Vasc Surg. 20I2;26(2):I859.

I7. Delis KT, Bjarnason H, Wennberg PW, Rooke TW, Gloviczki P. Successful iliac vein and inferior vena cava stenting ameliorates venous claudication and improves venous outflow, calf muscle pump function, and clinical status in post-thrombotic syndrome. Ann Surg. 2007;245(I):130-9.

I8. Gutzeit A, Zollikofer Ch L, Dettling-Pizzolato M, Graf N, Largiader J, Binkert CA. Endovascular stent treatment for symptomatic benign iliofemoral venous occlusive disease: long-term results 1987-2009. Cardiovasc Intervent Radiol. 20II;34(3):542-9.

19. Hartung O, Benmiloud F, Barthelemy P, Dubuc M, Boufi M, Alimi YS. Late results of surgical venous thrombectomy with iliocaval stenting. Journal of vascular surgery. 2008;47(2):38I-7.

20. Nazarian GK, Austin WR, Wegryn SA, Bjarnason H, Stackhouse DJ, Castaneda-Zuniga WR, et al. Venous recanalization by metallic stents after failure of balloon angioplasty or surgery: four-year experience. Cardiovasc Intervent Radiol. 1996;19(4):227-33.

2I. Neglen P, Hollis KC, Olivier J, Raju S. Stenting of the venous outflow in chronic venous disease: long-term stent-related outcome, clinical, and hemodynamic result. Journal of vascular surgery. 2007;46(5):979-90.

22. O'Sullivan GJ, Sheehan J, Lohan D, McCann-Brown JA. Iliofemoral venous stenting extending into the femoral region: initial clinical experience with the purpose-designed Zilver Vena stent. The Journal of cardiovascular surgery. 20I3;54(2):255-6I.

23. Rosales A, Sandbaek G, Jorgensen JJ. Stenting for chronic post-thrombotic vena cava and iliofemoral venous occlusions: mid-term patency and clinical outcome. European journal of vascular and endovascular surgery : the official journal of the European Society for Vascular Surgery. 20I0;40(2):234-40.

24. Titus JM, Moise MA, Bena J, Lyden SP, Clair DG. Iliofemoral stenting for venous occlusive disease. Journal of vascular surgery.53(3):706-I2.

25. Ye K, Lu X, Li W, Huang Y, Huang X, Lu M, et al. Long-Term Outcomes of Stent Placement for Symptomatic Nonthrombotic Iliac Vein Compression Lesions in Chronic Venous Disease. J Vasc Interv Radiol. 2012.

26. Kahn SR, Partsch H, Vedantham S, Prandoni P, Kearon C. Definition of postthrombotic syndrome of the leg for use in clinical investigations: a recommendation for 
standardization. J Thromb Haemost. 2009;7(5):879-83.

27. Arnoldussen CW, de Graaf R, Wittens CH, de Haan MW. Value of magnetic resonance venography and computed tomographic venography in lower extremity chronic venous disease. Phlebology / Venous Forum of the Royal Society of Medicine. 2013;28 Suppl I:I69-75.

28. Vogel D, Comerota AJ, Al-Jabouri M, Assi ZI. Common femoral endovenectomy with iliocaval endoluminal recanalization improves symptoms and quality of life in patients with postthrombotic iliofemoral obstruction. Journal of vascular surgery. 20I2;55(I):I2935.

29. Eklof B, Rutherford RB, Bergan JJ, Carpentier PH, Gloviczki P, Kistner RL, et al. Revision of the CEAP classification for chronic venous disorders: consensus statement. Journal of vascular surgery. 2004;40(6):I248-52.

30. Kahn SR. Measurement properties of the Villalta scale to define and classify the severity of the post-thrombotic syndrome. J Thromb Haemost. 2009;7(5):884-8.

3I. Kahn SR, Desmarais S, Ducruet T, Arsenault L, Ginsberg JS. Comparison of the Villalta and Ginsberg clinical scales to diagnose the post-thrombotic syndrome: correlation with patient-reported disease burden and venous valvular reflux. J Thromb Haemost. 2006;4(4):907-8.

32. Strijkers RH, Wittens CH, Kahn SR. Villalta scale: goals and limitations. Phlebology / Venous Forum of the Royal Society of Medicine. 2012;27 Suppl I:I30-5.

33. Vasquez MA, Rabe E, McLafferty RB, Shortell CK, Marston WA, Gillespie D, et al. Revision of the venous clinical severity score: venous outcomes consensus statement: special communication of the American Venous Forum Ad Hoc Outcomes Working Group. Journal of vascular surgery. 2010;52(5):1387-96.

34. Delis KT, Bountouroglou D, Mansfield AO. Venous claudication in iliofemoral thrombosis: long-term effects on venous hemodynamics, clinical status, and quality of life. Ann Surg. 2004;239(I):II8-26. 

Nederlandse samenvatting

Valorisation

Dankwoord

List of publications

Curriculum Vitae 
164 NEDERLANDSE SAMENVATTING 


\section{NEDERLANDSE SAMENVATTING}

Chronisch veneuze ziekte kan pathofysiologisch ingedeeld worden in een tweetal mechanismen; veneuze insufficiëntie (incompetente, lekkende veneuze kleppen leiden tot retrograde flow, dit noemt men ook wel reflux) en veneuze obstructie (het lumen van een vene wordt gedeeltelijk of in zijn totaliteit geblokkeerd). Veneuze obstructie kan in principe vóórkomen in alle veneuze segmenten in het lichaam, maar klinisch is dit het meest relevant in de grote venen. In de onderste extremiteiten betreffen dit de diepe venen en in mindere mate de vena saphena magna en parva. De belangrijkste oorzaken van diep veneuze obstructie zijn externe compressie op de vene (iliacaal veneus compressie syndroom, IVCS) en diep veneuze trombose (DVT); zowel in de acute fase als op de lange termijn. In geval van lange termijn problematiek in het kader van DVT spreekt men van het post-trombotisch syndroom (PTS). Dit betreft de chronische obstructie in een vene die wordt veroorzaakt door de (lokale) inflammatoire reactie die samengaat met een DVT. Momenteel zijn er multipele technieken beschikbaar om een trombus in de acute fase te verwijderen (de meeste hiervan worden overigens in het algemeen nog als relatief experimenteel gezien). Al deze technieken zijn er op gericht PTS op de (middel)lange termijn te voorkomen, deze technologieën liggen echter buiten het bereik van deze thesis. Behandelopties gericht op chronisch veneuze obstructie kunnen worden ingedeeld in drie typen.

I. Conservatieve behandeling: deze bestaat voornamelijk uit het gebruik van compressietherapie en in mindere mate van medicijnen. Conservatieve therapie is momenteel nog steeds de hoeksteen van de behandeling van PTS in de meeste landen en klinieken.

2. Bypass chirurgie: deze behandeling bestaat uit het aanleggen van ofwel een "crossover" bypass (de Palma operatie, er wordt een bypass gecreëerd van de ipsilaterale vena femoralis communis naar de contralaterale vena femoralis communis) ofwel een "inline" bypass (het creëren van een bypass door deze ipsilateraal voor en na de obstructie te anastomoseren). Deze types chirurgie zijn historisch altijd gereserveerd geweest voor de meest ernstige gevallen van PTS (ergo: ernstige klachten en geen respons op conservatieve behandeling) omwille van het invasieve karakter van deze ingrepen.

3. Percutane transluminale angioplastiek (PTA, ofwel "dotteren", een endoveneuze techniek) gecombineerd met stenting: deze technieken zijn de laatste drie decennia beschikbaar gekomen uit technische vooruitgangen binnen de interventie radiologie. Hierbij blaast men een speciaal type ballon op in de vene die geobstrueerd/geoccludeerd is met als gevolg dat het bloedvat weer "open" is, vervolgens laat men een stent achter (een soort metalen veertje) om het bloedvat ook op de lange termijn open te houden.

Door de komst van deze endoveneuze behandelingsoptie is de veneuze bypasschirurgie obsoleet geworden in de meeste gevallen. Conservatieve therapie is nog steeds een waardevolle additie aan de endoveneuze therapie; in gevallen van PTS en IVCS waarvoor stenting niet geïndiceerd is en in solitaire diep veneuze insufficiëntie. 


\section{Welke patiënten lijden aan PTS?}

DVT is een relatief veel voorkomende ziekte en omdat veel patiënten chronische complicaties van DVT zullen ontwikkelen is PTS dat ook. Men heeft uitgebreid wetenschappelijk onderzoek gedaan naar de epidemiologische aspecten van PTS en de preventie hiervan, echter verschilt de exacte incidentie sterk tussen verschillende studies. Zoals men in hoofdstuk 2 kan lezen laten de meeste recente studies een incidentie zien tussen de 20 en 80 procent voor PTS in het algemeen en tussen de 5 en 25 procent voor ernstige PTS. Verschillen in deze percentages kunnen verklaard worden door andere onderzoekspopulaties en verschillende definities van (ernstige) PTS. Veel risicofactoren voor de ontwikkeling van PTS zijn in de loop van de jaren onderzocht, de meest significante voor de dagelijkse klinische praktijk zijn; leeftijd, de aanwezigheid van obesitas, geslacht, een tweede episode van DVT ipsilateraal, de locatie van de initiële trombose (proximaal of distaal) en de aanwezigheid van residuale obstructie en/of reflux. Een aantal van deze risico factoren zijn uiteraard niet aan te pakken bij patiënten. Anderen laten echter zien wat het belang van adequate conservatieve therapie is na een DVT. Daarnaast zijn er meetbare stoffen in het bloed van patiënten, zoals inflammatoire markers en adhesie moleculen, die mogelijk in de toekomst kunnen bijdrage bij het creëren van een gepersonaliseerd risicoprofiel en geïndividualiseerde secundaire preventie.

Wanneer we kijken naar de demografische gegevens van de patiënten in de follow-up studies in deze thesis (hoofdstukken 3-5 en 7-9), kunnen we een aantal observaties doen over de populatie die zich in het algemeen presenteert met PTS en IVCS in onze kliniek. Er is een voorkeur voor het vrouwelijk geslacht en de meeste patiënten zijn relatief jong, begin veertig, op het moment van behandeling. De patiënten bestaan dus voor een belangrijk deel uit werkende jonge moeders, die ernstig beperkt worden in hun dagelijkse routine. De mogelijkheid om de levens van deze patiënten en hun families te verbeteren is daarom erg belangrijk. Het feit dat het risico op het ontwikkelen van een DVT en PTS toeneemt met de leeftijd komt uiteraard niet overeen met deze relatief jonge leeftijd bij presentatie van patiënten in ons centrum. Vermoedelijk is dit deels te verklaren vanuit een verwijzers-bias of behandelaars-bias voor het aanbieden van deze therapie aan patiënten die nog (fysiek) actief zijn in hun leven.

\section{Welke patiënten kan men stenten?}

Hoewel de indicaties voor het behandelen van een acute DVT wereldwijd relatief uniform geaccepteerd zijn, is voor het PTS juist het tegenovergestelde waar. De literatuur stelt dat PTS voorkomen kan worden bij een significant aantal mensen door het gebruik van compressietherapie in de maanden tot jaren na de DVT. Echter mist er consensus betreffende welke andere therapieën aangeboden kunnen/moeten aan welke PTS-patiënten. In onze studies was inclusie gebaseerd op twee belangrijke criteria. Allereerst moet er sprake zijn van een anatomische obstructie in het diepe venenstelsel welke stentbaar geacht wordt. Ten tweede moet de patiënt dermate ernstige klachten ondervinden dat een (minimaal invasieve, doch nog steeds invasieve) interventie acceptabel is.

De aanwezigheid van stentbare laesies en de ernst van obstructie hebben wij geëvalueerd 
middels twee beeldvormende technieken. Duplex ultrasonografie (DUS) is gebruikt om de niveaus van obstructie en de mate van stenose per segment te evalueren. Magnetische resonantie venografie (MRV) is gebruikt om dezelfde redenen. De voordelen van MRV boven DUS zijn dat de kwaliteit van het onderzoek niet afhangt van de uitvoerder en het feit dat met MRV een overzichtelijk beeld kan worden gemaakt van het gehele veneuze systeem. DUS heeft aan de andere kant weer het voordeel dat het erg dynamisch is en dat hiermee ook veneuze reflux kan worden geëvalueerd. Bovendien hebben wij DUS gebruikt tijdens follow-up om de "patency" (ofwel de openheid) van de stents te beoordelen. Hiernaast hebben wij uiteraard ook gebuikt gemaakt van conventionele venografie om de te behandelen vaten te beoordelen ten tijde van de interventie.

Eén van de belangrijkste taken van de beeldvorming was de ondersteuning in het indelen van de patiënten in drie subgroepen; de IVCS-patiënten, de PTS-patiënten die geholpen zouden gaan worden middels puur endovasculaire technieken (PTA en stenting) en de patiënten bij wie een combinatie nodig zou zijn van endovasculaire behandeling en open-chirurgie (de hybride behandeling). De combinatie van een afwezigheid van DVT in de voorgeschiedenis, geen post-trombotische verlittekening in de vaten op beeldvorming en de aanwezigheid van extraluminale compressie op een diepe vene brachten patiënten in de IVCS-subgroep. In patiënten bij wie wel post-trombotische verlittekening aanwezig was in de diepe venen was het van belang te weten in welke mate de inflow vaten van de vena femoralis communis betrokken waren bij de ziekte. Bij een minderheid van de patiënten werd deze inflow onvoldoende geacht voor een puur endovasculaire ingreep, deze patiënten werd een hybride ingreep aangeboden. Hierbij wordt de vena femoralis communis chirurgisch geopend en het post-trombotische littekenweefsel voorzichtig verwijderd met het idee dat hierdoor de inflow in de stents (die meer craniaal geplaatst worden) verbeterd wordt. Dit wordt de hybride ingreep genoemd, daar endovasculaire technieken worden gecombineerd met open-chirurgie. Naast het verwijderen van dit littekenweefsel wordt ook een arterioveneuze fistel (AVF) aangelegd, dit om de erg trombogene status per- en postoperatief te attaqueren. Wanneer werd ingeschat dat de inflow geen probleem zou vormen ten tijde van het stenten werden patiënten ingepland voor een puur endoveneuze ingreep op de angiosuite. Uiteindelijk leidde dit tot de volgende globale verdeling; een kwart van de patiënten werd behandeld middels puur endovasculaire technieken voor IVCS, de helft werd puur endovasculair behandeld voor PTS en een kwart werd behandeld middels de hybride techniek.

De evaluatie van de uitgebreidheid van de ernst van de symptomen was relatief iets subjectiever; elke patiënt waarbij de behandelend arts inschatte dat de klachten significant genoeg waren om stenting of de hydride ingreep uit te voeren kwam in aanmerking hiervoor, met in acht neming dat er ook een anatomische obstructie was uiteraard. Over het algemeen scoorden deze patiënten hoog binnen de "Clinical, Etiological, Anatomical and Pathofysiological-classification" (CEAP-classificatie), de "venous clinical severity score" (VCSS) en de Villalta schaal. Bij al deze scoresystemen geldt hoe hoger de score hoe ernstiger de klachten. Echter was dit niet bij alle patiënten het geval. De reden hiervoor is vermoedelijk dat geen van deze scoresystemen rekening houden met de specifieke klachten van veneuze claudicatie of met de beperkingen 
die een patiënt ondervindt tijdens het dagelijks functioneren. Om deze reden hebben we ervoor gekozen de genoemde scoresystemen wel te gebruiken om de uitkomst van behandeling te meten tijdens de studies, maar om deze niet mee te laten wegen bij de inclusie van patiënten.

\section{Wat is het technische effect van stentplaatsing?}

Stents worden geplaatst om bloedvaten, die eerst partieel of totaal geoccludeerd waren, open te houden. In circa $65-90 \%$ van de gevallen in onze studies werden patiënten eenmaal gestent en was daarmee de behandeling voltooid; geen secundaire interventies waren nodig en de stents bleven patent gedurende de follow-up periode (dit wordt de "primary patency" genoemd). In een aantal gevallen was een tweede interventie nodig om de stent open te houden (dus spoedige reocclusie te voorkomen), maar in deze gevallen was er dus nog nooit een reocclusie van de stents opgetreden (dit wordt de "assisted primary patency" genoemd). In deze gevallen was er sprake van een patency van $80-99 \%$ gedurende de follow-up. In een aantal andere casus was een tweede ingreep nodig om een geoccludeerde stent opnieuw open te maken (in die gevallen spreekt men van "secundary patency"). $\mathrm{Na}$ een dergelijke tweede interventie bleef $90-\mathrm{IOO} \%$ patent gedurende de follow-up periode.

Deze patency rates varieerden enigszins tussen de verschillende studies. Verschillen waren voornamelijk te wijten aan twee redenen: de verschillen in de lengte van followup tussen studies en het type ingreep dat was uitgevoerd bij een patiënt. De meeste stent reocclusies vonden plaatst in het eerste jaar na stenting. Echter, waren er ook gevallen van reocclusie later tijdens de follow-up. Om deze reden is het ook logisch dat de lagere patency rates gevonden werden bij de studies met de langere follow-up tijden. Belangrijker is het verschil in patency rates tussen de verschillende behandelingen. Bij patiënten met ernstigere post-trombotische afwijkingen waren over het algemeen agressievere technieken nodig, welke geassocieerd zijn met hogere kansen op reocclusie van de stents. Dit verschil is het duidelijkst te zien tussen de patiënten die behandeld zijn voor IVCS vergeleken met PTS Hierbij waren de resultaten bij de IVCS-patiënten beter. Een ander verschil berust op het type stent dat werd gebruikt. Toen wij onze behandelingen startten in 2009 waren enkel relatief rigide stents beschikbaar, omdat andere meer flexibele stents niet voldoende radiale kracht bezaten voor gebruik in het veneuze stelsel. Deze rigiditeit leidde tot stents die ombogen of breuken vertoonden gedurende de follow-up.Om die reden waren secundaire interventies nodig en nam de primaire patency rate af.

Specifiek van belang waren de casus waarbij er een chirurgische desobstructie van de vena femoralis communis (een endoflebectomie) nodig was in combinatie met PTA en stenting (de zogenaamde hybride techniek) en de patiënten waarbij beide benen behandeld moesten worden (unilaterale vs. bilaterale behandeling). De patency rates waren veel lager in de groep waarbij een hybride ingreep werd uitgevoerd; primary patency was $35-50 \%$, assisted primary patency was $60-70 \%$ en secundaire patency was $70-85 \%$. Hiervoor zijn twee belangrijke oorzaken aan te wijzen. Allereerst waren de hybride ingrepen nodig bij patiënten met de meest uitgebreide post-trombotische afwijkingen. Deze patiënten hadden om te beginnen al een veel lagere kwaliteit aan 
hun veneuze systeem. Ten tweede had de endoflebectomie zelf een sterk trombogeen effect door de mate van chirurgische schade. Om deze reden hebben we er ook voor gekozen ten tijde van de ingreep een AV-fistel te creëren, Echter bleek de kans op retrombose nog steeds relatief hoog. We vermoeden dat de AV-fistel zelf een reden kan zijn geweest van de reocclusie in een aantal gevallen, daar het bekend is dat de specifieke flowcondities die de fistel creëert kunnen leiden tot lokale intimahyperplasie en stenose. En wederom had ook in deze populatie de lengte van de gemiddelde followupduur en het type stent dat werd gebruikt een effect op de patency rates in vergelijking met andere studies. Wanneer we de bilateraal behandelde patiënten vergelijken met de unilateraal behandelde patiënten, zien we ook een enigszins lagere patency rate. Ook bij deze patiënten was een uitgebreidere pre-interventionele veneuze schade aanwezig. Ook van belang is dat in deze patiënten veelal niet alleen de iliofemorale trajecten werden gestent, maar ook de vena cava inferior.

\section{Verbeteren de symptomen bij patiënten?}

Zoals hierboven al vermeld missen de belangrijkste scoringssystemen binnen de veneuze literatuur (CEAP-classificatie, VCSS en de Vilalta schaal) een aantal belangrijke symptomen van PTS. Doch aangezien er momenteel geen betere middelen voorhanden zijn hebben we toch gebruik gemaakt van deze scoringssystemen. Deze scores zijn gevalideerd binnen de internationale literatuur en worden frequent gebruikt bij andere studies. Om deels tegemoet te komen aan de afwezigheid van veneuze claudicatio bij deze scoringssystemen, hebben we ervoor gekozen om separaat de aan- of afwezigheid van dit symptoom te scoren bij de patiënten vóór stenting en gedurende de follow-up. Hierbij dient gezegd te worden dat deze scoring niet gevalideerd is. Om deze reden hebben we ervoor gekozen deze dataverzameling zo simpel mogelijk te houden en hebben we alleen de aan- of afwezigheid van veneuze claudicatio klachten genoteerd, er is dus geen indeling gemaakt in ernst van dit symptoom. Ook van belang is het bekende feit dat de CEAP-classificatie relatief ongevoelig is voor veranderingen in de tijd. Om die reden hebben we ervoor gekozen de CEAP-classificatie alleen te gebruiken om per studie de patiënt populatie te beschrijven, niet om veranderingen na behandeling te meten.

Over het algemeen zagen we zowel een statistisch als klinisch relevante verbetering in symptomen bij patiënten in alle follow-up studies (hoofdstuk 3-5 en 7-9). VCSS-scores verminderden over het algemeen twee tot drie punten gedurende één tot twee jaar follow-up in alle drie de verschillende behandelgroepen. Villalta scores daalden ca. 5-7 punten in diezelfde groepen gedurende de follow-up. Veneuze claudicatio verdween in ca. 70-90\% van de patiënten die positief voor dit symptoom scoorden pre-interventioneel. Tussen de verschillende groepen was er geen groot verschil in puntendaling. Echter waren de baseline scores wel iets verschillend tussen de groepen; die bij de IVCS-groep waren iets lager dan bij de PTS-groep en de patiënten die een hybride ingreep nodig hadden scoorden iets hoger bij de baseline meting dan de patiënten die endovasculair behandeld zouden worden. Genezing van ulcera werd ook gescoord in de studies; de meeste ulcera genazen (ca. 80\%) en de meeste daarvan recidiveerden vervolgens niet (wederom ca. 80\%). 
Verslechtering in symptomatologie, uitgedrukt als een toename in VCSS en/of Villalta score na behandeling, werd gezien in minder dan I0\% van de behandelde patiënten. Dit werd het frequentst gezien in de IVCS-groep. Uit onze studies werd niet duidelijk of dit een tijdelijke of permanente stijging is. Een van de potentiële reden hiervoor kan zijn dat deze patiënten initieel gemisclassificeerd zijn als IVCS-patiënt. Het is namelijk bekend dat de compressie op de vena iliaca communis, zoals gezien wordt bij IVCS, ook aanwezig is bij een groot deel van de normale gezonde populatie. Om deze reden is het mogelijk dat mensen met een dergelijke compressie in combinatie met symptomen zoals gezien worden bij chronisch veneuze ziekte, doch met een andere oorzaak hiervoor dan de compressie, geïncludeerd zijn. Een ander punt van onduidelijkheid is de relatie tussen verlies van patency en andere complicaties. Een aantal patiënten met patente stents (met name in de IVCS groep) lieten namelijk een verslechtering in scores zien, maar aan de andere kant waren er ook patiënten met geoccludeerde stents die na een occlusie verbeterde scores lieten zien.

Een ander belangrijk feit is dat veel patiënten een lange tijd na hun (eerste) DVT-event zijn behandeld. De gemiddelde tijd tussen de eerste DVT-event en stenting/behandeling is namelijk Io jaar en sommige patiënten zijn zelfs meerdere decennia na hun DVT pas behandeld. Dit is een belangrijk verschil met de patiënten bij wie trombolyse of een andere trombus verwijderende techniek wordt toegepast ten tijde van een acute DVT om PTS te voorkomen. Daarbij is er een nauw tijdsvenster voor de behandeling (veelal enkele weken). Ons werk laat zien dat mensen dus vele jaren na een DVT nog steeds behandeld kunnen worden indien er voldoende PTS-gerelateerde klachten aanwezig zijn en er sprake is van een anatomische obstructie in de diepe venen.

\section{Wat zijn de nadelen van de behandeling met stents?}

Globaal genomen zijn de complicaties, welke werden gezien in deze studies, als acceptabel geïnterpreteerd. PTA en stenting wordt over het algemeen goed verdragen door patiënten en de complicaties die optraden waren over het algemeen mild en tijdelijk. In alle subgroepen was er sprake van een, in intensiteit tussen patiënten verschillende, mate van pijn per- en postinterventie, met name in de lage rug. Vermoedelijk werd dit veroorzaakt door de mechanische stress die de ballon en stent op het omliggende weefsel gaven. Over het algemeen ging deze pijn vanzelf over en/of was goed behandelbaar middels NSAID's. In de casus waarbij een hybride ingreep nodig was kwamen complicaties frequenter voor en waren ernstiger, maar de meestenwaren nog steeds beperkt tot de directe post-interventionele periode. In zowel de endoveneus als hybride behandelde PTS-populaties was reocclusie van de stents de meest belangrijke complicatie, zoals dit ook in de relevante wetenschappelijke literatuur beschreven wordt. Echter zagen wij in tegenstelling tot de literatuur geen stent-occlusies in de IVCS-groep. Er was wel verlies van primary patency in deze groep, dit werd echter veroorzaakt door persistente stenose na stenting. Oorzaken hiervoor waren; compressie op de stent, misplaatste stents (caudaal van de stenose) en andere typen van stent-falen. De onderliggende redenen voor patency verlies bij de PTSbehandelgroepen hangen vermoedelijk samen met problemen op de volgende drie niveaus; caudaal van de stent ofwel ter hoogte van het inflow traject, op het niveau van de 
stents zelf of boven het niveau van de stents ofwel in het outflow traject. Onderdeel van de standaard behandelingsprocedure was het "landen" van de stents in gezond weefsel, dus boven en onder de post-trombotische verlittekening, dit met als doel de inflow-en outflowproblemen te minimaliseren. Op het niveau van de outflow was dit vaak relatief makkelijk te bereiken, omdat de meeste DVT's en daarmee ook de post-trombotische afwijkingen stopten op het niveau van de cavale confluens. Om deze reden was stenting van de vena cava inferior meestal ook niet nodig. Deze verlittekening liep echter vaak wel door in de vena femoralis en vena femoralis profunda, waardoor de inflow richting de stents in potentieel gevaar kwam. Dit was uiteraard in veel gevallen de reden voor het primair uitvoeren van de hybride procedure, echter bleven ook daarbij de afwijkingen in de distale vena femoralis, femoralis profunda en poplitea onbehandeld. We vermoeden dan ook dat inflow problemen de grootste invloed hadden op de patency rates in de PTS-subpopulaties. Andere belangrijke potentiële beperkingen voor de patency rates bevonden zich op het niveau van de stents zelf. Van belang waren onder andere: stent-geometrische factoren (zoals angulatie en articulatie tussen meerdere stents), inadequate antistolling (relatief laag INR bij sommige patiënten), extraluminale compressie op de stents of het endoflebectomie gebied (bijvoorbeeld door hematoom of lymfocele die frequent postoperatief ontstonden na de hybride procedure) of stenose door intimahyperplasie veroorzaakt door de AV-fistel.

Op de lange termijn waren restenose en reocclusie de enige belangrijke complicaties. Op de korte termijn was er ook sprake van een aantal complicaties gerelateerd aan de invasiviteit van de ingreep. In de puur endovasculair behandelde patiënten was de enige complicatie gerelateerd aan bloedingen; relatief kleine bloedingen kwamen voor in minder dan Io procent van de gevallen en ernstige bloedingen in minder dan I procent. De belangrijkste reden voor het vóórkomen van deze complicaties was het feit dat patiënten werden behandeld onder volledige antistolling. Dit werd gedaan om de kans op stent-occlusie te verlagen, maar logischerwijs neemt de kans op bloedingen hierbij toe. In de groep die middels hybride technieken werd behandeld was het percentage bloedingscomplicaties groter (ca. 15 procent). Deze procedure werd ook onder volledige antistolling uitgevoerd, echter was het chirurgische trauma bij deze patiënten logischerwijs groter. Andere belangrijke complicaties in de hybride behandelde populatie waren: wondinfectie (ca. 30 percent), wond dehiscentie (ca. Io percent) en lymforroe (ca. 40 percent). Deze complicaties waren over het algemeen goed behandelbaar en hadden weinig tot geen invloed op de lange termijnresultaten. Echter waren ze wel een belangrijke oorzaak voor morbiditeit op de korte termijn, verlengde ziekenhuisopname en verlengde tijd tot patiënten weer volledig mobiel waren na een ingreep.

Ook van belang is het feit dat er tijdens de follow-up geen gevallen waren van klinische longembolie en ook de mortaliteit van andere oorzaken afwezig was.

\section{Wat kan de toekomst nog brengen?}

Gedurende de tijd dat deze thesis in de maak was is de endovasculaire behandeling van IVCS en PTS langzamerhand één van de geaccepteerde behandelingsopties geworden wereldwijd en daarmee ook opgenomen in multipele recente richtlijnen. Om deze 
reden is de commerciële interesse hierin ook snel toegenomen en komen er vele nieuwe gereedschappen op de markt. Vermoedelijk is de komst van de specifieke veneuze stent de belangrijkste eerste stap geweest in de afgelopen jaren. Vermoedelijk zal het veneuze stentontwerp geleidelijk aan steeds verder verbeterd worden. Hoewel het verbeterde ontwerp van de stents logischerwijs zou moeten leiden tot betere klinische resultaten, is hier op dit moment nog geen goed wetenschappelijk bewijs voor. Directe vergelijking tussen stents zal nodig zijn, echter is het maar de vraag of een dergelijke studie in de nabije toekomst zal worden uitgevoerd.

Uiteraard zijn de meeste verbeteringen te behalen in de groep die klinisch er het slechts aan toe is. In dit geval zijn dat de patiënten met zeer uitgebreide post-trombotische afwijkingen die behandeld worden middels de hybride procedure. Omdat de geopereerde vena femoralis communis frequent stenoseert of samenvalt tijdens de (vroege) follow-up, is versteviging van dit veneuze segment een mogelijke optie om de resultaten te verbeteren. Een manier hiervoor zou zijn om ook in dat gebied een stent-achtige device achter te laten, waardoor samenvallen van het vat of dichtdrukken ervan door hematomen of lymfoceles niet meer mogelijk is. Echter zou men idealiter helemaal geen open-chirurgie meer uitvoeren en dus patiënten met zeer uitgebreide verlittekening puur endovasculair behandelen. Stenting van de distale vena femoralis communis is wellicht een waardevol alternatief en zou eventueel ook superieur kunnen zijn aan de hybride operatie. In ieder geval zou dat het vóórkomen van chirurgische complicaties sterk moeten verlagen.

De grootste winst die te behalen is ligt echter bij de preventie van PTS. Momenteel zijn een groot aantal technieken en gereedschappen, zowel chemisch als mechanisch, beschikbaar aan het komen welke gericht zijn op het verwijderen van de trombus in de acute fase. Momenteel zijn de eerste klinische resultaten hiervan helaas enigszins teleurstellend, echter zouden deze behandelingen PTS een ziekte van het verleden kunnen maken. Dit zal echter geen optie zijn voor IVCS, hiervoor zal PTA en stenting dan altijd nog nodig zijn. 
174 VALORISATION 


\section{VALORISATION}

Yearly I-2 in I.Ooo individuals from the general population of Western countries will suffer a deep venous thrombosis (DVT). In the elderly the incidence can be as high as I in every Ioo individuals. Up to half of DVT patients will develop the postthrombotic syndrome (PTS). With the aging of the population as a whole, both the medical and economic impact of DVT and PTS will gravely increase. However, in both the medical world and layman media PTS is an underappreciated subject. Before the advent of deep venous stenting there was no causative treatment modality. Relatively effective symptom reduction therapy was possible in many PTS patients, mostly by use of compression garments and sometimes analgesics. However, some still suffered incapacitating symptoms, e.g. gross lower limb swelling and debilitating pain during mobilization. Moreover, many PTS patients never received this minimal level of care, and thus were undertreated. PTA and stenting in venous disease was introduced as a routine daily practice at the end of the 1990's in a number of centres worldwide, most notably in the United States of America. Since then it has slowly gained attention and implementation in more and more specialized centres worldwide. However, widespread knowledge about this treatment is still lacking in general medical daily care. This thesis is characterized by a number of unique studies, i.e. the description of the first clinical results of a specially designed dedicated venous stent (the sinus Venous stent) in chapter 4 and the first study reporting a mid-sized population treated by the combination of PTA, stenting, endophlebectomy and AV-fistula creation, offered as a standardized intervention in chapter 7 . Moreover, the study in chapter 8 describing the clinical outcome of the total population of treated patients is one of the largest series available in current literature.

Therefore, this thesis adds a substantial body of data in favour of interventional treatment of PTS and IVCS. Many patients who are currently not treated for the underlying cause of their venous symptoms can benefit from PTA and stenting. As chronic treatment with medication and compression garments can be very expensive, especially in cases of venous ulceration, PTA and stenting might drastically reduce healthcare costs on the long term.

\section{Target population in and outside the medical field}

Primarily the results of PTA and stenting in chronic venous obstructive disease are of special importance to (vascular) surgeons, (interventional) radiologists, dermatologists, phlebologists, internists, geriatrists and general practitioners. Moreover, anyone in the field of medical device development, be it researchers or medical device companies, can find new targets or support for their products. A whole new field within the specialties of surgery and radiology are explored in this thesis. Also, government bodies and health insurance companies might be interested in the role of PTA and stenting in combating ever increasing healthcare costs, as this treatment may prevent the high costs from decades of conservative treatment. 


\section{Activities and implementations resulting from this thesis}

The sole treatment by use of PTA and stenting has gained some attention during the last few years. However the routine use of endophlebectomy and AV-fistulas in the most severe cases of PTS is a relative novelty. Other centres worldwide might be moved to start using this treatment themselves, or find alternative ways to treat these gravely affected patients. Moreover, the use of dedicated venous stents can be implemented in many already ongoing or in new venous obstruction treatment protocols. Furthermore, these encouraging results with the first generation of dedicated venous stents can motivate medical corporations to invest in better tools, stents and other devices. However, the most important activity for the near future will be to bring the knowledge and the clinical potential of this treatment modality in the attention of the medical world as a whole.

\section{Innovation}

The most important innovation resulting from this thesis should be the improvement of care of patients suffering from deep venous pathology. Every patient suffering from PTS should have the opportunity to be evaluated by a physician knowledgeable about this subject, and if eligible be treated accordingly. Furthermore, the severity of the disease described in this thesis might add to the discussion of how DVT should be managed. As already stated many patients treated by conservative therapy for DVT (anticoagulation and compression) will develop PTS. The best management of PTS includes the prevention of PTS at the time of the initial DVT. Currently a number of thrombus removal techniques are under research, and some are already implement in specialized centres worldwide. PTA and stenting as a primary treatment might have a role in DVT prevention in IVCS patients. In their classical 1957 paper the authors May and Thurner recognized the role of the common iliac vein compression in left sided DVT pathogenesis, and indeed this was already hypothesized by Rudolf Virchow a century earlier. Treating this iliac compression, in patients who already suffer from chronic venous obstructive symptomatology, may have a profound effect in preventing DVT, and subsequent PTS development. The same can be said about the prevention of secondary DVT in PTS patient, however in these cases the thrombogenic effect of stenting itself needs to be taken into consideration.

\section{Realisation of future activities and research}

Convincing the medical world as a whole to take treatment of venous disease to the next level will be the most important aim of future research. To achieve this randomized controlled trials and great registries are needed. Development of a RCT protocol is currently taking place in our own centre. The American Venous Forum has already started a registry aimed at venous stenting in the United States of America. An European counterpart should be appropriate.

In order to improve the current treatment strategies, a number of subjects need to be studied more in-depth. Firstly, the protocol of post-interventional anticoagulation should be investigated. Currently, anticoagulation is not able to prevent a significant number of rethrombosis. Moreover, treatment might be too aggressive in a great number 
of patients, especially those without a prior thrombotic event; the IVCS patients. Secondly, even though the introduction of dedicated venous stent designs has helped in attacking a number of specific stent related complications, these complications are still present after a significant number of interventions. Further improvement of stent design might be helpful in this respect. Thirdly, the use of endophlebectomy and temporary AV-fistula creation has helped us in providing a causative treatment for even those PTS patients most severely affected by post-thrombotic vein damage. However, these operations are characterized by specific complications, especially the occurrence of stenoses at the level of the treated vein and the frequently problematic wound healing. Ideally these complications can be avoided. Options might be the preventive use of VAC therapy aimed at the wound healing disorders, and the use of special intra-operatively deployable inlays for the endophlebecomized common femoral vein.

In conclusion it can be stated that the world of deep venous reconstructions is still in its infancy. Much efforts will be needed to reach the next stage, but this has the potential to revolutionize the field of vein disease. 
178 DANKWOORD 


\section{DANKWOORD}

De kwaliteit van de hedendaagse medische zorg staat of valt met de kwaliteit van de samenwerking van haar uitvoerders. Voor promoveren binnen de geneeskunde geldt hetzelfde. Terugkijkend op de afgelopen zeven jaar kan ik dan ook niet anders dan concluderen dat de realisatie van dit proefschrift mogelijk is gemaakt door de samenwerkingsrelaties, of andersoortige verbindingen, met een groot aantal personen.

Prof. dr. Wittens, beste Cees, getipt door Rob schreef ik je een sollicitatiebrief. Je nodigde me uit voor een gesprek en vroeg me direct waarom ik tegenover je zat. Ik antwoordde dat ik over Io jaar een gepromoveerde vaatchirurg wilde zijn. "Gaan we regelen" zei je, einde sollicitatie gesprek. Je nam me aan en ging over tot de orde van de dag. De volgende 6 jaar zou een achtbaan van belevenissen en ervaringen blijken; code rood deadlines werden afgewisseld met reizen naar buitenlandse congressen, marathonpoli's tot diep in de nacht werden afgewisseld met feestjes in jouw achtertuin. De druk was soms hoog en wat je vroeg was soms veel, maar uiteindelijk werd ik van dit alles een betere wetenschapper, arts en persoon. Terugkijkend op deze periode ben ik het meest dankbaar voor alle kansen die je me gaf; de artikelen waarvoor jij was gevraagd die we samen schreven, de mogelijkheid om voordrachten op congressen binnen en buiten Europa te geven, het leren echoën en natuurlijk het Amsterdamse avontuur. Daarnaast waren Irma en jij ook buiten het ziekenhuis altijd zeer gastvrij.

Dr. de Graaf, beste Rick, als ambitieuze jonge interventieradioloog en bij-devaatchirurgie-verdwaalde radioloog in spé werden we samengebracht om de research en kliniek rondom de electieve interventies gestalte te geven. Enkele jaren later zou onze populatie gestente patiënten tot een van de grootste ter wereld behoren. In dezelfde periode ontpopte ook jij je tot een van de internationale experts binnen de veneuze wereld. Een wellicht belangrijker aspect was het feit dat de deur van je kantoor altijd open stond en de Nespresso cups met dozen tegelijk werden ingekocht. Voor alle grote, maar vooral ook kleine problemen was je vaak direct aanspreekbaar, niet alleen voor mij, maar voor het hele team; precies zoals een goed co-promotor het betaamt. Hoewel je enthousiasme soms misschien wat ondergesneeuwd was door een dikke laag nuchterheid en droge humor, was het uiteindelijk toch aanstekelijk genoeg om mijn carrièreplannen overhoop te gooien en mij de richting van de radiologie te doen opsturen.

Rob, letterlijk op dag één van ons eerste collegejaar geneeskunde leerden we elkaar kennen. Samen hebben we de facultaire introductie doorlopen. Het toeval verlangde dat we ook de eerste onderwijsgroepen samen zouden doorlopen. Later beiden actief bij studievereniging Reflex, op een blauwe maandag in maart nog eens een herendispuut opgericht met een aantal gelijkgezinden, om vervolgens beiden voor de chirurgie te kiezen in ons laatste jaar geneeskunde. Van toeval was toen geen sprake meer. Zeker niet toen we beiden bij Cees begonnen. Vele congressen, " zakenreizen” en co-publicaties 
verder koos jij er als eerste voor uit het chirurgische avontuur te stappen. Een keuze die de hele boyband later nog zou maken. Daarnaast zakte je door een door de liefde ingegeven migratie drang verder de Maas af. Ik zou uiteindelijk volgen om diezelfde reden. Het lot wilde dat je terug zou keren, uiteindelijk maar tijdelijk, naar de praktijk van Cees. Maar ten tijde van dit schrijven ga je weer een nieuw hoofdstuk in je leven in.

Ralph, toen er een nieuwe PhD-plek vrij kwam binnen ons team, wist ik direct wie hiervoor het meest geschikt zou zijn. Nadat ik Cees overtuigd had dat je er toch echt een andere werkethiek op na hield dan Rob en ik, was de zaak in principe al geregeld. Dit wist jij alleen nog niet, maar na een korte video-sollicitatie was de toevoeging van jou aan het veneuze team een feit. Doordat jouw werk voortborduurde op het mijne, hebben we samen een haast oneindig aantal keren die eindeloze Excel- en SPSS-sheets moeten doornemen. Daarnaast zaten we voor jouw drukmetingen soms tot ver na sluitingstijd op het HVC. Na de casino's van Sin City te hebben overvallen en gevangenen te hebben bevrijd uit de Californische penitentiaire inrichtingen middels een 300 pk muscle car, kwam ook jij tot de conclusie dat het beter was je geluk te beproeven in die andere stad aan de (nieuwe) Maas.

Irwin, jij was al jaren eerder bekeerd door Cees. Vanaf de eerste avondpoli was duidelijk dat MRV weliswaar beter reproduceerbaar was dan echografie, maar in kwaliteit toch soms het onderspit moest delven. Dit alles had natuurlijk te maken met de bekende "operator dependency" van de duplex sonografie. Gedurende mijn jaren in het MUMC+ en later in Amsterdam, was jij altijd bereid tot ondersteuning in de kliniek en wetenschap en stond je ons bij met gevraagd en ongevraagd commentaar. Maar ook voor whisky en sigaren in Oost-Europa draaide jij je hand niet voor om. Mijn dank voor jouw enorme aandeel in de dataverzameling en de kritische blik op de artikelen, maar bovenal voor het mij wegwijs maken in de wereld van de echografie, vaardigheden die ik nu dagelijks nodig heb.

Carsten, jij was ons eerste contact binnen de radiologie, de go-to-guy voor alles van interventie tot MRV. Terugkijkend, daarmee ook degene die mij de eerste duwtjes gaf richting mijn latere carrièrekeuzes. De I8-urige hellerit met APG dwars door Europa zal ik nooit vergeten. Evenals onze avonturen als zwembadbandieten in Italië en straatworstelaars in de Maastrichtse binnenstad. Hetzelfde geldt voor de hulp en advies die je me gaf op het moment dat Maastricht te klein voor me werd. En uiteraard ook mijn dank voor jouw hand in de hoofdstukken van dit boekwerk.

Yee Lai, het moment dat we aan elkaar werden voorgesteld was misschien wat ongelukkig, de hierop volgende jaren aan samenwerking waren dat zeker niet. Op UNS 40 werden we bij elkaar op de kamer geplaatst, niet veel later zou jij vanaf die kamer een waar remblokkenimperium opbouwen. Naast dat onze bureaus tegen elkaar aan stonden werden we ook boven- en onderburen boven dat vage café/tapas restaurant op de markt. Zoals het gehele team heb ook jij niet alleen een cruciale rol gespeeld in de data verzameling voor de in deze thesis verzamelde hoofdstukken, maar ook je input 
tijdens MDO's en researchvergaderingen heeft een duidelijke stempel gedrukt op de planning en analyses van de studies. Ook jij verkoos een toekomst buiten de chirurgie, maar nog wel binnen de flebologie. En ook jij zocht deze toekomst in het Rotterdamse.

Fabio, een of andere Italiaanse geneeskunde student uit Amsterdam zou het team komen versterken was de mededeling. Onduidelijk was in eerste instantie wat die precies zou gaan doen dan. Uiteindelijk zou jij gaan promoveren op de kwaliteit van leven data uit onder andere de patiënten uit de in deze thesis beschreven studies. Hoewel deze gegevens niet in dit boekje staan zijn ze van uitermate groot belang. Om deze reden hebben we veel samen gewerkt en artikelen geproduceerd. Daarnaast stond je ook in mijn korte periode van dakloosheid voor me klaar. Hiervoor mijn dank.

Jorinde, halverwege mijn periode bij de veneuze vaatchirurgie heeft Cees jou binnengehaald en pas toen werd mij duidelijk hoe groot het gat was dat jij zou gaan vullen. De dagelijkse klinische praktijk liep opeens veel vloeiender en patiënten kwamen plots niet meer alleen specifiek voor de professor vanuit het hele land naar Maastricht. Ook jouw rol bij de dataverzameling en de uitvoering van de operaties is onontbeerlijk geweest voor de samenstelling van dit werk.

Carina, een jaar voor Rob en mij had Cees jou al weten te strikken. Meer dan iedereen heb jij altijd oog gehouden voor de patiënt. Daarnaast stond je op elk moment klaar om bij te springen en vingers in dijken te stoppen, hiermee vormde je een essentieel onderdeel van het team. Niet alleen de kliniek bleef hierdoor als een geoliede machine doorlopen, maar ook de wetenschap. Mede hierdoor is ook jouw invloed op deze artikelen van onschatbare waarde gebleken.

Auch der Einfluss der Kollegen aus Aachen ist unerlässlich gewesen bei der Fertigstellung dieses Buches. Die Zusammenarbeit mit den Gefäßchirurgen sowohl im medizinischen Bereich als auch die Möglichkeit unseren Patienten mit euch zusammen in Aachen zu operieren, den Austausch von wissenschaftlicher Daten und die Publikationen haben dieses Buch geprägt. Insbesondere danke ich Euch, Jochen und Houman, weil Ihr immer bereit wart für Diskussionen und für die immer gastfreien Empfang in Eurem Krankenhaus.

Ineke, toen onze kleine veneuze wereld in Maastricht alsmaar groter begon te worden was er behoefte aan meer handen aan het dek. Gelukkig ben jij toen bereid gevonden om je expertise hiervoor in te zetten. Om de efficiëntie op de polikliniek te verhogen stonden we vaak back-to-back te duplexen, een voor mij nooit te vergeten ervaring.

Jolanda, toen ik nog niet wist wie je was werd me verteld dat je een van de oude secretaresses van Cees was, maar uiteindelijk zou blijken dat jij de enige was die een totaal overzicht had van het gaan en staan van de professor, het veneuze team, het DCOP, de tweede kliniek in Amsterdam, de buitenpoli in Rotterdam en eigenlijk de gehele veneuze wereld in Nederland. Hoewel we elkaar natuurlijk al goed kenden voor 
20I5, zal ik met name de tijd in Amsterdam nooit vergeten. Tegenslag na tegenslag, we overleefden ze allemaal.

Ook de overige leden van het veneuze team wil ik uiteraard graag bedanken voor hun inzet, hoewel misschien niet direct betrokken bij de studies, is iedereen uiteindelijk betrokken geweest bij de patiëntenzorg. Irma, al heel snel was duidelijk dat je meer was dan alleen de vrouw van. Niet alleen wist je altijd gezelligheid te brengen bij activiteiten na werktijd, maar je was binnen de kortste keren ook officieel onderdeel geworden van het team. Margriet, jouw toevoeging aan het team bleek hetgeen wat nodig was om eindelijk de research wat strakker en professioneler te regelen. Hoewel je weinig betrokken was bij mijn studies, ebde jouw invloed op de onderzoeken van collega's uiteindelijk wel door in mijn werk. Wijnand, ook jij hebt door je tijdelijk in het Maastrichtse te begeven een deel van de dataverzameling van de studies verzorgd, dank daarvoor. Cora, als geen ander wist jij orde aan te brengen in de chaos die werd voortgebracht door al die kerels die zich bezighielden met de veneuze chirurgie in Maastricht. Arina, hoewel we maar voor één studie echt hebben samengewerkt, was de aanwezigheid van een tegenwicht voor Cees in het MUMC zeer nodig en gewenst soms. Daarnaast uiteraard ook mijn dank aan prof. dr. de Haan, dr. Das en dr. van Zwam voor hun deel in de interventies en daarbij uiteraard ook alle laboranten op de interventie kamer. Last but not least in dit rijtje wens ik jou, Timme, veel succes als opvolger van mij en hoop snel jouw boekje in handen te hebben.

Ook mijn hartelijke dank aan Sander, Froukje en Charlotte voor de begeleiding tijdens mijn eerste stappen binnen de wetenschap. En natuurlijk ook aan Kirsten, Mo en alle andere collega's van de UNS 40 en UNS 50 voor alle hulp en gezelligheid.

Sommigen zien de $\mathrm{PhD}$-periode als een tweede studententijd. In lijn hiermee wil ik dan ook mijn dispuutsgenoten van e Causa Ignota bedanken voor het deels invullen van deze tijd; Marc, Etienne, Marco, Rik, Yves, Jeroen, Thies, Nick, Stijn, Kevin, Yvo, Frans, Flap en alle volgende generaties bedankt.

De laatste loodjes wegen het zwaarst zoals ook is gebleken bij de totstandkoming van dit werk, een periode die deels samenviel met mijn huidige opleiding tot specialist. Om deze reden ook mijn hartelijke dank aan Dammis Vroegindeweij, Jan-Hein Hensen, Anneke Sikkenk en alle overige radiologen, collega AIOS en laboranten voor de ondersteuning en het geduld dat soms nodig was tijdens deze periode.

Rob, ten tijde van dit schrijven moet het alweer 20 jaar geleden zijn dat we voor het eerst eruit werden gezet bij Engels, Frans of een van die andere vakken. Na de tijd op het PCD zijn we ieder onze eigen wegen ingeslagen, maar elkaar nooit uit het oog verloren. Mijn promotieperiode heb je vanaf de zijlijn meegemaakt, maar gelukkig was je nooit een vreemde in Maastricht. 
Mijn ouders wil ik uiteraard ook graag bedanken. Van jongs af aan hebben jullie mij gestimuleerd mij in te zetten voor mijn studies, hetgeen uiteindelijk heeft geculmineerd in deze thesis. Alle kansen die ik heb mogen krijgen in mijn leven heb ik uiteindelijk alleen maar kunnen aangrijpen door de investeringen die jullie hebben gedaan in mijn toekomst. Hetzelfde kan ik zeggen over mijn kleine zusje, Jennifer, je stond altijd klaar met raad of daad als daar nood voor was.

Shu Gi, deze thesis bleek uiteindelijk niet het enige dat zou voorkomen uit mijn tijd als onderzoeker in Maastricht. Je solliciteerde naar een student assistentschap bij een van de veneuze boys en zou uiteindelijk meewerken aan de dataverzameling en analyse van een van de eerste studies. Hetgeen culmineerde in hoofdstuk 3 van dit boekje. Na deze periode ging je je coschappen lopen en nam een volgende student je plek in. We zouden echter enige tijd later de weg naar elkaar opnieuw vinden en die keer was het voorgoed. De laatste tijd was je een constante steun voor me tijdens het afmaken van dit werk en ons nieuwe leven in Rotterdam. Jij was hiermee van begin tot eind de rode draad door dit proefschrift, hiervoor mijn oneindige dank. 
184 LIST OF PUBLICATIONS 


\section{LIST OF PUBLICATIONS}

van Vuuren TM, Kurstjens RL, de Wolf MA, van Laanen JH, Wittens CH, de Graaf R. Stent extension into a single inflow vessel is a valuable option after endophlebectomy. Phlebology. 20I7 Jan I:2683555I7739766. doi: Io.II77/0268355517739766. PMID: 29II354I

Kurstjens RL, Catarinella FS, Lam YL, de Wolf MA, Toonder IM, Wittens CH. The inability of venous occlusion air plethysmography to identify patients who will benefit from stenting of deep venous obstruction. Phlebology. 2017 Jan I:2683555I7723993. doi: IO.II77/o2683555I7723993.

van Vuuren TMAJ, de Wolf MAF, Arnoldussen CWKP, Kurstjens RLM, van Laanen JHH, Jalaie H, de Graaf R, Wittens CHA. Editor's Choice - Reconstruction of the femoro-ilio-caval outflow by percutaneous and hybrid interventions in symptomatic deep venous obstruction. Eur J Vasc Endovasc Surg. 20I7 Oct;54(4):495-503. doi: I0.IOI6/j.ejvs.2017.06.023. Epub 2017 Aug I.

Wienert, Flessenkämper, Stenger. Met medewerking van de Wolf, Hummel, Jalaie, Mühlberger, Wittens. Das postthrombotische Syndrom - Eine systematische Übersicht. Uitgever: Viavital Verlag Gmbh. 20 April 2017. ISBNio 3934371566. ISBNi3 9783934371569.

M.A.F. de Wolf, J.H.H. van Laanen, R.L.M. Kurstjens, M.J.S. Mensinck, M.J. de Geus, R. de Graaf, C.H.A. Wittens, H. Jalaie. Endophlebectomy and Arteriovenous Fistula Creation Ancillary to Deep Venous Stenting in Post-Thrombotic Syndrome. Br J Surg. 2017 Feb 2I. doi: I0.IO02/ bjs.I046I.

Kurstjens R, de Wolf M, Kleijnen J, de GraafR, Wittens C. The predictive value of haemodynamic parameters for outcome of deep venous reconstructions in patients with chronic deep vein obstruction - A systematic review. Phlebology. 2016 Oct 27. pii: 0268355516671464.

Kurstjens RL, van Vuuren TM, de WolfMA, de GraafR, Arnoldussen CW, Wittens CH. Abdominal and pubic collateral veins as indicators of deep venous obstruction. Journal of Vascular Surgery: Venous \& Lymphatic Disorders. 20I6 Oct;4(4):426-433. doi: I0.IOI6/j.jvsv.20I6.06.005.

Cees Wittens and Mark de Wolf. Oxford Textbook of Vascular Surgery. Chapter I0.7: Treatment of lower limb and pelvic deep vein incompetence. ISBN: 9780199658220. Published: 25 August 2016.

R.L.M. Kurstjens, MD; M.A.F. de Wolf, MD; S.A. Alsadah; C.W.K.P. Arnoldussen, MD; F. Catarinella, MD; Y.L. Lam, MD; R.H.W. Strijkers, MD; I.M. Toonder; C.H.A. Wittens, MD, PhD. The Value of Hemodynamic Measurements by Air Plethysmography In Diagnosing Venous Obstruction Of The Lower Limb. J Vasc Surg Venous Lymphat Disord. 2016 Jul;4(3):313-9.

Kurstjens RL, de Wolf MA, Strijkers RH, Arnoldussen CW, Toonder IM, Wittens CH. Reply to a letter to the editor regarding "The Value of Hemodynamic Measurements by Air Plethysmography In Diagnosing Venous Obstruction Of The Lower Limb". J Vasc Surg Venous 
Lymphat Disord. 20I6 Oct;4(4):538. doi: I0.IOI6/j.jvsv.20I6.04.00I.

R. Strijkers, M. de Wolf, C. Wittens. Risk factors of postthrombotic syndrome before and after DVT treatment. Phlebology. 2017 Jul;32(6):384-389. doi: I0.II77/02683555166520I0. Epub 20I6 Jun I. Kurstjens RL, de Wolf MA, Konijn HW, Toonder IM, Nelemans PJ, de Graaf R, Wittens CH. Intravenous pressure changes in patients with postthrombotic deep venous obstruction: results using a treadmill stress test. J Thromb Haemost. 2016 Apr 8. doi: I0.IIII/jth.I3333

H. Jalaie, K. Schleimer, M.E. Barbati, A. Gombert, J. Grommes, M.A.F. de Wolf, R. de Graaf, C.H.A. Wittens. Interventionelle Therapie des postthrombotischen Syndroms. Gefässchirurgie pp I-8. DOIIo.IOO7/s00772-0I5-0092-8

Comerota AJ, Sandset PM, Konstantinides S, de Graaf R, Wakefield TW, Arnoldussen CW, Lam YL, van Gent WB, de Wolf MA, Catarinella FS, Kurstjens RL, Alshabatat A, Wittens CH. Maastricht Consensus Conference on Thrombosis (MCCT): A roadmap for future research, February II-I3, 20I5, Maastricht, The Netherlands. Theme 4: Invasive management of (recurrent) VTE and PTS.Thromb Res. 20I5 Sep;I36 Suppl I:SI-S2. doi: IO.IOI6/j.thromres.20I5.07.033.

Mark A.F. de Wolf, Rick de Graaf, Ralph L.M. Kurstjens, Sarah Penninx, Houman Jalaie, Cees H.A. Wittens. Short term clinical experience with a dedicated venous nitinol stent: initial results with the sinus-Venous ${ }^{\circledR}$. Eur J Vasc Endovasc Surg. 2015 Oct;50(4):518-26. doi: I0.IOI6/j. ejvs.20I5.05.0II. Epub $2015 \mathrm{Jul}$ I4.

Wittens C, Davies AH, Bækgaard N, Broholm R, Cavezzi A, Chastanet S, de Wolf M, Eggen C, Giannoukas A, Gohel M, Kakkos S, Lawson J, Noppeney T, Onida S, Pittaluga P, Thomis S, Toonder I, Vuylsteke M, Kolh P, de Borst GJ, Chakfé N, Debus S, Hinchliffe R, Koncar I, Lindholt J, de Ceniga MV, Vermassen F, Verzini F, De Maeseneer MG, Blomgren L, Hartung O, Kalodiki E, Korten E, Lugli M, Naylor R, Nicolini P, Rosales A ; European Society for Vascular Surgery. Management of Chronic Venous Disease: Clinical Practice Guidelines of the European Society for Vascular Surgery (ESVS). Eur J Vasc Endovasc Surg. 20I5 Jun;49(6):678-737. doi: Io.IOI6/j. ejvs.2015.02.007. Epub 20I5 Apr

De Graaf R, de Wolf M, Sailer AM, van Laanen J, Wittens C, Jalaie H. Iliocaval Confluence Stenting for Chronic Venous Obstructions. Cardiovasc Intervent Radiol. 20I5 Oct;38(5):II98-204. doi: I0.IO07/so0270-0I5-I068-5. Epub 20I5 Mar I4.

Catarinella F, Nieman F, de Wolf M, Toonder I, de Graaf R, Wittens C. Quality-of-life in interventionally treated patients with post-thrombotic syndrome. Phlebology. 20I5 Mar;30(I Suppl):89-94. doi: IO.II77/02683555I556943I. PMID: 25729074. Also published in the conference booklet of the European Vascular Course 2015.

Arnoldussen C, de Wolf M, Wittens C. Diagnostic imaging of pelvic congestive syndrome. Phlebology. 20I5 Mar;30(I suppl):67-72. Review. PMID: 25729070. Also published in the conference booklet of the European Vascular Course 2015. 
Kurstjens R, de Graaf R, Barbati M, de Wolf M, van Laanen J, Wittens C, Jalaie H. Arteriovenous fistula geometry in hybrid recanalisation of post-thrombotic venous obstruction. Phlebology. 20I5 Mar;30(I Suppl):42-9. doi: I0.II77/02683555I4568270. PMID: 25729067. Also published in the conference booklet of the European Vascular Course 2015.

Kurstjens R, de Wolf M, van Laanen J, de Haan M, Wittens C, de Graaf R. Hemodynamic significance of collateral blood flow in chronic venous obstruction. Phlebology. 20I5 Mar;30(I Suppl):27-34. doi: I0.II77/02683555I5569433. PMID: 25729065. Also published in the conference booklet of the European Vascular Course 2015.

Strijkers RH, de Wolf MA, Arnoldussen CW, Timbergen MJ, de Graaf R, Ten Cate-Hoek AJ, Wittens CH. Venous In-stent Thrombosis Treated by Ultrasound Accelerated Catheter Directed Thrombolysis. Eur J Vasc Endovasc Surg. 20I5 Feb I9. pii: SIO78-5884(I5)ooo44-I. doi: IO.IOI6/j. ejvs.20I5.0I.006.

H. Jalaie, C. W. Arnoldussen, M. E. Barbati, R. Kurstjens, R. de Graaf, J. Grommes, K. Schleimer, M. A. de Wolf, C. Wittens. Welche Faktoren beeinflussen das Ergebnis der Rekanalisation bei chronisch venöser Obstruktion? Vasomed, 26. jahrgang 6-20I4, pp. 322-323.

M.A.F. de Wolf, MD \& C.H.A. Wittens, MD, PhD. Venous Stenting in Femoro-Iliac obstructive Lesions - Clinical Experience. Conference booklet of "XIV congresso de Sociedade Portuguesa de Angiologia e Cirurgia Vascular. June I9-2I, 2014.

RLM Kurstjens, MAF de Wolf, R de Graaf, and CHA Wittens. Hemodynamic changes in Iliofemoral disease. Phlebology, May 20I4; vol. 29, I suppl: pp. 90-96. Also published in the conference booklet of the European Vascular Course 2014.

H Jalaie, CWKP Arnoldussen, ME Barbati, RLM Kurstjens, R de Graaf, J Grommes, A Greiner, MA de Wolf, and CHA Wittens. What predicts outcome after recanalization of chronic venous obstruction: hemodynamic factors, stent geometry, patient selection, anticoagulation or other factors? Phlebology, May 20I4; vol. 29, I suppl: pp. 97-I03. Also published in the conference booklet of the European Vascular Course 20I4.

FS Catarinella, FHM Nieman, MAF de Wolf, and CHA Wittens. Short-term follow-up of Quality-of-Life in interventionally treated patients with post-thrombotic syndrome after deep venous occlusion. Phlebology, May 20I4; vol. 29, I suppl: pp. I04-III. Also published in the conference booklet of the European Vascular Course 2014.

J Grommes, KT von Trotha, MA de Wolf, H Jalaie, and CHA Wittens. Catheter-directed thrombolysis in deep vein thrombosis: Which procedural measurement predicts outcome? Phlebology, May 20I4; vol. 29, I suppl: pp. 135-I39. Also published in the conference booklet of the European Vascular Course 20I4. 
Mark A.F. de Wolf, Rob H.W. Strijkers, Rick de Graaf, Cees H.A. Wittens. Recent developments in the management of the post-thrombotic leg and venous compression syndromes. Turkish Journal of Vascular Surgery, Damar Cer Derg 20I3;22(2):155-60.

M.A.F. de Wolf, C.W.K.P. Arnoldussen and C.H.A. Wittens. Indications for endophlebectomy and/or arteriovenous fistula after stenting. Phlebology. 2013 Mar;28 Suppl I:I23-8. Also published in the conference booklet of the European Vascular Course 2013.

M.A.F. de Wolf, C.W. Arnoldussen, J. Grommes, S.G. Hsien, P.J. Nelemans, M.W. de Haan, R. de Graaf, C.H.A. Wittens. Minimally Invasive Treatment of Chronic Iliofemoral Venous Occlusive Disease. Journal of Vascular Surgery: Venous and Lymphatic Disorders, Vol. I, Issue 2, pI46-I53 De Maeseneer M, Hertoghs M, Lauwers K, Koeyers W, de Wolf M, Wittens C. Chronic venous insufficiency in patients with absence of the inferior vena cava. Journal of Vascular Surgery: Venous and Lymphatic Disorders Vol. I, Issue I, Pages 39-44.e220I2.

Mark A.F. de Wolf, MD; Cees H.A. Wittens, MD, PhD. Deep venous reconstruction is worthwhile: against the motion. Chapter 83 in the conference booklet of 34th Charing Cross Symposium, 2012.

Mark A.F. de Wolf, MD; Cees H.A. Wittens, MD, PhD; Susan R. Kahn, MD, MSc, FRCPC. Incidence and risk factors of the post-thrombotic syndrome. Phlebology March 20I2 vol. 27 no. suppl I 85-94. Also published in the conference booklet of the European Vascular Course 2012.

C.H.A Wittens, F.S. Catarinella, Y.L. Lam, R.H.W. Strijkers, M.A.F. de Wolf. Analyse en reactie op het CVZ rapport: 'Varices: medisch noodzakelijke versus cosmetische behandelingen'

J. Grommes; M. de Wolf, A.H. Mahnken, C. Arnoldussen; R. de Graaf; M. de Haan; C. Wittens. Das postthrombotische Syndroms: neue invasive Therapieoptionen zur Behandlung der tiefen venösen Obstruktion. Zusammenfassung Medreport zur Tagung DGP 20II Berlin.

J. Grommes; R. Strijkers; M. de Wolf, A. H. Mahnken; C. Wittens. Ultraschallunterstütze Thrombolyse zur Behandlung der TVT. Vasomed 20 II. 
190 CURRICULUM VITAE 


\section{CURRICULUM VITAE}

Mark Antonius Friedrich de Wolf werd op 24 maart 1985 geboren te Deurne, NoordBrabant. Tussen 1998 en 2004 volgde hij zijn middelbare schoolopleiding aan het Peelland College Deurne, waaraan hij diploma's op atheneum niveau behaalde in een tweetal profielen. Aansluitend startte hij zijn geneeskunde opleiding aan de Universiteit Maastricht, waaraan hij in 2010 afstudeerde als arts.

Hierop volgend startte hij zijn promotieonderzoek, bij diezelfde universiteit, onder supervisie van zijn promotor prof. dr. Cees Wittens en copromotor dr. Rick de Graaf. Zijn onderzoek is gericht op de uitkomst van diep veneuze reconstructies bij patiënten met chronisch veneuze ziekte. In 2013 switchte hij naar een klinische positie als artsassistent bij diezelfde afdeling veneuze chirurgie van het Maastricht universitair medisch centrum, hierbij zette hij zijn promotieonderzoek voort. In 2015 maakte hij de stap richting de Nederlandse hoofdstad om als arts te werken bij een nieuw opgezette kliniek gespecialiseerd in de behandeling van diep veneuze pathologie. Dit proefschrift is het resultaat van de research die hij gedurende zijn werkzaamheden bij deze afdelingen heeft ondernomen. Vanaf I mei 2016 is hij gestart aan de opleiding tot radioloog in het Maasstad ziekenhuis te Rotterdam (opleider dr. D. Vroegindeweij). 